\title{
INVESTIGATIONS OF NEAR-FIELD THERMAL-HYDROLOGIC- MECHANICAL-CHEMICAL MODELS FOR RADIOACTIVE WASTE DISPOSAL IN CLAY/SHALE ROCK
}

\author{
Hui-Hai Liu \\ Lianchong Li \\ Liange Zheng \\ James Houseworth \\ Jonny Rutqvist
}

Earth Sciences Division, Lawrence Berkeley National Laboratory

University of California, Berkeley, California 94720

June 20, 2011

This report has been authored by Lawrence Berkeley National Laboratory under Contract No. DE-AC0205CH11231 with the U.S. Department of Energy. The views and opinions of authors expressed in this article do not necessarily state or reflect those of the United States Government or any agency thereof or The Regents of the University of California. 


\section{TABLE OF CONTENTS}

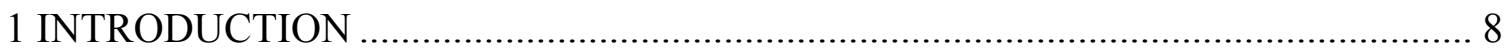

2 DEVELOPMENT OF CONSTITUTIVE RELATIONSHIPS ……................................. 9

2.1 An elastic strain-stress relationship under anisotropic stress conditions .................. 9

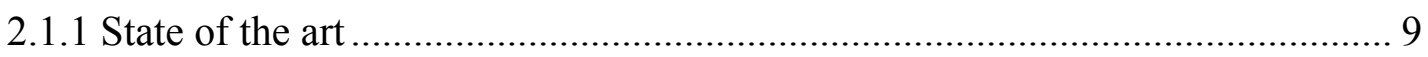

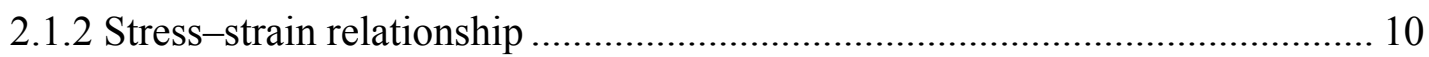

2.1.3 Comparisons with experimental observations ............................................... 14

2.1.4 Stress-dependent mechanical and hydraulic rock properties ............................ 25

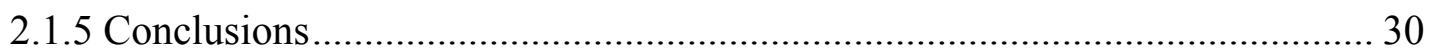

2.2 Unsaturated properties for non-Darcian water flow in clay................................. 30

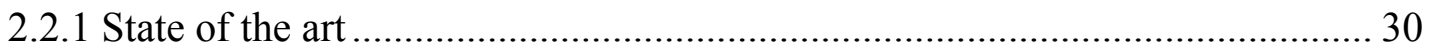

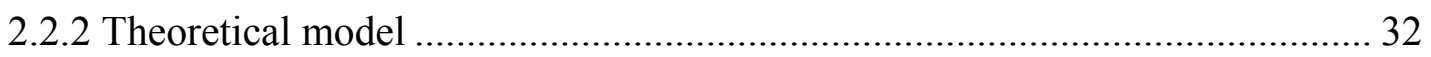

2.2.3 A comparison with experimental observations.............................................. 38

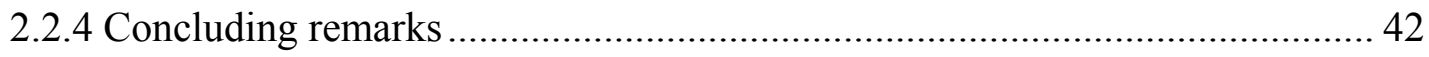

3 THM MODELING IN CLAY/SHALE ENVIRONMENT .......................................... 42

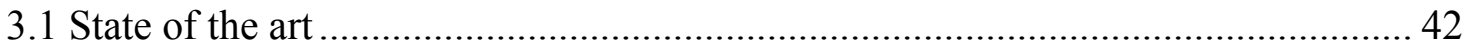

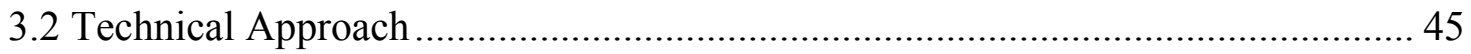

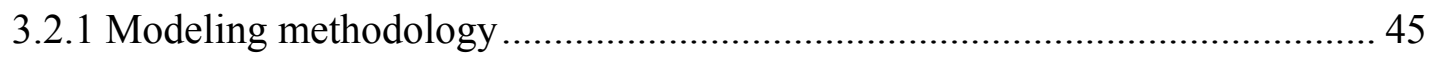

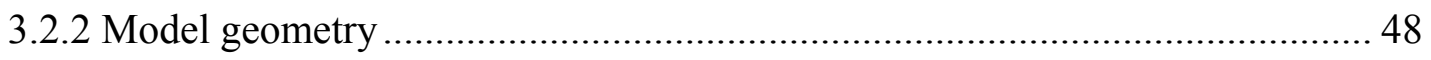

3.2.3 Boundary conditions and material parameters............................................... 50

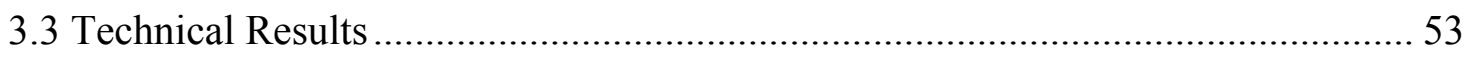

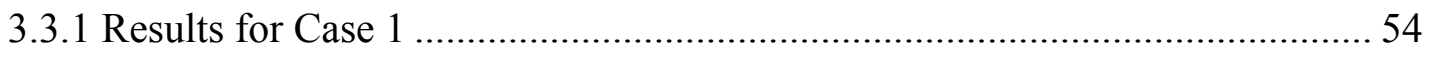

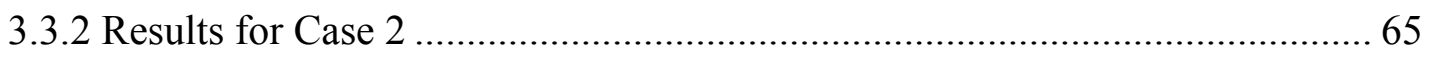

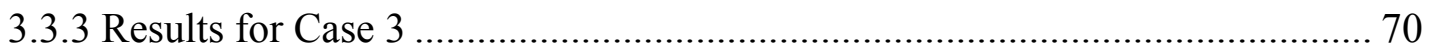

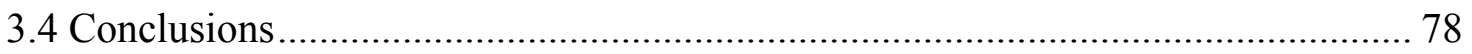

4 THC MODELING IN A CLAY/SHALE ENVIRONMENT ...................................... 80

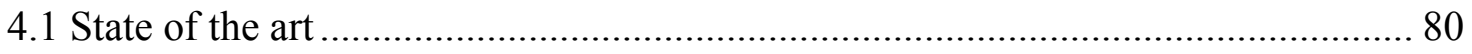

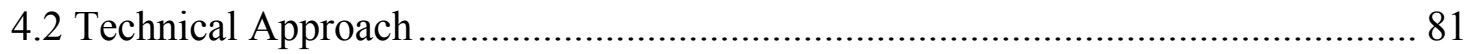

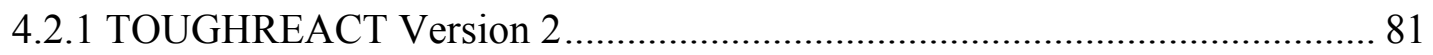

4.2.2 Application of DDL theory to calculate swelling pressure............................. 82

4.2.3 Calculation examples for swelling pressure ................................................ 86

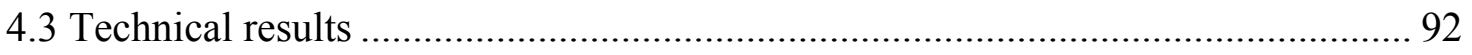

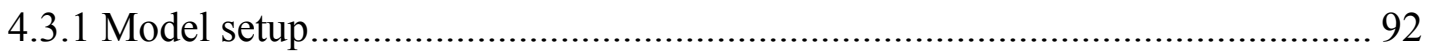




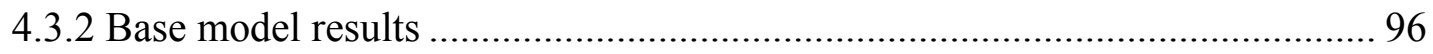

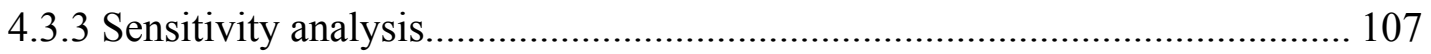

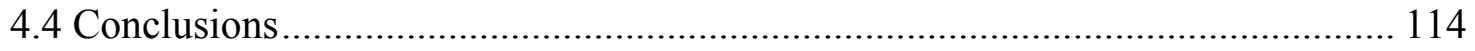

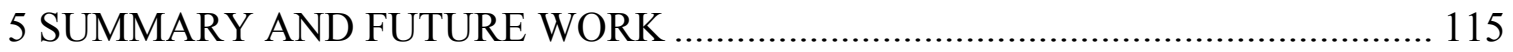

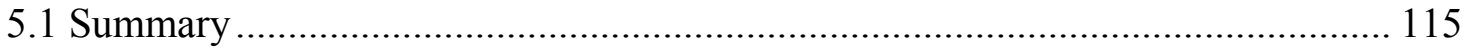

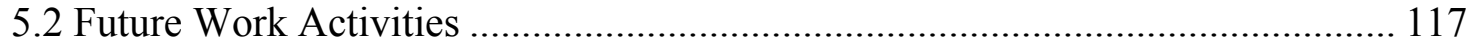

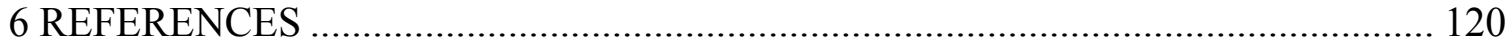




\section{LIST OF FIGURES}

Figure 1-1. Clay/shale-formation distribution in the USA (Gonzales and Johnson, 1984)

Figure 2-1. Matches between results calculated from Eq. (2-10) and experimental data from unconfined compression tests on clay rock (Corkum and Martin 2007a)

Figure 2-2. Matches between results calculated from Eq. (2-10) and experimental data from unconfined compression tests on clay rock (Olalla et al., 1999).

Figure 2-3. Comparisons between hard part strain and soft part strain

Figure 2-4. Matches between results calculated from Equation (2-13) and experimental data from triaxial compression tests on a sandstone (Tien et al., 1990)

Figure 2-5. Soft part strain and $\mathrm{R}$ (the ratio of soft part strain to the hard part strain) as a function of axial stress at different confining pressure for a sandstone......... 20

Figure 2-6. Matches between results calculated from Equation (2-13) and experimental data from triaxial compression tests on a conglomerate rock (Hu et al., 2004)

Figure 2-7. Soft part strain and R (the ratio of soft part strain to the hard part strain) as a function of axial stress at different confining pressure for a conglomerate rock.

Figure 2-8. Matches between results calculated from Equation (2-13) and experimental data from triaxial compression tests on shale rock (Xu et al., 2006a).

Figure 2-9. Soft part strain and $\mathrm{R}$ (the ratio of soft part strain to the hard part strain) as a function of axial stress at different confining pressure for a shale rock........ 24

Figure 2-10. Comparisons between results calculated from Equation (2-19) and experimental data from uniaxial strain tests for two sand specimens (Peng and Zhang, 2007)

Figure 2-11. Comparisons between the uniaxial test data for Bunter sandstone (Morgenstern and Tamuly Phukan 1969) and the compressibility-stress relationship (Equation (2-21))

Figure 2-12. Schematic demonstration of relations between shear stress and stress rate for a Newtoniain fluid and three typical non-Newtonian fluids .................... 33

Figure 2-13. A water element in a capillary tube 34

Figure 2-14. Comparisons between calculated (solid curves) and measured (data points) water flux as a function of hydraulic gradient for different capillary pressures. The calculation is based on Equation (2-33). Data from Cui et al. (2008)....

Figure 2-15. Calculated unsaturated hydraulic conductivity as a function of capillary pressure. The data points are determined from Figure 2-14. The solid curve is calculated from Eqs. (2-43) and (2-44) as an illustrative case. Data from Cui et al. (2008).

Figure 3-1. Swelling/shrinkage coefficient variation with the change in saturation ....... 47

Figure 3-2. Numerical model and grid mesh 
Figure 3-3. Location of key points for monitoring parameter variation in numerical simulation

Figure 3-4. Relationship between capillary pressure and water saturation (modified from Zhang et al., 2008b) .......................................................................... 51

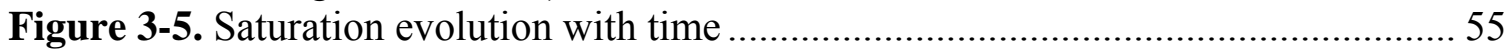

Figure 3-6. Saturation variation in the surrounding rock mass along line G-G' ............ 56

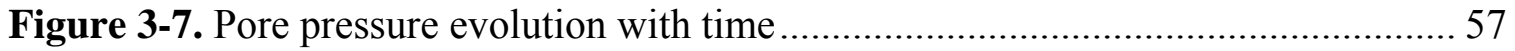

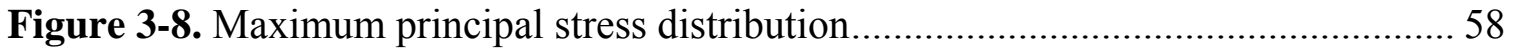

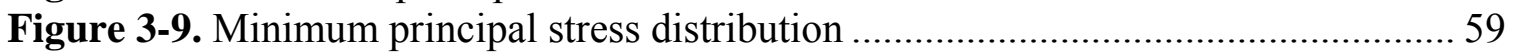

Figure 3-10. Numerically obtained displacement at points A, B, C, D, E and F

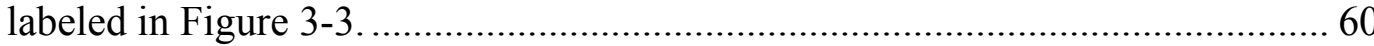

Figure 3-11. Numerically obtained displacement at points A, B, C, D, E and F (the case without considering the shrinkage effect) .............................................. 61

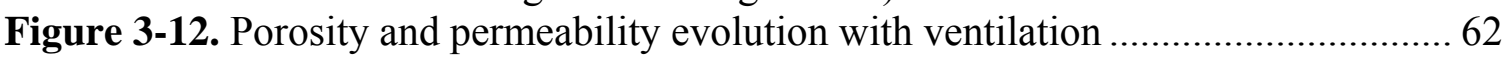

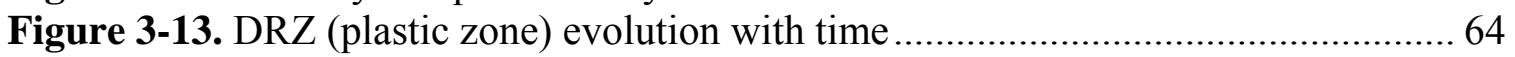

Figure 3-14. DRZ (plastic zone) for the cases (a) considering mechanical unloading only, and (b) without considering shrinkage effect ........................................6 65

Figure 3-15. Stress distribution for the case with horizontal oriented bedding planes $\left(\operatorname{dip}=0^{\circ}\right)$

Figure 3-16. Stress distribution for the case with vertical oriented bedding planes $\left(\operatorname{dip}=90^{\circ}\right)$ 68

Figure 3-17. Numerically obtained displacement at points A, B, C, D, E, and F. 69

Figure 3-18. Numerically obtained potential plastic zones for the cases (a) with the isotropic plane inclined at $0^{\circ}$ from horizontal, (b) with the isotropic plane inclined at $90^{\circ}$ from horizontal ....................................................................... 70

Figure 3-19. Numerical specimen for model validation ...................................... 70

Figure 3-20. Comparison between laboratory measurements and values obtained using the numerical method ....................................................................... 71

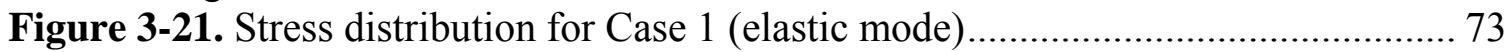

Figure 3-22. Stress distribution for Case 3 (elastic mode)........................................... 74

Figure 3-23. Numerically obtained stress at points D, E, and F ................................ 75

Figure 3-24. Numerically obtained displacement at points D, E, and F ...................... 76

Figure 3-25. Porosity and permeability evolution at points D, E, and F ...................... 77

Figure 3-26. DRZ mode for Case 3 at time $t=3$ days and 3 years............................ 78

Figure 4-1. Flow chart showing the determination of swelling pressure for a given void ratio using the diffuse double layer theory .................................................. 86

Figure 4-2. Comparison of calculated and measured swelling pressure as a function

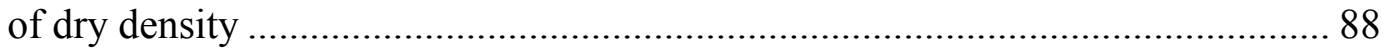

Figure 4-3. Calculated swelling pressure as a function of dry density for the different scenarios listed in Table 4-2.

Figure 4-4. A representative unit layer separation for parallel clay platelets (Schanz and Tripathy, 2009), where $t$ is the thickness of the swelling clay platelets......... 90

Figure 4-5. A representative unit layer structure for parallel swelling clay and nonswelling mineral platelets, where $\mathrm{D}$ is the half width between two nonswelling mineral platelets and $\mathrm{T}$ is the thickness one nonswelling mineral platelet. 
Figure 4-6. Comparison of calculated and measured swelling pressure lower Dogger opalinum shale in northern Switzerland (Sridharan and Jayadeva, 1982)........... 92

Figure 4-7. 2-D mesh used in the THC model ............................................................... 93

Figure 4-8. Spatial distribution of chloride at different times..................................... 97

Figure 4-9. Spatial distribution of sodium at different times.................................... 97

Figure 4-10. Spatial distribution of ionic strength at different times........................... 98

Figure 4-11. Spatial distribution of illite volume fraction change (dimensionless) at

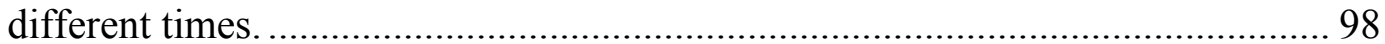

Figure 4-12. Spatial distribution of smectite volume fraction change (dimensionless) at different times.

Figure 4-13. Spatial distribution of chlorite volume fraction change (dimensionless)

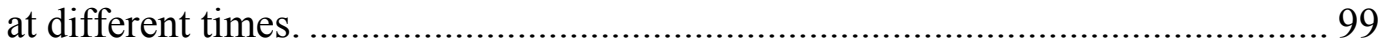

Figure 4-14. The concentration of exchangeable cations at the 0 and $100 \mathrm{yr} . \ldots \ldots \ldots . . . . . .100$

Figure 4-15. The concentration of exchangeable cations at the 0 and 100 year, with vertical axis in logarithmic scale................................................................. 101

Figure 4-16. The weighted average valence of exchangeable cations at different

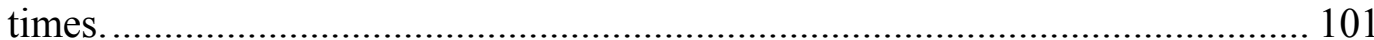

Figure 4-17. Spatial distribution of swelling pressure at different times..................... 102

Figure 4-18. The percentage of swelling pressure change comparing with initial swelling pressure at different times. .......................................................... 103

Figure 4-19. The change in porosity due to swelling at different times. ...................... 104

Figure 4-20. The change in porosity due to mineral precipitation/dissolution at

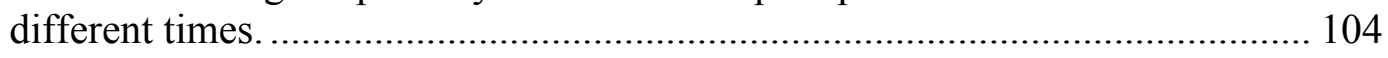

Figure 4-21. Spatial distribution of ionic strength at 1 year. ................................... 105

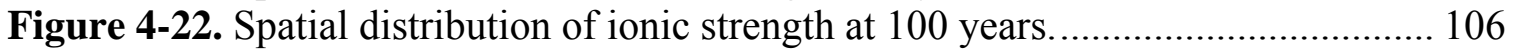

Figure 4-23. Spatial distribution of swelling pressure at 1 year. ............................... 106

Figure 4-24. Spatial distribution of swelling pressure at 100 years............................ 107

Figure 4-25. Comparison of swelling pressure at 100 years computed in the base model and a sensitivity run that does not consider the effect of the decrease of the volume fraction of smectite................................................................. 108

Figure 4-26. Computed ionic strength at 1 and 100 years in the base and sensitivity run

Figure 4-27. Computed smectite volume fraction change at 1 and 100 years in the base and sensitivity run.

Figure 4-28. Computed illite volume fraction change at 1 and 100 years in base and sensitivity run.

Figure 4-29. Computed concentration of aqueous sodium and calcium at 100 year in the sensitivity run.

Figure 4-30. Computed concentration of exchangeable sodium and calcium at 100 year in the base and sensitivity run.

Figure 4-31. Computed weighted average valence at 1 and 100 year in the base and sensitivity run

Figure 4-32. Computed swelling pressure at 1 and 100 years in the base and sensitivity run

Figure 4-33. Porosity change (\%) due to mineral precipitation/dissolution and swelling at 100 years in the sensitivity run. 


\section{LIST OF TABLES}

Table 2-1. Fitted parameter values from the experiment data for Opalinus Clay rock.... 15

Table 2-2. Fitted parameter values from the experimental data for sandstone. ............... 20

Table 2-3. Fitted parameter values from the experimental data for conglomerate rock .. 22

Table 2-4. Fitted parameter values from the experimental data for shale rock................ 24

Table 2-5. Fitted parameter values from the experimental data for sandstone samples .. 27

Table 2-6. Fitted parameter values from the experimental data for Bunter sandstone .... 30

Table 3-1. Flow parameters for the Opalinus Clay ………………………………...... 52

Table 3-2. Mechanical parameters for the Opalinus Clay ………..................................... 53

Table 3-3. Supplementary mechanical parameters for Case 3 ........................................ 71

Table 4-1. Properties of FEBEX bentonite that Tripathy et al. (2004) used to

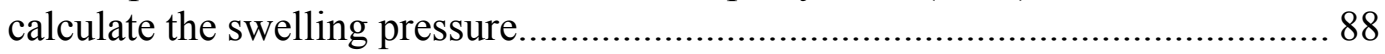

Table 4-2. Parameter A and B for U-Kd relation (Equation (4-2)) under different combinations of parameters

Table 4-3. Mineral composition of the bentonite used in the model (taken from the Kunigel-V1 bentonite (Ochs et al., 2004)).

Table 4-4. Mineral composition of the clay formation used in the model (taken from the Opalinus Clay (Thury, 2002).

Table 4-5. Lists the pore water composition of EBS bentonite and host clay rock. ........ 94

Table 4-6. Thermal and hydrodynamic parameters.

Table 4-7. Kinetic properties for minerals considered in the model (Xu et al., 2006b)... 96 


\section{INTRODUCTION}

Clay/shale has been considered as potential host rock for geological disposal of highlevel radioactive waste throughout the world, because of its low permeability, low diffusion coefficient, high retention capacity for radionuclides, and capability to self-seal fractures. For example, Callovo-Oxfordian argillites at the Bure site, France (Fouche et al., 2004), Toarcian argillites at the Tournemire site, France (Patriarche et al., 2004), Opalinus Clay at the Mont Terri site, Switzerland (Meier et al., 2000), and Boom clay at the Mol site, Belgium (Barnichon and Volckaert, 2003) have all been under intensive scientific investigation (at both field and laboratory scales) for understanding a variety of rock properties and their relationships to flow and transport processes associated with geological disposal of radioactive waste. Figure 1-1 presents the distribution of clay/shale formations within the USA.

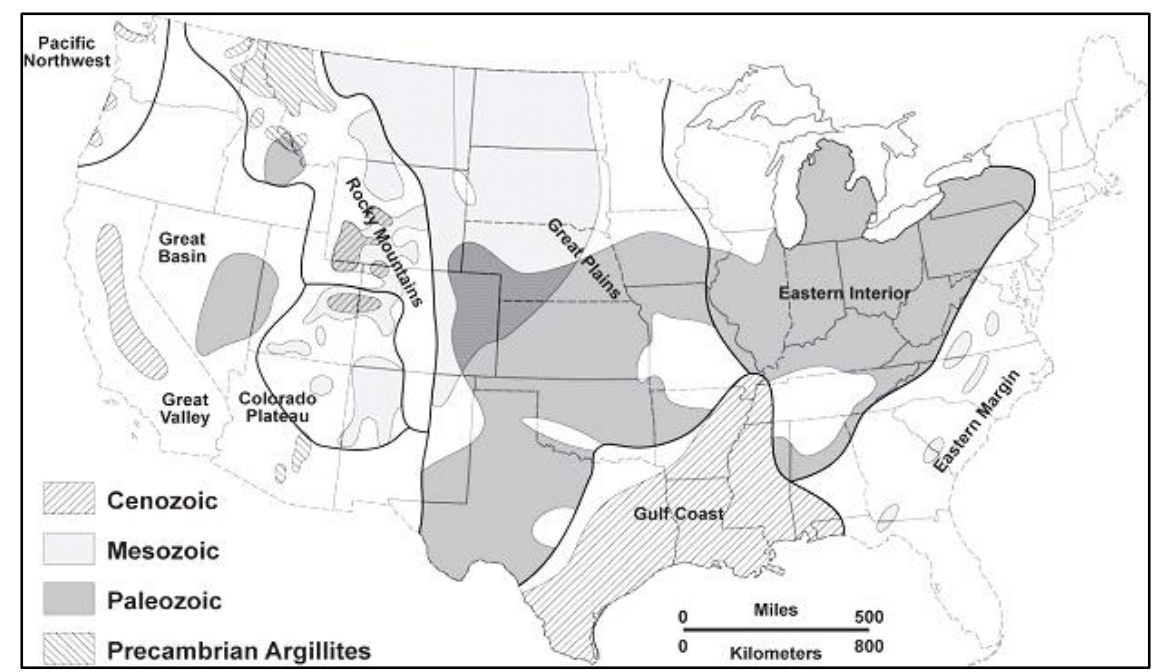

Figure 1-1. Clay/shale-formation distribution in the USA (Gonzales and Johnson, 1984)

Clay/shale rocks may be generally classified as indurated or plastic clays (Tsang et al., 2005). The latter (including Boom clay) is a softer material without high cohesion; its deformation is dominantly plastic. For both clay and shale, coupled thermal, hydrological, mechanical, and chemical (THMC) processes are expected to have a significant impact on the long-term safety of a clay repository. For example, the disturbed-rock zone (DRZ) near repository tunnels can modify local permeability (resulting from induced fractures), potentially leading to less confinement capability (Tsang et al., 2005). Because of clay's tendency to swell or shrink (depending on whether the clay is in imbibition or drainage processes), fracture properties in the DRZ are quite dynamic and evolve over time as hydromechanical conditions change. Understanding and 
modeling the coupled processes and their impact on repository performance are critical for any defensible performance assessment of a radioactive waste repository in a clay/shale host rock.

This report documents research activities focused on understanding and modeling DRZ evolution and the associated coupled processes, including the development of constitutive relationships for elastic deformation of clay rock (Section 2), a THM modeling study (Section 3) and a THC modeling study (Section 4). The chapter summary and a discussion of future work activities are given in Section 5.

\section{DEVELOPMENT OF CONSTITUTIVE RELATIONSHIPS}

Constitutive relationships refer to relationships among hydraulic, mechanical, thermal, and mechanical properties. This section documents the progress made in developing relationships among stress, strain, and related stress-dependent hydraulic/mechanical properties (Section 2.1), as well as the development of an unsaturated property model for non-Darcian flow in clay materials (Section 2.2).

\subsection{An elastic strain-stress relationship under anisotropic stress conditions}

\subsubsection{State of the art}

The stress-strain relationship is the most fundamental part of constitutive relationships. Hooke's law has been generally used to describe this stress-strain relationship for elastic mechanical processes. According to Hooke's Law, for elastic material, the proportionality in the stress-strain relationship should be constant. However, this proportionality is in fact not always constant in many cases, but rather stress-dependent (e.g., Cazacu, 1999; Lionço and Assis, 2000; Brown et al., 1989; Johnson and Rasolofosaon, 1969; Brady, 1969). A number of efforts have been made to relate this stress-dependent behavior to the microstructures of "cracks" in porous rock (Walsh, 1965; Nur, 1971; Mavko and Nur, 1978). An excellent review of these efforts is provided in a chapter entitled "Micromechanical Models" in Jaeger et al. (2007). Because it is generally difficult to characterize small-scale structures accurately and then relate their properties to large-scale mechanical properties that are of practical interest, it is desirable to have a macroscopic-scale theory that does not rely on the detailed description of smallscale structures, and that can physically incorporate the stress-dependent behavior of 
relevant mechanical properties. A theory of this kind was developed within the framework of Hooke's law by Liu et al. (2009).

Liu et al. (2009) argued that different varieties of Hooke's law should be applied within regions of the rock having significantly different stress-strain behavior, and that a rock body could be conceptualized into two distinct parts. These two parts are called a "hard part" that only experiences small deformation and a "soft part" that experiences large deformation. The natural strain (volume change divided by rock volume at the current stress state), rather than the engineering strain (volume change divided by the unstressed rock volume), should be used in Hooke's law for accurate modeling of the elastic deformation of the soft part of the pore volume, subject to a relatively large degree of relative deformation (i.e., cracks or fractures). This approach permits the derivation of constitutive relationships between stress and a variety of mechanical and/or hydraulic rock properties. The theoretical predictions of this method are generally consistent with empirical expressions (from field data) and also laboratory rock experimental data for sandstone rock (Liu et al., 2009). Liu et al. (2010) primarily demonstrated the validity of Liu et al.'s (2009) stress-strain relationship for a clay rock. As indicated later in this section and Section 2.3 below, consideration of the soft part is important for modeling coupled processes in clay repositories. However, the work of Liu et al. (2009) is limited to isotropic stress conditions corresponding to the hydrostatic stress state. In reality, a clay repository is generally subject to complex, anisotropic stress conditions. Here we have extended the work of Liu et al. (2009) to such conditions.

\subsubsection{Stress-strain relationship}

\section{Stress-strain relationships under isotropic stress conditions}

The new stress-strain relationship to be developed herein is based on the work of Liu et al. (2009) for isotropic (or hydrostatic) stress conditions. Thus, for convenience, the results of Liu et al. (2009) are briefly discussed in this subsection.

The major reasoning of Liu et al. (2009) is that the two strains (natural and engineering) should be carefully distinguished, and the natural (or true) strain should be used in Hooke's law for accurately describing material deformation (Freed, 1995). When a uniformly distributed force is imposed on the surface of a homogeneous and isotropic material body subject to elastic deformation, natural (or true)-strain-based Hooke's law can be expressed as 


$$
d \sigma_{h}=-K \frac{d V}{V}=K d \varepsilon_{v, t}
$$

where $V$ is the total volume of the material body under the current stress state, $\sigma_{h}$ is the hydrostatic stress, and $K$ is the bulk modulus. The subscript $h$ refers to hydrostatic (or isotropic) stress conditions, and $\varepsilon_{v, t}$ is the natural volumetric strain. The engineeringstrain-based Hooke's law can be expressed as

$$
d \sigma_{h}=-K \frac{d V}{V_{0}}=K d \varepsilon_{v, e}
$$

where $V_{0}$ is the undressed bulk volume, $\varepsilon_{v, e}$ is the engineering volumetric strain. Note that the two strains are practically identical for small mechanical deformations.

In the literature of rock mechanics, the engineering strain has been exclusively used, under the assumption that the elastic strain is generally small. However, Liu et al. (2009) indicated that the strain could be considerably larger within some portion of a rock body because of its inherent heterogeneity, and divide rock mass into two parts to consider the impact of heterogeneity: (1) the portion of pores with different sizes and geometries subject to larger deformation is conceptualized as a "soft" part in the rock body; and (2) the remaining portion subject to small deformation is conceptualized as a "hard" part. For the soft part, the natural (or true)-strain-based Hooke's law is applied. For the hard part, the engineering -strain-based Hooke's law is applied. In this work, we also use subscripts 0 , e, and t to denote the unstressed state, the hard part, and the soft part, respectively. According to Liu et al. (2009), the stress-strain relationship for porous and fractured rock under hydrostatic stress state can be expressed as:

$$
\begin{aligned}
& -\frac{d V}{V_{0}}=\gamma_{e} \frac{d \sigma_{h}}{K_{e}}+\gamma_{t} \exp \left(-\frac{\sigma_{h}}{K_{t}}\right) \frac{d \sigma_{h}}{K_{t}} \\
& d V=d V_{e}+d V_{t} \\
& V_{0}=V_{0, e}+V_{0, t} \\
& \gamma_{t}=\frac{V_{0, t}}{V_{0}} \\
& \gamma_{e}=1-\gamma_{t}
\end{aligned}
$$

where $K_{e}$ and $K_{t}$ refer to bulk modulus for the hard and soft parts, respectively.

\section{Stress-strain relationship under anisotropic stress conditions}


Without losing generality, we consider stress-strain relationships corresponding to the three principal stresses. To extend the work of Liu et al. (2009), we further assume that the principal strain resulting from the soft part is a function of the principal stress along the same direction only, and has nothing to do with the other principal stresses. The validity of this assumption will be evaluated by comparing our results with experimental observations.

Following the procedure of Liu et al. (2009) to derive Equation (2-3), we can obtain the expressions for principal strains:

$$
\begin{aligned}
& d \varepsilon_{1}=\frac{\gamma_{e}}{E_{e}}\left[d \sigma_{1}-v\left(d \sigma_{2}+d \sigma_{3}\right)\right]+\frac{\gamma_{t}}{E_{t}} \exp \left(-\frac{3 \sigma_{1}}{E_{t}}\right) d \sigma_{1} \\
& d \varepsilon_{2}=\frac{\gamma_{e}}{E_{e}}\left[d \sigma_{2}-v\left(d \sigma_{1}+d \sigma_{3}\right)\right]+\frac{\gamma_{t}}{E_{t}} \exp \left(-\frac{3 \sigma_{2}}{E_{t}}\right) d \sigma_{2} \\
& d \varepsilon_{3}=\frac{\gamma_{e}}{E_{e}}\left[d \sigma_{3}-v\left(d \sigma_{1}+d \sigma_{2}\right)\right]+\frac{\gamma_{t}}{E_{t}} \exp \left(-\frac{3 \sigma_{3}}{E_{t}}\right) d \sigma_{3}
\end{aligned}
$$

where $\sigma_{1}, \sigma_{2}, \sigma_{3}$ are principal stresses, $\varepsilon_{1}, \varepsilon_{2}, \varepsilon_{3}$ are principal strains, $v$ is Poisson ratio, and $E_{e}$ and $E_{t}$ refer to Young's (elastic) modulus for the hard and soft parts, respectively. The elastic modulus can be related to bulk modulus by

$$
K_{e}=\frac{E_{e}}{3(1-2 v)} K_{t}=\frac{E_{t}}{3}
$$

Based on the assumption that strains are zero under unstressed state, principal strains can be solved from Equation (2-8) as

$$
\begin{aligned}
& \varepsilon_{1}=\frac{\gamma_{e}}{E_{e}}\left[\sigma_{1}-v\left(\sigma_{2}+\sigma_{3}\right)\right]+\frac{\gamma_{t}}{3}\left[1-\exp \left(-\frac{3 \sigma_{1}}{E_{t}}\right)\right] \\
& \varepsilon_{2}=\frac{\gamma_{e}}{E_{e}}\left[\sigma_{2}-v\left(\sigma_{1}+\sigma_{3}\right)\right]+\frac{\gamma_{t}}{3}\left[1-\exp \left(-\frac{3 \sigma_{2}}{E_{t}}\right)\right] \\
& \varepsilon_{3}=\frac{\gamma_{e}}{E_{e}}\left[\sigma_{3}-v\left(\sigma_{2}+\sigma_{1}\right)\right]+\frac{\gamma_{t}}{3}\left[1-\exp \left(-\frac{3 \sigma_{3}}{E_{t}}\right)\right]
\end{aligned}
$$

In (2-8) and (2-10), the first term on the right-hand side results from the hard part and the second term on the right-hand side from the soft part. Note that the second term, unlike the first term, is only a function of the corresponding principal stress and not related to other stresses, as a result of the assumption mentioned above. In other words, we ignore Poisson's ratio for the soft part, as demonstrated in (2-9). 
Our treatment of Poisson's ratio, as the first step, is considered a rough approximation; further research may be needed to refine the treatment by incorporating the Poisson's ratio for the soft part. Poisson's ratio, $v$, is defined as the negative of the ratio of transverse strain to the longitudinal strain, under conditions of uniaxial stress (Jaeger et al., 2007). Although the use of approximate or typical values in most rock-mechanics applications does not create significant problems, Poisson's ratio plays an undeniably important role in the elastic deformation of rocks and rock masses subjected to static or dynamic stresses. Furthermore, its effects emerge in a wide variety of rock engineering applications, ranging from basic laboratory tests on intact rocks to field measurements for in situ stresses or deformability of rock masses (Gercek, 2007). Poisson (1829) recommended the value of Poisson's ratio as $1 / 4$. Wertheim (1848) recommended the value of Poisson's ratio as 1/3. Franz Ernst Neumann (1798-1895) recommended that the value of Poisson's ratio was not constant, but rather different with different materials. To make the Young's, shear, and bulk modulus of a material positive, the theoretical value of Poisson's ratio must lie in the range -1 and $1 / 2$ (Jaeger et al., 2007). Moreover, according to Gercek (2007), the values of Poisson's ratio for many elements and materials are between 0 and 0.5 . While one may anticipate that the porosity of rock will influence the value of Poisson's ratio, the geometry (size and shape), orientation, distribution, and connectivity of pores are expected to complicate that influence (Gercek, 2007). In this study, we assume that only the hard part of the rock is subject to Poisson's effect. As demonstrated later in this section, this assumption may be adequate for most practical applications in clay and other formations.

Note that our current development is consistent with the work of Liu et al. (2009), in that it is based on the volumetric strain under isotropic conditions. It is well known that the engineering volumetric strain is the sum of three principal strains (Jaeger et al., 2007):

$$
d \varepsilon_{v}=\frac{d V}{V_{0}}=d \varepsilon_{1}+d \varepsilon_{2}+d \varepsilon_{3}
$$

where $\varepsilon_{\mathrm{v}}$ is the volumetric strain. Combining (2-8) and (2-11) yields 


$$
\begin{aligned}
d \varepsilon_{v}= & \frac{\gamma_{e}(1-2 v)}{E_{e}}\left(d \sigma_{1}+d \sigma_{2}+d \sigma_{3}\right) \\
& +\frac{\gamma_{t}}{E_{t}} \exp \left(-\frac{3 \sigma_{1}}{E_{t}}\right) d \sigma_{1} \\
& +\frac{\gamma_{t}}{E_{t}} \exp \left(-\frac{3 \sigma_{2}}{E_{t}}\right) d \sigma_{2} \\
& +\frac{\gamma_{t}}{E_{t}} \exp \left(-\frac{3 \sigma_{3}}{E_{t}}\right) d \sigma_{3}
\end{aligned}
$$

Inserting (2-9) into (2-12) will result in the stress-strain relationship (Equation (2-3)) reported by Liu et al. (2009) when the three principal stresses are the same. Thus, our current results are a generalization of the work of Liu et al. (2009).

\subsubsection{Comparisons with experimental observations}

To evaluate the validity of our theoretical approach, we use the developed stress-strain relationship (Eq. 2-10) to fit the uniaxial compression data presented in Corkum and Martin (2007a) and Olalla et al. (1999) for Opalinus Clay rock. In Corkum and Martin (2007a), rock samples were $83 \mathrm{~mm}$ diameter, saw-cut core samples from boreholes BRA1 and BRA-2, drilled with oil- and air-drilling fluids, respectively (Corkum and Martin 2007a). In Olalla et al. (1999), rock samples were $78 \mathrm{~mm}$ in diameter.

To avoid (as much as possible) the non-uniqueness of parameter values determined from curve fitting, we use a simple procedure to estimate parameter values from uniaxial stress versus uniaxial strain data. As shown in Figures 2-1 and 2-2, measured relationships between stress and strain are very well represented by a straight line for relatively high stresses. The slope of the straight line is used to determine $\frac{E_{e}}{\gamma_{e}}$, because the exponential terms on the right hand side of (2-10) are negligible for high stress values. The strain value at the intersection between the straight line and the strain axis in Figures 2-1 and 22 gives the value of $\frac{\gamma_{t}}{3}$, considering that the straight line represents the first term on the right-hand side of (2-10). The above procedure enables direct determination of values for $E_{e}, \gamma_{e}$ and $\gamma_{t}$. The remaining parameter $E_{t}$ can be estimated using a data point at relatively low stress. As indicted in Figures 2-1 and 2-2, the data are in excellent 
agreement with our theoretical results, suggesting that our assumption regarding the Poisson's effect seems to be adequate. Fitted parameter values are given in Table 2-1

The curve-fitted results of Opalinus Clay rock indicate that $\gamma_{t}$ ranges from $0.036 \%$ to $0.48 \%$ for the eleven clay rock samples under consideration. It is smaller than the typical porosity of clay rock, which suggests that the so-called soft part is only a small percentage of pore volume, if we consider the soft part to be purely from the pore space. (Note that the nonlinear response of porous rock mainly depends on the soft part rather than the entire pore space.) As shown in Table 2-1, $E_{t}$ ranges from 0.6 MPa to 3.6MPa, which, as expected, is much smaller than $E_{e}$. When applied stress loading on a rock frame increases, the shape of the soft-part pores changes, even tending to completely close, whereas the hard-part pores remain hard and resist closure-while the stress-sensitivity or nonlinear response of the rock is generally attributed to the deformation or closure of some pores. Macbeth (2004) also found that the pressure sensitivity of sand stones is due to the closure of intra- and intergranular cracks, small-aspect-ratio pore spaces, and broken grain contacts, none of which consume any significant portion of the pore volume. Shapiro and Kaselow (2005) assumed that the main reason for load-induced changes in the elastic properties of rock is the load-induced deformation of the pore space, and the compliant part of the pore space played the more important role.

Our work here is generally consistent with these previous studies. However, it differs from those studies in that our work is directly based on the notion that Hooke's law should use natural strains and rock mass that can be conceptualized into hard and soft parts. This allows for derivation of our stress-strain relationship, one that can be further used, in a systematic way, to generate formulations for stress-dependent rock properties with physically defined parameters, whereas most previous studies focus primarily on some specific mechanical parameters, rather than general stress-strain relationships.

Table 2-1. Fitted parameter values from the experiment data for Opalinus Clay rock

\begin{tabular}{|c|c|c|c|c|}
\hline Specimen & $E_{e}(\mathrm{MPa})$ & $\gamma_{e}$ & $\begin{array}{c}E_{t}( \\
\mathrm{MPa})\end{array}$ & $\gamma_{t}$ \\
\hline bra2-2a & 2537.5 & 0.99310 & 0.9 & 0.00230 \\
\hline bra1-7a & 2643.5 & 0.99490 & 2.0 & 0.00170 \\
\hline bra1-3a & 2438.8 & 0.99640 & 3.6 & 0.00120 \\
\hline bra2-2b & 2414.4 & 0.99817 & 3.0 & 0.00061 \\
\hline
\end{tabular}




\begin{tabular}{|c|c|c|c|c|}
\hline bra1-7b & 2682.9 & 0.99892 & 2.1 & 0.00036 \\
\hline $9949 \mathrm{a}$ & 2080.0 & 0.99520 & 0.9 & 0.00480 \\
\hline 9963 & 2448.8 & 0.99640 & 0.6 & 0.00360 \\
\hline $9949 \mathrm{~b}$ & 2326.9 & 0.99703 & 1.6 & 0.00297 \\
\hline 9972 & 2164.5 & 0.99793 & 1.7 & 0.00207 \\
\hline 9957 & 2804.4 & 0.99844 & 1.8 & 0.00156 \\
\hline $9984 \mathrm{~b}$ & 3345.1 & 0.99847 & 1.8 & 0.00153 \\
\hline
\end{tabular}

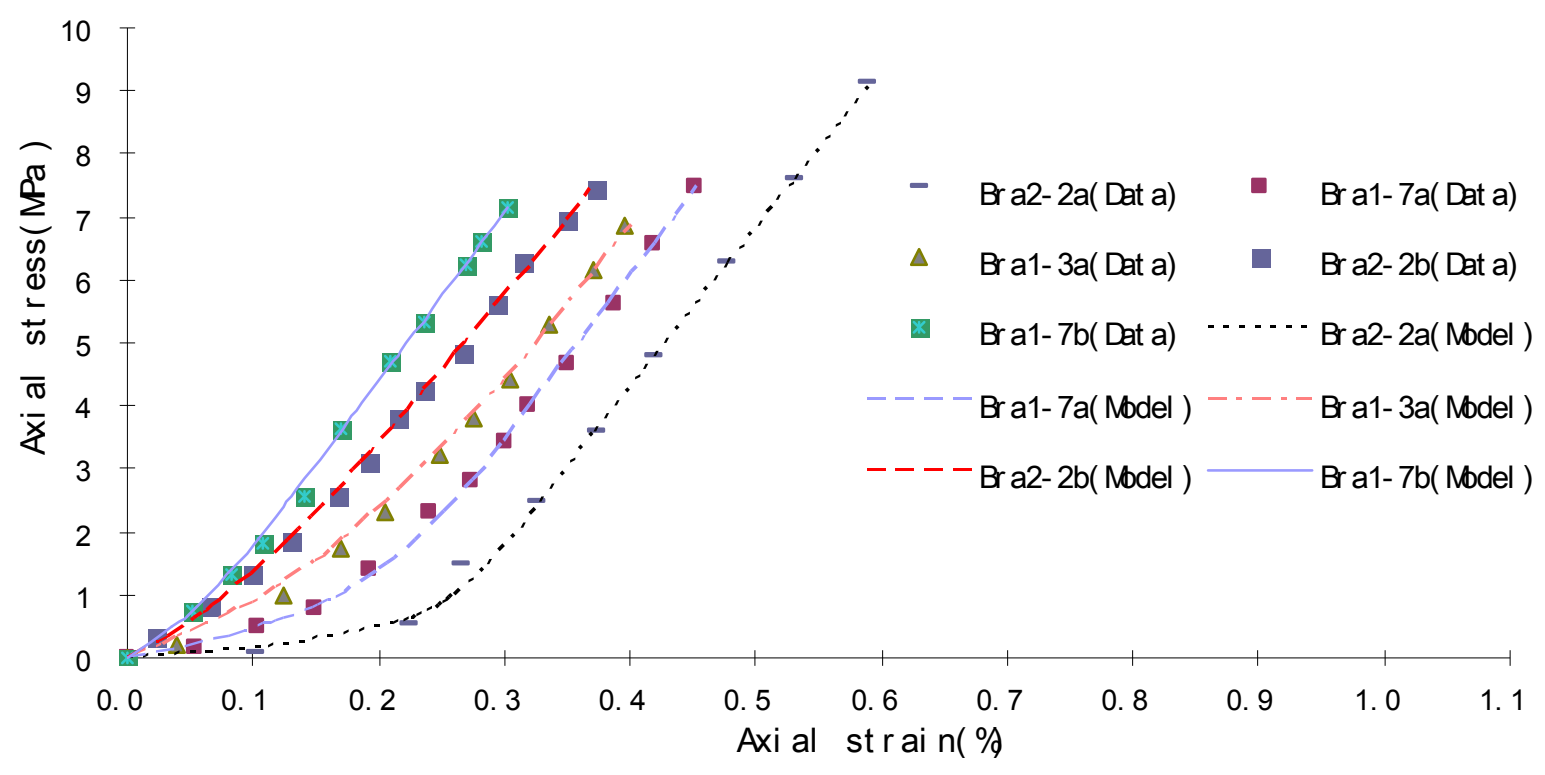

Figure 2-1. Matches between results calculated from Eq. (2-10) and experimental data from unconfined compression tests on clay rock (Corkum and Martin 2007a) 


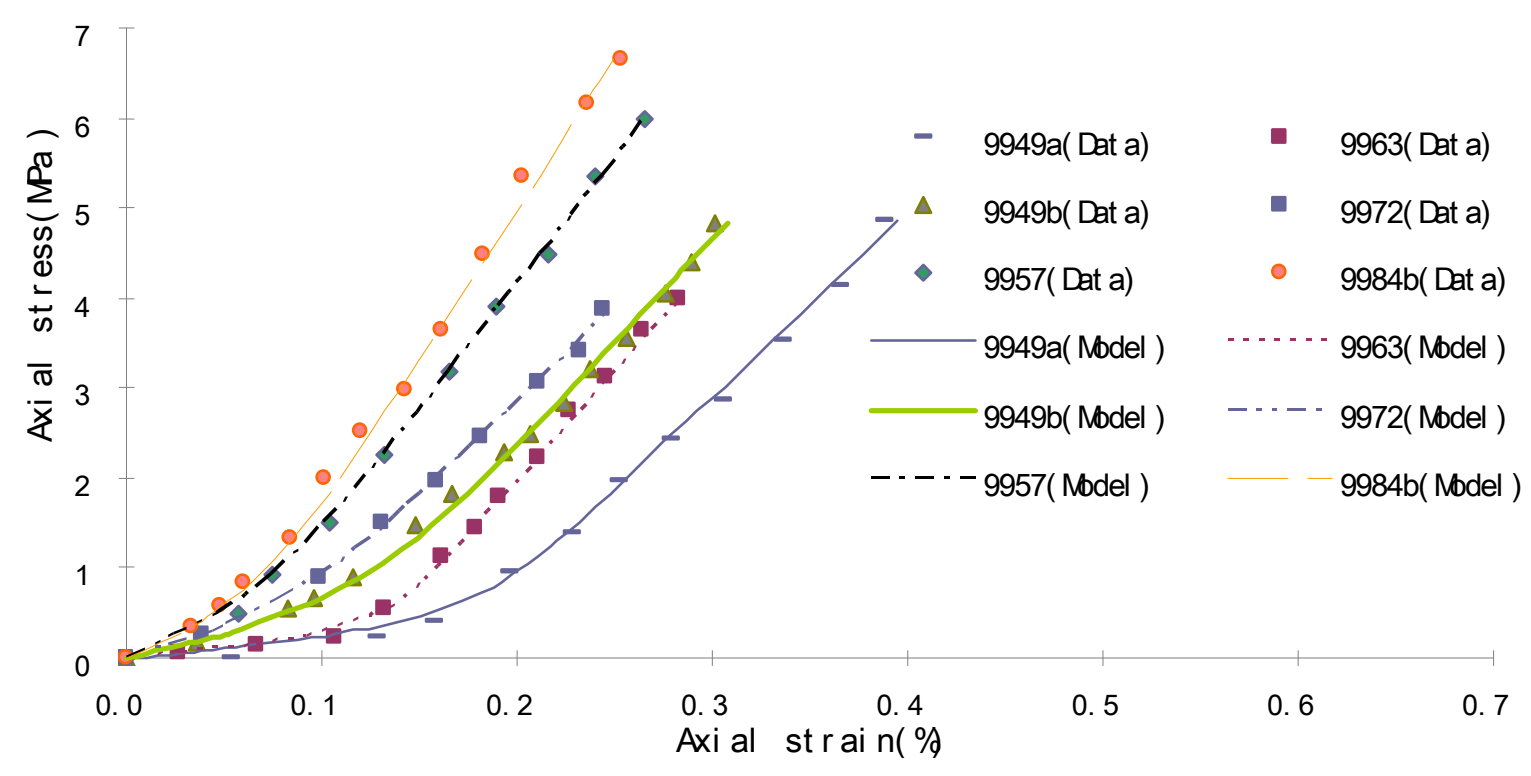

Figure 2-2. Matches between results calculated from Eq. (2-10) and experimental data from unconfined compression tests on clay rock (Olalla et al., 1999).

To further evaluate the impact of the soft part on rock mechanical deformation, Figure 23 shows strain-stress curves calculated from (2-10) by considering the hard part only, soft part only, and hard part + soft part, respectively. Clearly, the soft part has a larger strain than the hard part at the early stage of uniaxial loading, even though the volumetric ratio $\gamma_{t}$ is much lower than that for the hard part. The curves in Figure 2-3 also suggest that the soft-part strain is important for porous rock, especially at low stresses.

(a)

(b) 

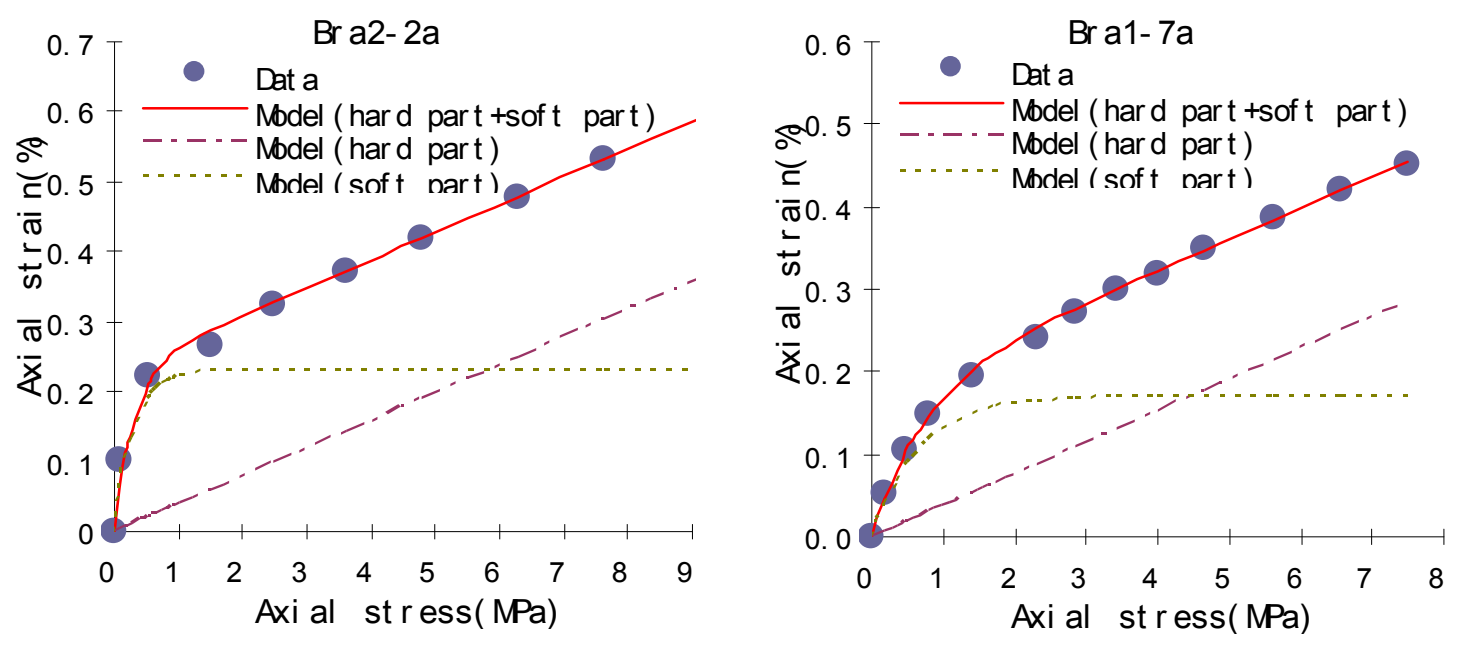

(c)

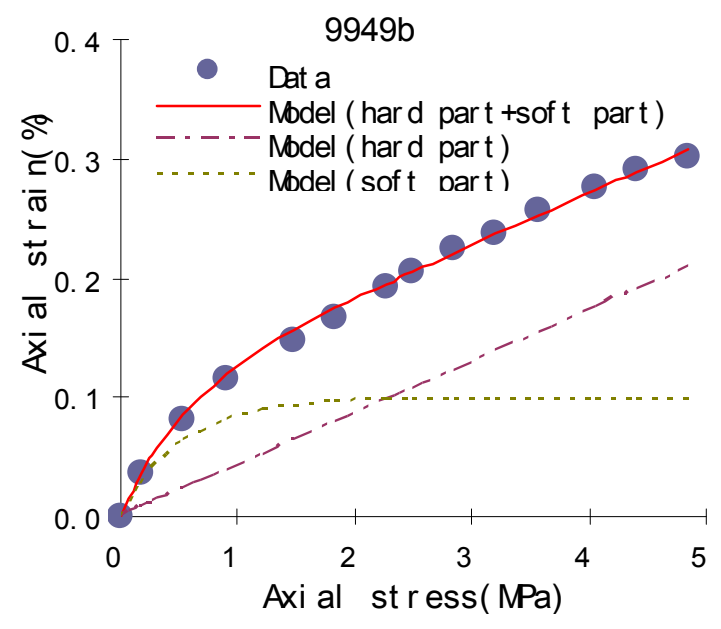

(d)

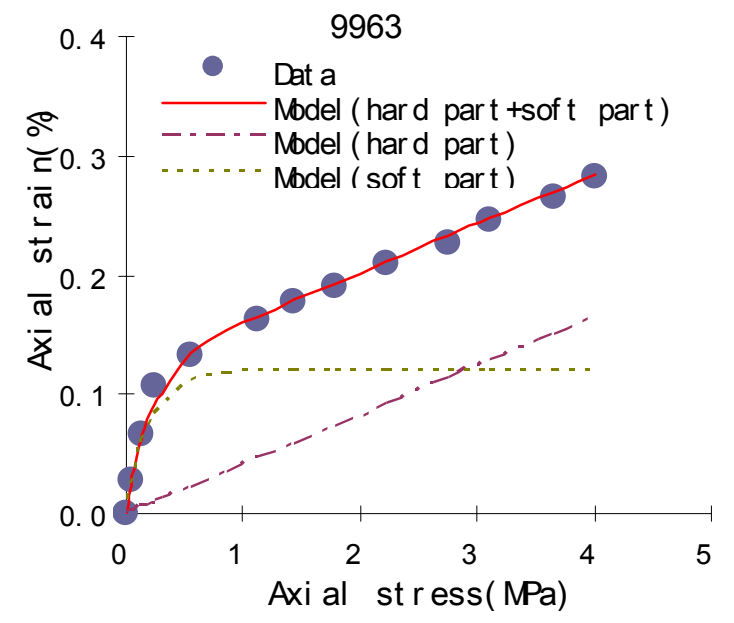

Figure 2-3. Comparisons between hard part strain and soft part strain

To further verify our stress-strain relationship, we compare our theoretical results with data from triaxial compression tests for a porous white sandstone (drilled from a construction site near metropolitan Taipei) (Tien et al., 1990), a shale rock (Xu et al., 2006a), and a conglomerate rock ( $\mathrm{Hu}$ and Liu, 2004). These triaxial tests involve a cylindrical rock sample subjected to confining pressure $\sigma_{c}$ (corresponding to axial strain $\varepsilon_{0}$ ), keeping a constant confining pressure and then controlled increases in axial stresses. In these tests, the measured relationships between deviatoric stress $\left(\sigma_{1}-\sigma_{c}\right)$ and axial strain $\left(\varepsilon_{1}-\varepsilon_{c}\right)$ are generally reported and used in our evaluation. When the confining pressure is constant, applying Equation (2-10) yields: 


$$
\varepsilon_{1}-\varepsilon_{c}=\frac{\gamma_{e}}{E_{e}}\left(\sigma_{1}-\sigma_{c}\right)+\frac{\gamma_{t}}{3} \exp \left(-\frac{3 \sigma_{c}}{E_{t}}\right)\left[1-\exp \left(-\frac{3\left(\sigma_{1}-\sigma_{c}\right)}{E_{t}}\right)\right]
$$

Figures 2-4, 2-6, and 2-8 show the satisfactory matches of (2-13) with observed data from rock samples under triaxial compression conditions. The curve-fitted results indicate that the $\gamma_{t}$ value ranges from $2.4 \%$ to $3.3 \%$ for the sandstone rock, from $0.9 \%$ to $1.02 \%$ for the conglomerate rock, and is $1.65 \%$ for the shale rock under consideration. Because different rock samples are used for different stress conditions during triaxial compression tests, some variation in fitted values for rock parameters are observed for a given rock type. The fitted parameter values are listed in Table 2-2, 2-3 and 2-4.

To further demonstrate the relative importance of the soft part, Figures 2-5, 2-7 and 2-9 show the results of both the soft-part strain and the ratio of soft-part strain to the hard-part strain as a function of axial stress. ( $\mathrm{R}$ denotes the ratio in those figures.) These curves describe the overall deformation behavior of the soft part, showing significant increase in strain with stress initially and then a slow change in strain. All samples show a decrease in $\mathrm{R}$ with increased confining pressure for a given deviatoric stress, and with increased axial stress at a given deviatoric stress.

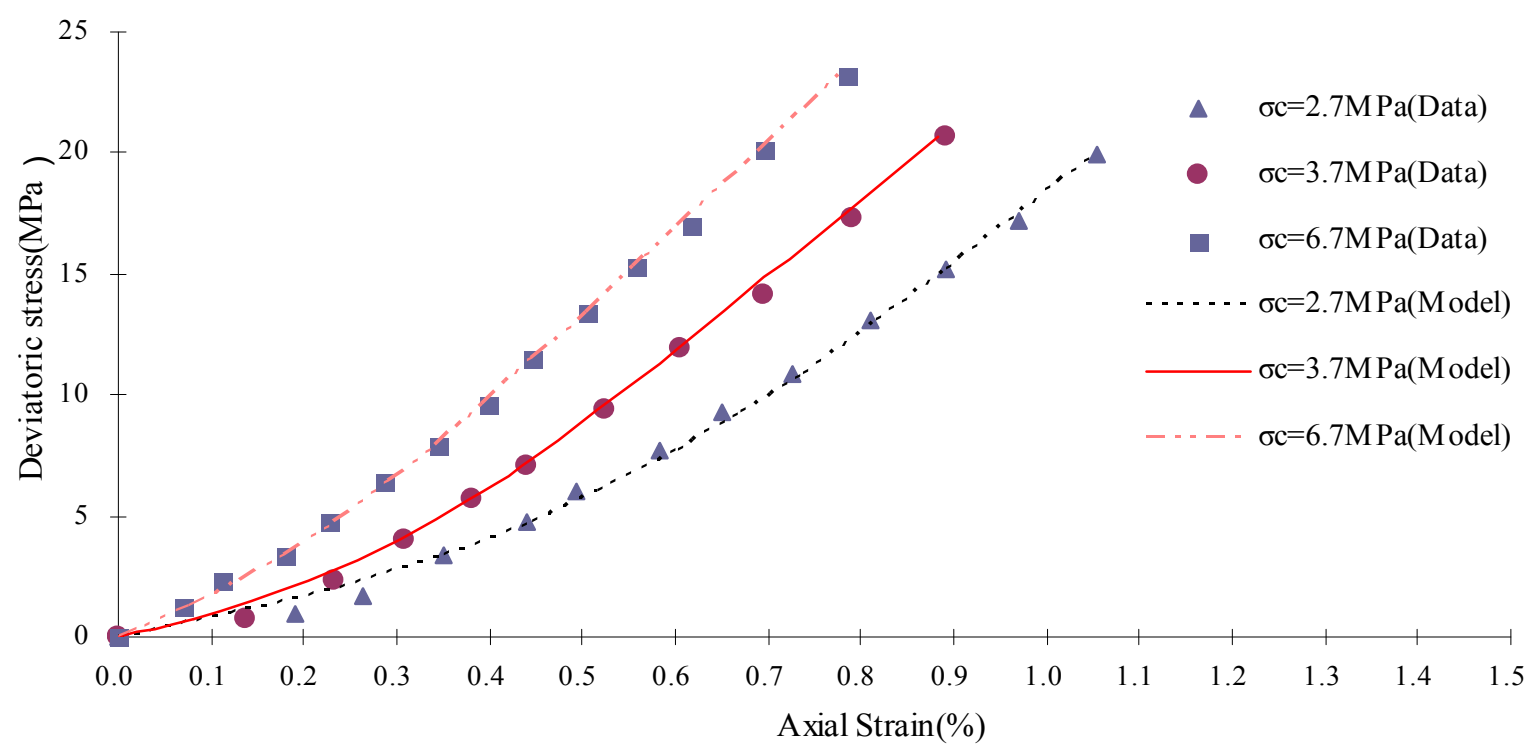

Figure 2-4. Matches between results calculated from Equation (2-13) and experimental data from triaxial compression tests on a sandstone (Tien et al., 1990) 

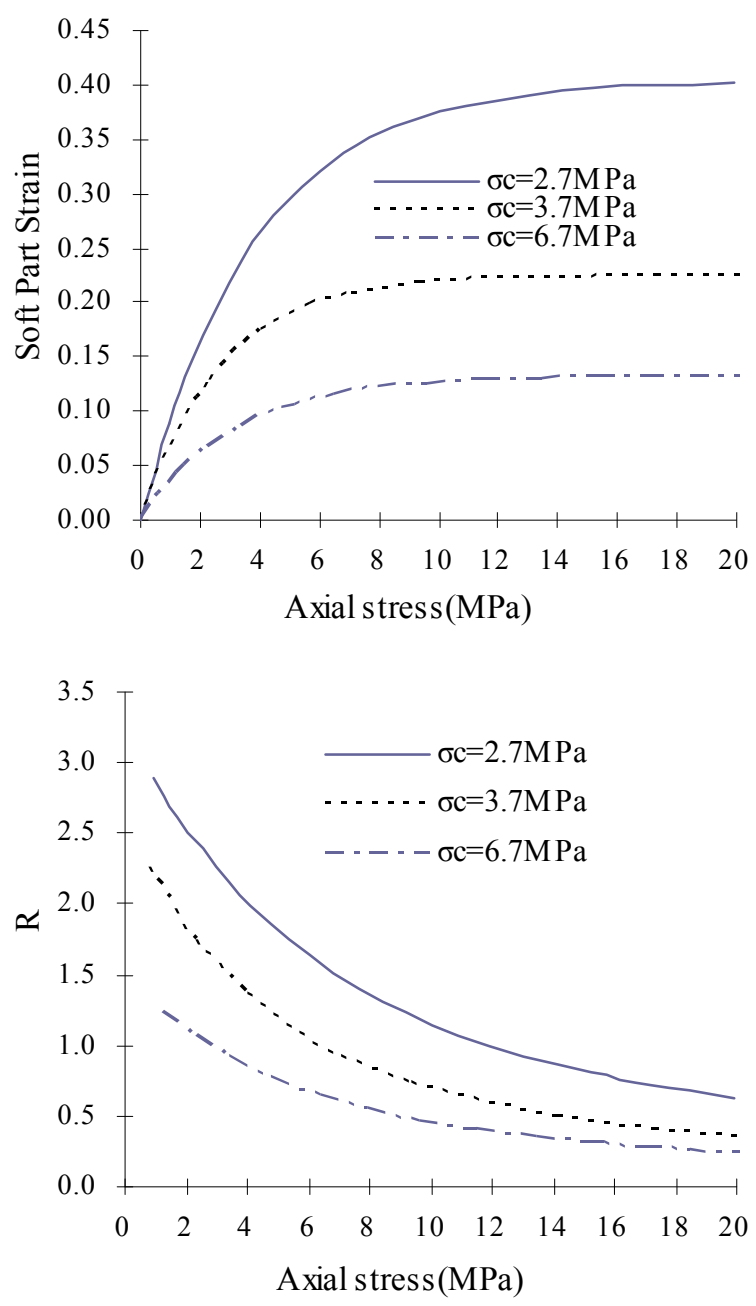

Figure 2-5. Soft part strain and $\mathrm{R}$ (the ratio of soft part strain to the hard part strain) as a function of axial stress at different confining pressure for a sandstone.

Table 2-2. Fitted parameter values from the experimental data for sandstone.

\begin{tabular}{|c|c|c|c|c|}
\hline Confining pressure $(\mathrm{MPa})$ & $E_{e}(\mathrm{MPa})$ & $\gamma_{e}$ & $E_{t}(\mathrm{MPa})$ & $\gamma_{t}$ \\
\hline 2.7 & 3070.0 & 0.97534 & 11.4 & 0.02466 \\
\hline 3.7 & 3140.0 & 0.97343 & 8.1 & 0.02657 \\
\hline 6.7 & 3600.0 & 0.96786 & 9.6 & 0.03214 \\
\hline
\end{tabular}




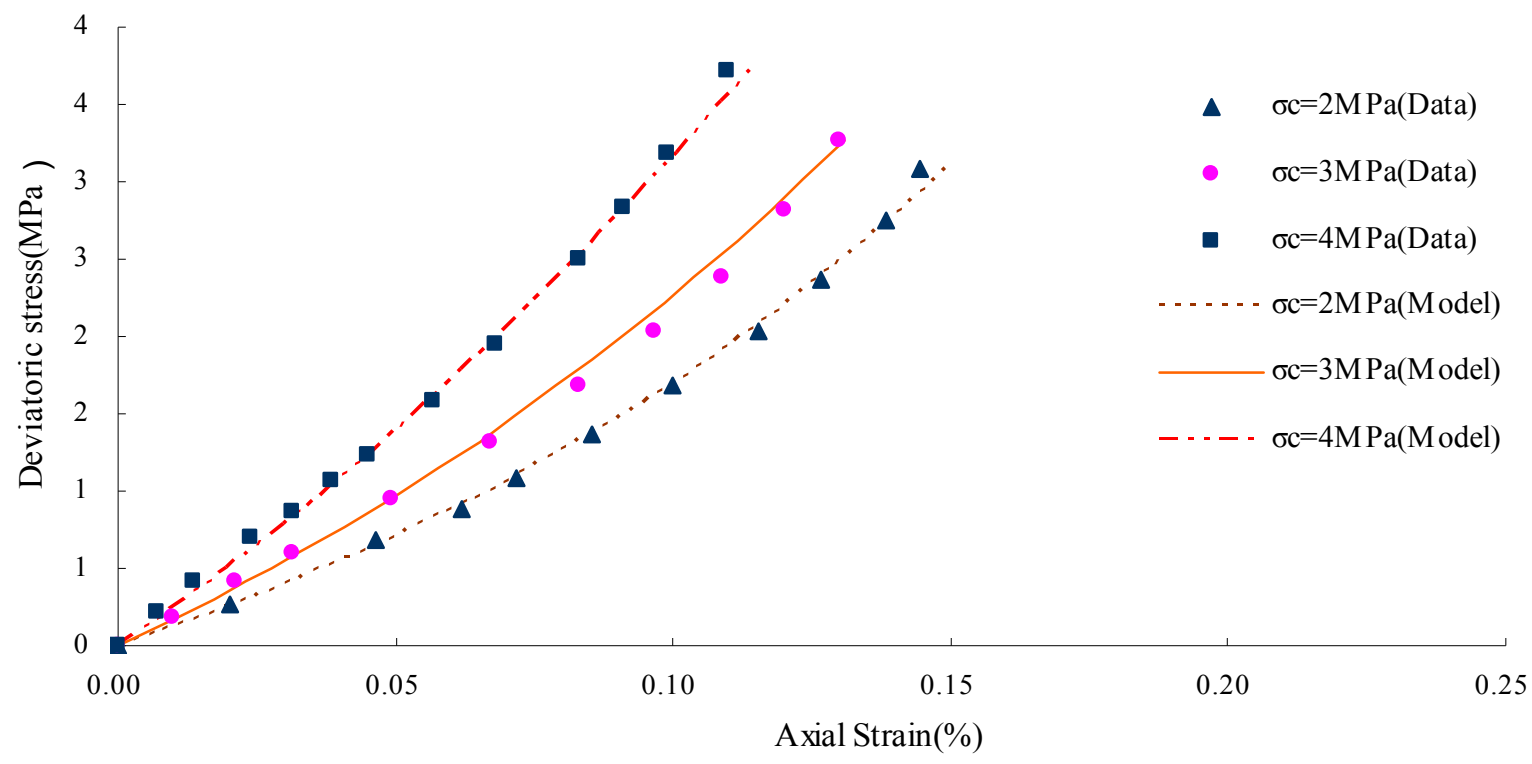

Figure 2-6. Matches between results calculated from Equation (2-13) and experimental data from triaxial compression tests on a conglomerate rock (Hu et al., 2004) 

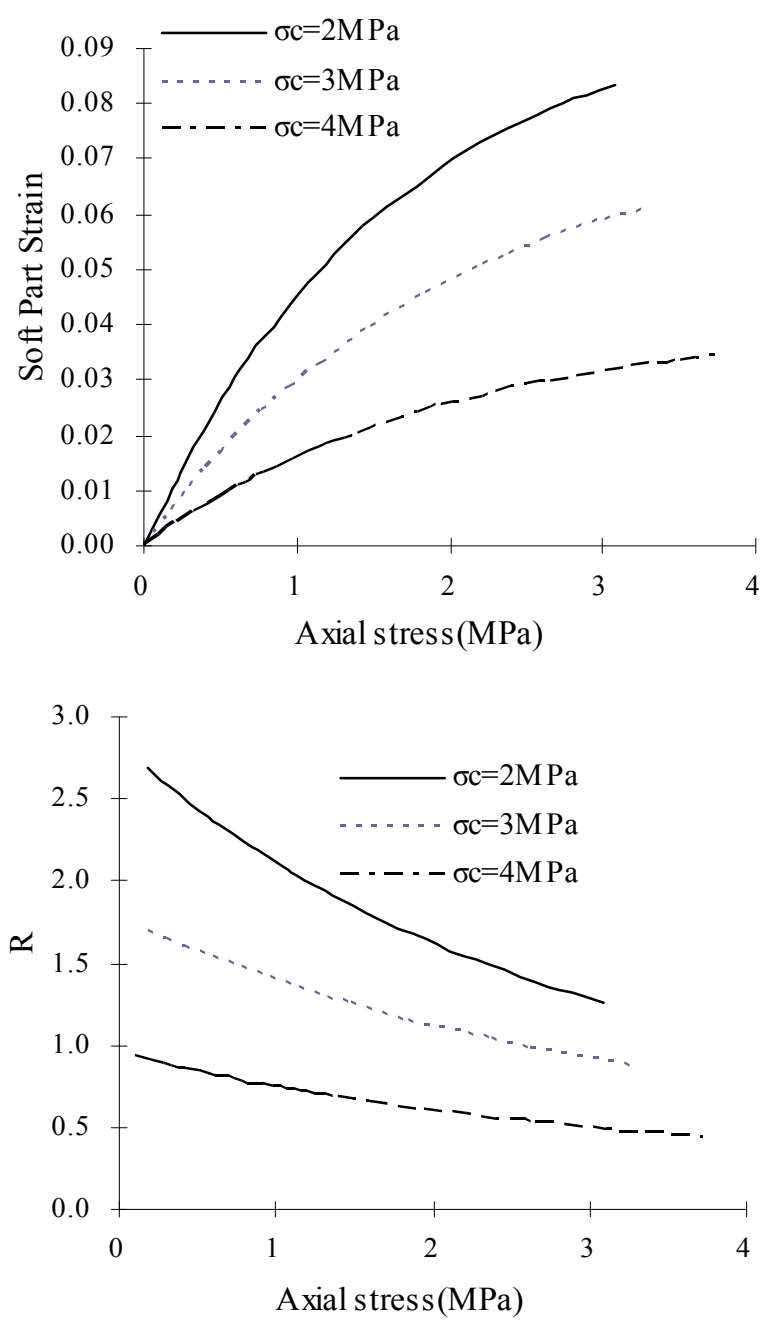

Figure 2-7. Soft part strain and $\mathrm{R}$ (the ratio of soft part strain to the hard part strain) as a function of axial stress at different confining pressure for a conglomerate rock.

Table 2-3. Fitted parameter values from the experimental data for conglomerate rock

\begin{tabular}{|c|c|c|c|c|}
\hline Confining pressure $(\mathrm{MPa})$ & $E_{e}(\mathrm{MPa})$ & $\gamma_{e}$ & $E_{t}(\mathrm{MPa})$ & $\gamma_{t}$ \\
\hline 2 & 4670.0 & 0.99100 & 4.8 & 0.00900 \\
\hline 3 & 4670.0 & 0.98980 & 6.0 & 0.01020 \\
\hline 4 & 4670.0 & 0.98980 & 6.0 & 0.01020 \\
\hline
\end{tabular}




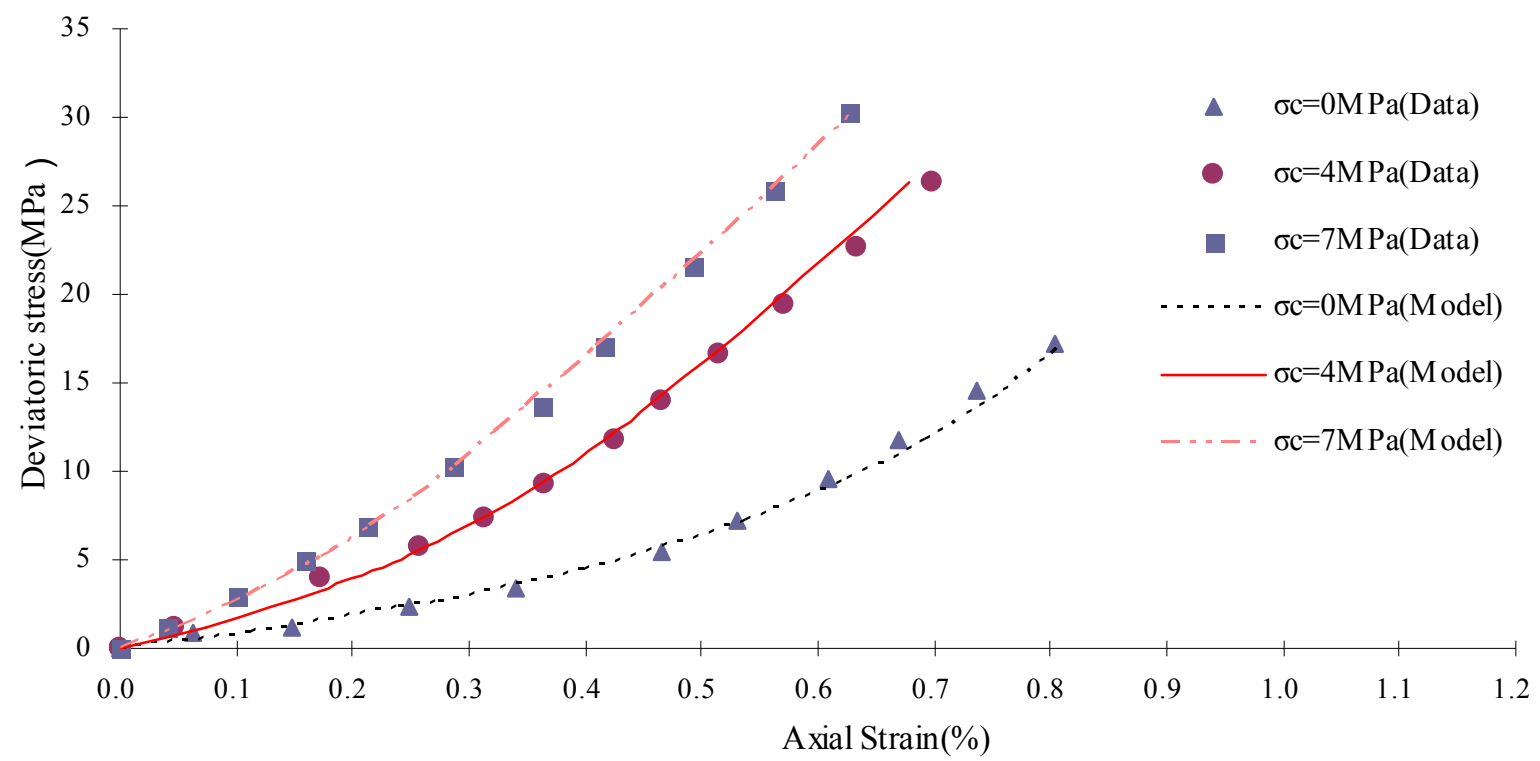

Figure 2-8. Matches between results calculated from Equation (2-13) and experimental data from triaxial compression tests on shale rock (Xu et al., 2006a). 

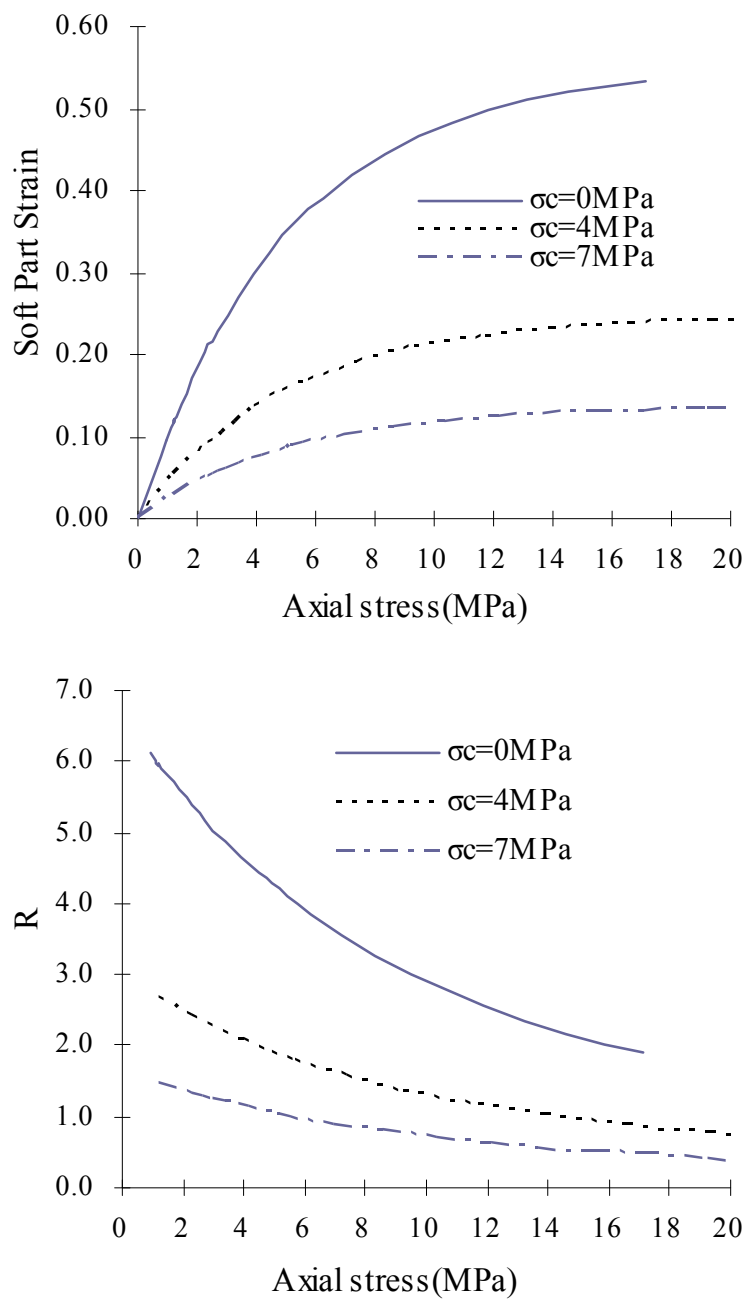

Figure 2-9. Soft part strain and $\mathrm{R}$ (the ratio of soft part strain to the hard part strain) as a function of axial stress at different confining pressure for a shale rock.

Table 2-4. Fitted parameter values from the experimental data for shale rock.

\begin{tabular}{|c|c|c|c|c|}
\hline $\begin{array}{c}\text { Confining } \\
\text { pressure }(\mathrm{MPa})\end{array}$ & $E_{e}(\mathrm{Mpa})$ & $\gamma_{e}$ & $E_{t}(\mathrm{Mpa})$ & $\gamma_{t}$ \\
\hline 0 & 6100.0 & 0.98350 & 15.0 & 0.01650 \\
\hline 4 & 6100.0 & 0.98350 & 15.0 & 0.01650 \\
\hline 7 & 6100.0 & 0.98350 & 15.0 & 0.01650 \\
\hline
\end{tabular}




\subsubsection{Stress-dependent mechanical and hydraulic rock properties}

Our newly developed stress-strain relationship (Equation 2-10) allows derivation of a variety of additional constitutive relationships among mechanical and hydraulic properties. This subsection presents the stress dependence of porosity and compressibility, as illustrative examples. While our focus here is on a clay repository, our developed results can be applied to other geological formations as well. Experimental data for clay rock are generally limited to the stress dependence of rock properties. Therefore, data from sandstones are used here for evaluating the stress-dependence relationships of porosity and compressibility.

\section{Porosity}

Rock porosity is an important parameter for modeling coupled hydrological and mechanical processes, because flow processes occur in pore spaces. Following Liu et al. (2009), we assume that the soft part is a fraction of pore space. In this case, the rock porosity is defined by

$$
d \phi=\frac{d V^{p}}{V}=\frac{d V_{e}^{p}+d V_{t}}{V} \approx \frac{d V_{e}^{p}+d V_{t}}{V_{0}}
$$

where $V$ is the bulk volume of rock and superscript $p$ refers to pore space. Liu et al. (2009) indicated that for the purpose of calculating porosity, the total rock volume $V$ could be approximated with the undressed volume $V_{0}$, because their difference is small in practical applications.

For pores associated with the hard part of the rock, we have

$$
\frac{d V_{e}^{p}}{V_{0}}=\frac{V_{0, e}^{p}}{V_{0}} \frac{d V_{e}^{p}}{V_{o, e}^{p}}=-\left(\phi_{0}-\gamma_{t}\right) C_{e}\left(d \sigma_{1}+d \sigma_{2}+d \sigma_{3}\right)
$$

To derive the above equation, we use the following relationships:

$$
\frac{V_{0, e}^{p}}{V_{0}}=\phi_{0}-\gamma_{t}
$$

and

$$
C_{e}=-\frac{1}{3 V_{0, e}^{p}} \frac{\partial V_{e}^{p}}{\partial \sigma_{i}} \quad(\mathrm{i}=1,2,3)
$$


where $V_{\sigma_{e}}$ is the pore volume within the hard part of the rock under unstressed conditions, $\phi_{0}$ is porosity under unstressed conditions, and $C_{e}$ is pore compressibility (constant).

From Equation (2-12) and its derivation procedure, it can be mathematically shown that the porosity change owing to the soft part, $\frac{d V_{m}^{2}}{V_{0}}$, is the same as the last three terms on the right hand of (2-12). Thus, we have

$$
\begin{aligned}
d \phi= & -\left(\phi_{0}-\gamma_{t}\right) C_{e}\left(d \sigma_{1}+d \sigma_{2}+d \sigma_{3}\right)- \\
& \frac{\gamma_{t}}{E_{t}} \times\left[\exp \left(-\frac{3 \sigma_{1}}{E_{t}}\right) d \sigma_{1}+\exp \left(-\frac{3 \sigma_{2}}{E_{t}}\right) d \sigma_{2}+\exp \left(-\frac{3 \sigma_{3}}{E_{t}}\right) d \sigma_{3}\right]
\end{aligned}
$$

Using the condition that unstressed porosity is $\phi_{0}$, we obtain:

$$
\begin{aligned}
\phi= & \phi_{0}-\gamma_{t}-\left(\phi_{0}-\gamma_{t}\right) C_{a}\left(\sigma_{1}+\sigma_{2}+\sigma_{3}\right) \\
& +\frac{\gamma_{t}}{3}\left[\exp \left(-\frac{3 \sigma_{1}}{E_{t}}\right)+\exp \left(-\frac{3 \sigma_{2}}{E_{t}}\right)+\exp \left(-\frac{3 \sigma_{3}}{E_{t}}\right)\right]
\end{aligned}
$$

We use experimental results from uniaxial tests to verify our porosity-stress relation, or Equation (2-19), while relevant data are very limited for more complex stress conditions. Peng and Zhang (2007) reported a data set of porosity (as a function of axial stress) under uniaxial strain conditions for two sandstone specimens cored $1000 \mathrm{~m}$ below the sea floor. Satisfactory matches between results calculated from Equation (2-19) and porosity data are shown in Figure 2-10. The curve-fitted results indicate that values for $\gamma_{t}$ range from $1.77 \%$ to $2.04 \%$ for the sandstone samples under consideration, and that are $15.0 \mathrm{MPa}$ for $E_{t}$ (Table 2-5). Note that the value for $E_{t}$ is generally consistent with that reported in Table 2-2. However, the estimated $\gamma_{t}$ values are much higher than those given in Table 22, which may be a result of rock porosity values in this part of the study being much higher. 

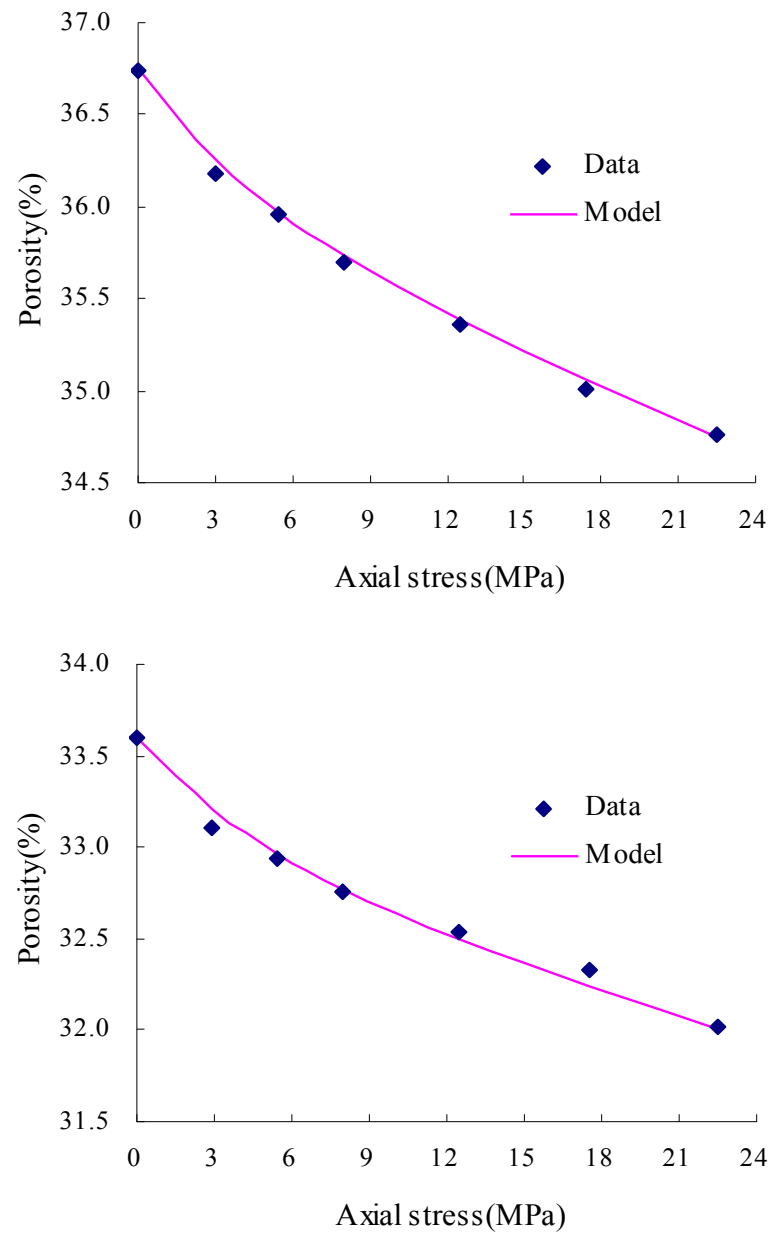

Figure 2-10. Comparisons between results calculated from Equation (2-19) and experimental data from uniaxial strain tests for two sand specimens (Peng and Zhang, 2007)

Table 2-5. Fitted parameter values from the experimental data for sandstone samples

\begin{tabular}{|c|c|c|c|c|}
\hline Specimens & $\phi_{0}(\%)$ & $C_{a}\left(10^{-3} \mathrm{MPa}^{-1}\right)$ & $E_{t}(\mathrm{MPa})$ & $\gamma_{t}$ \\
\hline 1 & 36.75 & 1.70 & 15.0 & 0.0204 \\
\hline 2 & 33.60 & 1.44 & 15.0 & 0.0177 \\
\hline
\end{tabular}

Note that a similar form of relationship between stress and porosity was also reported by Shapiro and Kaselow (2005). They assumed that pore space contains so-called compliant porosity (similar to the "soft part" in this study) and also derived a number of relationships between stress and other mechanical properties under anisotropic conditions (Shapiro and Kaselow, 2005). However, several important differences can be observed 
when comparing our theory with theirs. First, our theory is based on the natural-strainbased Hooke's law, which is fundamentally different from the physical origin of Shapiro and Kaselow (2005). Second, their theory is theoretically valid only for rock with moderate or small porosity, on the order of 0.1 or less (Shapiro and Kaselow, 2005). As evidenced by the corresponding derivation procedures, our results are not subject to this limitation. Finally, the validity of Shapiro and Kaselow's (2005) theory requires that their compliant porosity must be a very small part of total porosity. Again, our theory is not limited by this, largely because our theory as mentioned above has a different physical origin. It can be applied to cases in which soft porosity is large. For example, Liu et al. (2009) successfully derived the relationship between stress and fracture aperture. Unlike the "soft" part of porous rock, the "soft" part in a fracture corresponds to a much larger portion of fracture voids than the hard part (Liu et al., 2009).

\section{Bulk Compressibility}

Bulk compressibility is often used to quantify the ability of a rock to reduce in volume with applied pressure. It may be defined in different ways; in this study, we define bulk compressibility (associated with a principal stress $\sigma_{i}$ ) by

$$
C_{i}=\frac{\partial \varepsilon_{v}}{\partial \sigma_{i}} \quad(i=1,2,3)
$$

Based on the above equation and (2-12), the compressibility can readily be determined as

$$
C_{i}=\frac{\gamma_{e}(1-2 \gamma)}{E_{e}}+\frac{\gamma_{t}}{E_{t}} \exp \left\{-\frac{3 \sigma_{i}}{E_{t}}\right\} \quad(i=1,2,3)
$$

Morgenstern and Tamuly Phukan (1969) investigated the relationship between modulus of compressibility and stress for Bunter sandstone. We use results from Morgenstern and Tamuly Phukan's (1969) uniaxial tests to verify our compressibility-stress relation (Equation (2-21)). For uniaxial tests, we need only consider $C_{1}$, because $\sigma_{2}=\sigma_{3}=0$. As shown in Figure 2-11, our relationship satisfactorily matches the data, further supporting our overall theoretical results developed for anisotropic conditions. The estimated parameter values for sandstone are presented in Table 2-6. Note that the compressibility, $C$, defined by Morgenstern and Tamuly Phukan (1969) is three times the compressibility given in (2-21). In Figure 2-11, the former is used. 

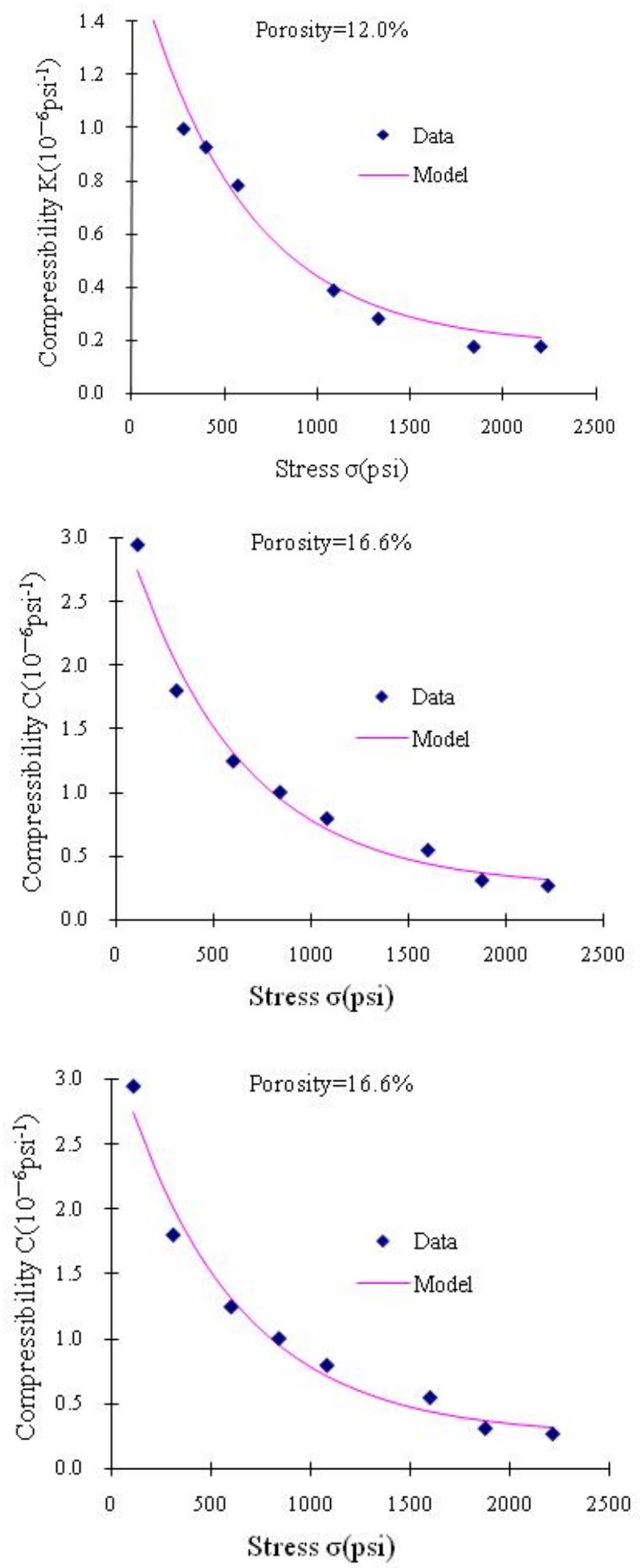

Figure 2-11. Comparisons between the uniaxial test data for Bunter sandstone (Morgenstern and Tamuly Phukan 1969) and the compressibility-stress relationship (Equation (2-21)). 
Table 2-6. Fitted parameter values from the experimental data for Bunter sandstone

\begin{tabular}{|c|c|c|c|c|}
\hline$\phi(\%)$ & $E_{e}\left(10^{3} \mathrm{psi}\right)$ & $\gamma_{e}$ & $E_{t}\left(10^{3} \mathrm{psi}\right)$ & $\gamma_{t}$ \\
\hline 12.0 & 9914.000 & 0.99914 & 1.725 & 0.00086 \\
\hline 15.3 & 7187.544 & 0.99827 & 1.725 & 0.00173 \\
\hline 16.8 & 7187.544 & 0.99827 & 1.725 & 0.00173 \\
\hline
\end{tabular}

\subsubsection{Conclusions}

Liu et al. (2010) reported a stress-strain relationship for clay and other rocks under elastic and isotropic conditions. In this study, we extend that work to anisotropic stress conditions. It was shown that the new relationship could satisfactorily represent a number of experimental observations. Furthermore, based on this relationship, we derived additional constitutive relationships between stress and selected mechanical or hydraulic rock properties (compressibility and porosity). The consistency between these relations and data further supports the usefulness and validity of our stress-strain relationship, which is a critical input to coupled-process simulators. The constitutive model reported here was not incorporated into the simulations presented in Sections 3 and 4 because it was only recently developed.

\subsection{Unsaturated properties for non-Darcian water flow in clay}

\subsubsection{State of the art}

Because of the impact of heat-transport processes (caused by radionuclide decay within waste packages) and water-flow processes between clay rock and an engineered barrier, an unsaturated zone generally develops within the near field of a clay repository. Furthermore, in radioactive waste disposal at great depth, compacted expansive clay soils (bentonites) are often considered as buffer materials within an engineered barrier system, to be placed between the radioactive waste and the host rock. The bentonite is usually compacted at low water content, such that it is progressively wetted by water from the host formation. The unsaturated wetting process is accompanied by the bentonite swelling to ensure acceptable sealing of open spaces between waste packages and the corresponding host formation. Therefore, accurately modeling unsaturated flow in clay materials is critical for assessing the performance of both clay rock and buffer materials for isolating radioactive wastes at a disposal site. 
It has been documented in the literature that water flow in clays cannot be adequately described by the commonly used Darcy law, which states that water flux is directly proportional to hydraulic gradient. For example, Hansbo (2001) reported that water flux is proportional to a power function of hydraulic gradient when the gradient is less than a critical value, whereupon the relationship between water flux and gradient becomes linear for large gradient values. He explained this behavior by positing that a certain hydraulic gradient is required to overcome the maximum binding energy of mobile pore water. Moreover, Dixon et al. (1999) presented measured hydraulic conductivity data for clays, They found no "critical" or "threshold" gradients from their observations, but did find that there were "transitional" gradients that define two separate regions of Darcian flow. Lower hydraulic conductivities were observed for hydraulic gradients less than the transitional gradient. Dixon et al. (1999) indicated that clay could contain considerable quantities of structured water that shears at gradients above the transitional gradient, allowing it to participate in advective flow. Finally, Zou (1996) proposed a nonlinear flux-gradient relation depending on the activation energy of pore liquid. He assumed that the activation energy of pore water in clay (or fine-grained materials) is not only variable with the distance from the solid particle surface, but also with the flow velocity of pore water. His model, including several empirical parameters, was able to fit a number of data sets that show nonlinear flux-gradient relations at low hydraulic gradients and linear relations at high gradients. More studies of non-Darcian behavior for water flow in clay can be found in references cited in Hansbo (2001), Dixon et al. (1999), and Zou (1996). Although some inconsistency seems to exist among these studies, most studies demonstrated the existence of non-Darcian's flow behavior in clay under conditions of relatively low hydraulic gradients.

Note that such studies are all for saturated flow conditions; investigations for unsaturated flow in clay are very limited. It is expected that non-Darcian flow behavior becomes more significant under unsaturated conditions, because in such conditions, pore water exists as water films or occurs in relatively small pores, and therefore is subject to relatively strong interactions with the clay surface. This seems to be supported by experimental observations recently reported by Cui et al. (2008). They observed nonDarcian behavior for the full range of observed hydraulic gradients under unsaturated conditions.

While several models have been proposed for describing non-Darcian flow in clay in saturated conditions, a systematic investigation of constitutive models for unsaturated flow in clay materials is still lacking. The objective of this work is to develop such a model under unsaturated conditions, by considering pore water as a non-Newtonian fluid. 


\subsubsection{Theoretical model}

This section presents a theoretical model describing non-Darcian flow under unsaturated conditions. The model will be verified in the next section with data from a laboratory experiment. Theoretical development of the model is based on the hypothesis that pore water in clay materials is non-Newtonian and that flow is driven by the hydraulic gradient.

\subsubsection{Newtonian and non-Newtonian fluids}

In general, fluids can be classified as Newtonian or non-Newtonian. The former has a constant viscosity; thus, its shear stress is directly proportional to the shear rate defined as the velocity gradient perpendicular to the plane of shear. For non-Newtonian fluid, the viscosity is not constant anymore, but rather a function of shear rate and/or time. For example, Figure 2-12 shows typical relations between shear stress and shear rate for a Newtonian fluid and three non-Newtonian fluids. Pseudoplastic or shear-thinning fluids have a lower apparent viscosity at higher shear rates, and dilatant, or shear-thickening fluids increase in apparent viscosity at higher shear rates (e.g., Wu and Pruess, 1998). Bingham plastic fluids have a linear shear stress/shear strain relationship and require a finite yield stress before they begin to flow. In other words, the plot of shear stress against shear strain does not pass through the origin (Figure 2-12).

A relatively simple way to describe non-Newtonian behavior is to express the apparent viscosity $\left(\mu_{e}\right)$ as a power function of shear rate $\frac{\partial u}{\partial y}$ (e.g., Christopher and Middleman, 1965):

$$
\mu_{e}=\kappa\left(\frac{\partial u}{\partial y}\right)^{n-1}
$$

where $\kappa$ is a constant, $u$ is water velocity parallel to the plane of shear, $y$ is a coordinate perpendicular to the plane of shear, and $\mathrm{n}$ is a dimensionless number. The corresponding fluids are called "power-law fluids." In this case, the shear stress of fluid, $\tau$, is given by

$$
\tau=\mu_{e}\left(\frac{\partial u}{\partial y}\right)=\kappa\left(\frac{\partial u}{\partial y}\right)^{n}
$$

Equations (2-22) and (2-23) correspond to pseudoplastic fluid ( $n<1)$, Newtonian fluid ( $n$ $=1$ ), and dilatant fluid $(n>1)$, respectively. In this study, we focus on power-law fluids following Equations (2-22) and (2-23); Bingham plastic fluid is not considered. As demonstrated below, these equations seem to capture the non-Darcian behavior of pore water under unsaturated conditions reasonably well. Note that the methodology 
developed in this study can be easily applied to Bingham plastic fluids as well, when needed.

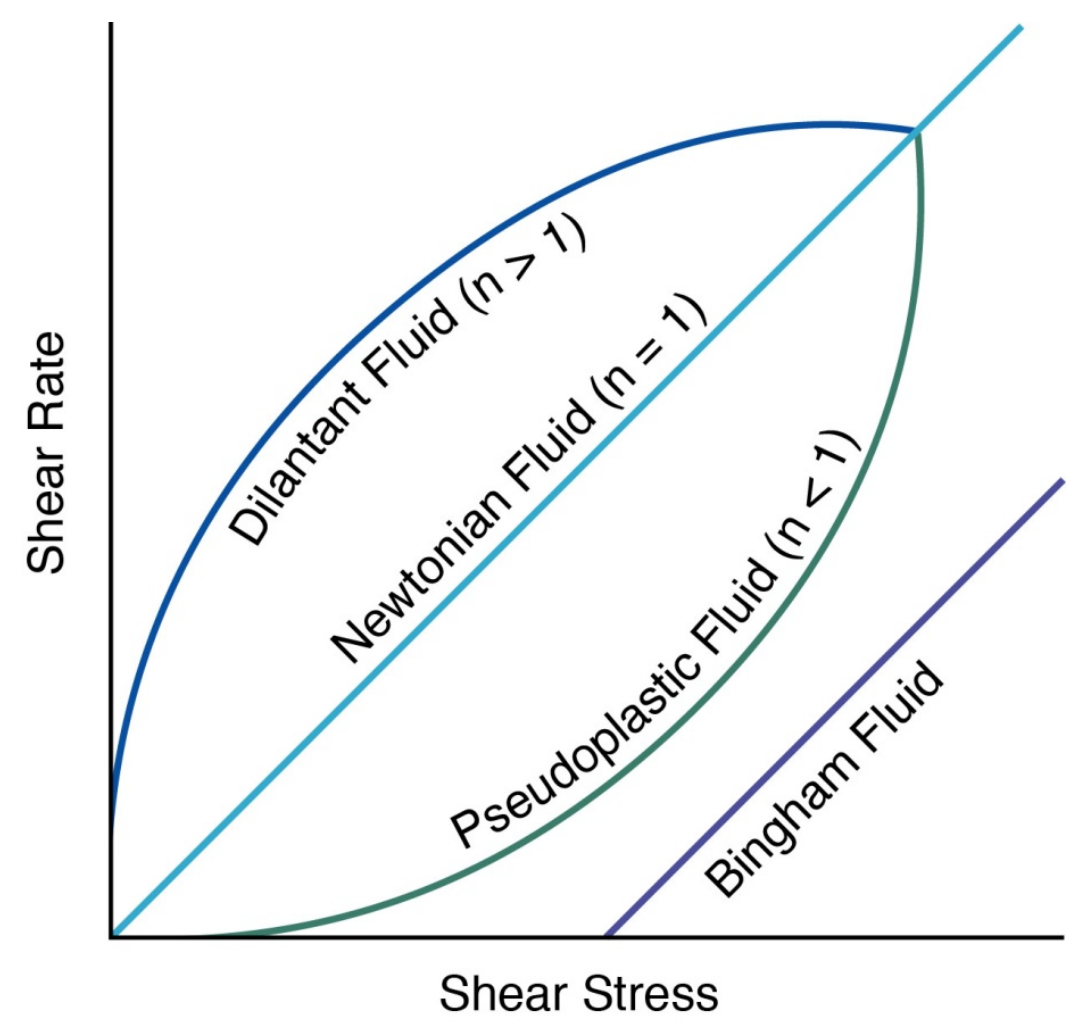

ESD11-020

Figure 2-12. Schematic demonstration of relations between shear stress and stress rate for a Newtoniain fluid and three typical non-Newtonian fluids

It is well documented in the literature that water properties will change near the clay surface as a result of water-clay interaction. Like other researchers (e.g., Zou, 1996), we believe that the observed non-Darcian behavior for water flow is caused by nonNewtonian properties of pore water in clay materials. These properties should be a direct result of strong water-clay interaction. However, this argument is largely based on observations at core scales and to the best of our knowledge has not been directly confirmed by measured viscosity and shear rate data at pore scale. Thus, it is appropriate to treat the considered correlation between non-Darcian behavior and non-Newtonian properties as a hypothesis at this point. 


\subsubsection{Relationship between flux and hydraulic gradient for a capillary tube}

In this subsection, we derive a relationship between water flux and hydraulic gradient for a capillary tube with radius $R$ (Figure 2-13). This will be used as the basis for developing corresponding relationships for clay materials. For simplicity, we consider a horizontal capillary tube here, while our result can be easily extended to capillary tubes with other orientations.

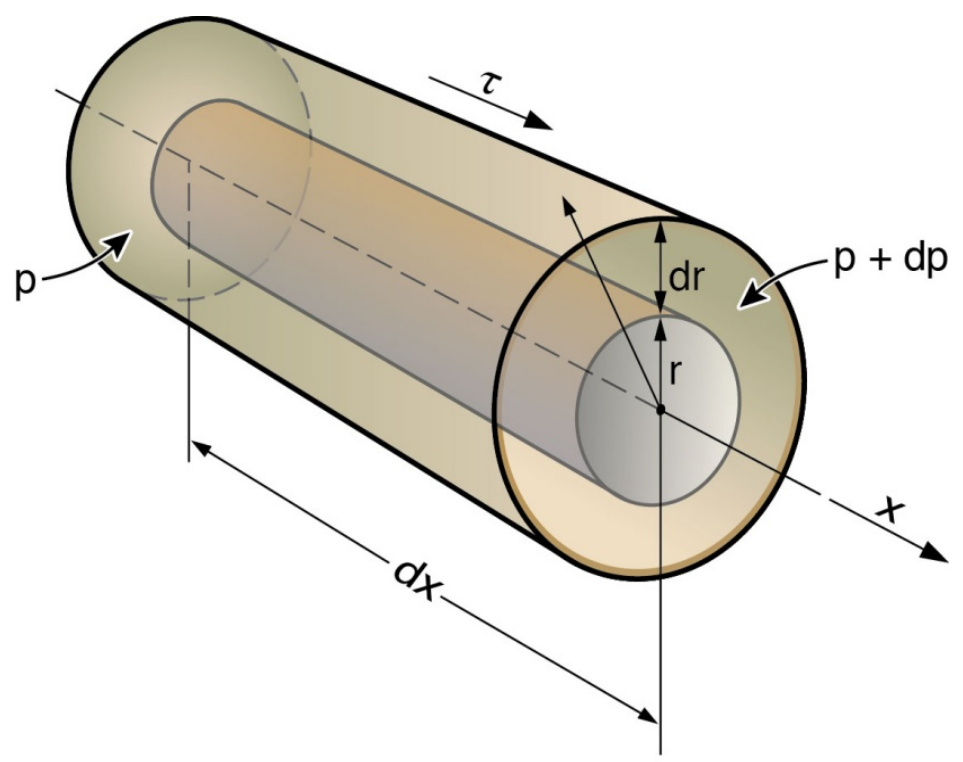

ESD11-021

Figure 2-13. A water element in a capillary tube

Considering water to be a non-Newtonian fluid in the capillary tube and using Equations (2-22) and (2-23), we can write the shear stress relationship as

$$
\tau=\kappa\left(\left|\frac{d u}{d r}\right|\right)^{n}
$$

where $r$ is radius coordinate. For a water surface with radius $r$ and length $d x$ (Figure 2$23)$, the total shearing force is

$$
F=\tau(2 \pi r) d x
$$

Then, the net shearing force for a water element with thickness $d r$ within the capillary tube, $d F$, is given by $d F=2 \pi(d x) d(r \tau)$. For laminar flow, the inertial effect can be ignored. In this case, the shearing force should be balanced by an opposing pressure on the water element that is $(d p)(d r)(2 \pi r)$. Therefore, we have

$$
d F=2 \pi(d x) d(r \tau)=(d p)(d r)(2 \pi r)
$$

Combining (2-24) and (2-26) yields: 


$$
r \frac{d p}{d x}=\frac{d(r \tau)}{d r}=\frac{d\left(r \kappa\left[\left|\frac{d u}{d r}\right|\right]^{n}\right)}{d r}
$$

The above equation can be solved for shear rate (or velocity gradient $\frac{d u}{d r}$ )

$$
\frac{r^{2}}{2} \frac{d p}{d x}+C=\kappa r\left(\left|\frac{d u}{d r}\right|\right)^{n}
$$

where $\mathrm{C}$ is a constant and determined to be zero by the following boundary condition (that is a result of symmetry):

$$
\left.\frac{d u}{d r}\right|_{r=0}=0
$$

Note $\left|\frac{d u}{d r}\right|=-\frac{d u}{d r}$ for the capillary tube under consideration. Then (2-28) can be rewritten as

$$
-\frac{d u}{d r}=\left(\frac{d p}{d x}\right)^{1 / n}\left(\frac{r}{2 \kappa}\right)^{1 / n}
$$

Further, using non-slip conditions on the surface of the capillary tube $(u=0$ at $r=R)$, the solution to (2-30) is given as

$$
u(r)=\left(\frac{d p}{d x}\right)^{1 / n} \int_{R}^{r}\left(\frac{r}{2 \kappa}\right)^{1 / n} d r=\left(\frac{d p}{d x}\right)^{1 / n}\left(\frac{1}{2 \kappa}\right)^{1 / n} \frac{n}{n+1}\left[R^{1+\frac{1}{n}}-r^{1+\frac{1}{n}}\right]
$$

The above equation gives the velocity distribution along the radius direction. The average water flux across the cross-sectional area of the tube is then determined by

$$
q_{C}=\frac{\int_{0}^{R} u(r)(d r)(2 \pi r)}{2 \pi R^{2}}=\left(\frac{1}{2 \kappa}\right)^{1 / n} \frac{n(n+1)}{2(n+1)(3 n+1)} R^{1+\frac{1}{n}}\left(\frac{d p}{d x}\right)^{\frac{1}{n}}
$$

\subsubsection{Theoretical model for unsaturated clay materials}

The pore space in a porous medium is often conceptualized as a group of capillary tubes with different tortuosity values and sizes (van Genuchten, 1980; Burdine, 1953). Thus, Equation (2-32) for a single capillary tube can be extended to represent the relationship between water flux, $q$, and hydraulic gradient $\frac{d H}{d x}$ in porous media: 


$$
q=-K\left(\left|\frac{d H}{d x}\right|\right)^{\frac{1}{n}} i
$$

where $H$ is the hydraulic head, $K$ is hydraulic conductivity, and $i$ is the unit vector for hydraulic gradient. Note that for a single capillary tube, $K$ is proportional to $R^{1+\frac{1}{n}}$, rather than $R^{2}$. (The latter is valid for Newtonian fluids.) The relationship between hydraulic conductivity for a capillary tube and $\mathrm{R}$ is the foundation for studying relative permeability under unsaturated conditions. Equations similar to (2-33) were also reported by a number of researchers (e.g., Pascal 1983; Wu and Pruess, 1998; Lopez et al., 2003). Most previous studies deal with single-phase fluid flow except $\mathrm{Wu}$ and Pruess (1998), who, however, did not consider how non-Newtonian behavior affected unsaturated flow properties. As discussed below, the major focus of this study is on determining how nonNewtonian behavior impacts the unsaturated properties of clay materials.

For unsaturated media, capillary pressure $P_{c}$ can be related to water saturation by the well-known Brooks-Corey (1964) relationship:

$$
\begin{array}{ll}
S_{e}=\left(\frac{P_{c}}{P_{d}}\right)^{-\lambda} & \text { for } P_{c}<P_{d} \\
S_{e}=1 & \text { for } P_{c} \geq P_{d}
\end{array}
$$

In (2-34), $\lambda$ is a fitting factor related to pore-size distribution, $P_{d}$ is the air entry value, and $S_{e}$ is the effective saturation defined by

$$
S_{e}=\frac{\theta-\theta_{r}}{\theta_{s}-\theta_{r}}
$$

where $\theta, \theta_{s}$ and $\theta_{r}$ are water content, saturated water content, and residual water content, respectively.

In the literature, the relative permeability for unsaturated media has often been provided by the Burdine (1953) model:

$$
K_{r}=\frac{K}{K_{s a t}}=S_{e}^{2} \frac{\int_{0}^{S_{e}} P_{c}^{-2} d S_{e}}{\int_{0}^{1} P_{c}^{-2} d S_{e}}
$$

where $K_{\text {sat }}$ is saturated hydraulic conductivity. In Equation (2-36), $S_{e}^{2}$ represents tortuosity, and $\frac{1}{P_{c}}$ characterizes the size (or radius) of the capillary tube (or pore space) under saturation $S_{e}$. The power value of -2 in the two integrals is results from the fact 
that, for Newtonian fluids, hydraulic conductivity for a capillary tube is proportional to the square of its radius. Therefore, Equation (2-36) is valid for Newtonian fluid only, because for a non-Newtonian fluid, the hydraulic conductivity of a capillary tube is not proportional to the square of the radius. Based on Equation (2-32), the Burdine (1953) model needs to be rewritten as

$$
K_{r}=\frac{K}{K_{\text {sat }}}=S_{e}^{2} \frac{\int_{0}^{S_{e}} P_{c}^{-\left(1+\frac{1}{n}\right)} d S_{e}}{\int_{0}^{1} P_{c}^{-\left(1+\frac{1}{n}\right)} d S_{e}}
$$

Combining Equations (2-34) and (2-37) yields

$$
K_{r}=\left(\frac{P_{c}}{P_{d}}\right)^{-\left(\frac{1}{n}+1+3 \lambda\right)}
$$

and

$$
K_{r}=S_{e^{3+\frac{1+\frac{1}{n}}{\lambda}}}
$$

In deriving Equations (2-38) and (2-39), we assumed that pore geometry does not change with saturation or capillary pressure. The hydraulic conductivity change is purely a function of changes in saturation. In reality, clay swells (or shrinks) with changes in saturation. In this case, the relative conductivity is given by

$$
K_{r}^{*}=\frac{K}{K_{\text {ref }}}=\left(\frac{K_{r}}{K_{\text {ref }, r}}\right)\left(\frac{K_{\text {sat }}}{K_{\text {ref }, \text { sat }}}\right)=\left(\frac{P_{c} P_{r e f, d}}{P_{d} P_{r e f, c}}\right)^{-\left(\frac{1}{n}+1+3 \lambda\right)}\left(\frac{K_{\text {sat }}}{K_{\text {ref }, \text { sat }}}\right)
$$

The subscript $r e f$ refers to the reference case in which measurements are available. For mechanically deforming media, it is convenient to define relative hydraulic conductivity respective to a reference case. In this case, relative conductivity can be larger than one. Also, in (2-40), we assumed, for simplicity, that pore-size distribution (or parameter $\lambda$ ) remains unchanged during swelling/shrinkage.

Based on the principle of Leverett (1941) scaling, relative changes in pore size can be approximately characterized by those in porosity $\phi$. By definition of air entry value $P_{d}$ and using (2-32), we have

$$
\frac{P_{r e f, d}}{P_{d}}=\frac{\phi}{\phi_{r e f}}
$$




$$
\frac{K_{\text {sat }}}{K_{\text {ref }, \text { sat }}}=\left(\frac{\phi}{\phi_{r e f}}\right)^{\left(1+\frac{1}{n}\right) \alpha}
$$

where parameter $\alpha>1$ accounts for the fact that the porosity ratio may underestimate the corresponding size ratio for those well-connected pores that determine the hydraulic conductivity. Dixon et al. (1999) showed that $\alpha>2.3$ for some saturated clay materials within a Darcian-flow regime.

Combining (2-40), (2-41), and (2-42), we obtain

$$
K_{r}^{*}=\left(\frac{P_{c}}{P_{r e f, c}}\right)^{-\left(\frac{1}{n}+1+3 \lambda\right)}\left(\frac{\phi}{\phi_{r e f}}\right)^{(\alpha-1)\left(1+\frac{1}{n}\right)-3 \lambda}
$$

In the right-hand side of (2-43), the first and second terms represent conductivity changes resulting from changes in capillary pressure and swelling (shrinkage), respectively. The second term needs to be determined by measurements or estimated using geomechanical simulators. Equations (2-33), (2-34), and (2-43) give the constitutive relationships required for modeling unsaturated flow in clay materials. Their validity will be evaluated in the next section by examining their consistency with data.

\subsubsection{A comparison with experimental observations}

As previously indicated, non-Darcian flow is a result of non-Newtonian properties of pore water in clay. However, experimental studies of non-Newtonian flow in porous media are very limited for unsaturated flow conditions. Most recently, Cui et al. (2008) reported the measurement results of unsaturated hydraulic conductivity for a compacted sand-bentonite mixture. To the best of our knowledge, this work provided the first reliable data set of water flux as a function of hydraulic gradient under unsaturated conditions.

The tests of Cui et al. (2008) were conducted under two different conditions: constant volume and free swelling. In this study, we focus on the data for constant-volume conditions only, reasoning that under constant-volume conditions and for a given capillary pressure, hydraulic processes and pore structures are approximately the same at different locations within the soil sample (Cui et al., 2008). Experimental determinations of the flux-gradient relationships required the use of this approximation. Cui et al. (2008) used the instantaneous profile method to determine the unsaturated hydraulic conductivity for infiltration tests of a vertical soil column. The soil column $(50 \mathrm{~mm}$ in diameter, $250 \mathrm{~mm}$ high) was directly compacted in the metallic cylinder (50 $\mathrm{mm}$ in inner diameter). The bottom of the test cell was connected to a water source, and the upper end to an air source under atmospheric pressure. Capillary pressures were monitored at 
several locations along the soil column. Under transient water-flow conditions, vertical distributions of capillary pressure were directly measured as a function of time. The relationship between water content and capillary pressure was independently measured under constant volume conditions. This relationship enables us to estimate vertical distributions of water content from capillary-pressure measurements. Based on these vertical distributions at different times, and on the mass balance at each location within the soil column, one could estimate the water flux at that location as a function of capillary pressure and hydraulic gradient. The details of this instantaneous method can be found in Daniel (1982) and Cui et al. (2008).

Figure 2-14 shows measured water flux (data points) as a function of hydraulic gradient under several capillary pressures. Obviously, very strong nonlinear (non-Darcian) behavior emerges at all the different capillary pressures, indicating that Darcy's law will not be valid for the range of hydraulic gradients under consideration. Based on Figure 8 of Cui et al. (2008), the unit of hydraulic gradient in Figure $2-14$ is $\mathrm{kPa} / \mathrm{m}$. This seems to support the notion that non-Darcian flow behavior becomes more significant under unsaturated conditions, because in unsaturated materials, pore water exists as water films or occurs in relatively small pores, and therefore is subject to relatively strong interactions with the clay surface, as previously indicated.

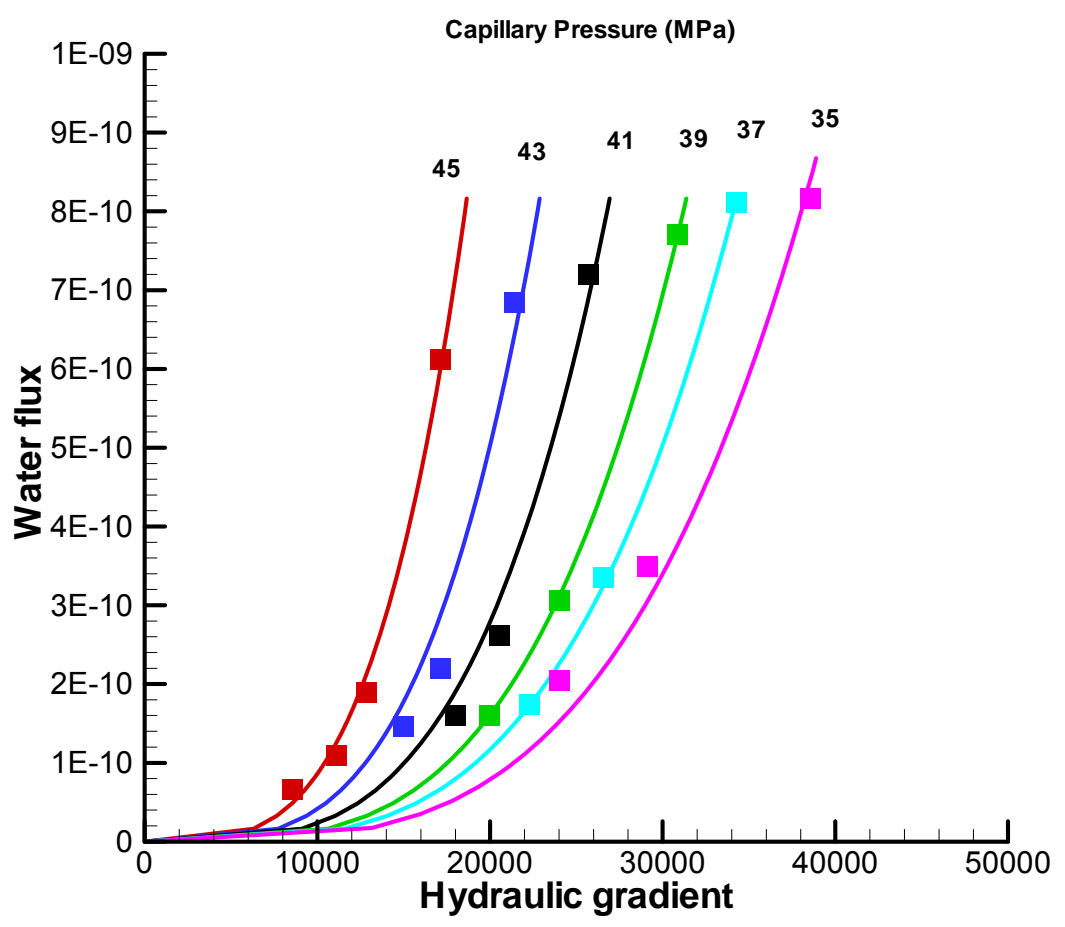

Figure 2-14. Comparisons between calculated (solid curves) and measured (data points) water flux as a function of hydraulic gradient for different capillary pressures. The calculation is based on Equation (2-33). Data from Cui et al. (2008) 
Figure 2-14 also matches Equation (2-33) (solid lines) with data for the six capillary pressures. The single value of $n=0.28$ seems to be able to fit all the data points reasonable well. In general, $n$ can be considered a measure of non-Newtonian behavior that may be saturation (or capillary pressure) dependent. Thus, $n$ may also be a function of saturation as well in a general case. At least the data of Cui et al. (2008) support the use of a constant $n$ for different capillary pressures-but more evaluations are needed before the issue can be fully resolved.

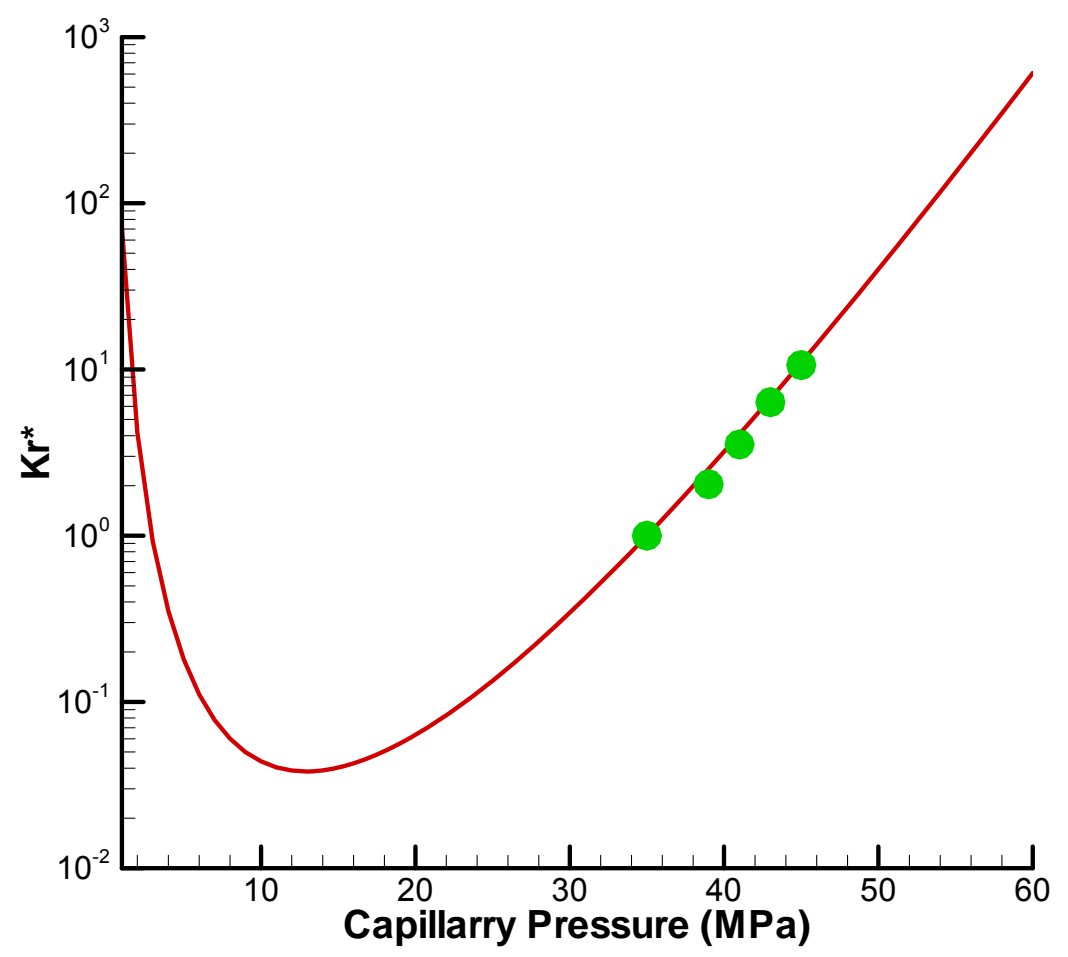

Figure 2-15. Calculated unsaturated hydraulic conductivity as a function of capillary pressure. The data points are determined from Figure 2-14. The solid curve is calculated from Eqs. (2-43) and (2-44) as an illustrative case. Data from Cui et al. (2008).

Figure 2-15 gives the values for relative hydraulic conductivity defined in Equation (240). The properties at capillary pressure of $35 \mathrm{MPa}$ are used as reference properties. Thus, $K_{r}^{*}=1$ in Figure 2-15 at that capillary pressure. Note that for Darcian unsaturated flow in a rigid material, hydraulic conductivity always decreases with capillary pressure, which is not the case here. This highlights the importance of the fact that conventional unsaturated flow theory and methodology cannot be simply borrowed for clay materials. The data presented in Figure 2-15 are from laboratory measurements reported by Cui et al. (2008). They present results for relative hydraulic conductivity versus capillary 
pressure over a wider range of capillary pressure than shown here. However, because we compute hydraulic conductivity using the non-Darcian constitutive model given in Equation (2-33), we require data for flux and hydraulic gradient to establish relative hydraulic conductivity. The flux and hydraulic gradient data provided Cui et al. (2008) needed to compute relative hydraulic conductivity is limited to the capillary pressure range of the data given in Figure 2-15.

The observed relationship between hydraulic conductivity and capillary pressure can be explained with Equation (2-43), in which the first and second terms represent conductivity changes resulting from changes in capillary pressure and swelling (shrinkage), respectively. For the observed range of capillary pressures, the effects of shrinkage (as a result of increasing capillary pressure) may dominate the changes in $K_{r}^{*}$. To further demonstrate our reasoning, assume that porosity and capillary pressure follow the following relationship:

$$
\frac{\phi}{\phi_{r e f}}=\exp \left[\beta\left(\frac{P_{c}}{P_{r e f, c}}-1\right)\right]
$$

where $\beta$ is a fitting factor. The above equation is based on the consideration that the amount of clay swelling seems to be an exponential function of capillary pressure (Pham et al., 2007), and that porosity change is proportional to the amount of swelling (or shrinkage) under constant-volume conditions.

The solid curve in Figure 2-15 is calculated using Equations. (22) and (23) with $n=0.28$ (obtained from Figure 2-14), $\lambda=0.21$ (obtained from Figure 2 of Cui et al., 2008), $\alpha=3.27$, and $\beta=1.13$, and matches the observed conductivities. Note that $K_{r}^{*}$ decreases with increasing capillary pressure for small levels of capillary pressure and then increases with increasing capillary pressure for higher levels of capillary pressure. This is because for relatively small capillary pressures, the behavior of $K_{r}^{*}$ is dominated by the first term on the right-hand side of Equation (2-43), and for relatively large capillary pressures, the behavior of $K_{r}^{*}$ is dominated by the second term, representing the effects of clay shrinkage. Although the definition of hydraulic conductivity in Cui et al. (2008) is different from ours, their results show similar behavior to the solid curve in Figure 2-15. However, it is important to emphasize that the solid curve in the figure should be considered as an illustrative case, because (2-44) is based on some rough assumptions. The accurate determination of porosity change under test conditions of Cui et al. (2008) needs to be rigorously based on coupled hydro-mechanical processes. Nevertheless, comparisons between our theoretical results and data (Figures 2-14 and 215) support the usefulness of our approach. 


\subsubsection{Concluding remarks}

Unsaturated flow occurs in the engineered barrier and the near field of a clay repository for high-level radioactive waste. Therefore, accurately modeling unsaturated flow in clay materials is important for assessing the performance of a geological repository in isolating the radioactive waste. The non-Darcian behavior of water flow in clay materials has been demonstrated in the literature. While several models have been proposed for dealing with non-Darcian behavior for saturated flow conditions, a systematic study of modeling unsaturated non-Darcian flow is still lacking. Based on the hypothesis that pore water in clay becomes non-Newtonian as a result of water-clay interaction, we proposed constitutive relationships for unsaturated flow, including a relationship between water flux and hydraulic gradient and among capillary pressure, water saturation, and hydraulic conductivity. An evaluation based on a set of laboratory experimental observations supports the usefulness of the proposed relationships. The constitutive model reported here was not incorporated into the simulations presented in Sections 3 and 4 because it was only recently developed.

\section{THM MODELING IN CLAY/SHALE ENVIRONMENT}

\subsection{State of the art}

An essential feature that needs to be considered for the long-term safety of a clay repository is the disturbed-rock zone (DRZ) near the repository, and its hydromechanical and geochemical evolution with time. The creation of a DRZ is expected for all manmade openings in geologic formations. Macro- and microfracturing, and in general the rearrangement of rock structures that will occur in this zone, leads to drastic increases in flow permeability through the fractures and cracks induced by excavation, ventilation, and other operational factors. The implications of such high permeability and its time evolution under various repository scenarios need to be evaluated as part of a waste repository safety assessment. Various issues, such as processes creating fractures in the DRZ, the degree of permeability increase, and the potential for sealing or healing (with permeability reduction) in the zone, need to be carefully evaluated.

As reviewed by Tsang et al. (2005), the DRZ evolution is closely related to specific stages of repository development: the excavation stage, the open drift stage, the early closure stage (including resaturation and heating phases), and the late closure stage

(including cooling and self-sealing phases). In this research, the stability and associated DRZ mode of the surrounding indurated clay (Opalinus Clay) in the open drift stage are the main concerns. In the open drift stage, the desaturated zone close to the walls of a 
deep underground repository, excavated into clay rock, could have a detrimental impact on its performance (Ghorbani, et al., 2009; Bock et al., 2010).

Experimental evidence has shown that the process of disaggregation of DRZ could be expected to start as a consequence of seasonal variations in tunnel ventilation (Bock et al., 2010). Desiccation cracks would occur if soil shrinkage was constrained or the induced surface tensile stress exceeded the bonding strength of grains. The presence of cracks in clay significantly modifies the transport processes that occur in the clay profile. For example, in the context of the ventilation experiment at the Mont Terri URL (Mayor et al., 2007; Bock et al., 2010), significant fluctuations in capillary pressure were monitored in the DRZ during drying and wetting periods, respectively. Ventilation of underground openings, particularly if low-humidity air has direct access onto the tunnel wall rock, can cause a desaturation of DRZ rock and transportation of the pore water towards the excavated surface, where it evaporates. For the Opalinus Clay rocks, the desaturation zone in the DRZ rock may be expanded over a depth of no more than a certain distance (about 2 to $4 \mathrm{~m}$ ) from the tunnel wall, which would have an effect on the short-term and long-term stability of tunnels. Clay is a highly complex material, with cracking behavior governed by a considerable number of factors (e.g., mineral composition, temperature, relative humidity, layer thickness and size, surface plant cover). The essential mechanism of damage and dynamics of DRZ propagation is still not well understood, although in recent years much attention has been paid to the damage phenomenon induced by shrinkage in clay by researchers. While considerable progress has been made in hydromechanical (HM) modelingin the DRZ, some important issues remain unsolved.

One is the mechanical anisotropy and related damage mode. The extension of the desaturated zone parallel to the bedding plane is usually larger than that perpendicular to the bedding plane, due to the high permeability parallel to the bedding in clay rocks and the small Young's modulus perpendicular to the bedding plane, which leads to large displacement under isotropic stress conditions. This could be one of the reasons for breakout after excavation in clay rock. The creation and development of a DRZ is a coupled mechanical-hydraulic process. The former is dominated by the redistribution of the stress around an opening due to mechanical unloading. DRZ development, however, is dominated by hydraulic de-/resaturation due to the ventilation of the opening. This process is also closely related with the rock permeability dependent on damage evolution (Tsang, et al., 2005; Shao et al., 2008).

Variation in the strength and deformability of rocks with increasing/decreasing water content should be further studied. It is commonly accepted that water has a detrimental effect on the mechanical behavior of rock. This has led to a number of investigations on 
the influence of water content on rock mechanical properties. These investigations have been conducted for a wide variety of rock types, tensile strength, compressive strength (with uniaxial, triaxial or point load), and modulus of elasticity (Towner, 1987; Causarano, 1993; Panayiotopoulos, 1996; Kouakou and Morel, 2009; Erdal et al., 2010). All laboratory observations suggest that adsorbed pore water is a key factor dominating the thermo-hydromechanical properties and processes in indurated claysand a small increase in the water content may lead to a marked reduction in strength and deformability. While most of the previous studies have mainly concentrated on experimental tests, systematic investigations are necessary to identify governing mechanisms, to develop robust constitutive models and related numerical routines, and to quantify precisely the THM behavior of indurated clays under the relevant conditions expected in practical engineering (Zhang et al., 2007).

The stress-strain relationship is fundamental for modeling mechanical deformation and the associated coupled processes in porous and fractured rocks. Laboratory testing indicated that the stress-strain behavior of Opalinus Clay was highly nonlinear, with low stiffness at low stress levels. This is an important aspect of the material's behavior that is not adequately captured by conventional elasto-plastic analyses (Bobet et al., 1998; Corkum and Martin, 2007a, 2007b). A phenomenologically based model, generally called a stress-dependent modulus (SDM), was developed based on observations from field and laboratory studies by Corkum and Martin (2007a). Liu et al. (2009) (see also Section 2.1) proposed a more rigorous relationship. The new relationship has satisfactorily represented a number of experimental observations. However, prior to this report, the relationship of Liu et al. (2009) has not yet been used in modeling coupled HM process in clay under field conditions. As the Opalinus Clay is unloaded around an underground opening, the zones with lower stress level come into being, where could correspond to the non-linear behavior of Opalinus Clay. Therefore it's necessary to incorporate the relationship into a coupled-process simulator and used it to find how the non-linear behavior of Opalinus Clay affects the DRZ around the underground opening.

The goal of this study is to use numerical tools to investigate the short-term rock-mass deformation and pore pressure around an underground excavation in Opalinus Clay. The processes of water evaporation, volume shrinkage/swelling, DRZ initiation and propagation are numerically monitored during the entire drying period. The relationships between shrinkage effect, anisotropic properties, and the stress-dependent deformability of clay and DRZ extent are also discussed. 


\subsection{Technical Approach}

\subsubsection{Modeling methodology}

The earliest developments of TOUGH-FLAC at the Lawrence Berkeley National Laboratory (LBNL) were presented in Rutqvist et al. (2002) and Rutqvist and Tsang (2003). The simulator has since been applied to studying coupled geomechanical processes under multiphase flow conditions for a wide range of applications, including radioactive waste disposal, $\mathrm{CO}_{2}$ sequestration, geothermal energy extraction, naturally occurring $\mathrm{CO}_{2}$ upwelling with surface deformations, and gas production from hydratebearing sediments (Rutqvist, 2011).

These applications have been accompanied by recent exploratory code development. The most significant new development is a revised architecture, enabling a more rigorous and tighter coupling procedure with improved computational efficiency. This enhancement was made possible by linking FLAC3D to the newly released TOUGH+code for analyzing the geomechanical performance of hydrate-bearing sediments and unsaturated soil (Rutqvist et al., 2011). One great advantage of this approach to coupled-processes modeling is that both TOUGH2 and FLAC3D are being continuously developed and widely used, and therefore contain many constitutive and equation-of-state modules that can be readily applied to a wide range of scientific and engineering problems.

The stress-strain relationship is fundamental for modeling mechanical deformation and the associated coupled processes in porous and fractured rock. To capture the constitutive behavior of Opalinus Clay, the theoretical relationship represented by Equation (3-1), proposed by Liu et al. (2009) for elastic deformation, was implemented into the TOUGHFLAC code.

$$
K=\left\{\begin{array}{cc}
\frac{1}{\frac{\gamma_{e}}{K_{e}}+\frac{\gamma_{t}}{K_{t}} \exp \left(-\frac{\sigma_{m}}{K_{t}}\right)} & \sigma_{m}>0 \\
\frac{\gamma_{e}}{K_{e}} & \sigma_{m} \leq 0
\end{array}\right.
$$

where $K$ is bulk modulus, $K_{e}$ and $K_{t}$ refer to bulk moduli for the hard and soft part, respectively, the parameters $\gamma_{e}$ and $\gamma_{t}$ are volumetric portion of the hard and soft part under unstressed condition (Liu et al., 2009), and $\sigma_{m}$ is mean stress, equal to $\left(\sigma_{1}+\sigma_{2}+\sigma_{3}\right) / 3$. At present, the effects of stress anisotropy, discussed in Section 2.1, is not considered in the model and will be incorporated into our future studies. 
During drying, the volume of an aggregate in Opalinus Clay decreases, resulting in the formation of shrinkage cracks and surface subsidence. Upon rewetting, the aggregate regains water and swells, cracks close, and the soil surface returns to its original position. The evaluation of the swelling-shrinkage potential of expansive clays is very important. In this study, the Opalinus Clay (rock matrix) surrounding the underground opening becomes practically fully saturated with ventilation. The clay matrix is assumed to behave with a volumetric swelling/shrinkage, and a corresponding stress that depends on the changes in water saturation, $\Delta S_{l}$, is considered. The incremental swelling/shrinkage stress is calculated according to

$$
\Delta \sigma_{s}^{\prime}=3 K \Delta S_{l} \beta_{s}
$$

where $\sigma_{s}^{\prime}$ is the induced swelling stress (an effective stress), $K$ is the bulk modulus, and $\beta_{s}$ is a moisture swelling coefficient. Based on the laboratory tests related to the shrinkage/swelling features of Opalinus Clay (Montes-Hernandez, et al., 2003; Zhang et al., 2008a), it was found that $\beta_{s}$ is not a constant, but rather varies with saturation, as shown in Figure 3-1. In this study, we assumed that the evolution of $\beta_{s}$ conforms to the law formulated by Equation (3-3). The direct dependence of the stress variable on suction and saturation degree bears the following coupling: drying, which corresponds to suction increases, will cause an increase in effective stress and therefore shrinkage of the solid matrix. In contrast, wetting is the origin of swelling.

$$
\beta_{s}= \begin{cases}-0.0017 \operatorname{Ln}\left(\Delta S_{l}\right)+0.0219 & \Delta S_{l}>0 \\ 0.016 e^{3.2112 \cdot \Delta S_{l}} & \Delta S_{l}<0\end{cases}
$$



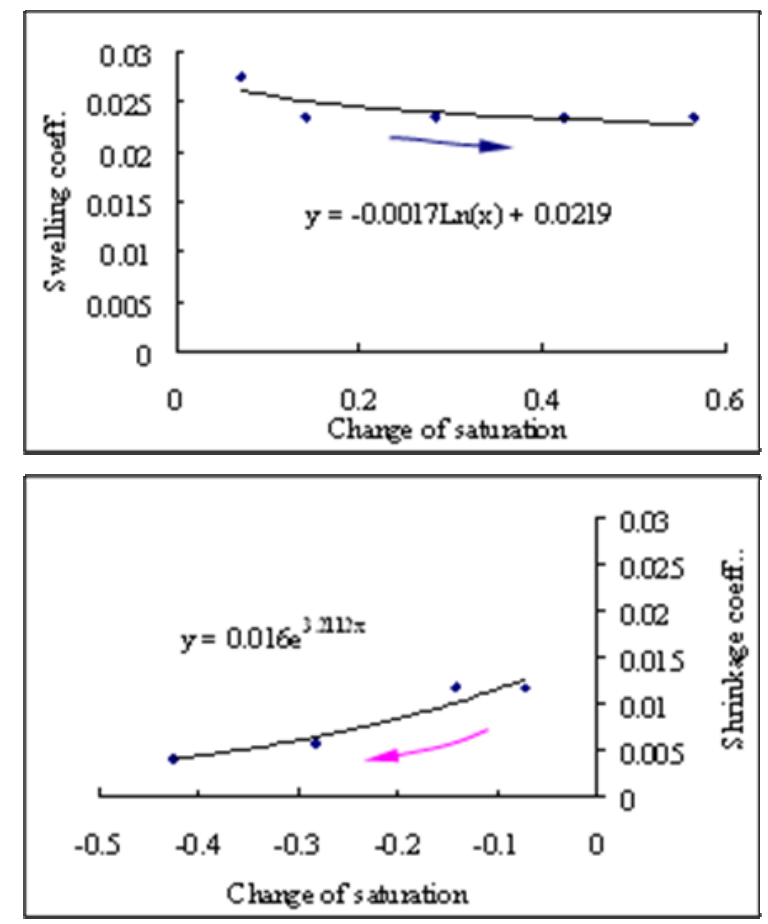

Figure 3-1. Swelling/shrinkage coefficient variation with the change in saturation

By changing the water content, the clay rocks exhibit significant variations in strength and deformability (Pham et al., 2007; Zhang et al., 2008a; Erguler and Ulusay, 2009). In order to account for such changes and variations in mechanical parameters in the numerical simulation, the following expressions are incorporated into the TOUGH-FLAC routine.

$$
\begin{aligned}
C & =10.0 e^{-0.07 w} \\
\sigma_{t} & =3.0 e^{-0.07 w}
\end{aligned}
$$

where $C$ and $\sigma_{t}$ are the cohesion and tensile strength of clay, respectively, $w$ is the water content, $w=(\phi /(1-\phi)) \cdot\left(\rho_{l} / \rho_{m}\right) \cdot S_{l} \quad\left(\phi\right.$ is the porosity of clay, $\rho_{l}$ is the density of fluid (water), and $\rho_{m}$ is the density of the clay matrix).

To consider the influence of stress on porosity and permeability, we employed the following equation to represent the porosity of rock matrix (Liu et al., 2009),

$$
\phi=\left(\phi_{0}-\gamma_{t}\right)\left(1-C_{e} \sigma^{\prime}\right)+\gamma_{t} \exp \left(-\frac{\sigma^{\prime}}{K_{t}}\right)
$$

where $\phi_{0}$ is porosity at zero stress, and $C_{e}$ is the compressibility for the hard fraction of pore volume. 
Once porosity is known, the permeability of a rock matrix can be estimated based on the relationship between permeability and porosity. The relationship between permeability and porosity is a key constitutive equation for modeling subsurface fluid flow and is fundamental to the quantification of a range of geological processes. Based on the analysis of a huge universe of experimental clay-rock data, Yang and Aplin (2010) pointed out that much of the permeability range observed at a given porosity could be explained by variation in lithology. Using clay content as the quantitative lithology descriptor, they proposed that permeability is a function of porosity and clay content:

$$
\begin{aligned}
& K=\exp \left(-69.59-26.79 F_{c}+44.07 F_{c}^{0.5}+\left(-53.61-80.03 F_{c}+132.78 F_{c}^{0.5}\right) \cdot e\right. \\
& \left.+\left(86.61+81.91 F_{c}-163.61 F_{c}^{0.5}\right) \cdot e^{0.5}\right)
\end{aligned}
$$

where $F_{c}$ is the clay content, $e=\phi /(1-\phi)$. In this study, Equation (3-7) is employed to represent the permeability of rock matrix.

\subsubsection{Model geometry}

Among underground openings with different cross-sectional shapes, the o U-shaped cross-sectional opening is the most common form of tunnel. In this study, we construct a numerical model with a geometry containing one U-shaped tunnel and consisting of about 1,452 zones and 3,002 grid points. The configuration of the tunnel, located in the central part of the model, is shown in Figure 3-2. To minimize the boundary effect on the areas of interest in the model while limiting the number of model elements to a reasonable size, some simplifications with regard to model size and boundary conditions were selected. Referring to the previous studies on tunnels in Opalinus Clay (Corkum and Martin, 2007b; Shao et al., 2008; Popp et al., 2008), in our study, the Z-axis was set as vertical in the model, while the horizontal $\mathrm{Y}$ - and $\mathrm{X}$-axes were aligned parallel and perpendicular to the tunnel, respectively. The dimensions of the model were $60 \mathrm{~m}$ in the $\mathrm{X}$-direction, $1 \mathrm{~m}$ in the Y-direction, and $60 \mathrm{~m}$ in the Z-direction. In simulation, the variations in deformation, saturation, porosity, and permeability in the rock matrix around the tunnel opening were monitored. The figuration of monitoring key points is marked in Figure 3-3. 


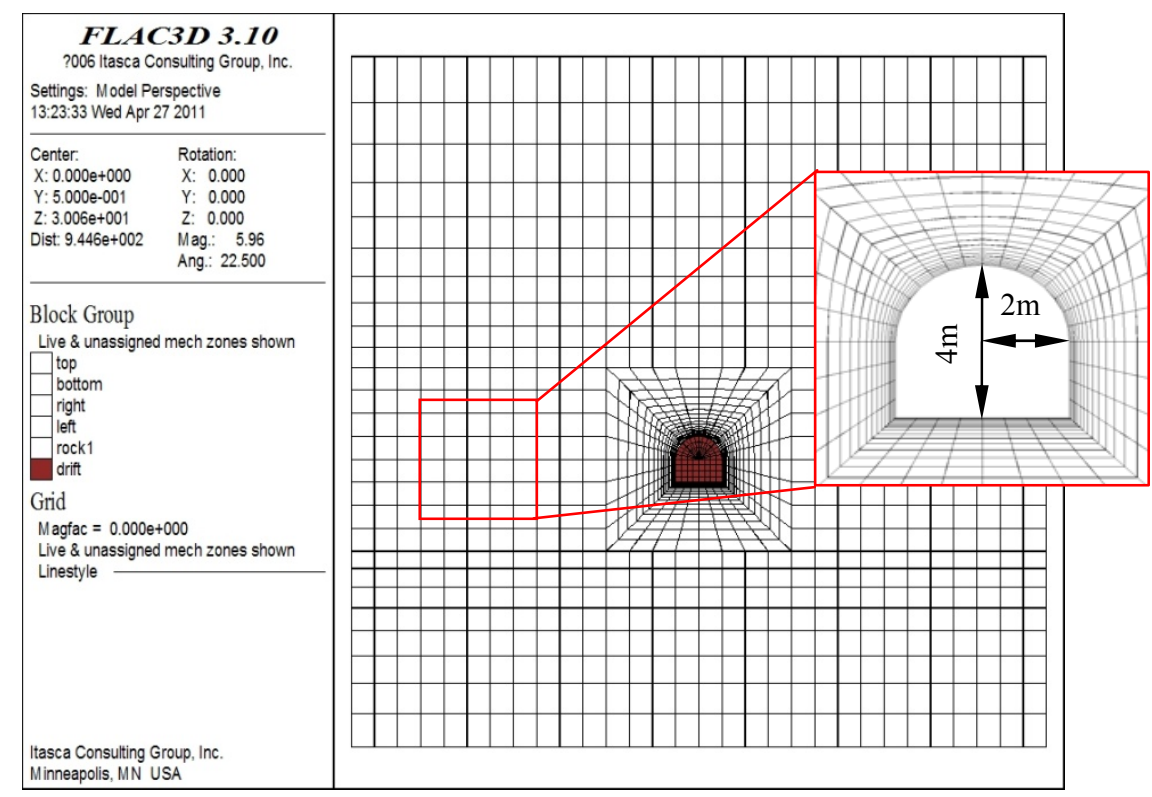

Figure 3-2. Numerical model and grid mesh

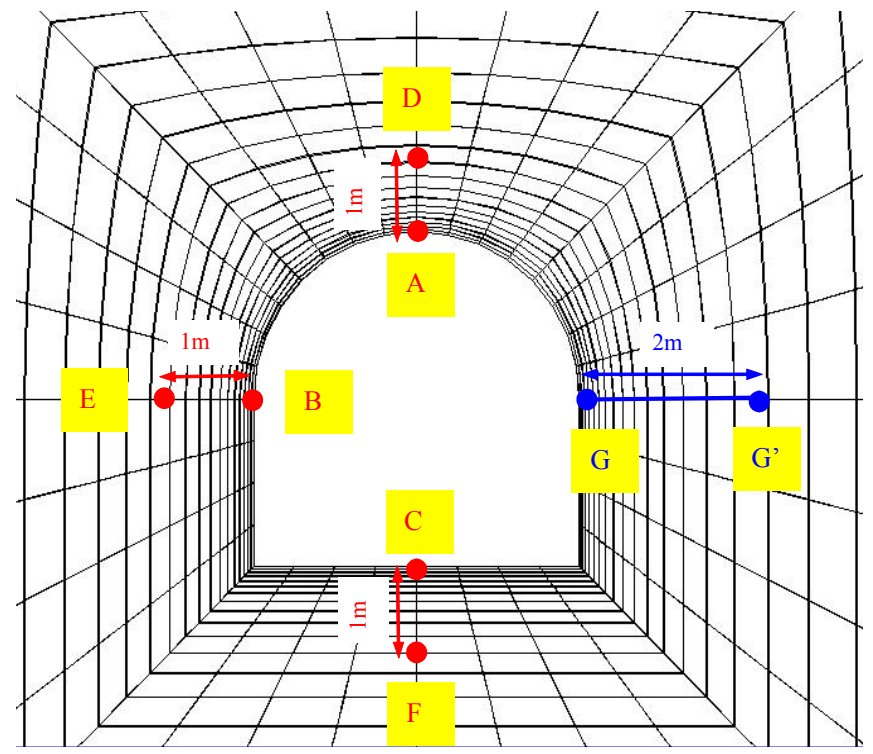

Figure 3-3. Location of key points for monitoring parameter variation in numerical simulation

In TOUGH2, the numerical grid is defined by finite volume elements, with one node located within the element boundaries connected to neighboring elements' center nodes. In a FLAC3D numerical grid, on the other hand, corner nodes define the element shapes. The geometry and element numbering should be consistent in TOUGH2 and FLAC3D for a particular problem. In this study, a special FISH routine in FLAC3D has been programmed to produce a mesh consistent with the meshes employed in TOUGH2. The FISH routine can directly translate FLAC3D meshes into TOUGH2 meshes. With the 
numerical grids defined, input files are prepared for TOUGH and FLAC3D, including material properties, boundary conditions, and initial conditions.

\subsubsection{Boundary conditions and material parameters}

An accurate assessment of the in situ stress conditions is important for analyzing underground excavations. These boundary conditions are particularly significant when the engineering objective is to understand the rock-mass response to excavation. Based on laboratory and field investigations (Bossart et al., 2002; Shao et al., 2008), we assumed that the tunnel is located about $200 \mathrm{~m}$ underneath the ground surface. The general mechanical boundary conditions are employed: a total stress of $\sigma_{z}=5 \mathrm{MPa}$, representing the stress induced by the overlying rock layers, is applied on the top boundary of the model, and normal displacements are constrained on the right and left side and bottom boundary.

With regard to ventilation, one of the most important factors influencing the formation of the DRZ may be the humidity level after the excavation of the tunnel. In this study, the grid elements representing the empty tunnel (air) are modeled as an equivalent porous medium. The tunnel is set up with relative humidity at the entrance; then the tunnel is modeled explicitly and the ventilation is imposed with a pressure boundary at the tunnel wall (i.e., the air humidity). The unsaturated zones within the excavation are characterized by relatively high capillary pressures. The corresponding capillary pressure is given by Kelvin's equation incorporating humidity (Edlefsen and Anderson, 1943):

$$
P_{c}=\ln (R H) \cdot \rho_{w} \frac{R T}{M_{W}}
$$

where $R H$ is the relative humidity, $\rho_{\mathrm{w}}$ is the density of water, $R$ is the gas constant, $T$ is the absolute temperature (degree Kelvin), and $M_{\mathrm{w}}$ is the molecular weight of water. Field test results shown that the humidity of the air within the tunnel varies with the season. In this study, an average relative humidity of $80 \%$, which amounts to a capillary suction pressure of about $30 \mathrm{MPa}$, is selected (Mayer et al., 2007; Shao et al., 2008). Based on the capillary pressure curve for Opalinus Clay (Zhang et al., 2008b), as shown in Figure $3-4$, the Opalinus Clay surrounding the tunnel is desaturated. 


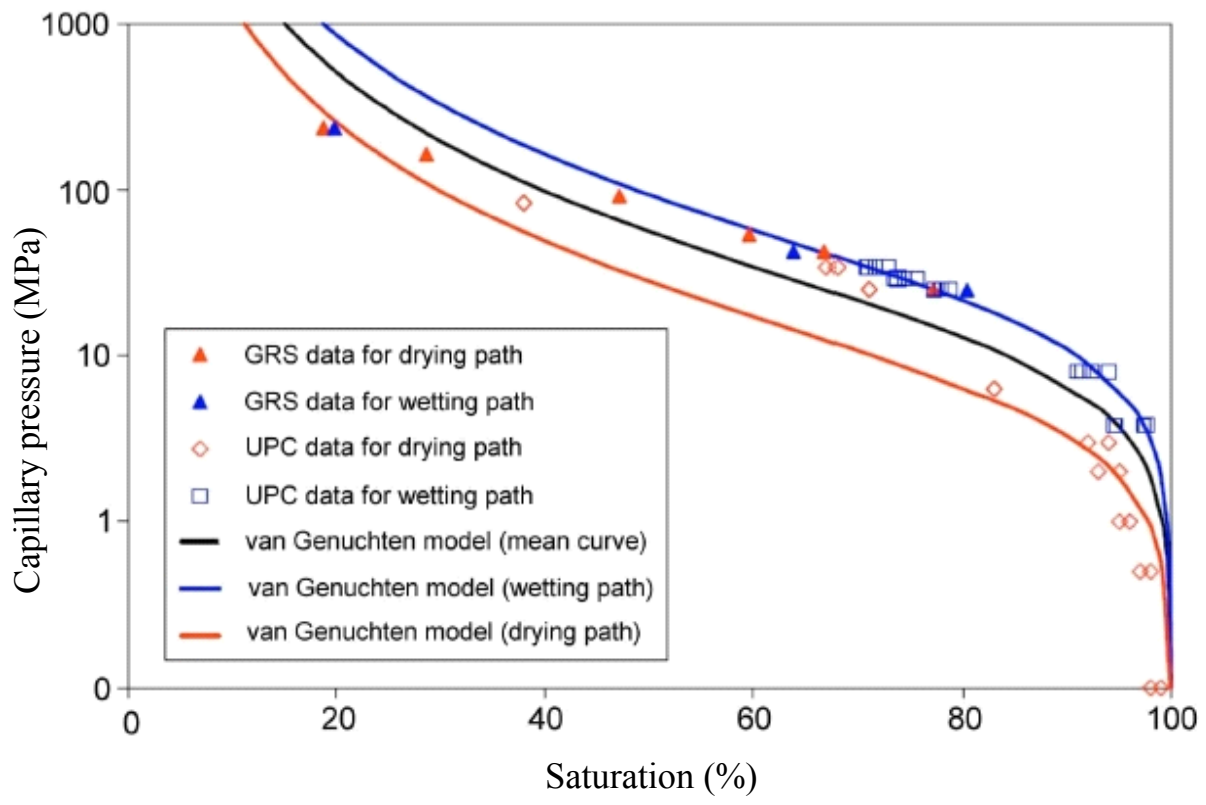

Figure 3-4. Relationship between capillary pressure and water saturation (modified from Zhang et al., 2008b)

The underground water table is assumed to be located $100 \mathrm{~m}$ underneath the ground surface, and the rock matrix under the water table is saturated initially. A pore pressure, $P_{l}=1000000+(60-Z) \rho_{l} g \mathrm{~Pa}$ (where $\mathrm{Z}$ is height), is directly incorporated into the numerical model. The outer boundary condition is an imposed constant pressure. Since the ventilation-induced desaturation and associated mechanical responses are the main concerns in this study, the temperature at the tunnel opening and within the rock matrix are assumed to be a constant, $20^{\circ} \mathrm{C}$.

The calculations were performed with a full hydromechanical coupling. For two-phase flow, the van Genuchten function fitted by laboratory data was used. The relationship describing the capillary pressure as a function of the saturation and the water relative permeability as a function of the saturation are given by the van Genuchten (1980) formulation, which has been used successfully to fit the data from the gas injection tests in the Opalinus Clay (Mayer et al., 2007). The capillary pressure as a function of the saturation is given by

$$
\begin{aligned}
& P_{c}=\frac{1}{\alpha} \cdot\left(S_{e c}^{n / 1-n}-1\right)^{1 / n} \\
& S_{e c}=\frac{S_{w}-S_{w r}}{S_{w \max }-S_{w r}}
\end{aligned}
$$

The residual saturation $S_{w r}$ is the minimum value of the water saturation achievable when gas is displacing water. The parameter $n$ is a pore-size distribution index (shape factor), and the parameter $1 / \alpha$ is a "pseudo air entry pressure" for the gas phase. 
Using the integral formulation of Mualem (1976), the relative permeability of the water $\mathrm{kr}$, w (van Genuchten, 1980) is defined as follows:

$$
k_{r, w}=S_{e c}^{1 / 2} \cdot\left(1-\left(1-S_{e c}^{n / n-1}\right)^{(n-1) / n}\right)^{2}
$$

The gas phase relative permeability $k_{r, g}$ is arbitrarily chosen as (Pruess et al., 1999)

$$
\begin{aligned}
& k_{r, g}=\left(1-S_{e}\right)^{2} \cdot\left(1-S_{e}^{2}\right) \\
& S_{e}=\frac{S_{w}-S_{w r}}{1-S_{g r}-S_{w r}}
\end{aligned}
$$

$S_{g r}$ is the residual gas saturation. Note that the non-Darcian flow behavior, discussed in Section 2.2, is not considered here yet, but will be incorporated within future studies.

The key flow parameters for Opalinus Clay are presented in Table 3-1. The values originate from the extensive laboratory and in situ tests performed on the Opalinus Clay (Mayer et al., 2007; Zhang et al., 2008b). The rock matrix (Opalinus Clay) is assumed to be initially almost saturated $\left(S_{l}=0.999\right)$. Comparisons between simulations with $100 \%$ and $99 \%$ saturation have shown that the impact of the initial saturation of the rock on the simulation results is negligible.

Table 3-1. Flow parameters for the Opalinus Clay

\begin{tabular}{lll}
\hline Parameter & Value & Unit \\
\hline Porosity & 0.16 & $\mathrm{~m}^{2}$ \\
\hline Intrinsic permeability & $1.0 \mathrm{e}^{-20}$ & \\
\hline Initial liquid saturation & 1.0 & \\
\hline Residual water saturation & $0.7 \%$ & \\
\hline Residual gas saturation & $1 \%$ & $\mathrm{~Pa}$ \\
\hline $\begin{array}{l}\text { Van Genuchten } \quad 1 / \alpha \quad \text { Gas } \quad \text { entry } \\
\text { pressure) }\end{array}$ & $1.0 \mathrm{e}^{7}$ & \\
\hline Van Genuchten $\mathrm{m}=(\mathrm{n}-1) / \mathrm{n}$ & 0.3 & \\
\hline
\end{tabular}

For the mechanical part, a pore-elastic-plastic model was used. There are thirteen basic constitutive models provided in FLAC3D, arranged into null, elastic, and plastic model groups. The commonly used criteria for plastic model groups are those of MohrCoulomb, Hoek and Brown, Cam-Clay, and so on, among which the Mohr-Coulomb model is the conventional one used to represent failure in soils and rocks (Itasca Consulting Group Inc. 2001). For the Mohr-Coulomb model, the main argument against the criterion is that its linear approximation is often not a good enough fit to the experimental strength data, and it cannot adequately characterize the fracture patterns of tensile regions. The arguments in favor of the Mohr-Coulomb criterion are its widespread 
use in geomechanics, its relative simplicity, its implementation in all pertinent geotechnical computer codes, and its proven suitability for indurated argillaceous media. In this study, the evolution of damage, failure, and post-failure behavior is described by the Mohr-Coulomb criterion (shear yield function) with tension cut-off (tension yield function). The position of a stress point on this envelope is controlled by a nonassociated flow rule for shear failure and an associated rule for tension failure. Note that the application of the Mohr-Coulomb criterion for clay rock needs to be further evaluated, and more advanced constitutive models are under development for clay rock.

Opalinus Clay is of interest not only as a host formation for radioactive waste repositories, but also as a formation through which new transportation tunnels have been constructed. For this reason, a number of investigations have been conducted, and the corresponding results of these studies have been published. The mechanical parameters employed in this study range from laboratory experiments and to field research (Corkum et al., 2007b; Zhang et al., 2008b; Bock, et al., 2010; Jobmann et al., 2010). The strength and deformation properties of Opalinus Clay at dried state are shown in Table 3-2.

Table 3-2. Mechanical parameters for the Opalinus Clay

\begin{tabular}{lll}
\hline Parameter & Value & Unit \\
\hline Bulk density $\left(\rho_{m}\right)$ & 2450 & $\mathrm{~kg} / \mathrm{m}^{3}$ \\
\hline Young's modulus $(E)$ & 7 & $\mathrm{GPa}$ \\
\hline Poisson's ratio $(v)$ & 0.3 & \\
\hline Tensional strength $\left(\sigma_{t}\right)$ & 3 & $\mathrm{MPa}$ \\
\hline Cohesion $(C)$ & 10 & $\mathrm{MPa}$ \\
\hline Friction $(\varphi)$ & 25 & $\circ$ \\
\hline Clay content $\left(F_{c}\right)$ & $60 \%$ & \\
\hline
\end{tabular}

\subsection{Technical Results}

In this section, three cases were considered. In Case 1, the calculation was carried out with the application of an elasto-plastic approach, assuming that the rock matrix was isotropic. In Case 2, the calculation was carried out exclusively with the application of an elastic approach, assuming that the rock matrix was transversely isotropic and the elastic deformation is described by conventional Hooke's law. In Case 3, the calculation was carried out with the application of an elasto-plastic approach incorporated into the constitutive model proposed by Liu et al. (2009), assuming that the rock matrix was 
isotropic. In each of the cases above, simulation was first conducted for excavation of a U-shaped tunnel opening before simulation of the ventilation effect was conducted.

\subsubsection{Results for Case 1}

\section{Saturation evolution}

Particularly if low-humidity air has direct access into the tunnel wall rock, ventilation of underground openings can cause a desaturation of the near-field rock and transportation of the pore water towards the excavated surface, where it evaporates. One of the most important numerical results in this case is the calculated saturation $\left(S_{l}\right)$ around the tunnel opening. Figure 3-5 illustrates the progressive change in saturation at two different elapsed times. In this simulation, the initial saturation of liquid (water) is $99.9 \%$ within rock matrix. During the ventilation period, a desaturation zone gradually penetrates into rock matrix although the evolution is slow due to the low permeability of Opalinus Clay. At the start of day 3, the saturation is less than $99 \%$ only within a small ring around the tunnel wall (thickness $\approx 9 \mathrm{~cm}$ ). Even after the end of 3 years, the model indicates that the rock matrix $S_{l}$ values are lower than $95 \%$ only within a small zone around the tunnel walls (thickness $\approx 40 \mathrm{~cm}$ ). These results agree well with the monitoring data for a ventilation test on Opalinus Clay (Mayor et al., 2007). 


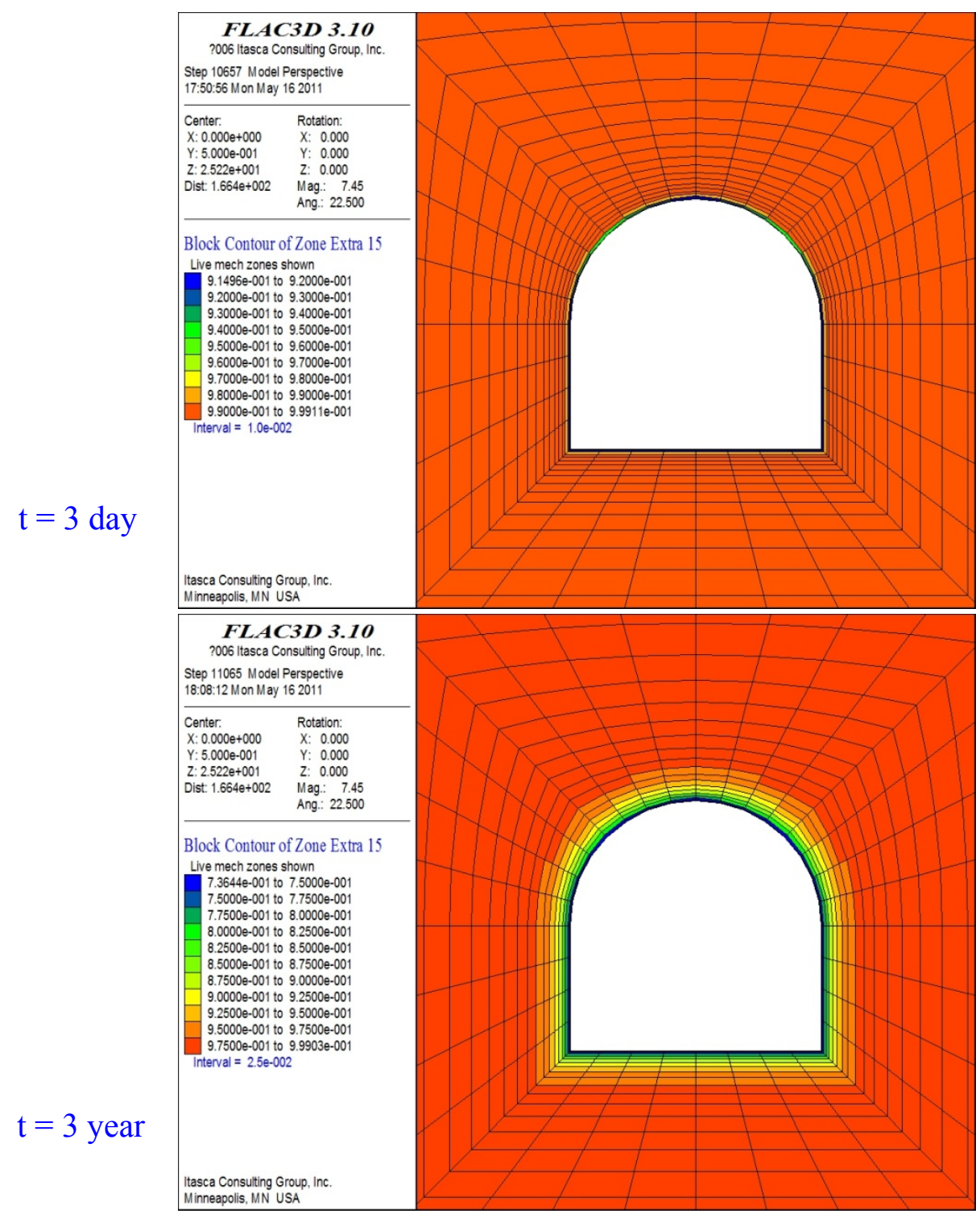

Figure 3-5. Saturation evolution with time

Figure 3-6 plots the saturation evolution in the typical elements along line G-G' in Figure $3-3$. The maximum decrease for saturation in the vicinity of the tunnel walls is about $26 \%$. According to the model calculations, the decreasing rate of the saturation is relatively fast, and there is sharply decreasing saturation within the vicinity of the tunnel walls in the early days of ventilation. Although the variation in saturation tends to smoothen after 30 days of ventilation, the desaturation continues to move into the rock matrix, until finally the rock-matrix $S_{l}$ values are lower than $99 \%$ in a relatively wide zone around the tunnel walls (thickness $=1 \mathrm{~m}$ ), which indicate that the shrinkage effect induced by desaturation will continue as ventilation continues. 


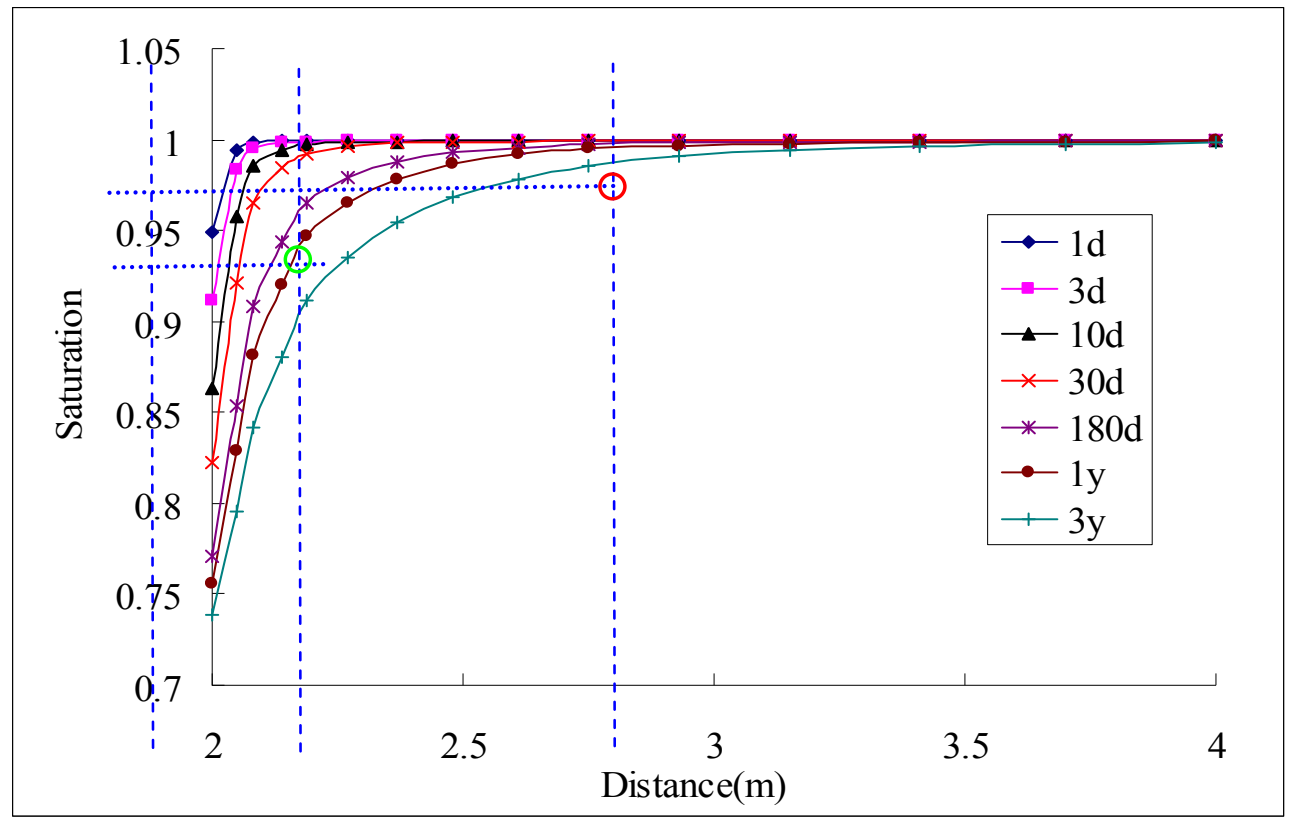

Figure 3-6. Saturation variation in the surrounding rock mass along line G-G'

\section{Pore water pressure}

Figure 3-7 presents the calculated pore-water pressure field around the tunnel surface. In the early days of ventilation, the pore pressure shows a very sharp gradient within the zone adjacent to the tunnel surface. Just on the tunnel wall, the calculated value of gas pressure $P_{g}$ is $0.1 \mathrm{MPa}$, equal to the atmospheric pressure in the tunnel. At the end of three years of ventilation, the calculated liquid pressure $\left(P_{l}\right)$ isolines around the tunnel show that negative values for $P_{l}$ develop up to a distance of $\sim 1.8 \mathrm{~m}$ from the tunnel walls, indicating that a the rock remains in suction up to such a distance. Beyond $1.8 \mathrm{~m}$ from the tunnel walls in rock matrix, the pore pressure evolution shows a tendency to stabilize at a constant value. 


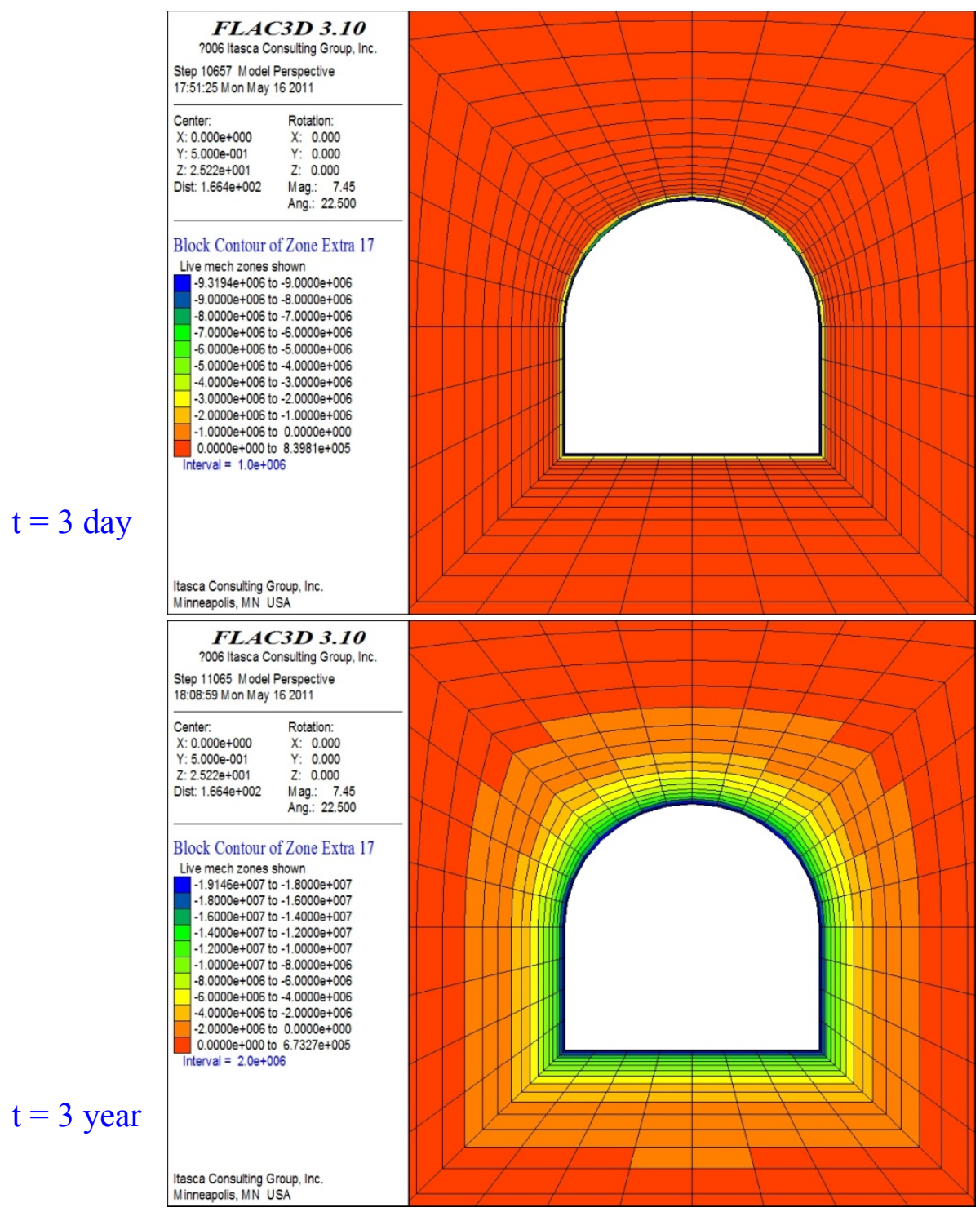

Figure 3-7. Pore pressure evolution with time

\section{Stress and displacement}

Any excavation of an underground opening (borehole, tunnel, gallery, shaft, etc.) causes a redistribution of the geologic stress field in the vicinity of the new opening. The degree of redistribution could be quite significant, depending on numerous factors such as structure of the host rock, size, shape, and orientation of the excavation, geological stress field, and even the manner in which the excavation was technically carried out. The results based on numerical analysis with TOUGH-FLAC are given in Figure 3-8 and 3-9 (where the positive sign represents tensile stress and the negative sign represents compressive stress). It is shown that the drying-out process influences the stress distribution as a result of the shrinkage effect. Stress concentration is generally increased at and near the excavation surface where the saturation is relative low. Away from the 
tunnel walls, the degree of stress concentration gradually lessens until the outer boundary is reached. In the early days of ventilation, the tensile stress zone is mainly found in the roof and floor, while the compressive stress is concentrated near the vertical sides of the tunnel. During ventilation, the tensile-stress concentrated zone induced by shrinkage gradually moves into the rock matrix. About 10 days after ventilation, evident tensilestress concentration can be observed within the zone near the vertical sides of the tunnel. Finally, after 3 years, the average value of maximal tensile stress within the zone $0.5 \mathrm{~m}$ away from the tunnel surface reaches $2.0 \mathrm{MPa}$, which has exceeded the tensile strength of the rock matrix.

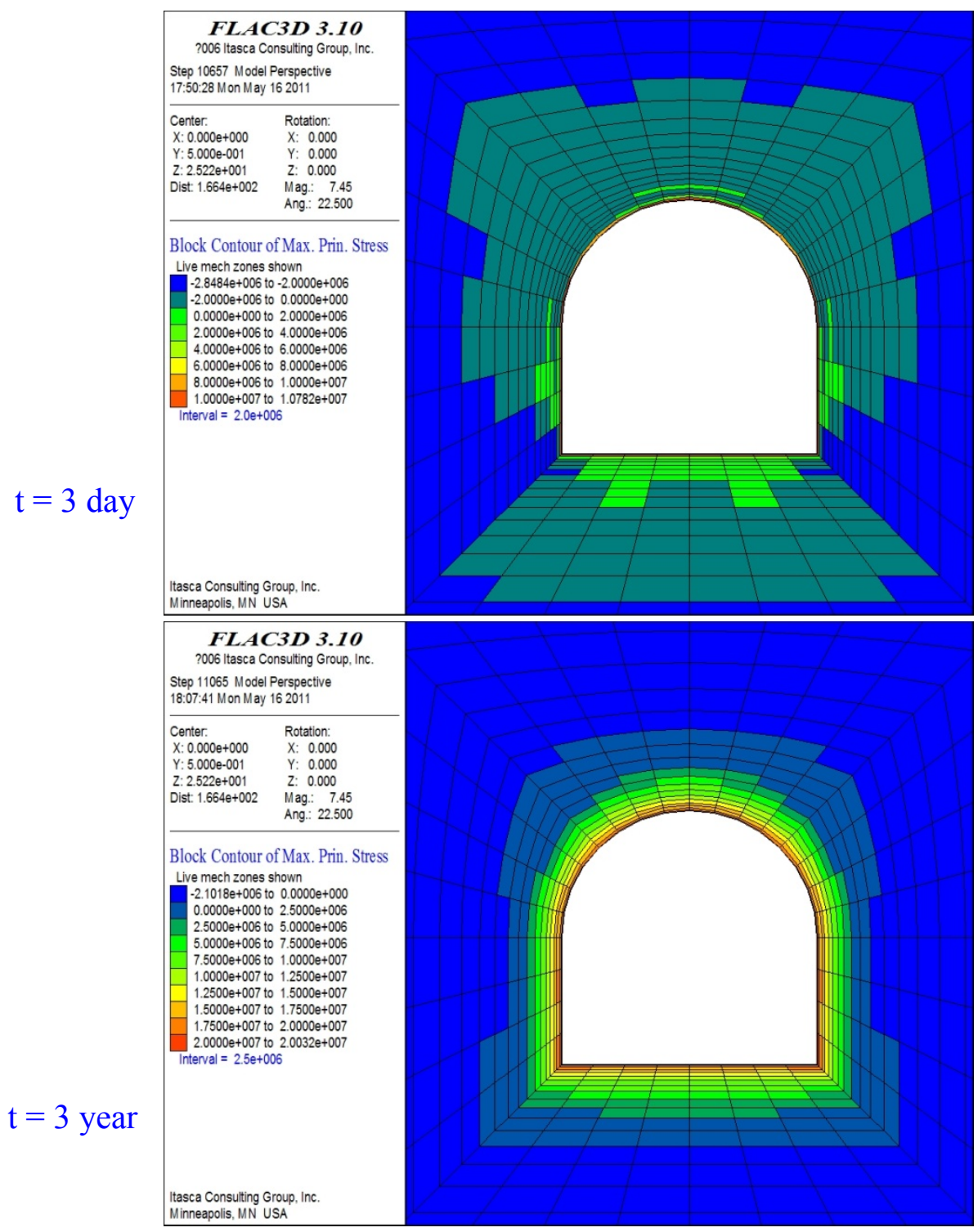

Figure 3-8. Maximum principal stress distribution 


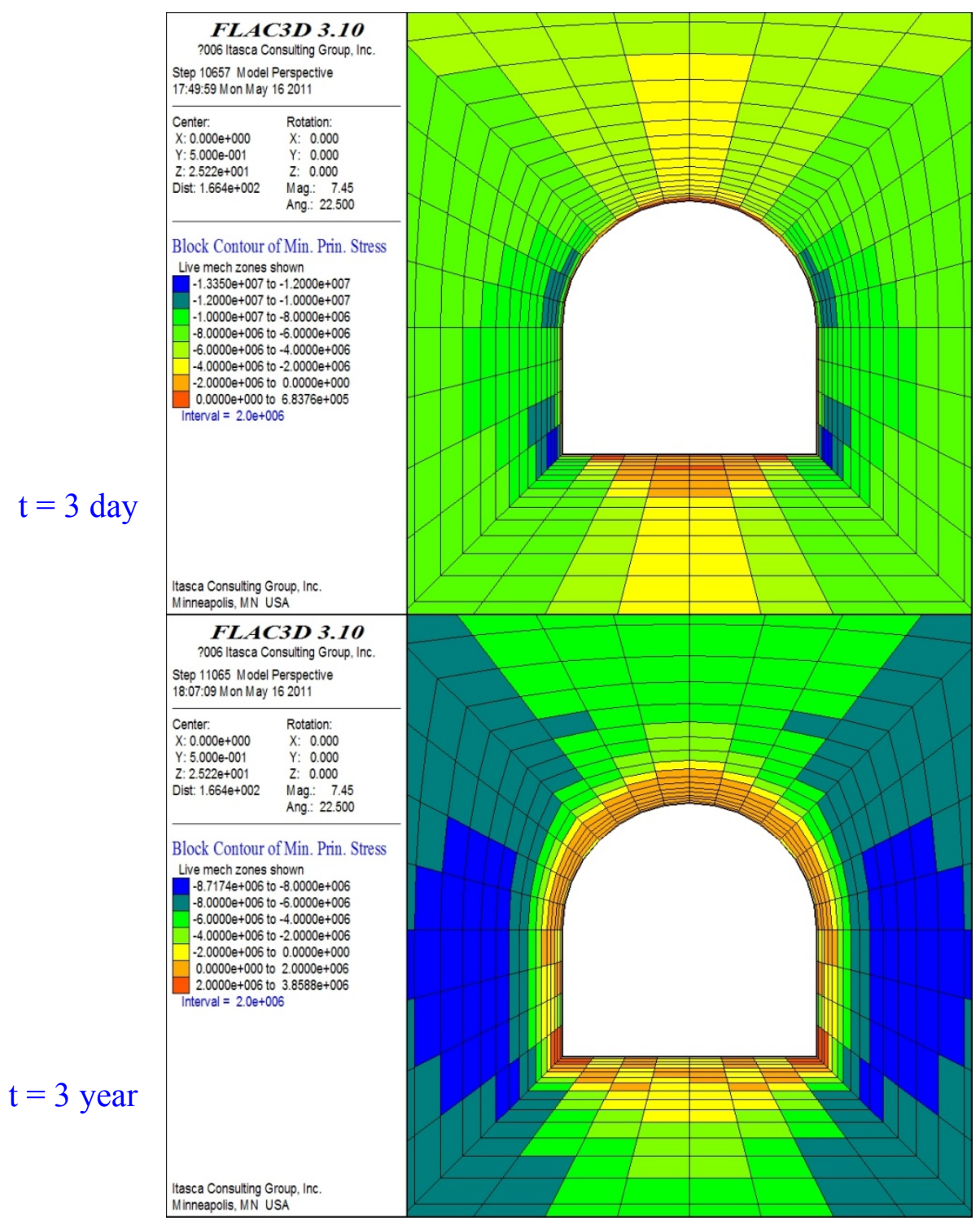

Figure 3-9. Minimum principal stress distribution

In general, the deformations measured at points $\mathrm{A}, \mathrm{B}, \mathrm{C}, \mathrm{D}, \mathrm{E}$, and $\mathrm{F}$ around the tunnel show unique signatures, with all deformations trending towards the tunnel or towards the rock matrix (As shown in Figure 3-10, a displacement is designated as positive when the deformation motion is in a positive direction along the axis and negative for a displacement that is in a negative direction along the axis.). Due to the shrinkage of the Opalinus Clay during ventilation, the deformations at points $\mathrm{A}, \mathrm{B}$, and $\mathrm{C}$ along the tunnel boundary show a slight movement towards the rock matrix and gradually reach a convergence after one year. The deformations at points $\mathrm{D}, \mathrm{E}$, and $\mathrm{F}$ show an opposite tendency to that at points $\mathrm{A}, \mathrm{B}$, and $\mathrm{C}$ with respect to a transition between negative and positive movement. At points $\mathrm{D}, \mathrm{E}$, and $\mathrm{F}$, deformation convergence was not observed even after three years. Although the maximal displacement is not beyond $3 \mathrm{~mm}$, it can 
also be pointed out that the mechanical coupling has an evident effect on the macroscopic behavior of the rock matrix during the desaturation process.

Numerical results show that the evolution of stress is a result of two sources: (1) shrinkage stress caused by saturation changes, and (2) poroelastic stress from average pore-pressure changes under unsaturated conditions. The calculated maximal displacement for the corresponding deformation at points $\mathrm{A}, \mathrm{B}, \mathrm{C}, \mathrm{D}, \mathrm{E}$ and $\mathrm{F}$, is not beyond $1 \mathrm{~mm}$, as shown in Figure 3-11. The shrinkage effect on the mechanical response of the underground opening in the open drift stage is remarkable.

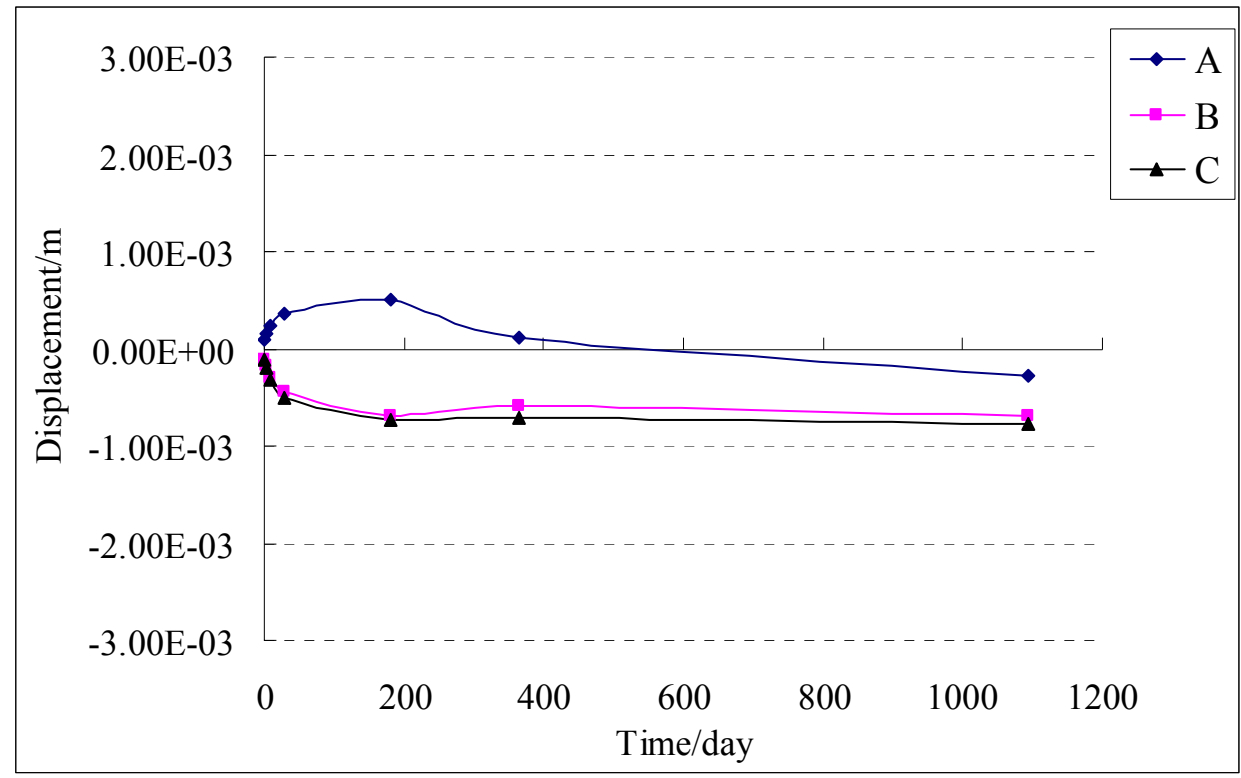

(a) Displacement evolution with time for points A, B, and C, respectively

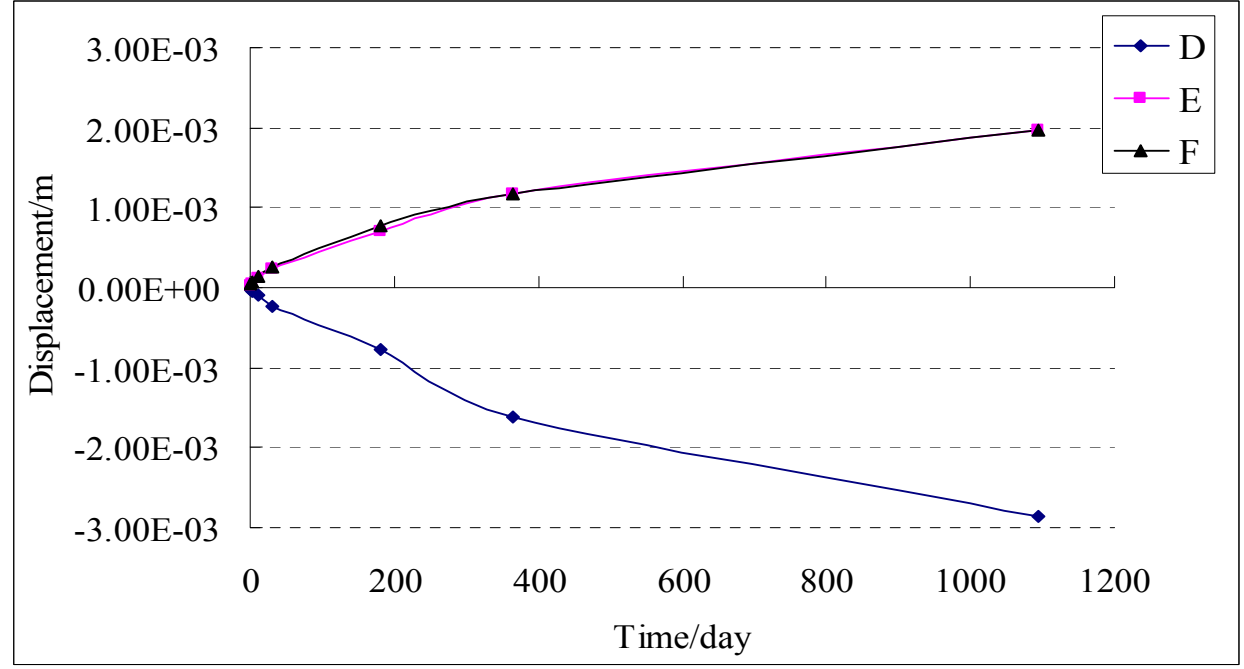

(b) Displacement evolution with time for points D, E, and F, respectively

Figure 3-10. Numerically obtained displacement at points A, B, C, D, E and F labeled in Figure 3-3. 


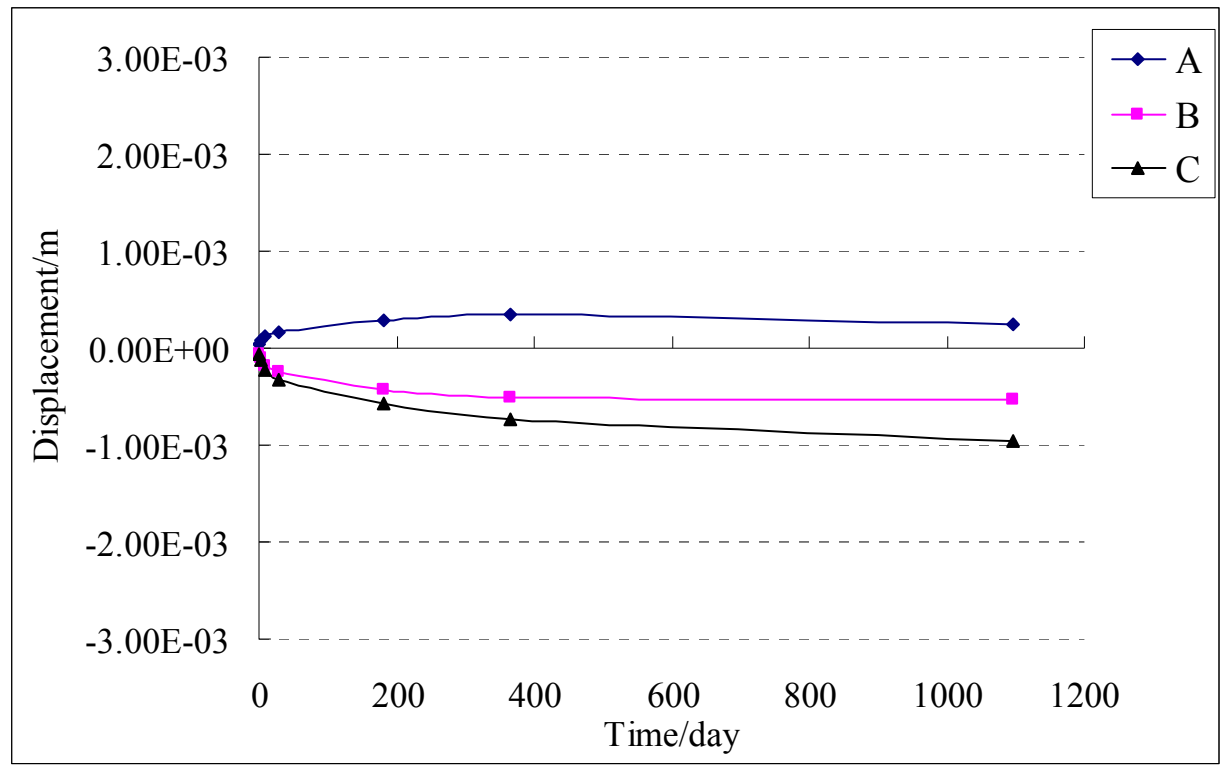

(a) Displacement evolution with time for point A, B and C, respectively

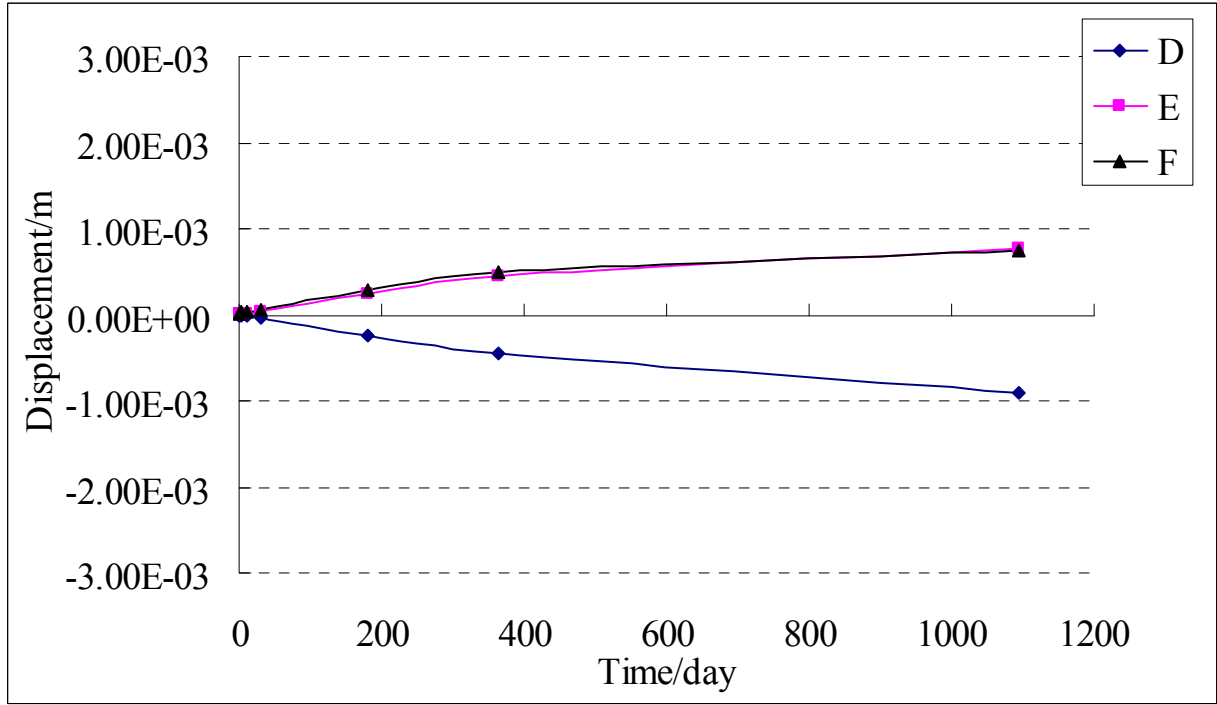

(b) Displacement evolution with time for points D, E, and F, respectively

Figure 3-11. Numerically obtained displacement at points A, B, C, D, E and F (the case without considering the shrinkage effect)

With the evolution of stress, changes in porosity and permeability are observed. Figure 312 plots the porosity and permeability evolution in the typical elements along line G-G'. The results indicate a significant signature of TH-induced change in porosity and permeability; both porosity and permeability first decrease as a result of the compressive stress induced by the overlying rock layers. During ventilation, porosity and permeability gradually increase within the zones adjacent to the tunnel walls, due to tensile stress 
induced by desaturation. At the end of three years' ventilation, variations in porosity and permeability were limited to a radial distance of about $2.0 \mathrm{~m}$ from the tunnel wall.

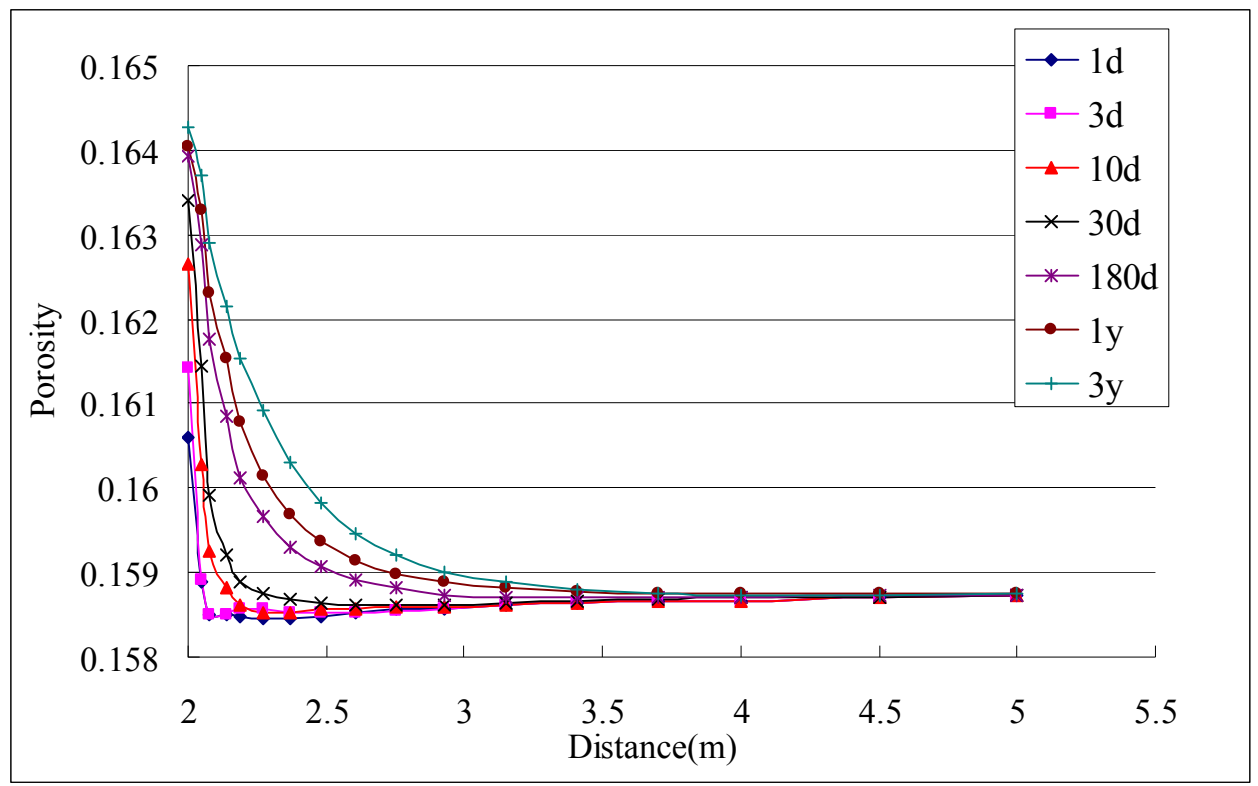

(a) porosity variation

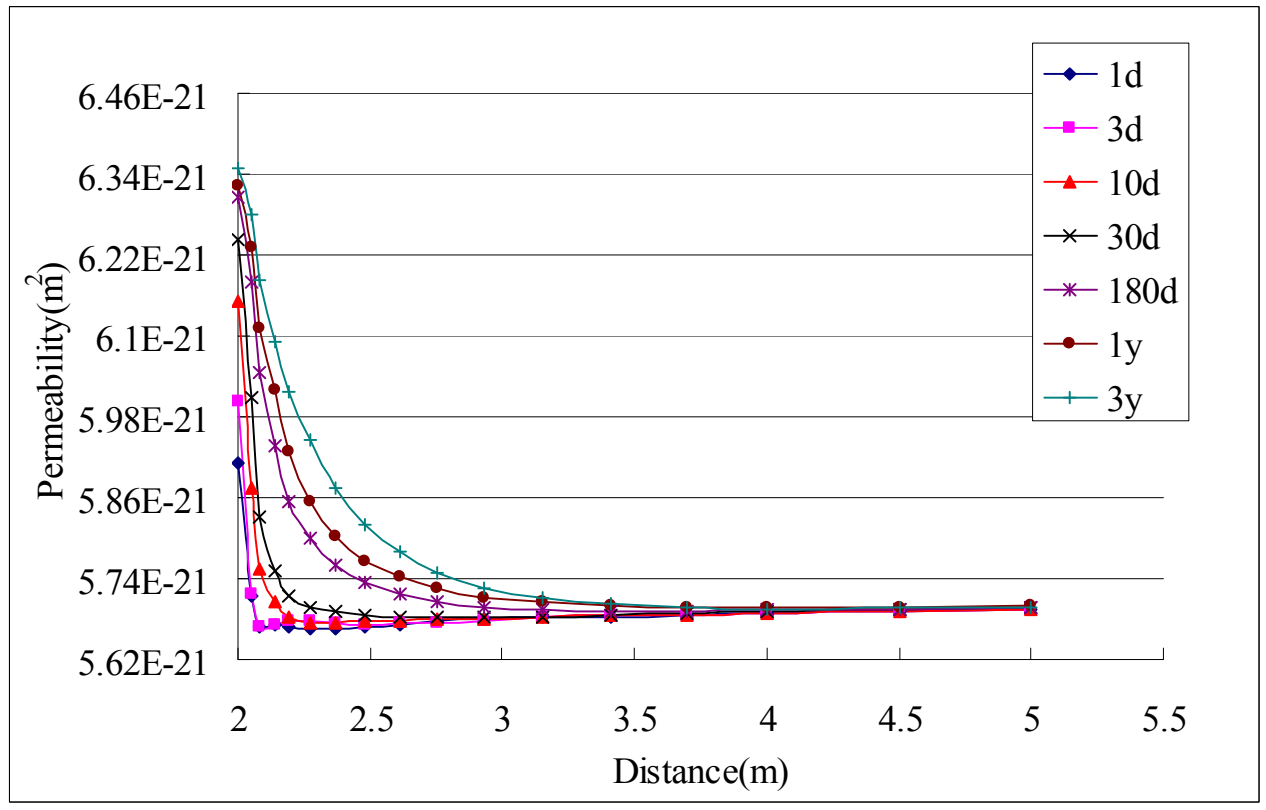

(b) permeability variation

Figure 3-12. Porosity and permeability evolution with ventilation

\section{DRZ around tunnel}

The DRZ primarily developed in the vicinity of the tunnel surface, as expected. Figure 313 illustrates the progressive change in the DRZ; the observations are taken at six different ventilation times. In the early days of ventilation, the DRZ growth rate is 
relatively fast, indicating unstable damage growth, corresponding to the saturation variation and the stress field evolution in the rock matrix. Because shrinkage is the major mechanism of DRZ development, tension is the major form of failure.

During ventilation, the DRZ continues to grow, particularly in the vicinity immediately adjacent to the opening roof and sidewalls (as the DRZ in the floor has expanded quite deeply, as a result of the cross-sectional shape of the tunnel). The extent of the DRZ stays practically constant for relatively long and extreme desaturation periods, despite the suction or pore pressure developed up to a distance of $\sim 2.0 \mathrm{~m}$ into the rock matrix. The DRZ extends only about $40 \mathrm{~cm}$ from the tunnel surface. Figure 3-14 shows the final damage mode for the cases (a) without considering both pore pressure and shrinkage, and (b) considering pore pressure but without shrinkage. It is evident that the creation and development of a DRZ is a coupled mechanical-hydraulic process: with creation dominated by the redistribution of the stress around the tunnel due to mechanical unloading, and with development dominated by hydraulic de-resaturation due to ventilation of the tunnel opening. 


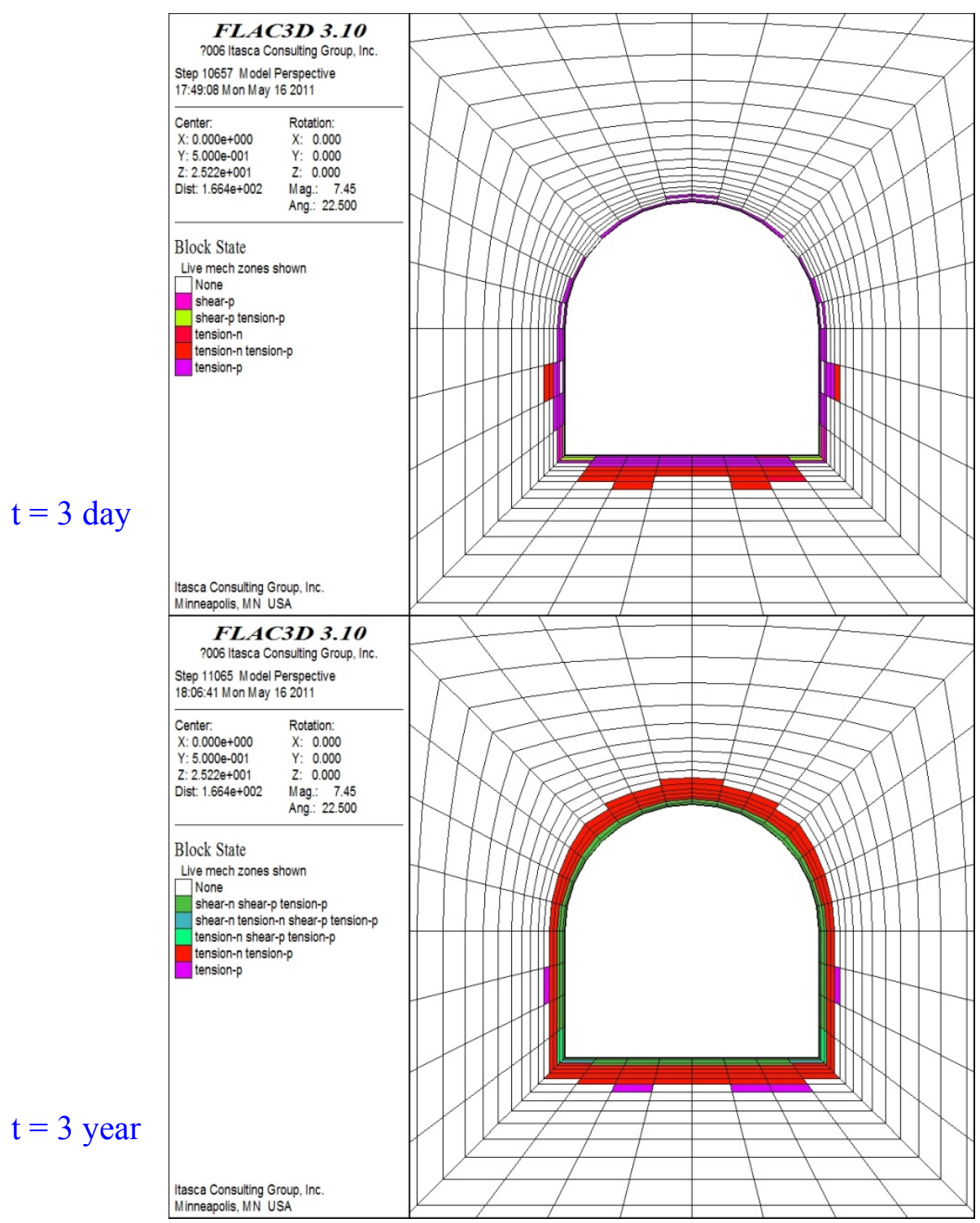

Figure 3-13. DRZ (plastic zone) evolution with time 
(a)
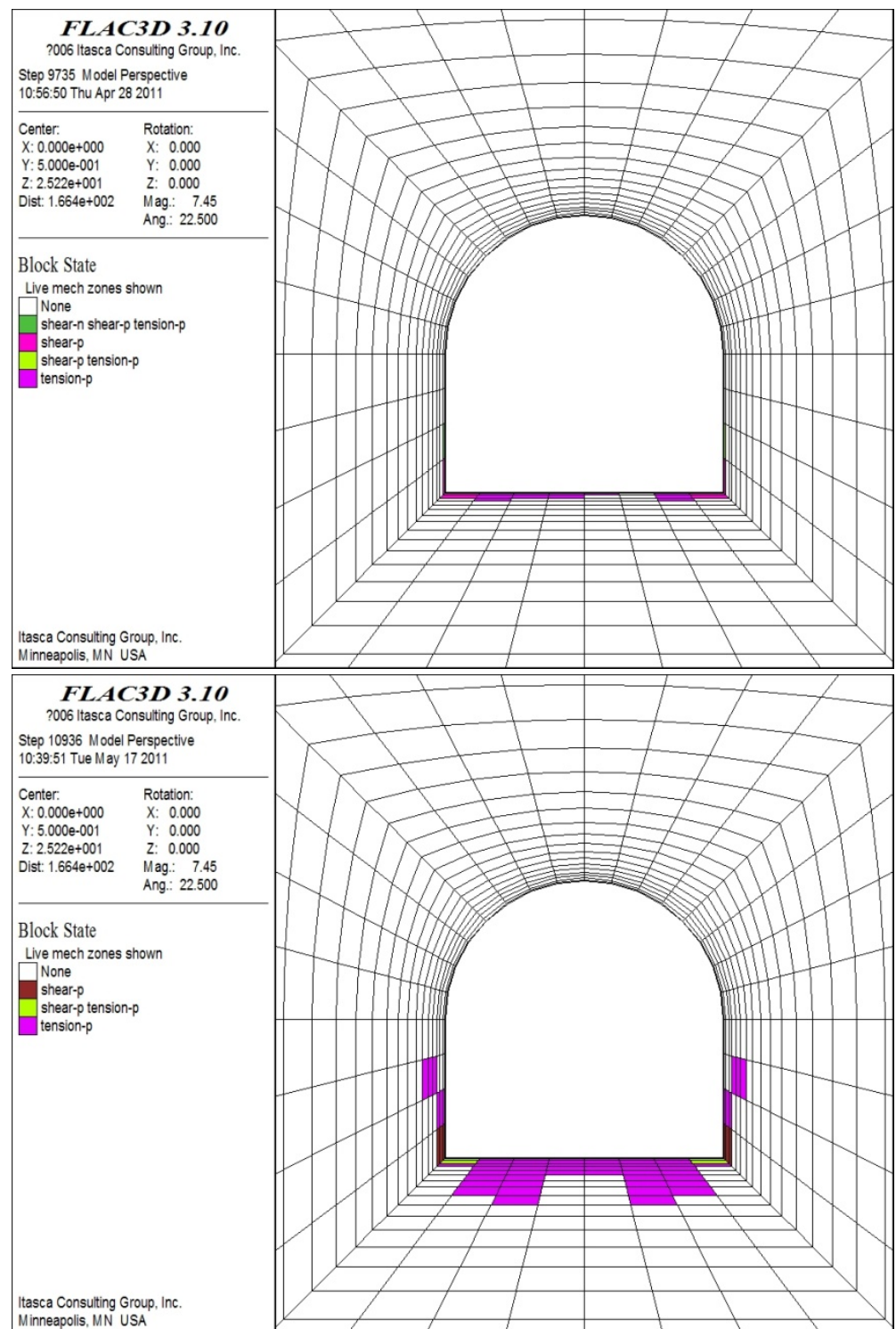

Figure 3-14. DRZ (plastic zone) for the cases (a) considering mechanical unloading only, and (b) without considering shrinkage effect

\subsubsection{Results for Case 2}

Bedding in the Opalinus Clay is a prominent geological feature consisting of persistent ubiquitous planes spaced in the millimeter range. This is consequently reflected in the transverse-isotropic nature of the mechanical properties: Young's modulus ranges from 4 GPa perpendicular to bedding to10 GPa parallel with bedding, which causes the stress redistribution around an underground tunnel to be anisotropic. The interplay of these anisotropic properties and behavior is an open question, one that requires not only model 
development and study, but also field or laboratory tests to measure such anisotropic effects.

In Case 2, understanding the influence of the bedding planes on the stress distribution and the induced damage map around the tunnel was achieved through a series of numerical simulations. It was decided to keep the same input parameters as in the model of Case 1, but only consider elastic responses. Two scenarios were modeled to assess the impact of the geological heterogeneities. The first scenario considered a transverse isotropic rock matrix with the isotropic plane inclined at $0^{\circ}$ from horizontal. In the second scenario, the bedding anisotropy was represented with the isotropic plane inclined at $90^{\circ}$ from horizontal. Given the stiffness properties with respect to bedding orientation, two different deformation properties were considered: Young's modulus of 10 and $4 \mathrm{GPa}$ parallel with and perpendicular to the bedding, respectively. For clarity, only elastic model results are compared in the stress field and deformation plots.

Figure 3-15 and 3-16 show the developed stress distribution. They clearly demonstrate that the stress distribution depends strongly on the bedding orientation. For the case with horizontal oriented bedding planes $\left(\operatorname{dip}=0^{\circ}\right)$, the tensile stress is mainly concentrated within the region adjacent to the side walls of the tunnel, while in the second case, the tensile stress is uniformly distributed around the entire tunnel surface. 
(a)

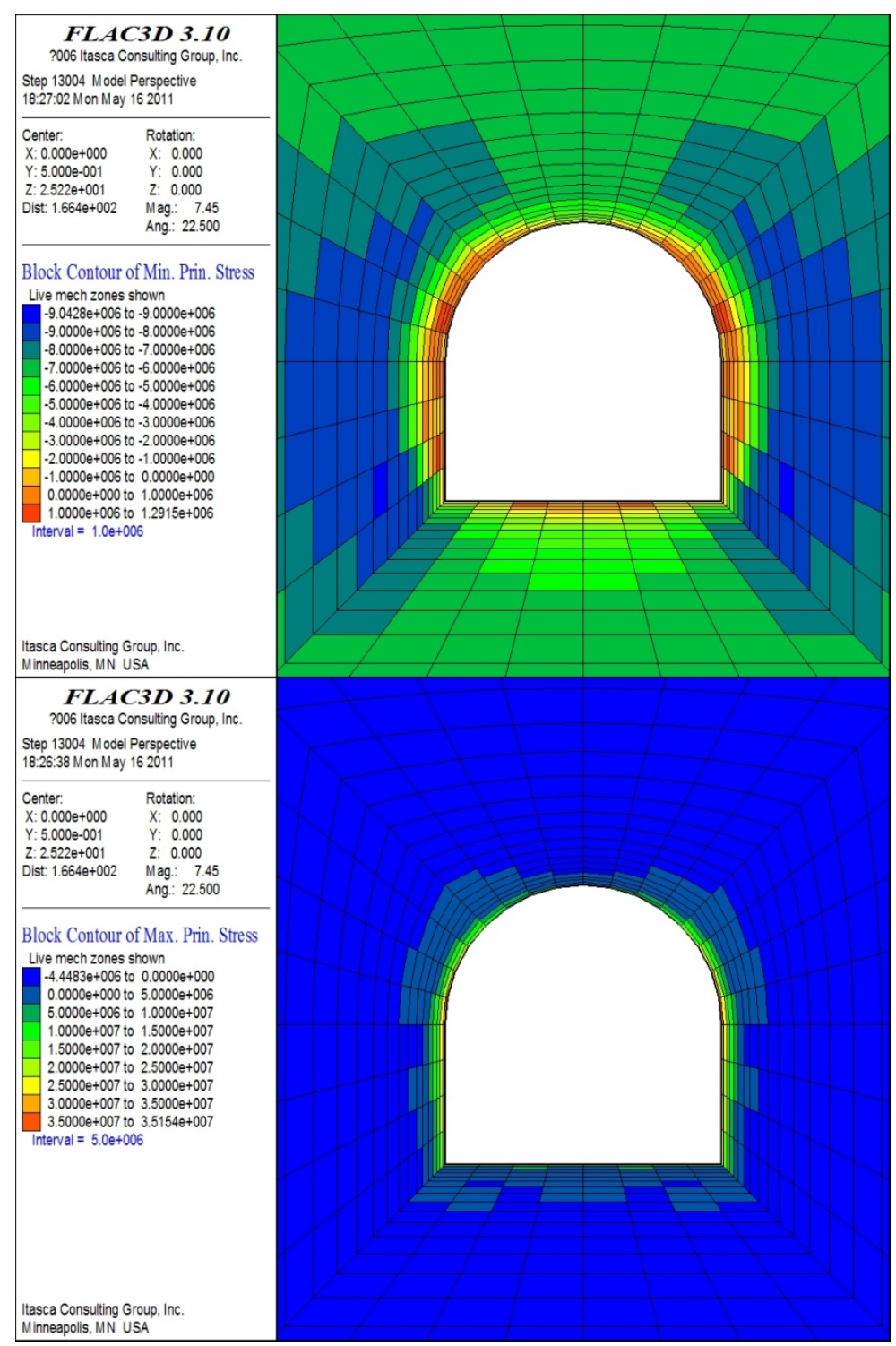

Figure 3-15. Stress distribution for the case with horizontal oriented bedding planes $\left(\operatorname{dip}=0^{\circ}\right)$ 


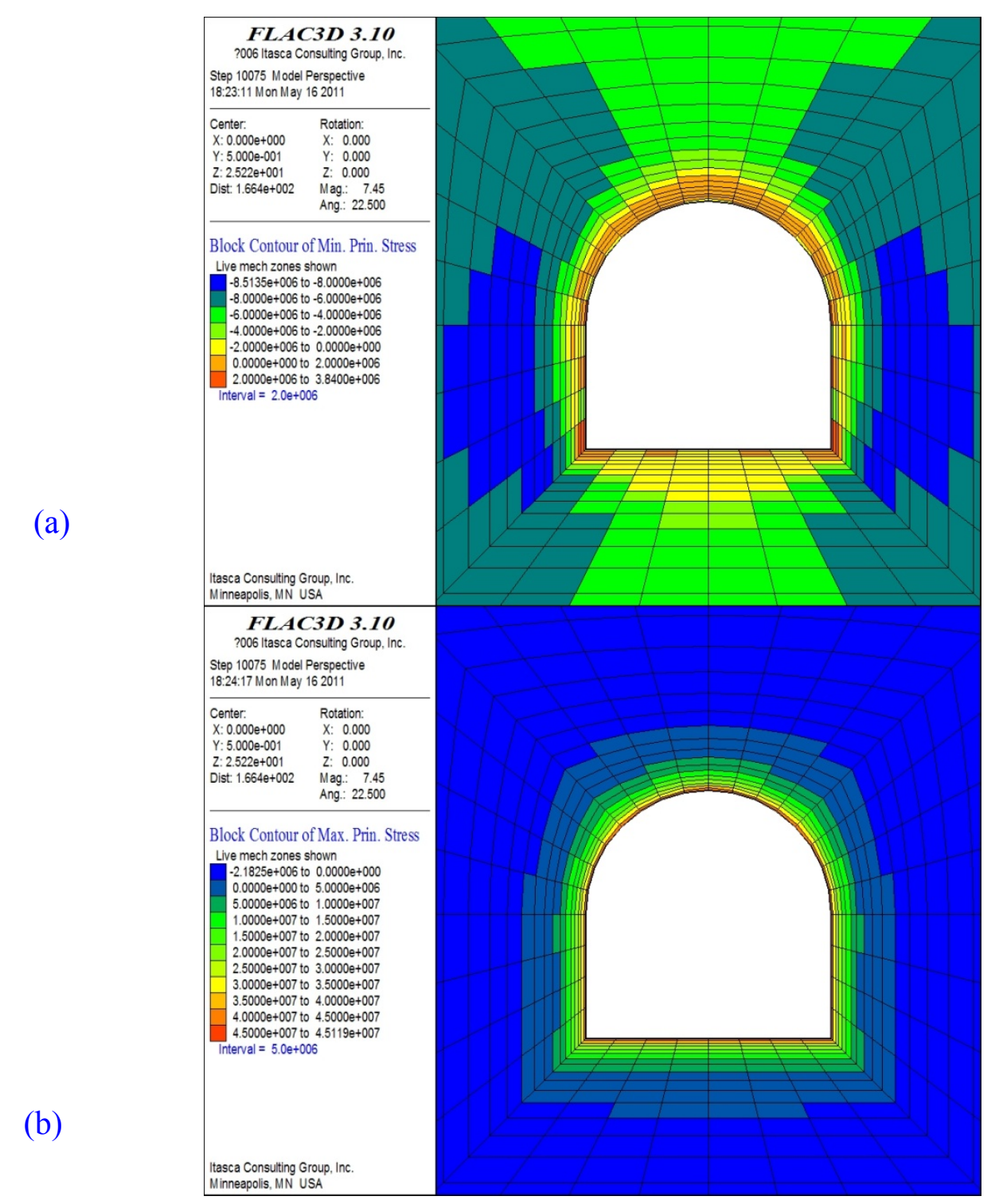

Figure 3-16. Stress distribution for the case with vertical oriented bedding planes $\left(\operatorname{dip}=90^{\circ}\right)$

The deformations at points $\mathrm{A}, \mathrm{B}$, and $\mathrm{C}$ along the tunnel boundary show a slight movement towards the rock matrix, gradually reaching convergence after one year for both cases, as shown in Figure 3-17 (a). The deformations at points D, E, and F show an opposite tendency, with a transition between negative and positive movement compared with that at points A, B, and C. Deformation convergence was not observed even after three years, as shown in Figure 3-17 (b). Although the general developing trend of deformation is the same, there is an obvious difference in the magnitude, particularly for the displacement in roof and floor zones. The small Young's modulus perpendicular to the bedding plane leads to large displacement under isotropic stress conditions. 


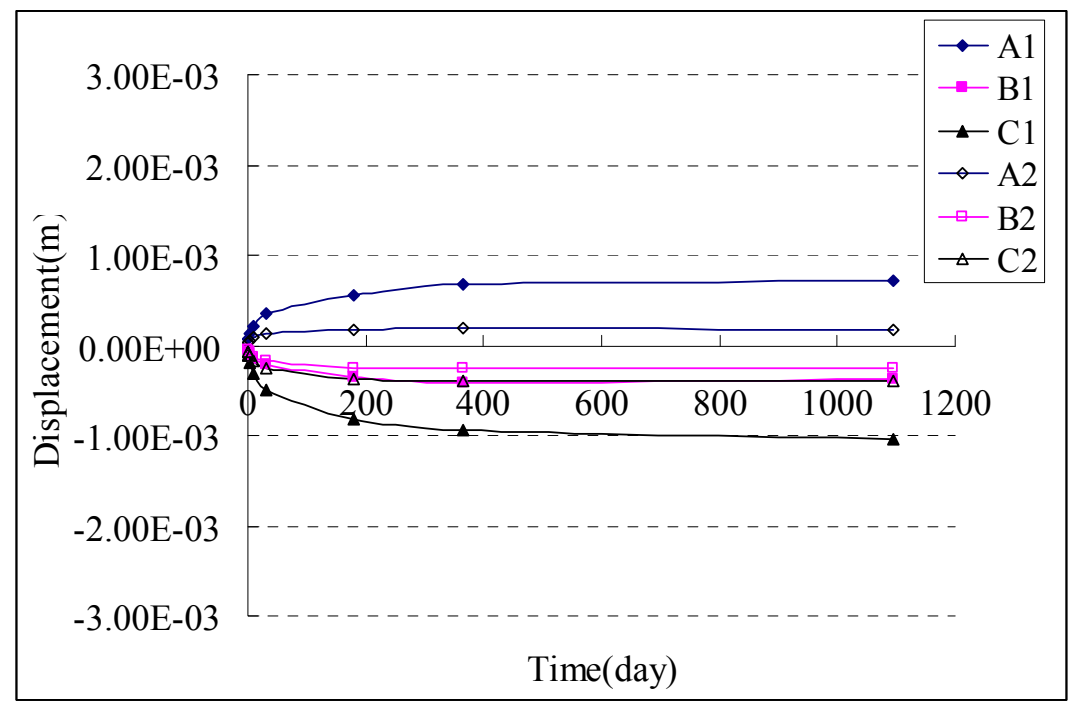

(a) Displacement evolution with time for point A, B and C, respectively

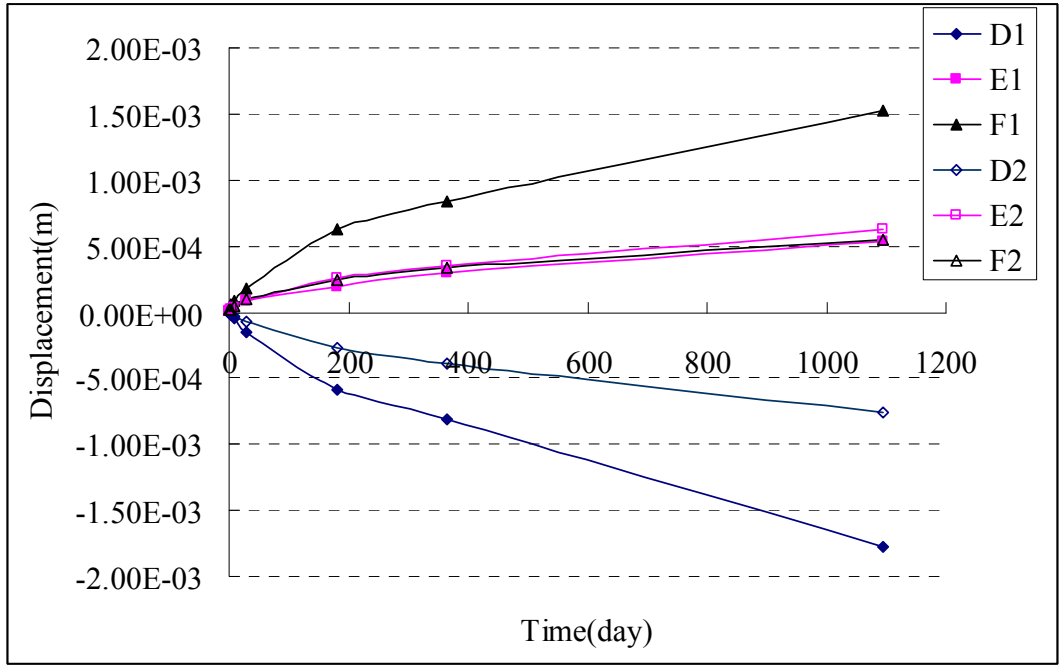

(b) Displacement evolution with time for point D, E and F, respectively

Figure 3-17. Numerically obtained displacement at points A, B, C, D, E, and F

The potential plastic zones (the area enclosed by the red line in Figure 3-18), where tensional stress exceeds tensional strength, further depends on the relative orientation of the principal stresses and the stress magnitude within the zones adjacent to the tunnel surface. This is because the zones subjected to tensional stress around the tunnel with parallel bedding planes are obviously smaller than those with perpendicular bedding planes. Only extensional failure is observed at the side walls of the tunnel with horizontal oriented bedding planes, while extensional failure appears symmetrical around the entire tunnel surface for the case with vertical oriented bedding planes. Obviously, the observed failure pattern is caused by the anisotropy of the material parameters, rather than the far field stress. 
(a)

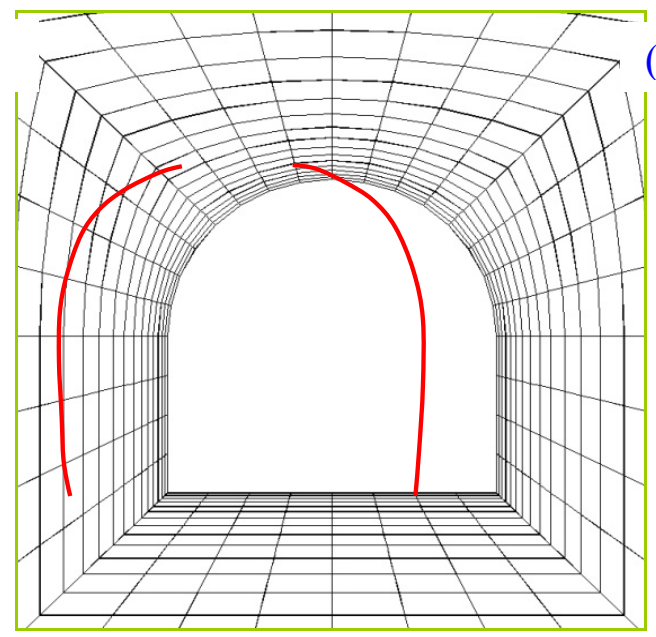

(b)

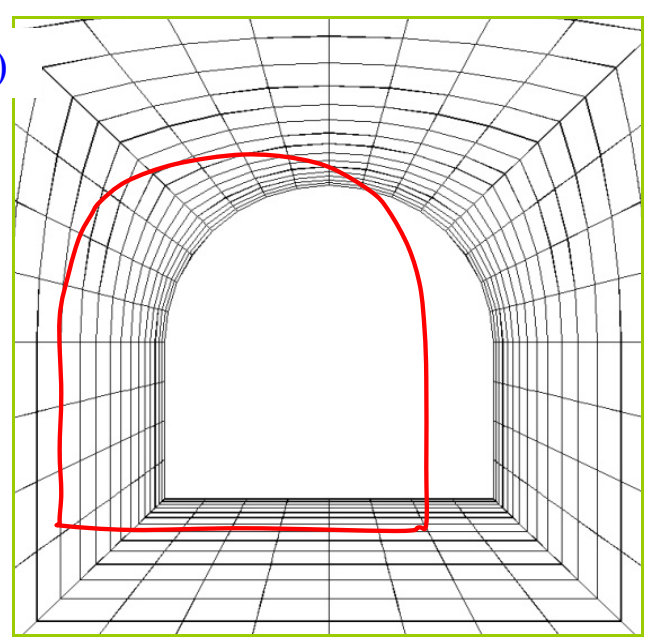

Figure 3-18. Numerically obtained potential plastic zones for the cases (a) with the isotropic plane inclined at $0^{\circ}$ from horizontal, (b) with the isotropic plane inclined at $90^{\circ}$ from horizontal

\subsubsection{Results for Case 3}

In Case 3, we first validate the model by comparing the stress-strain states in a numerical specimen with available data from the literature (Corkum and Martin, 2007a, 2007b; Liu et al., 2009). Uniaxial tests were numerically performed on the $83 \mathrm{~mm}$ diameter core specimen, shown in Figure 3-19, with FLAC3D.

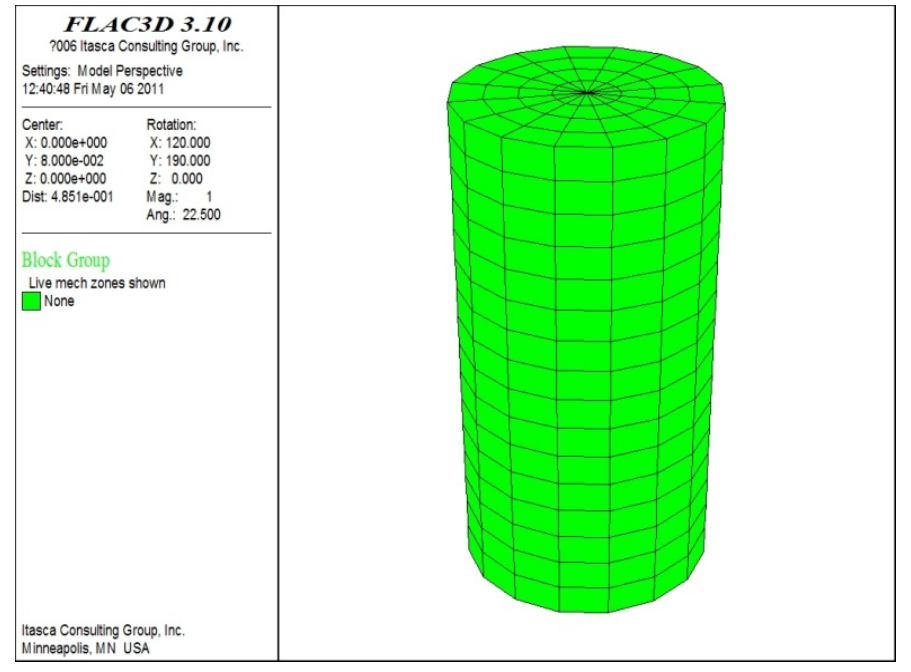

Figure 3-19. Numerical specimen for model validation 
Stress-strain plots for the three specimens are shown in Figure 3-20, indicating a significant low-stiffness, nonlinear response at low stress levels, which indicates that our numerical results are in excellent agreement with the experimental data. Corkum and Martin (2007a) have demonstrated that the mechanical response of Opalinus Clay is unique and reflective of a microstructure dominated by diagenetic bonding and stored latent strain energy. They showed that the low-stress, low-stiffness nonlinear stress-strain response of laboratory samples is the true material behavior. However, it is not fully understood how such nonlinear behavior impacts DRZ evolution around the underground opening. Further analyses are needed to investigate this effect.

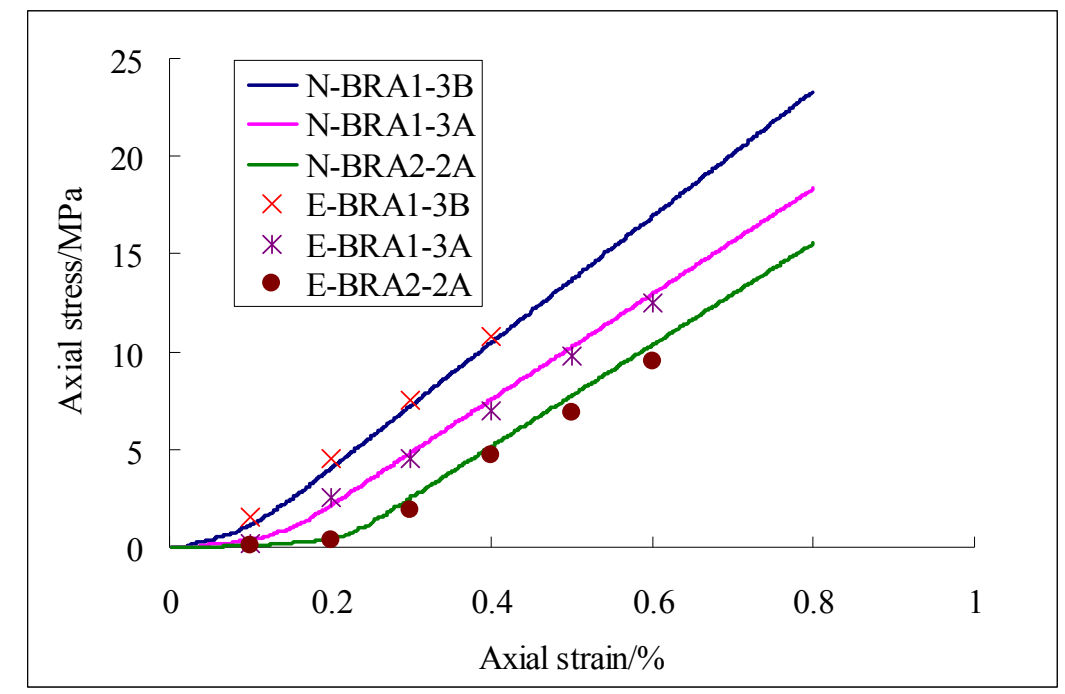

Figure 3-20. Comparison between laboratory measurements and values obtained using the numerical method

For the simulation on DRZ features in Case 3, it was decided to keep the same input parameters as in the model of Case 1, but further consider the nonlinear behavior of Opalinus Clay. We compared the numerically obtained (short-term excavation) ventilation-induced mechanical response with that in Case 1. The supplementary parameters are listed in Table 3-3.

Table 3-3. Supplementary mechanical parameters for Case 3

\begin{tabular}{lll}
\hline Parameters & Value & Unit \\
\hline$E_{e}$ & 3999 & $\mathrm{MPa}$ \\
\hline$\gamma_{e}$ & 0.999 & \\
\hline$E_{t}$ & 1 & $\mathrm{MPa}$ \\
\hline$\gamma_{t}$ & 0.001 & \\
\hline
\end{tabular}


To directly and clearly compare the results of modelling to those in Case 1, the results based on elastic analysis are presented first. This comparison was done using the stress distribution around the tunnel and the deformation variations at points $\mathrm{D}, \mathrm{E}$, and $\mathrm{F}$.

After 3 years of ventilation, the final maximum and minimum principal stresses for Case 1 and Case 3 are shown in Figure 3-21 and 3-22, respectively. Generally, the tensilestress concentrated zone induced by shrinkage is located within the region adjacent to the tunnel surface. However there are differences in the stress distribution mode and magnitude. For the case considering nonlinear behavior, the zones with compressive stress evidently increased, particularly near the side walls of the tunnel; the zones with a compressive stress beyond $8 \mathrm{MPa}$ have extended to $\sim 4 \mathrm{~m}$ away from the sidewalls of the tunnel. 


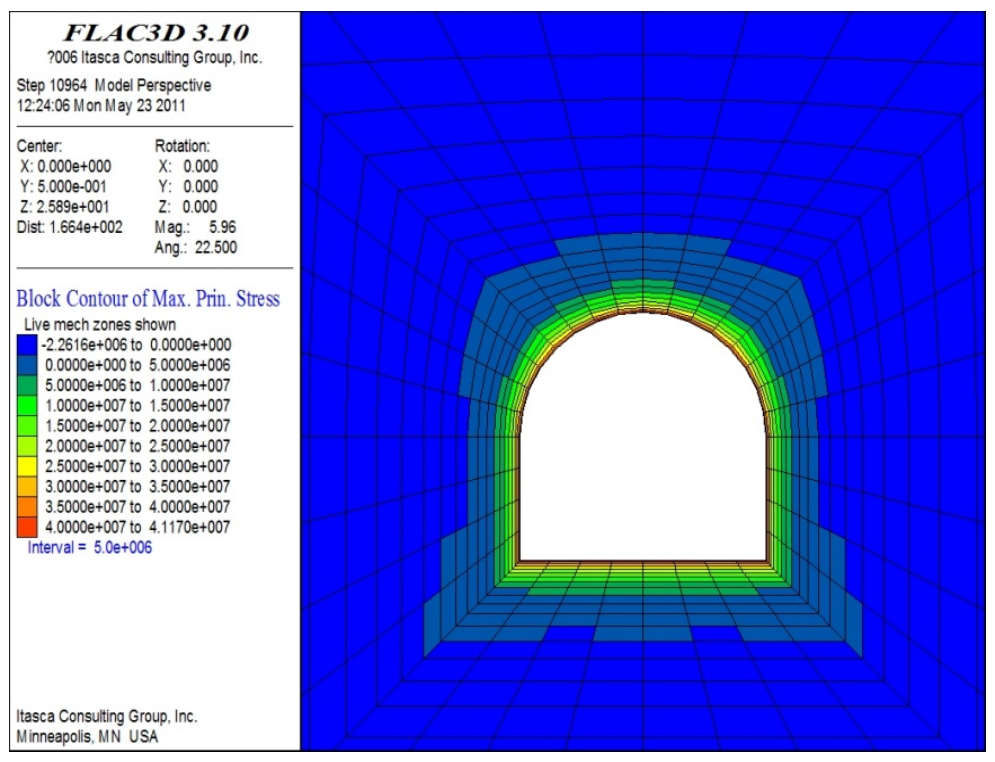

(a)maximum principal stress

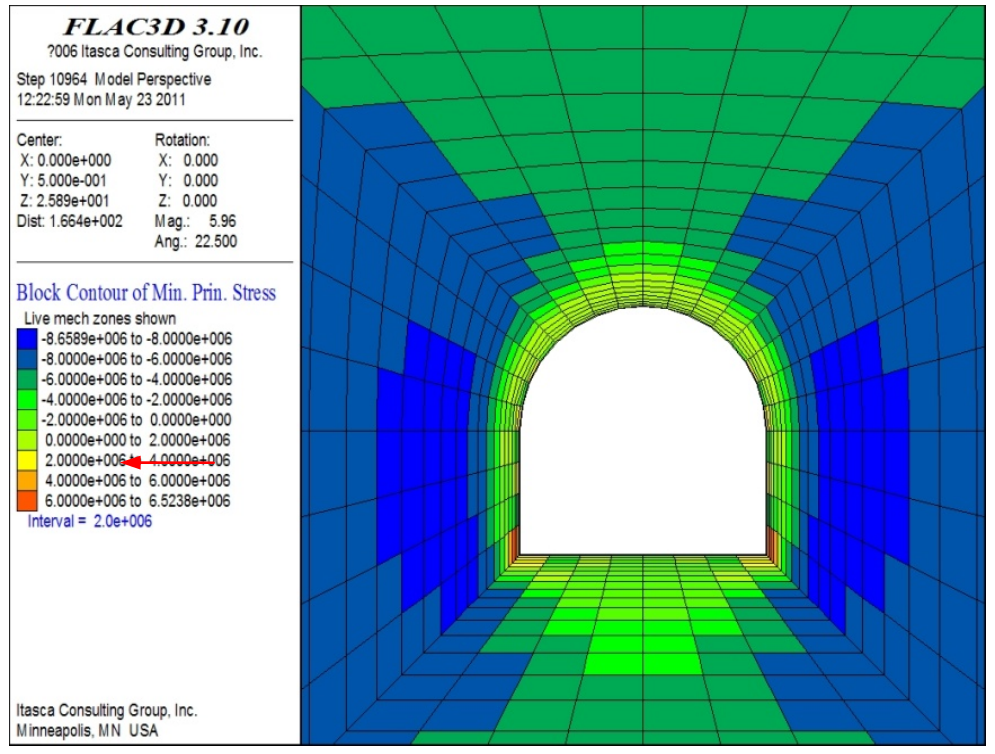

(b)minimum principal stress

Figure 3-21. Stress distribution for Case 1 (elastic mode) 


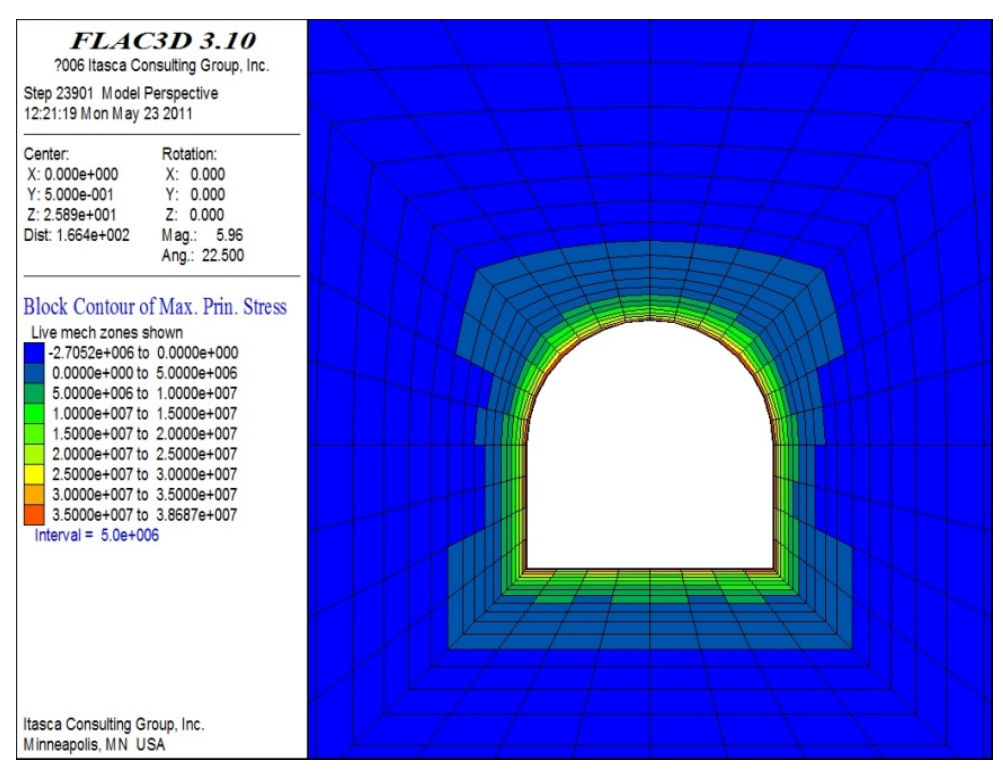

(a)maximum principal stress

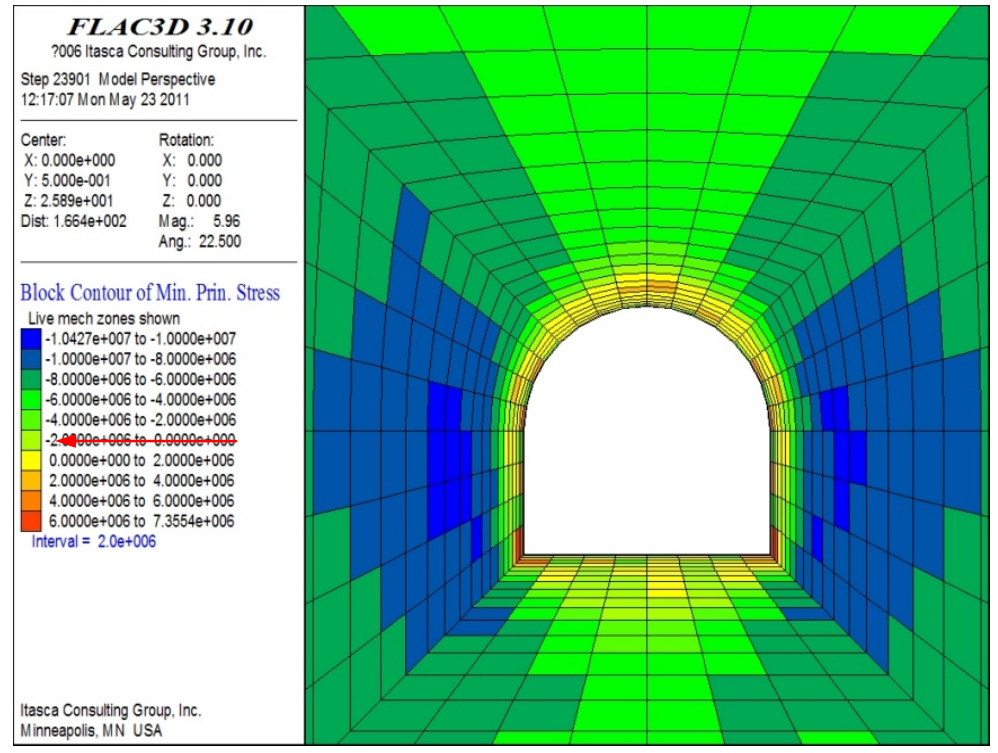

(b)minimum principal stress

Figure 3-22. Stress distribution for Case 3 (elastic mode)

Figure 3-23 shows the numerically obtained stress variation during the ventilation process. The average values of the compressive stress at point $\mathrm{E}$ increased about 1.1 $\mathrm{MPa}$ compared with those in Case 1, while the compressive stress at points D and F decreased. For points $\mathrm{D}$ and $\mathrm{F}$, the minimum principal stress evolved from a compressive state to a tensional state. Especially at point $\mathrm{F}$, the tensional stress is slightly higher than those in Case 1. 
For both cases, the deformations at points $\mathrm{D}, \mathrm{E}$, and $\mathrm{F}$ show an evident movement towards the tunnel opening, as shown in Figure 3-24. Although the general developing trend of deformation is the same, the magnitude is obviously different, particularly for the displacement in roof and floor zones. A relatively large displacement at point $\mathrm{F}$ was obtained for Case 3, while the displacements at points D and $\mathrm{E}$ are slightly less than those in Case 1.

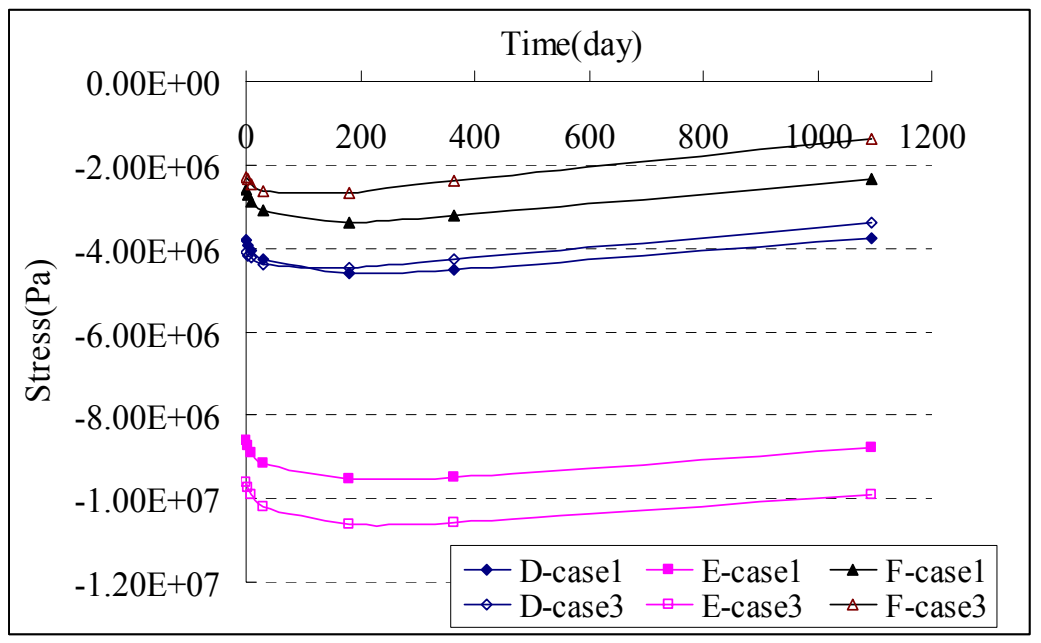

(a) maximum principal stress evolution with time for point D, E and F, respectively

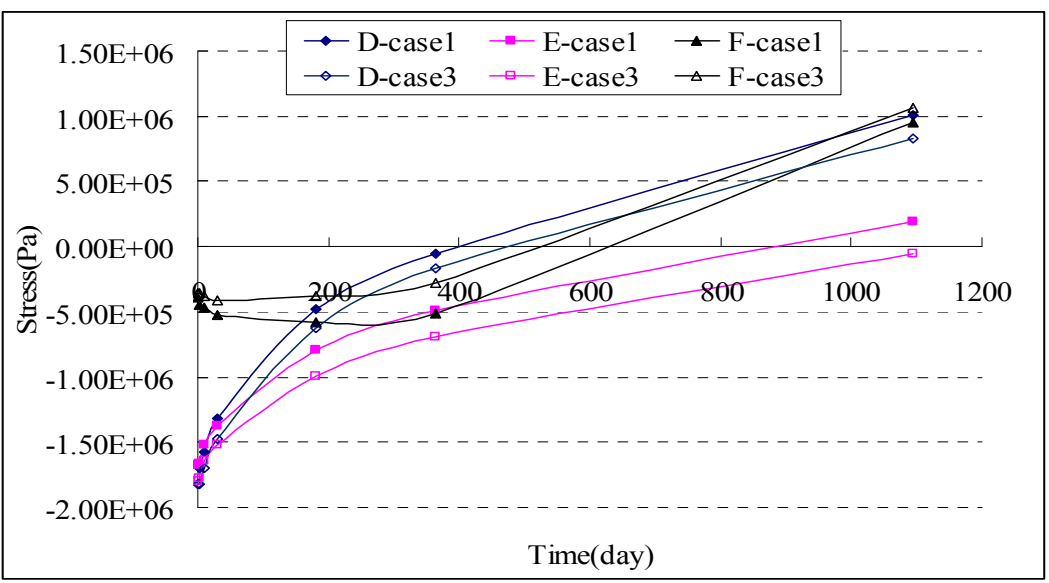

(b) minimum principal stress evolution with time for point $\mathrm{D}, \mathrm{E}$ and $\mathrm{F}$, respectively

Figure 3-23. Numerically obtained stress at points D, E, and F 


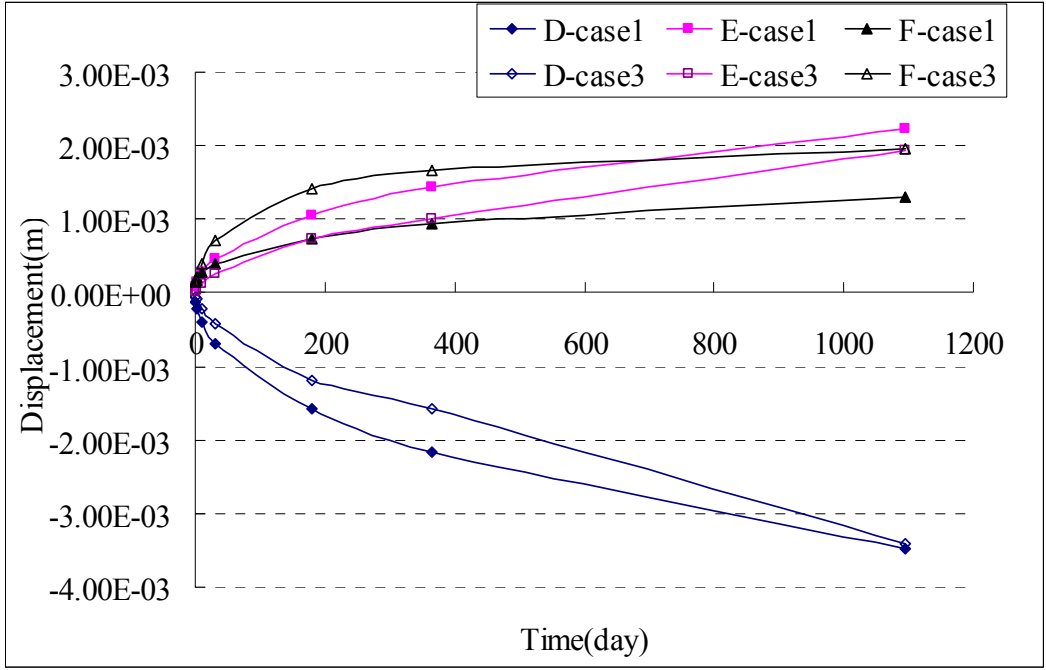

Figure 3-24. Numerically obtained displacement at points D, E, and F

As shown in Figure 3-25, during the period of ventilation, the variation in porosity and permeability correspond to the evolution of stress. The porosity and permeability gradually increase within the zones adjacent to the tunnel walls, due to tensile stress induced by desaturation. The average values for porosity and permeability at point $\mathrm{E}$ are smaller than those in Case 1, while those at point $\mathrm{F}$ have evidently increased. The average values for porosity and permeability at point $\mathrm{D}$ has changed little, since the variation in stresses at point D was limited. 


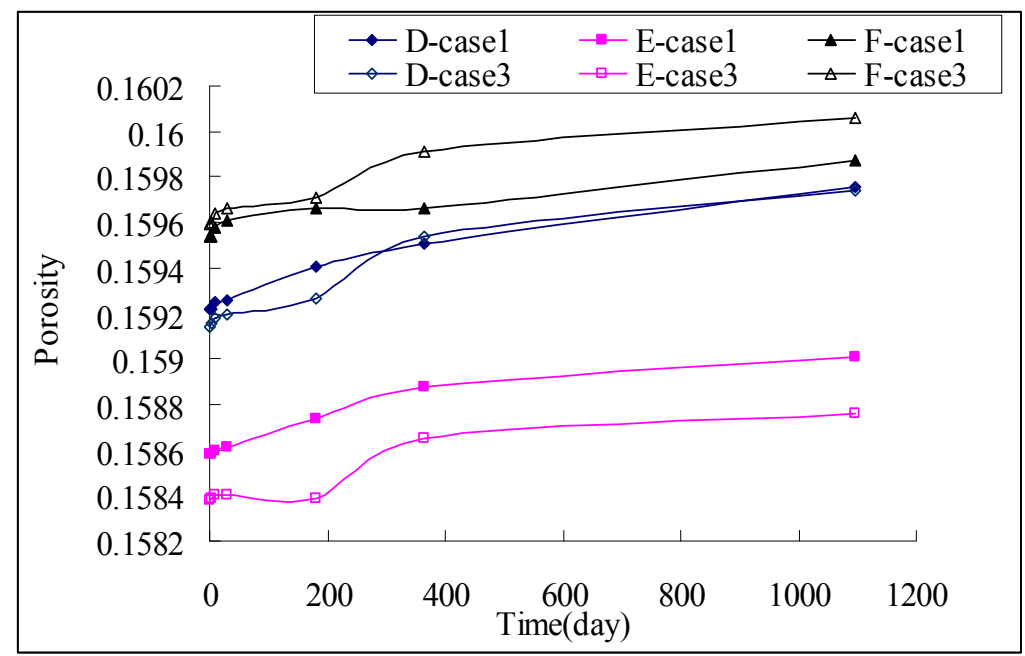

(a) porosity variation

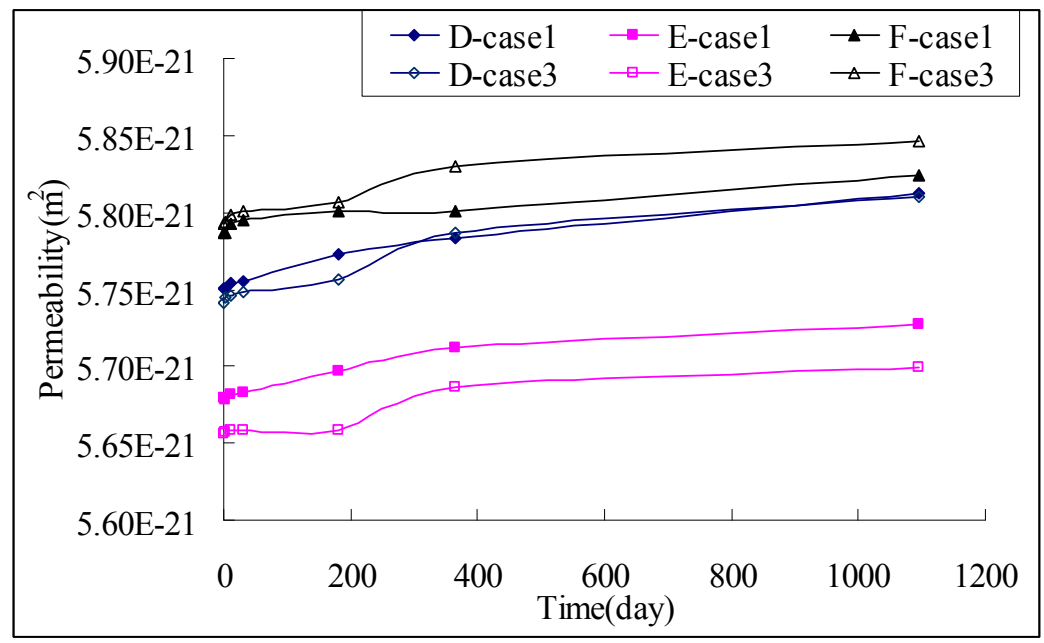

(b) permeability variation

Figure 3-25. Porosity and permeability evolution at points D, E, and F

Similarly, the DRZ is mainly developed in the vicinity of the tunnel surface. Figure 3-26 illustrates the progressive change DRZ at ventilation times of 3 days and 3 years. Our calculations show that the extent of the DRZ near the tunnel roof decreased slightly, and near the tunnel floor increased slightly as compared with Case 1, and shown in Figure 313. The DRZ development in this case is dominated by tension failure induced by the hydraulic desaturation due to the ventilation of the tunnel opening. However the employed constitutive law, Equation (3-1), in the calculation of this case is the same as the conventional Hooke's law for tensional state, which means that the influence on the DRZ above was obtained by regulating the compressive stress distribution around the tunnel. Nonetheless, based on a comparison of the results, it can be pointed out that the non-linear behavior in the Opalinus Clay has an evident influence on hydromechanical 
behavior, including stress, displacement, porosity, permeability variation, and DRZ mode around the tunnel.

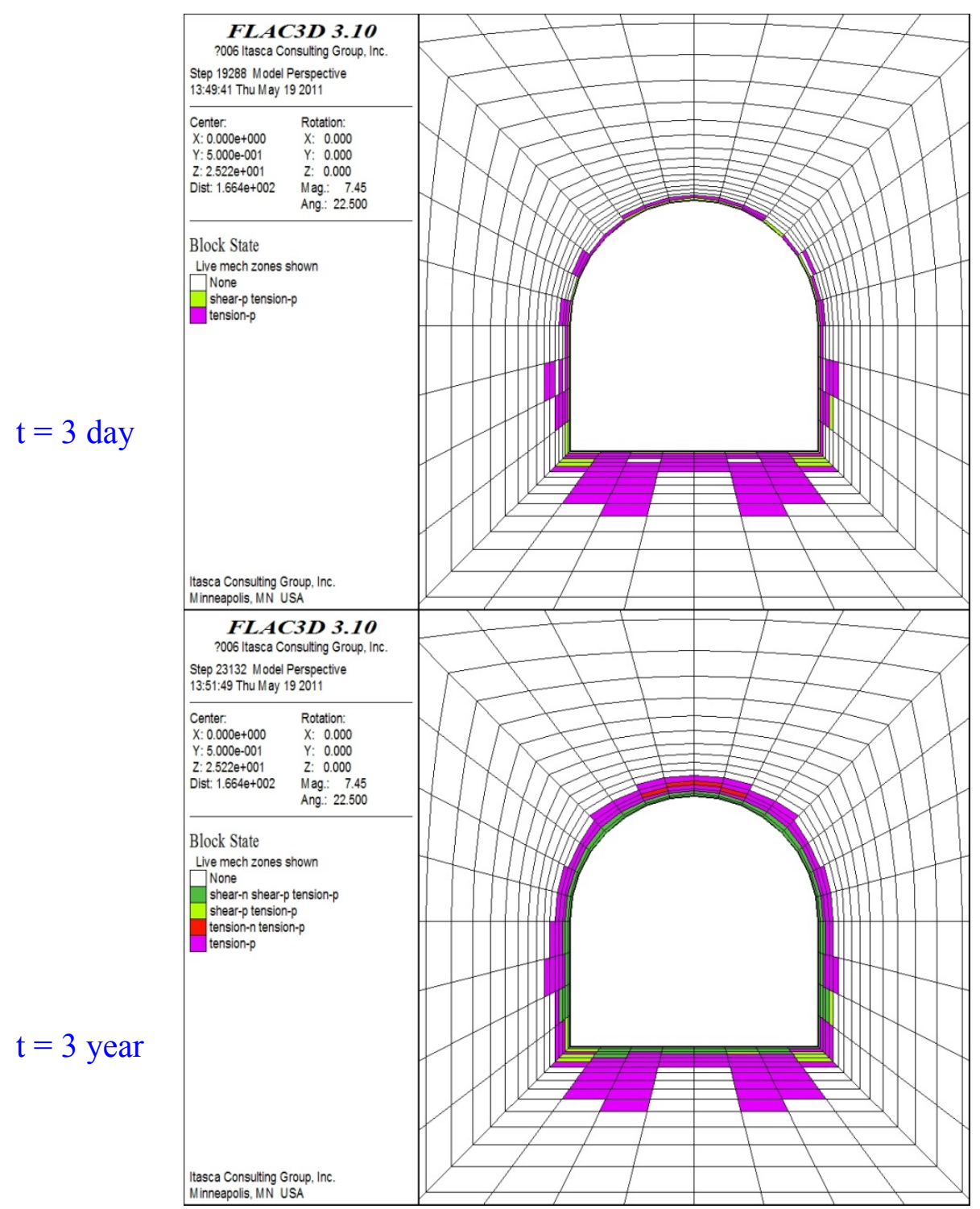

Figure 3-26. DRZ mode for Case 3 at time $t=3$ days and 3 years

\subsection{Conclusions}

In this study, the near-field coupled HM processes associated with ventilation in a clay repository were investigated with TOUGH-FLAC. In the improved TOUGH-FLAC, a series of relationships reflecting dynamic variations in mechanical parameters are incorporated into the TOUGH-FLAC routine, and a special FISH routine in FLAC3D has 
been programmed to translate FLAC3D mesh into TOUGH2 meshes, to ensure mesh compatibility between TOUGH2 and FLAC3D.

Numerical simulations indicate that after 3 years of ventilation, the underground tunnel was affected by the ventilation in a narrow zone around the tunnel (thickness less than 40 $\mathrm{cm}$ ), where the degree of rock saturation was lower than $95 \%$. For the initially saturated Opalinus Clay matrix, the water evaporation process has three stages: (1) a stage with a rapid desaturation rate, when most of the rock matrix remains saturated and the tunnel surface is dried by air entry suction; (2) a stage with a relatively gentle desaturation rate; and (3) a final, stable stage, in which further ventilation does not result in any more water loss. Correspondingly, tunnel surface damage (DRZ induced by shrinkage stress) generally takes place in three stages: initiation of primary damage; development of subdamage; and then relative stability, with no new damage developing. It is also observed that DRZ development is parallel to the tunnel surface, which is consistent with the desaturation zone development.

DRZ-phenomena are found to be strongly related to the existing lithological rock properties, i.e., rock anisotropy due to the bedding planes. When considering elastic deformation only, we show that the zones subjected to tensional stress around the tunnel with parallel bedding planes are obviously smaller than those with perpendicular bedding planes, and relatively larger displacement occurs in the roof and floor for the tunnel with parallel bedding planes. The potential plastic zones, where tensional stress exceeds tensional strength of rock matrix, depend on the relative orientation of the principal stresses and the stress magnitude within the zones adjacent to the tunnel surface. Only extensional failure is observed at the side walls of the tunnel with horizontally oriented bedding planes $\left(\mathrm{dip}=0^{\circ}\right)$, while extensional failure appears symmetrical around the entire tunnel surface for the case with vertically oriented bedding planes $\left(\operatorname{dip}=90^{\circ}\right)$.

Experimental tests have shown that the stress-strain curve of Opalinus Clay behaves in a highly nonlinear manner, with low stiffness at low stresses. We have implemented a constitutive model capturing the stress-strain nonlinearity of Opalinus Clay into the TOUGH-FLAC code. The model included both linear and nonlinear components dependent on stress levels, in which the nonlinear component reflected the behavior of Opalinus Clay at low stresses, where most of the deformation around the tunnel occurs. The unloading and ventilation-induced response of Opalinus Clay to tunneling based on numerical modeling was found to be closely related to the nonlinear response of Opalinus Clay observed in laboratory samples. Using our constitutive model, we found a larger radial elastic deformation on the roof and floor of the tunnel, and considerably different stress distributions, porosity-permeability variations, and DRZ modes around the tunnel. By regulating the stress distribution around the tunnel, we found that the mode of damage 
zones near the tunnel roof and floor showed evident differences with those calculated by the conventional Hooke's law, indicating the importance of incorporating more accurate constitutive models for modeling the coupled processes.

\section{THC MODELING IN A CLAY/SHALE ENVIRONMENT}

\subsection{State of the art}

Clay/shale formations are one of the host rock candidates for radioactive waste disposal throughout the world. These formations have been studied especially extensively in Europe- the Opalinus Clay at Mont Terri (Thury, 2002) and the Callovo-Oxfordian clay at ANDRA's underground research facility, France (Samper et al., 2008; Jougnot et al., 2010). One advantage of emplacing radioactive waste in clay formations is the potential self-sealing capability of clay due to swelling. The self-sealing capability might have particular importance for disturbed rock zones (DRZ). It is therefore necessary to study the changes in swelling properties within clay rock, especially in the near-field area during the disposal of radioactive waste. Because the clay rock is usually in a saturated condition, the swelling-property changes in clay rock are mostly due to the geochemical changes, including (1) changes in ion concentration of the bulk water, which may also change the swelling properties; (2) cation exchange changes in the composition of the water in the interlayer space, and therefore changes in the swelling of the rock and (3) swelling minerals such as smectite may dissolve (for example, as the $\mathrm{pH}$ increases) or precipitate (due to the dissolution of silicates), which subsequently modify the swelling of the rock.

The studies of geochemically induced change in clay swelling properties are relatively limited. Thury (2002) reported that in contact with water, decompressed Opalinus Clay swells; the swelling varies when the swelling tests are carried out with various water types (deionized water, low mineralized water, synthetic pore water and $\mathrm{KCl}$ solution). The maximum measured swelling heave (obtained with deionized water) perpendicular to bedding is $9 \%$, and is up to 10 times greater than that parallel to bedding. More highly mineralized waters result in smaller swelling heaves by $2 \%$ only. Wakim et al. (2009) experimentally evaluated the effect of aqueous solution chemistry on the swelling and shrinkage of shales under saturated conditions, and reported that the more concentrated solution led to less swelling of shale. Kamei et al. (2005) and Cuadros (2006) indicated that illitization, the transformation from smectites to illite, is usually part of the diagenesis process of clay formation. Illitization apparently changes the swelling properties of clay formation. Several simulations by Montes-Hernandez et al. (2005) have shown that the $\mathrm{Na} / \mathrm{Ca}$-montmorillonite-to-Ca-montmorillonite conversion due to cation 
exchange in the interface was a significant chemical transformation that could change swelling properties. Studies of mixed-ion montmorillonites by El-Swaify and Henderson (1967) showed that the moisture retention in interlayer spacing by osmotic swelling at a particular equilibrium pressure has a near-linear relationship with exchangeable $\mathrm{Na}$ percentage. The neo-formation of chlorites (nonswelling clays) (Montes-Hernandez et al., 2005) was also observed as a potential chemical transformation that could also lower the swelling properties of the clay rocks.

Although the possible change in clay-rock swelling properties which has been demonstrated with short term and small-scale lab tests (Thury, 2002; Wakim et al., 2009) and by indirect measurement (such as the occurrence of illitization-Kamei et al., 2005; Cuadros, 2006) point out the need to evaluate the geochemically induced swelling/shrinkage of host clay rock, no such evaluation has been reported, as far as our literature survey has found. In this report, coupled THC models that include EBS and host clay rock are linked with a swelling model based on the Gouy-Chapman diffuse double layer (DDL) theory, in which the changes in swelling properties within the nearfield area of host clay rock are evaluated. The coupled THC models provide the geochemical changes in the near-field host rock, and the swelling model calculates the swelling pressure.

\subsection{Technical Approach}

In this report, an approach that combines a coupled THC model with a swelling model based on the Gouy-Chapman DDL theory is adopted to evaluate the changes in swelling properties for near-field host clay rock. First, the change in geochemical parameters (i.e., the concentration of the bulk solution, the exchangeable cations, and the volume fraction of swelling clay minerals) in the host clay rock are calculated with a THC model using TOUGHREACT Version 2, and then the swelling pressure is calculated based on the input from THC model. Eventually, the changes in hydraulic properties are computed and fed back to the THC model as needed.

In this section, the simulator TOUGHREACT V2 is discussed briefly and then the swelling model based on DDL theory is presented, along with some calculation examples.

\subsubsection{TOUGHREACT Version 2}

TOUGHREACT is a numerical simulation program for chemically reactive nonisothermal flows of multiphase fluids in porous and fractured media (Xu and Pruess, 2001; Spycher et al., 2003; Sonnenthal et al., 2005; Xu et al., 2006b; Xu et al., 2011; 
Zhang et al., 2008c; Zheng et al., 2009). The program was written in Fortran 77 and developed by introducing reactive chemistry into the multiphase fluid and heat flow simulator TOUGH2 (Pruess, 2004). The program can be applied to one-, two- or threedimensional porous and fractured media with physical and chemical heterogeneity. The code can accommodate any number of chemical species present in liquid, gas, and solid phases. A variety of subsurface thermal, physical, chemical, and biological processes are considered under a wide range of conditions of pressure, temperature, water saturation, ionic strength, and $\mathrm{pH}$ and $\mathrm{Eh}$.

Processes for fluid flow and heat transport are the same as in the original TOUGH2 code. Transport of aqueous and gaseous species by advection and molecular diffusion is considered in both liquid (aqueous) and gas phases. Depending on computer memory and CPU performance, any number of chemical species in the liquid, gas, and solid phases can be accommodated. In the 2004 version, aqueous complexation, acid-base, redox, gas dissolution/ exsolution, and single-site cation exchange are considered under the local equilibrium assumption. Mineral dissolution and precipitation can proceed either subject to local equilibrium or kinetic conditions.

Over the last several years, many new capabilities have been developed within different research projects at Lawrence Berkeley National Laboratory. We have incorporated these new capabilities into Version 2 of TOUGHREACT. Major additions and improvements in Version 2 include:

- Intra-aqueous reaction kinetics and biodegradation,

- Surface complexation models, including double layer,

- Multi-site exchange,

- Improvements in the reactive surface area algorithm for mineral-water reactions, and fugacity coefficient corrections for gas-water reactions,

- Improvement in coupling and mass balance between chemistry and physics parts, including changes in rock and fluid properties due to reactions, and accounting for $\mathrm{CO}_{2}$ fixed as carbonates in flow simulation (for use in the ECON module).

- Improvement in functionalities such as printout mineral reaction rate, and both aqueous component and species concentrations in different unit options,

- Improvement in computational efficiency.

A detailed description of TOUGHREACT Version 2 is given by Xu et al. (2011).

\subsubsection{Application of DDL theory to calculate swelling pressure}

The swelling of clays can be calculated in several ways. Elastoplastic models (Gens and Alonso, 1992; Thomas and He, 1998) such as the Barcelona Basic Model (BBM) (Alonso 
et al., 1990) and the Barcelona Expansive Model (BExM) (Alonso et al., 1999) are widely used. Recently, chemical components are also incorporated into the stress-strain relation, such as incorporation of the concentration of exchangeable cations (Guimarães et al., 2007) and consideration of the aqueous concentration via chemical potential (Ghassemi and Diek, 2003). Another approach involves a constitutive equation to relate the deformation of compacted bentonite to the distance between two montmorillonite layers based on the DDL theory (e.g., Komine and Ogata, 1996; 2003; Schanz and Tripathy et al., 2009).

To determine the approach for calculating the swelling pressure of the near-field host clay rock, it is necessary to determine the swelling processes that the clay rock might suffer, i.e., what type of swelling we are dealing with. In expansive clay-water-ion systems, there are basically two types of swelling processes: crystalline and osmotic. Crystalline swelling refers to swelling that occurs at relatively low water content and is primarily a consequence of the hydration of interlayer exchangeable cations. Swelling occurs as water enters the mineral interlayer as a sequence of successive molecular layers, which results in a step-wise separation of the interlayer for up to three or four layers of water. Osmotic swelling occurs at higher water contents and is associated with continuing interlayer separation that develops from movement of water into the interlayer due to the difference in ion concentration within the interlayer and within the bulk pore water. Osmotic water adsorption results from concentration differences among dissolved ions between the interlayer pore water (overlapping double layers) and the free (bulk) water. It is a long-range interaction, which mostly depends on ionic concentration, the type of exchangeable ion (e.g., $\mathrm{Ca}$ vs. Na), $\mathrm{pH}$ of the pore water, and clay mineralogy (van Olphen, 1977). Corresponding osmotic swelling results from the balance of attractive and repulsive forces that develop between overlapping electrical double layers. Crystalline swelling, which occurs mainly in the initial hydration, will be transformed to osmotic swelling when clay approaches full saturation. Wayllace (2008) reported that such transformation will occur when the RH\% is around 97; Onikata et al. (1999) indicated, from a microscopic point of view, that the $\mathrm{d}(001)$-value of 20 to 40 is probably a critical value, where the electrostatic attractive force between the 2:1 layers by way of the cations is sufficiently weak that the crystalline swelling is transformed into osmotic swelling.

Based on the fact that (1) the host clay rocks that went through a long term diagenesis process are mostly fully saturated and (2) the drive force is mostly the geochemical changes, the clay rocks will undergo osmotic swelling when contacting with EBS. Typically, clay host rock contents higher cations than EBS bentonite, which imply that near the interface area, clay host rocks likely loss ion to EBS bentonite, which will induce an disequilibrium of chemical potential and therefore osmotic swelling. 
According to the DDL theory (Bolt, 1956), during the osmotic swelling process, the swelling pressure is the difference between the osmotic pressure in the central plane between two clay plates and the osmotic pressure in the equilibrium solution. In other words, the swelling pressure is the pressure required to keep the clay-water system at the required void ratio, when it is allowed to adsorb water or electrolyte (Tripathy et al., 2004). Bolt (1956) and van Olphen (1977) presented a method for calculating the swelling pressure in a clay-water electrolyte system. Sridharan and Jayadeva (1982) improved on Bolt (1956) and van Olphen (1977) and presented the diffuse double layer theory in a lucid form that could be readily used for understanding the engineering behavior of clays. The equations used by Sridharan and Jayadeva (1982) to determine swelling pressure are as follows:

$$
e=G \gamma_{w} S d
$$

where $e$ is the void ratio, $G$ is the specific gravity of soil solids, $\gamma_{w}$ is the unit weight of water, $S$ is the specific surface area of soil $\left(\mathrm{m}^{2} / \mathrm{g}\right.$ swelling clay), $d$ is half the distance between parallel clay platelets.

$$
\int_{z}^{u} \frac{1}{\sqrt{(2 \cosh \mathrm{y}-2 \cosh \mathrm{u})}} d y=\int_{0}^{d} d \xi=-K d
$$

where $u$ is the nondimensional midplane potential, $z$ is the nondimensional potential at the clay surface, $y$ is the nondimensional potential at distance $\mathrm{x}$ from the clay surface and $x$ is the distance from the clay surface, $\xi$ is the distance function $(=K x) . \mathrm{K}(1 / \mathrm{m})$ is the double layer parameter:

$$
K=\sqrt{\left(\frac{n\left(e^{\prime}\right)^{2} v^{2}}{2 \varepsilon k T}\right)}
$$

where $e^{\prime}$ is the elementary electric charge $\left(=1.6 \times 10^{-19} \mathrm{C}\right), k$ is Boltzmann's constant $\left(1.3806 \times 10^{-23} \mathrm{j} / \mathrm{K}\right), n$ is the molar concentration of ions in pore fluid (molal), $\mathrm{v}$ is the valency of the interlayer cation, $T$ is the absolute temperature, $\varepsilon$ is the dielectric constant of the pore fluid, given by $\varepsilon=\varepsilon_{0} D$, in which $\varepsilon_{0}$ is the permittivity of the vacuum $\left(8.8542 \times 10^{-12} \mathrm{C}^{2} \mathrm{~J}^{-1} \mathrm{~m}^{-1}\right)$ and $D$ is the ratio of the electrostatic capacity of condenser plates separated by the given material to that of the same condenser with vacuum between the plates (Mitchell and Soga, 2005) 


$$
\begin{aligned}
-\left(\frac{d y}{d \xi}\right)_{x=0} & =\sqrt{(2 \cosh \mathrm{z}-2 \cosh \mathrm{u})} \\
& =\Gamma \sqrt{\left(\frac{1}{2 \varepsilon n k T}\right)} \quad \text { at } \quad x=0, y=z \\
& =\left(\frac{B}{S}\right) \sqrt{\left(\frac{1}{2 \varepsilon n k T}\right)}
\end{aligned}
$$

where $\Gamma$ is the surface charge density (base exchange capacity per specific surface), and $B$ is the base exchange capacity of the clay (meq/100 $\mathrm{g}$ solid).

$$
p=2 n k T(\cosh u-1)
$$

where $p$ is the osmotic pressure or swelling pressure (Pa). For any given pore-fluid medium, determination of the swelling pressure using Langmuir's equation (i.e., Equation (4-5)) requires the nondimensional midplane potential function, $u$.

Determination of $u$ is an indirect and time-consuming process. A relationship between $u$ and the nondimensional distance function, $K d$, must be established to determine $u$ for any given value of $K d$ and vice versa. Equations (4-2)-(4-5) are used for this purpose. Tripathy et al. (2004) illustrate the procedure of obtaining the $u$-Kd relation clearly, with the flow chart shown in Figure 4-1. For any given pressure, $u$ can be found from Equation (4-5). For known $B, S, n$ and $u$ values $(d y / d \xi)_{x=0}$ and then $\mathrm{z}$ can be calculated from Eq. (44). From Equation (4-2), for known $u$ and $z$ values, $K d$ can be found. After determining $u$ and $K d$ values for a series of pressures, an $u-K d$ relation can be established for one particular group of $B, S$ and $n$. For any void ratio, $e$, knowing $K$ from Equation (4-3) and $d$ from Equation (4-1), $K d$ can be found. Then the $u$ value for the corresponding $K d$ value can be determined from the established $u-K d$ relationship. The swelling pressure is therefore can be calculated from Equation (4-5). 


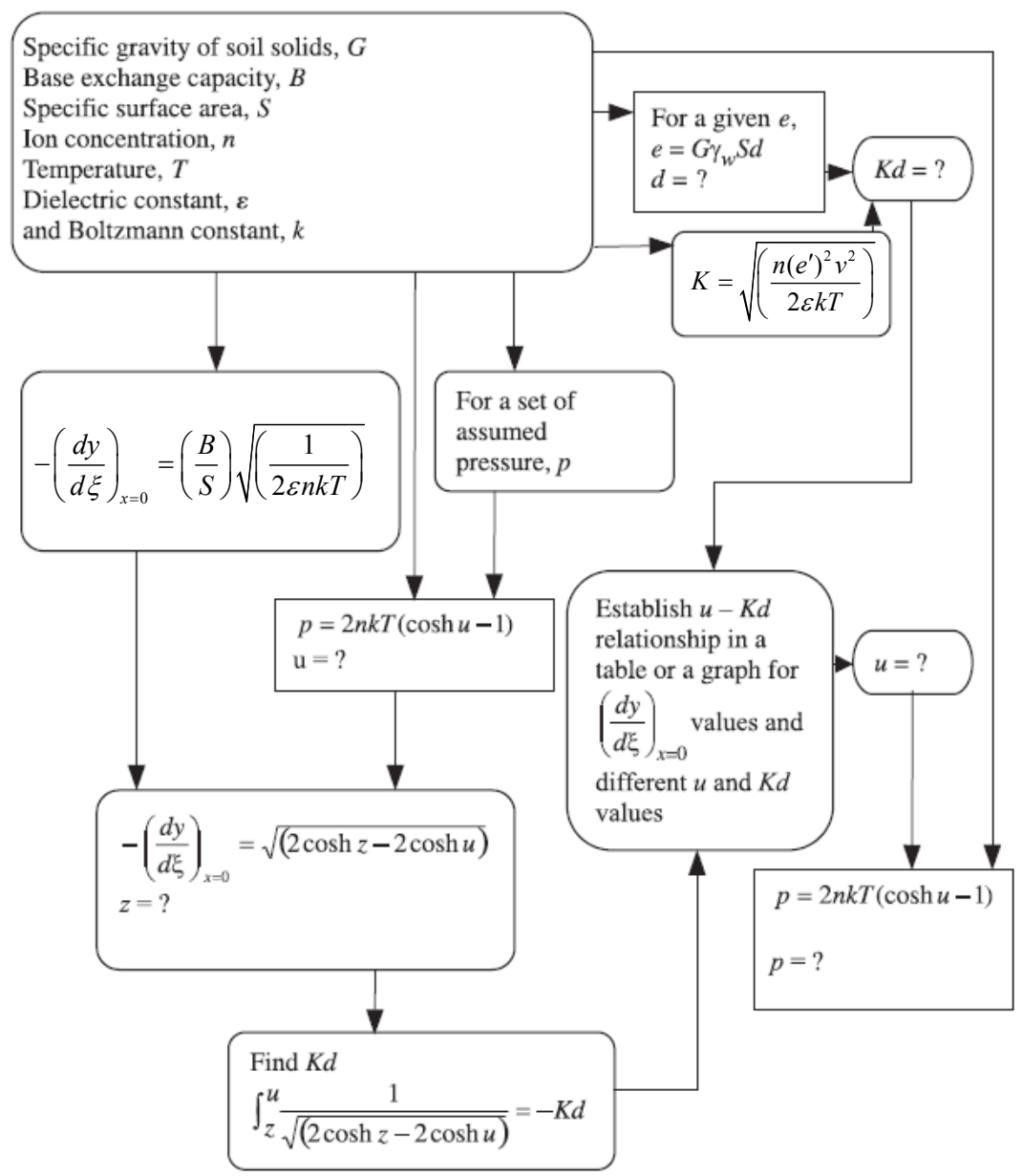

Figure 4-1. Flow chart showing the determination of swelling pressure for a given void ratio using the diffuse double layer theory

\subsubsection{Calculation examples for swelling pressure}

Subroutines for calculating swelling pressure based on DDL theory have been implemented in TOUGHREACT V2. In this section, we present two calculation examples: one is for the FEBEX bentonite (ENRESA, 2000), the other is for the lower Dogger opalinum shale in northern Switzerland (Madsen and Muller-vonmoss, 1985). We use the first example to show the importance of $u$-Kd relations and the second example to illustrate the necessary modification of Eq. (4-1) when applying DDL theory to natural clayey sediments.

While DDL theory has been applied extensively to assess the compressibility (or swelling) of initially saturated clays (Bolt, 1956; van Olphen, 1977; Sridharan and Jayadeva, 1982; Madsen and Muller-vonmoss, 1985; Mitchell and Soga, 2005), 
researchers have also applied the theory to calculate the swelling pressure of unsaturated compacted bentonite that is used in EBS (Komine and Ogata, 1996; Komine and Ogata, 2003; Tripathy et al., 2004; Schanz and Tripathy, 2009). Tripathy et al. (2004) and Schanz and Tripathy (2009) present an extensive review of the application of the DDL theory to compacted bentonite and discussed some of the limitations. Tripathy et al. (2004) applied the DDL theory to calculate the swelling pressure of FEBEX bentonite (ENRESA, 2000) and tested it against the measured swelling pressure. Here, we seek to reproduce the calculation made by Tripathy et al. (2004) and discuss the importance of $u$ $K d$ relation.

The key of performing such a calculation is to establish the relationship between $u$, the nondimensional midplane potential, and $K d$, the nondimensional distance function. Usually, the $u-K d$ relation is given in the following form:

$$
u=a+b \log 10(K d)
$$

where $a$ and $b$ are fitting constants.

As shown in Figure 4-1, in order to establish the $u-K d$ relation, one needs to calculate the $u$ from a series of hypothetical swelling pressures and then calculate $K d$ based on Equation (4-2). The $u$-Kd relation is affected by the specific surface area $(S)$, baseexchange capacity $(B)$, and ion concentration of bulk water $(n)$. In addition, the range of pressure also slightly affects the $u-K d$ relationship. Tripathy et al. (2004) present a $u$-Kd relation based on a pressure range from $0.05 \mathrm{MPa}$ to $50 \mathrm{MPa}$ and assuming $n=10^{-4}$ molal:

$$
u=3.07-3.664 \log 10(K d)
$$

Table 4-1 lists the relevant properties of FEBEX bentonite that Tripathy et al. (2004) used to calculate the swelling pressure. Using the same properties, our code yields a similar $u-K d$ relationship (see $a$ and $b$ value in Table 4-2). Schanz and Tripathy (2009) noted that the difference between the $u$-Kd relationship derived from the DDL theory and those back-calculated from the experimental data is the main reason for the difference between calculated and measured swelling pressure. Figure 4-2 shows the swelling pressure calculated based on the theoretical and experimental $u$ - $K d$ relationship. It shows that we must back-calculate the $u$ - $K d$ relationship in order to fit the measured data for compact bentonite. 
Table 4-1. Properties of FEBEX bentonite that Tripathy et al. (2004) used to calculate the swelling pressure.

\begin{tabular}{|l|l|l|l|l|}
\hline $\begin{array}{l}\text { Specific } \\
\text { gravity G }\end{array}$ & $\begin{array}{l}\text { Specific } \\
\text { surface area } \\
(\mathrm{m} 2 / \mathrm{g})\end{array}$ & $\begin{array}{l}\text { Base exchange } \\
\text { capacity } \\
(\mathrm{meq} / 100 \mathrm{~g})\end{array}$ & $\begin{array}{l}\text { Ion concentration of } \\
\text { bulk water (molality) }\end{array}$ & $\begin{array}{l}\text { Weight average } \\
\text { of valencies (v) }\end{array}$ \\
\hline 2.70 & 725 & 102 & $10^{-4}$ & $1.66-1.73$ \\
\hline
\end{tabular}

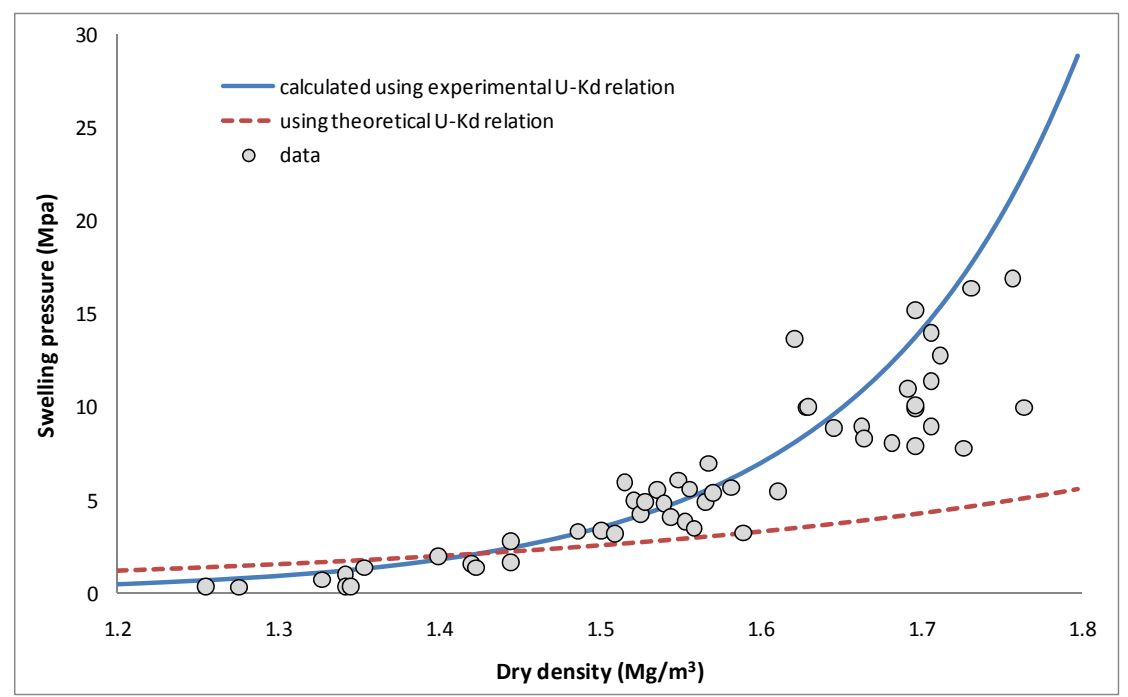

Figure 4-2. Comparison of calculated and measured swelling pressure as a function of dry density

The sensitivity of the $U-K d$ relation to specific surface area, base exchange capacity, and ion concentration of bulk water were further checked by varying these parameters. Table 4-2 lists parameter $a$ and $b$ in Equation (4-6) under different combinations of parameters. As the $U-k d$ relations changes, the calculated swelling pressures change correspondingly. Figure 4-3 shows the variation in the swelling pressure for those scenarios listed in Table 4-2. Note that when the ion concentration increases from $10^{-4}$ to $10^{-2}$, changes in swelling pressure are rather minimal, whereas a further increase in ion concentration to 0.1 lead to remarkable changes in swelling pressure. Figure 4-4 also shows that specific surface area and base exchange capacity have significant effects on swelling pressure. 
Table 4-2. Parameter A and B for U-Kd relation (Equation (4-2)) under different combinations of parameters

\begin{tabular}{|l|l|l|l|l|l|}
\hline $\begin{array}{l}\text { Run } \\
\text { number }\end{array}$ & $\begin{array}{l}\text { Specific } \\
\text { surface } \\
\text { area } \\
\left(\mathrm{m}^{2} / \mathrm{g}\right)\end{array}$ & $\begin{array}{l}\text { Base } \\
\text { exchange } \\
\text { capacity } \\
(\mathrm{meq} / 100 \\
\mathrm{g})\end{array}$ & $\begin{array}{l}\text { Ion } \\
\text { concentration } \\
\text { of bulk water } \\
\text { (molality) }\end{array}$ & $\mathrm{a}$ & $\mathrm{b}$ \\
\hline Base & 725 & 102 & $10^{-4}$ & 3.07 & -3.71 \\
\hline Run1 & 725 & 102 & $10^{-2}$ & 2.21 & -3.66 \\
\hline Run2 & 725 & 102 & $10^{-1}$ & 1.81 & -3.43 \\
\hline Run3 & 725 & 51 & $10^{-4}$ & 3.54 & -3.17 \\
\hline Run4 & 362.5 & 102 & $10^{-4}$ & 2.67 & -4.13 \\
\hline
\end{tabular}

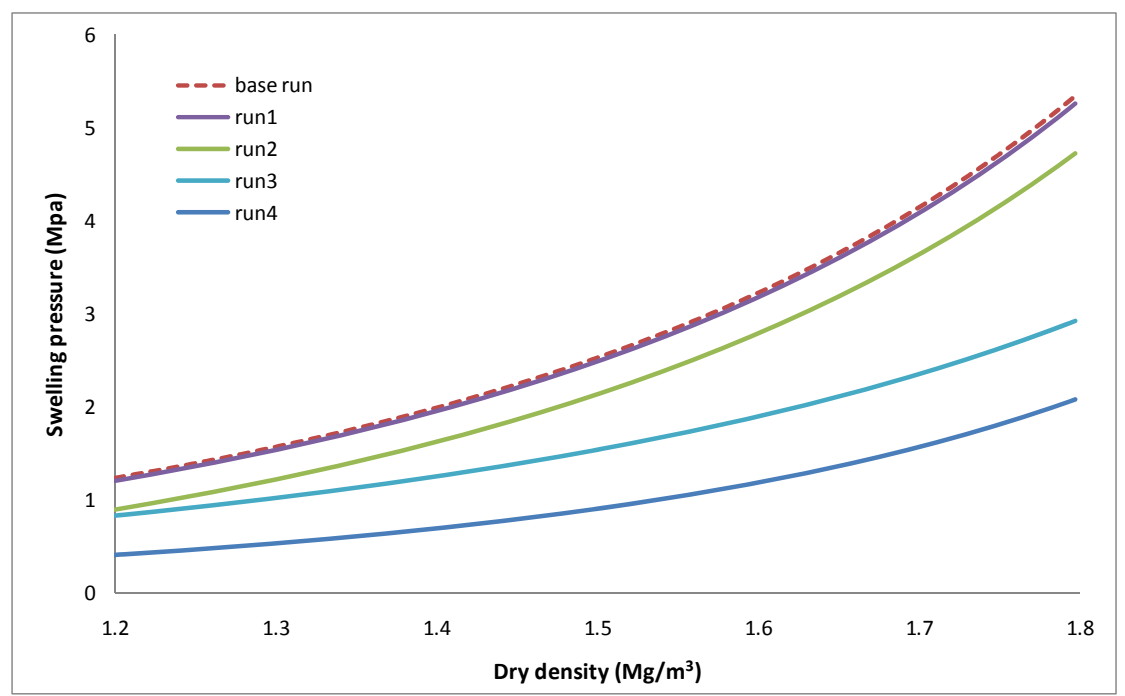

Figure 4-3. Calculated swelling pressure as a function of dry density for the different scenarios listed in Table 4-2.

Using the DDL theory to calculate the swelling pressure was originally established for pure clay. Natural clay formation, however, is never composed of one type of pure clay mineral. For example, the Opalinus Clay, a candidate for host rock formation for radioactive waste disposal in Europe (Thury, 2002), contains only about $10 \%$ illitesmectite mixture. For the clay formations that have a mixture of swelling and nonswelling minerals, Equation (4-1) is obviously questionable because the pore space includes not only the interlayer space where the swelling occurs, but also the pore spaces that are surrounded by nonswelling minerals. The derivation of Equation (4-1) is based on the assumption that the clay platelets are parallel, as shown in Figure 4-4. As we extend the idealized structure of pure swelling clay (Figure 4-4) to a mixture of swelling 
clay and nonswelling minerals (Figure 4-5), Equation (4-1) will be modified correspondingly.

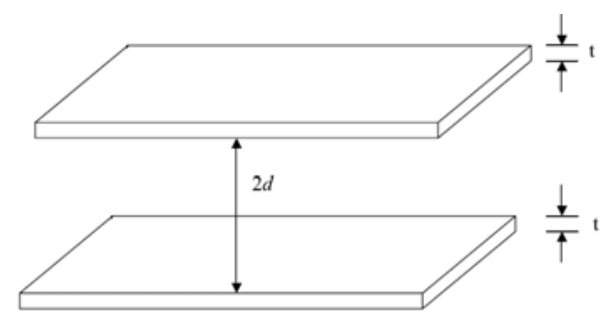

Figure 4-4. A representative unit layer separation for parallel clay platelets (Schanz and Tripathy, 2009), where $t$ is the thickness of the swelling clay platelets.

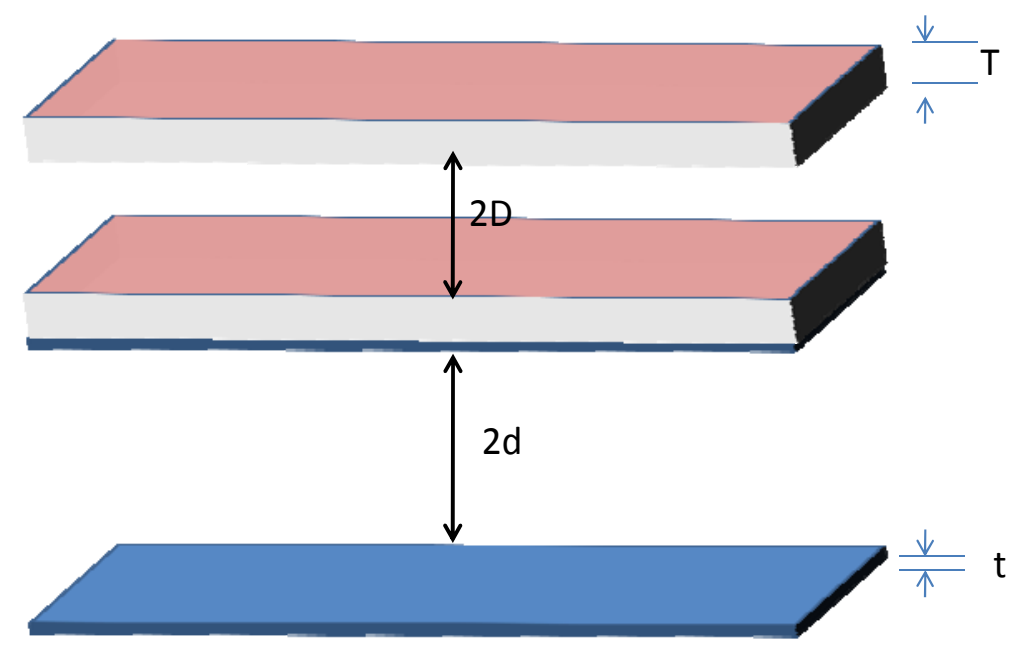

Figure 4-5. A representative unit layer structure for parallel swelling clay and

nonswelling mineral platelets, where $\mathrm{D}$ is the half width between two nonswelling mineral platelets and $\mathrm{T}$ is the thickness one nonswelling mineral platelet.

Assuming the platelet (both swelling and nonswelling minerals) has a plan area of A, the volume of the void is

$$
V_{v}=2 A(d+D)
$$

The volume of the solids is

$$
V_{s}=2 A(t+T)
$$

and void ratio is

$$
e=\frac{V_{v}}{V_{s}}=\frac{d+D}{t+T}
$$


Neglecting the contribution from the edges, the specific area (surface area per unit mass of swelling clay) of the swelling clay is given by

$$
S=\frac{2 A}{M_{t} f^{s}}
$$

where $M_{t}$ is the total mass of the solid and $f^{s}$ is the mass fraction of the swelling clay in the mixture. The specific gravity of the solid is given by:

$$
G=\frac{M_{t}}{V_{s} \gamma_{w}}
$$

The mass of the solid is

$$
M_{t}=G V_{s} \gamma_{w}=\frac{G \gamma_{w} 2 A(d+D)}{e}
$$

Substituting $M t$ in Equation (4-13) to Equation (4-11), we have:

$$
e=G \gamma_{w} S f^{s}(d+D)
$$

Taking $f^{d}=D / d$, then Equation $4-14$ can be rewritten as:

$$
e=G \gamma_{w} S f^{s} d\left(1+f^{d}\right)
$$

Typically a nonswelling clay mineral such kaolinite or illite has a the basal spacing $(\mathrm{d}(001))$ of around $10 \mathrm{~A}$, whereas a swelling clay (smectite) that suffers osmotic swelling has the $\mathrm{d}(001)$ value of 20 to $40 \mathrm{~A}$ (Onikata et al., 1999). $f^{d}$ therefore ranges from 0.25 to 0.5 . Note that in a broader sense, $f^{d}$ represents the ratio of pore space associated with nonswelling minerals to that associated with swelling minerals.

Madsen and Muller-Vonmos (1985) measured the swelling pressure of nineteen drill core samples of the lower Dogger opalinum shale in northern Switzerland. The samples contain around $50 \%$ clay-size materials, of which about $30 \%$ are swelling clays. The mass fraction of swelling clay, $f^{s}$, is therefore equal to 0.3 , assuming that swelling clays are smectite, which typically has a cation exchange capacity of $100 \mathrm{meq} / 100 \mathrm{~g}$ and a specific surface area of $800 \mathrm{~m}^{2} / \mathrm{g}$ (Sridharan and Jayadeva, 1982). Figure 6 shows the calculated result with two different $f^{d}: 0.25$ and 0.5 . It seems that the $f^{d}$ of 0.25 gives a better match with the measured data and is therefore used for the calculations in this report. 


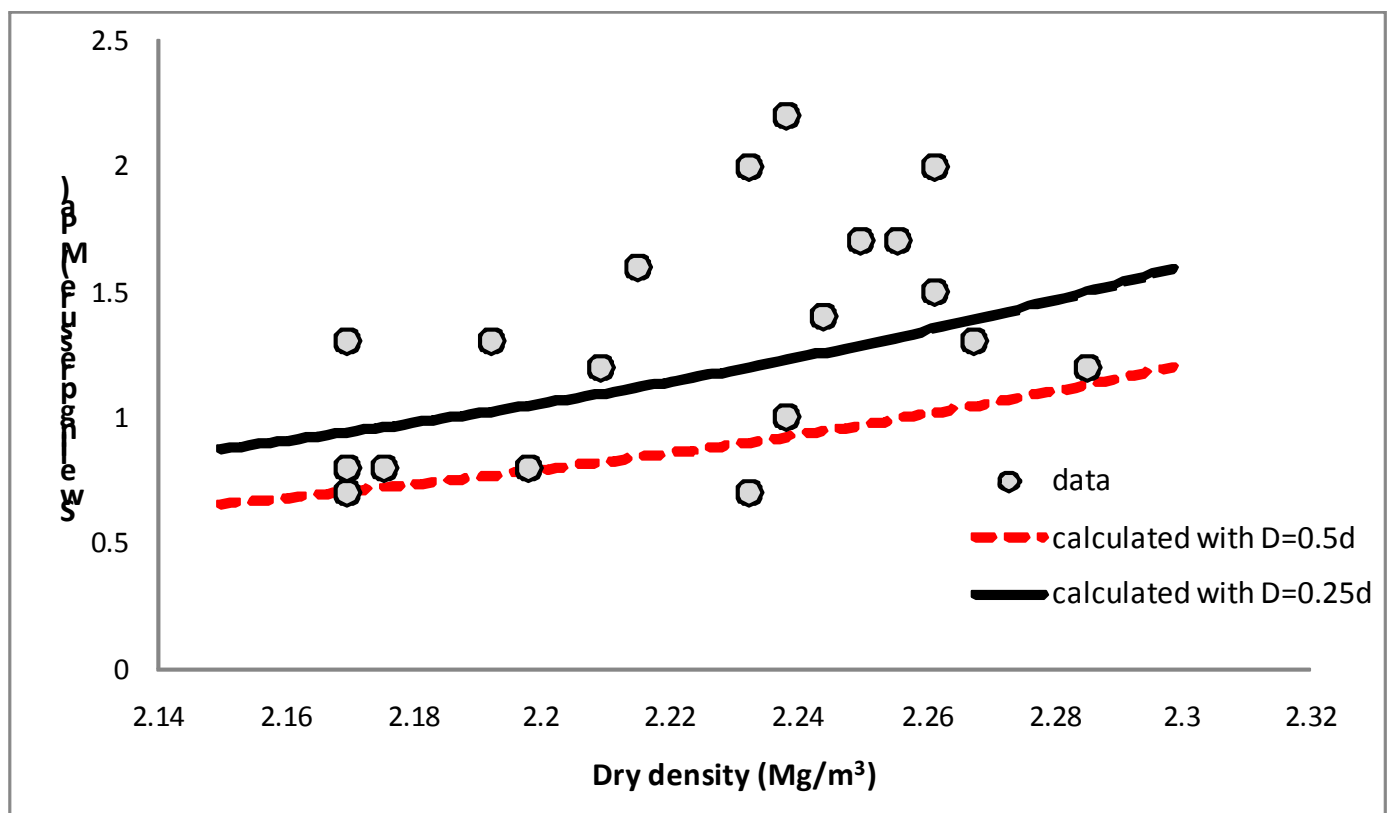

Figure 4-6. Comparison of calculated and measured swelling pressure lower Dogger opalinum shale in northern Switzerland (Sridharan and Jayadeva, 1982)

\subsection{Technical results}

\subsubsection{Model setup}

Both the 1-D and 2-D THC models are developed in the calculations presented here. The mesh for the 2-D model is shown in Figure 4-7. The mineralogical composition of bentonite (Table 4-3) is taken from the Kunigel-V1 bentonite (Ochs et al., 2004). The clay formation is assumed to be Opalinus Clay investigated in the Mont Terri underground rock laboratory in Switzerland (Thury, 2002) and the mineral composition is given in Table 4-4. 


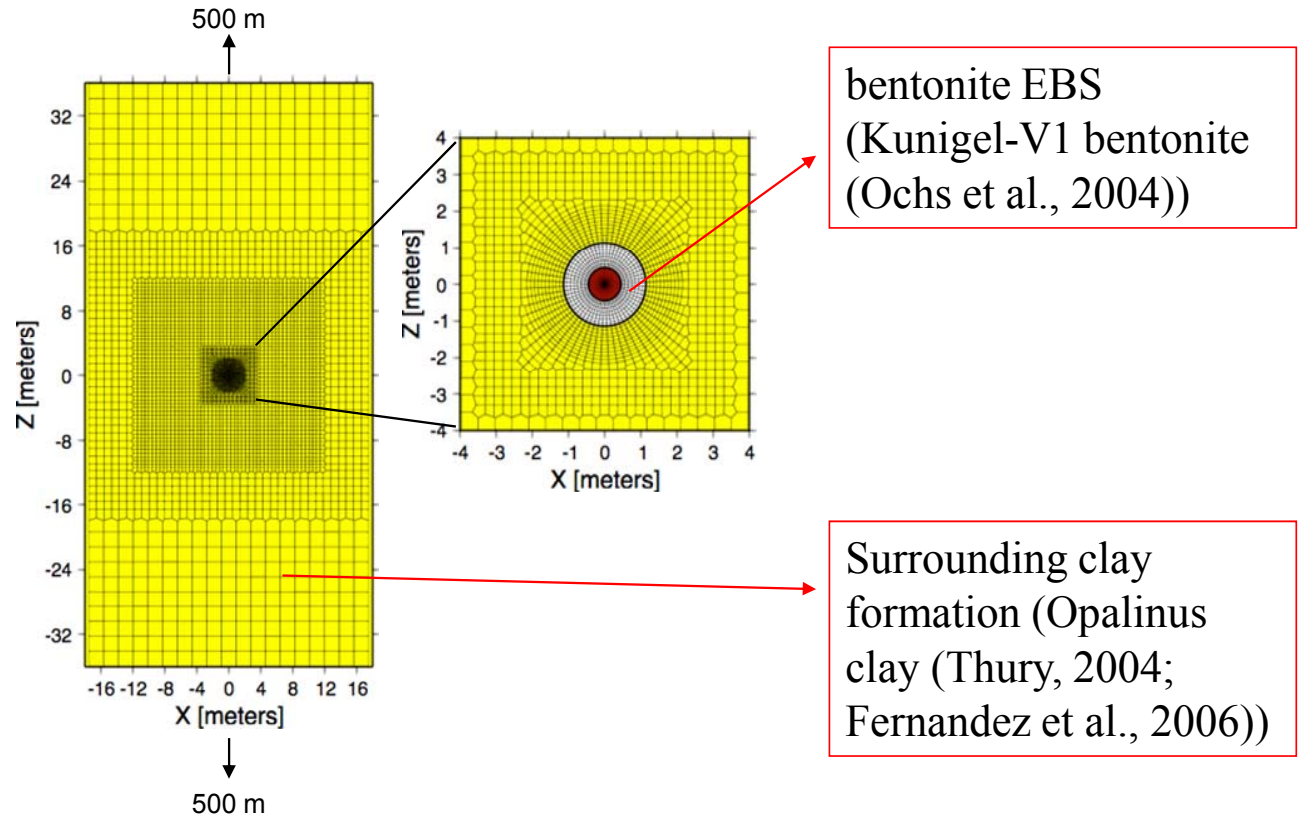

Figure 4-7. 2-D mesh used in the THC model

Table 4-3. Mineral composition of the bentonite used in the model (taken from the Kunigel-V1 bentonite (Ochs et al., 2004)).

\begin{tabular}{|c|c|}
\hline Mineral & Abundance (volume fraction) \\
\hline Smectite-na & 0.475 \\
\hline Quartz & 0.335 \\
\hline K-Feldspar & 0.041 \\
\hline Calcite & 0.0235 \\
\hline Dolomite & 0.029 \\
\hline Pyrite & 0.006 \\
\hline
\end{tabular}


Table 4-4. Mineral composition of the clay formation used in the model (taken from the Opalinus Clay (Thury, 2002).

\begin{tabular}{|c|c|}
\hline Mineral & Abundance (volume fraction) \\
\hline Calcite & 0.1 \\
\hline Illite & 0.223 \\
\hline Kaolinite & 0.174 \\
\hline Chlorite & 0.1445 \\
\hline Smectite-na & 0.1426 \\
\hline Quartz & 0.1845 \\
\hline Siderite & 0.01256 \\
\hline Ankerite & 0.00798 \\
\hline Pyrite & 0.01 \\
\hline
\end{tabular}

The pore-water composition of the bentonite (Ochs et al., 2004) and clay formation (Fernandez et al., 2007) are listed in Table 4-5.

Table 4-5. Lists the pore water composition of EBS bentonite and host clay rock.

\begin{tabular}{|c|c|c|}
\hline & $\begin{array}{c}\text { EBS Bentonite: Kunigel-V1 } \\
\text { (Ochs et al., 2004) }\end{array}$ & $\begin{array}{c}\text { Opalinus Clay } \\
\text { (Fernandez et al., 2007) }\end{array}$ \\
\hline $\mathrm{pH}$ & 8.40 & 7.60 \\
\hline $\mathrm{Eh}$ & -0.23 & -0.27 \\
\hline $\mathrm{Cl}$ & $1.50 \mathrm{E}-05$ & $3.32 \mathrm{E}-01$ \\
\hline $\mathrm{SO}_{4}^{-2}$ & $1.10 \mathrm{E}-04$ & $1.86 \mathrm{E}-02$ \\
\hline $\mathrm{HCO}_{3}^{-}$ & $3.50 \mathrm{E}-03$ & $5.20 \mathrm{E}-03$ \\
\hline $\mathrm{Ca}^{+2}$ & $1.10 \mathrm{E}-04$ & $2.26 \mathrm{E}-02$ \\
\hline $\mathrm{Mg}^{+2}$ & $5.50 \mathrm{E}-05$ & $2.09 \mathrm{E}-02$ \\
\hline $\mathrm{Na}^{+}$ & $3.60 \mathrm{E}-03$ & $2.76 \mathrm{E}-01$ \\
\hline $\mathrm{K}^{+}$ & $6.20 \mathrm{E}-05$ & $2.16 \mathrm{E}-03$ \\
\hline $\mathrm{Fe}^{+2}$ & $1.00 \mathrm{E}-10$ & $2.96 \mathrm{E}-07$ \\
\hline $\mathrm{SiO}_{2}(\mathrm{aq})$ & $3.40 \mathrm{E}-04$ & $1.16 \mathrm{E}-04$ \\
\hline $\mathrm{AlO}_{2}^{-}$ & $3.54 \mathrm{E}-08$ & $3.89 \mathrm{E}-06$ \\
\hline
\end{tabular}

In our current model, it is assumed that smectite is the only swelling mineral, with a specific surface area of $800 \mathrm{~m}^{2} / \mathrm{g}$ smectite (Sridharan and Jayadeva, 1982). The cation exchange capacity is taken from Thury (2002) which is $11.68 \mathrm{meq} / 100 \mathrm{~g}$ solid. The mass fraction of smectite $f^{s}$ is assumed to be equal to its volume fraction, as shown in Table 4 . 
Table 4-6 lists the thermal and hydrodynamic parameters used in the model. Those for bentonite are taken from Liu et al., (2010), while those for clay formation are mostly taken from Thury (2002).

Table 4-6. Thermal and hydrodynamic parameters.

\begin{tabular}{|l|l|l|}
\hline parameter & Clay formation & Bentonite \\
\hline Grain density $\left[\mathrm{kg} / \mathrm{m}^{3}\right]$ & 2700 & 2700 \\
\hline Porosity $\phi$ & 0.15 & 0.41 \\
\hline Saturated permeability $\left[\mathrm{m}^{2}\right]$ & $1.0 \times 10^{-20}$ & $2.0 \times 10^{-21}$ \\
\hline Relative permeability, $\mathrm{k}_{\mathrm{r} 1}$ & $m=0.6, \mathrm{~S}_{\mathrm{rl}}=0.01$ & $\mathrm{~K}_{\mathrm{rl}}=\mathrm{S}^{3}$ \\
\hline Van Genuchten $\alpha[1 / \mathrm{Pa}]$ & $6.8 \times 10^{-7}$ & $3.3 \times 10^{-8}$ \\
\hline Van Genuchten $m$ & 0.6 & 0.3 \\
\hline Compressibility, $\beta[1 / \mathrm{Pa}]$ & $3.2 \times 10^{-9}$ & $5.0 \times 10^{-8}$ \\
\hline $\begin{array}{l}\text { Thermal expansion coeff., } \\
{\left[1 /{ }^{\circ} \mathrm{C}\right]}\end{array}$ & 0.0 & $1.0 \times 10^{-4}$ \\
\hline Dry specific heat, $\left[\mathrm{J} / \mathrm{kg}{ }^{\circ} \mathrm{C}\right]$ & 800 & 8000 \\
\hline $\begin{array}{l}\text { Thermal conductivity }[\mathrm{W} / \mathrm{m} \\
\left.{ }^{\circ} \mathrm{C}\right] \text { dry } / \text { wet }\end{array}$ & $2.2 / 2.2$ & $0.5 / 1.3$ \\
\hline Tortuosity for vapor phase & $\phi^{1 / 3} S_{\mathrm{g}}{ }^{10 / 3}$ & $\phi^{1 / 3} S_{\mathrm{g}}^{10 / 3}$ \\
\hline
\end{tabular}

Mineral dissolution/precipitation are kinetically controlled, except that calcite is assumed to be in equilibrium. The kinetic law for mineral dissolution/precipitation is given in $\mathrm{Xu}$ et al. (2006b). The kinetic rate for the mineral considered in our model is given in Table 4-7. Note that the surface areas listed in Table 4-7 are calculated for tuff (Sonnenthal et al., 2005); their applicability to the clay formation being considered is questionable. Further refinement of the surface area calculation is needed for when the THC model is applied to a realistic scenario. 
Table 4-7. Kinetic properties for minerals considered in the model (Xu et al., 2006b)

\begin{tabular}{|c|c|c|c|c|c|c|c|c|c|}
\hline \multirow[t]{3}{*}{ Mineral } & \multirow{3}{*}{$\begin{array}{l}\text { A } \\
\left(\mathrm{cm}^{2} / \mathrm{g}\right)\end{array}$} & \multicolumn{8}{|c|}{ Parameters for Kinetic Rate Law } \\
\hline & & \multicolumn{2}{|c|}{ Neutral Mechanism } & \multicolumn{3}{|c|}{ Acid Mechanism } & \multicolumn{3}{|c|}{ Base Mechanism } \\
\hline & & $\begin{array}{l}\mathbf{k}_{25} \\
\left(\mathrm{~mol} / \mathrm{m}^{2} / \mathrm{s}\right)\end{array}$ & $\begin{array}{l}\mathrm{E}_{\mathrm{a}} \\
(\mathrm{KJ} \\
/ \mathrm{mol})\end{array}$ & $\mathbf{k}_{25}$ & $\mathbf{E}_{\mathbf{a}}$ & $\mathbf{n}\left(\mathbf{H}^{+}\right)$ & $\mathbf{k}_{25}$ & $\mathbf{E}_{\mathbf{a}}$ & $\mathbf{n}\left(\mathbf{H}^{+}\right)$ \\
\hline \multicolumn{10}{|l|}{ Primary: } \\
\hline Calcite & \multicolumn{9}{|c|}{ Assumed at equilibrium } \\
\hline Quartz & 9.8 & $1.023 \times 10^{-14}$ & 87.7 & & & & & & \\
\hline K-feldspar & 9.8 & $3.89 \times 10^{-13}$ & 38 & $8.71 \times 10^{-11}$ & 51.7 & 0.5 & $6.31 \times 10^{-12}$ & 94.1 & -0.823 \\
\hline Kaolinite & $1.95 \times 10^{5}$ & $6.91 \times 10^{-14}$ & 22.2 & $4.89 \times 10^{-12}$ & 65.9 & 0.777 & $8.91 \times 10^{-18}$ & 17.9 & -0.472 \\
\hline Illite & $6.68 \times 10^{5}$ & $1.66 \times 10^{-13}$ & 35 & $1.05 \times 10^{-11}$ & 23.6 & 0.34 & $3.02 \times 10^{-17}$ & 58.9 & -0.4 \\
\hline Chlorite & 9.8 & $3.02 \times 10^{-13}$ & 88 & $7.76 \times 10^{-12}$ & 88 & 0.5 & & & \\
\hline Dolomite & 12.9 & $2.52 \times 10^{-12}$ & 62.76 & $2.34 \times 10^{-7}$ & 43.54 & 1 & & & \\
\hline Ankerite & 9.8 & $1.26 \times 10^{-9}$ & 62.76 & $6.46 \times 10^{-4}$ & 36.1 & 0.5 & & & \\
\hline Smectite-Na & $5.64 \times 10^{5}$ & $1.66 \times 10^{-13}$ & 35 & $1.05 \times 10^{-11}$ & 23.6 & 0.34 & $3.02 \times 10^{-17}$ & 58.9 & -0.4 \\
\hline Na-montmorillonite & $5.64 \times 10^{5}$ & $1.66 \times 10^{-13}$ & 35 & $1.05 \times 10^{-11}$ & 23.6 & 0.34 & $3.02 \times 10^{-17}$ & 58.9 & -0.4 \\
\hline
\end{tabular}

\subsubsection{Base model results}

Although the current simulation domain includes both engineered barrier system (EBS) bentonite and natural system (NS) clay rock, we present the model results for host clay rock exclusively, in order to stay focused on the objective of this report-evaluating the geochemically induced changes in swelling properties for the host clay rock in the nearfield area. During the period of EBS hydration, chemical species are transported from host clay rock to EBS by advection and diffusion. Figure 4-8 shows the spatial distribution of chloride at different times. Chloride is barely affected by chemical reactions in our current model and therefore primarily undergoes advection and diffusion. As illustrated in Figure 4-8, a sharp decrease in chloride concentration occurs at the very beginning of hydration, in the area close to the EBS-NS interface. Such a decrease propagates further away from the EBS-NS interface as time increases and the concentration of chloride bounces back, because of the inflow of water from the surrounding far-field area. While affected by the chemical reaction such as dissolution of smectite and cation exchange, sodium (Figure 4-9) exhibits similar behavior to chloride. As the major ion in the pore water decreases, the ionic strength decreases as well (see Figure 4-10). Note that we use ionic strength to represent the ion concentration $n$ (e.g., Eq. (4-3)) in the swelling model. 


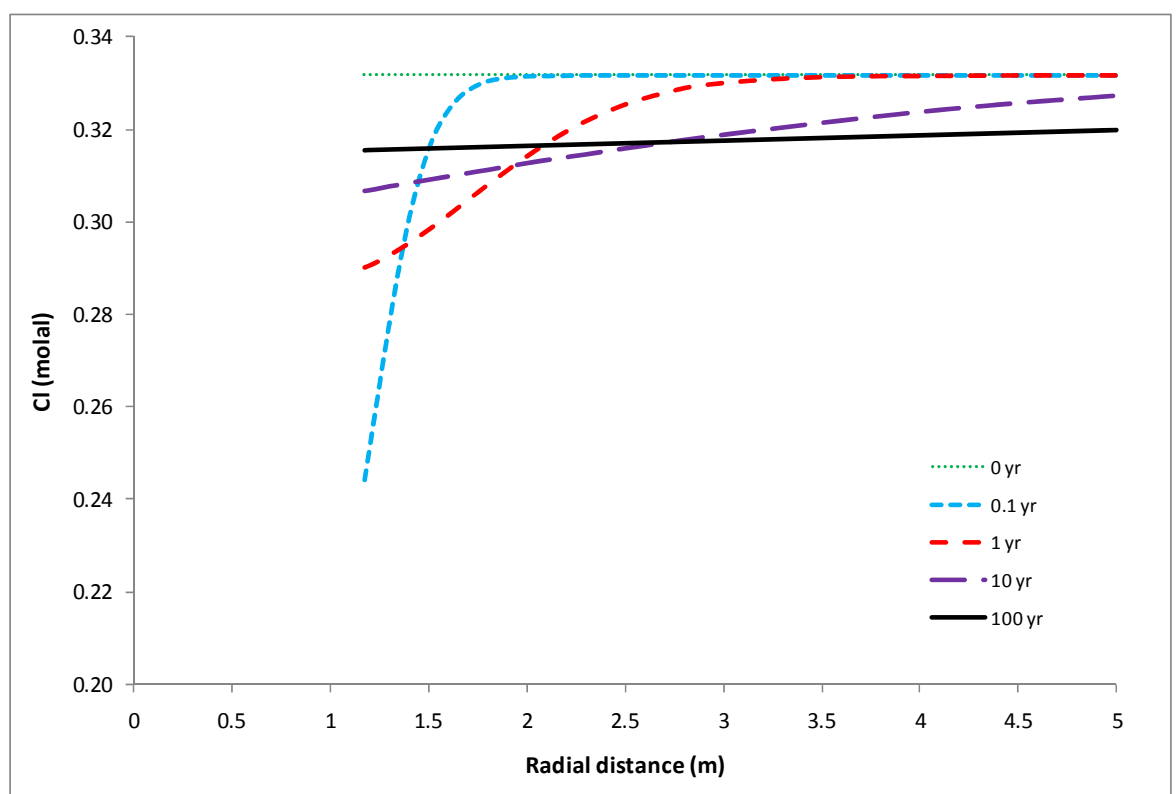

Figure 4-8. Spatial distribution of chloride at different times.

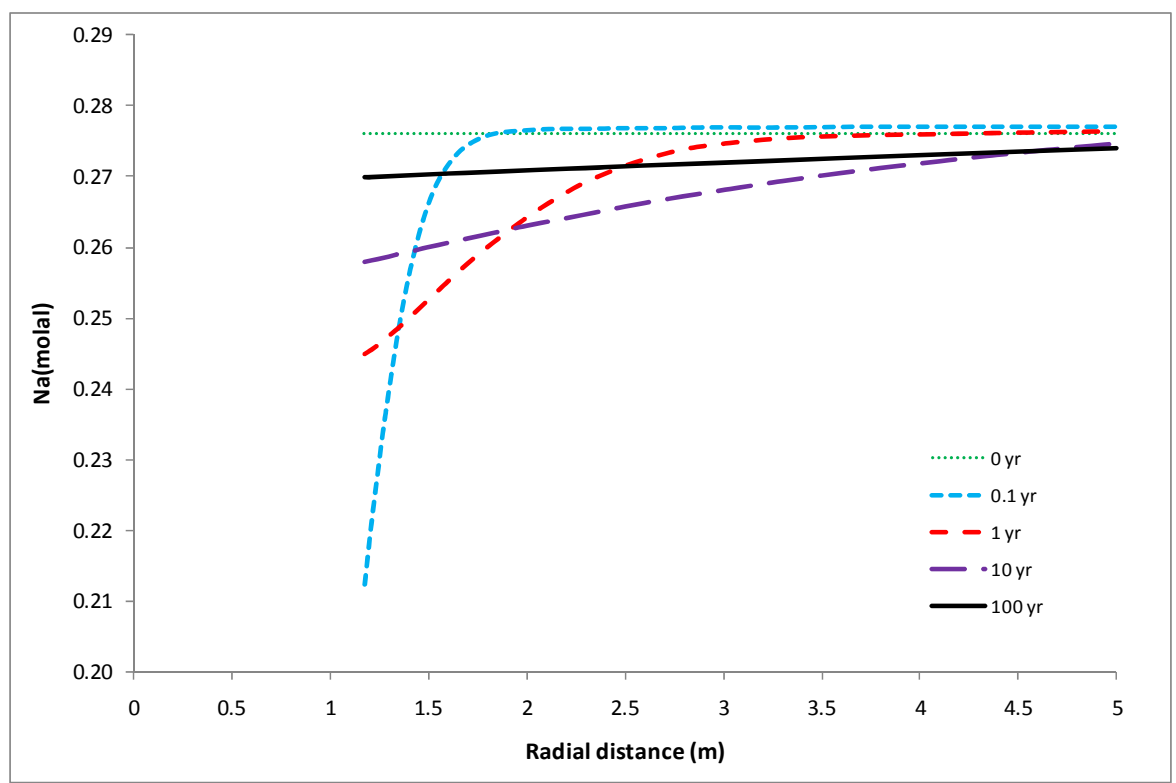

Figure 4-9. Spatial distribution of sodium at different times. 


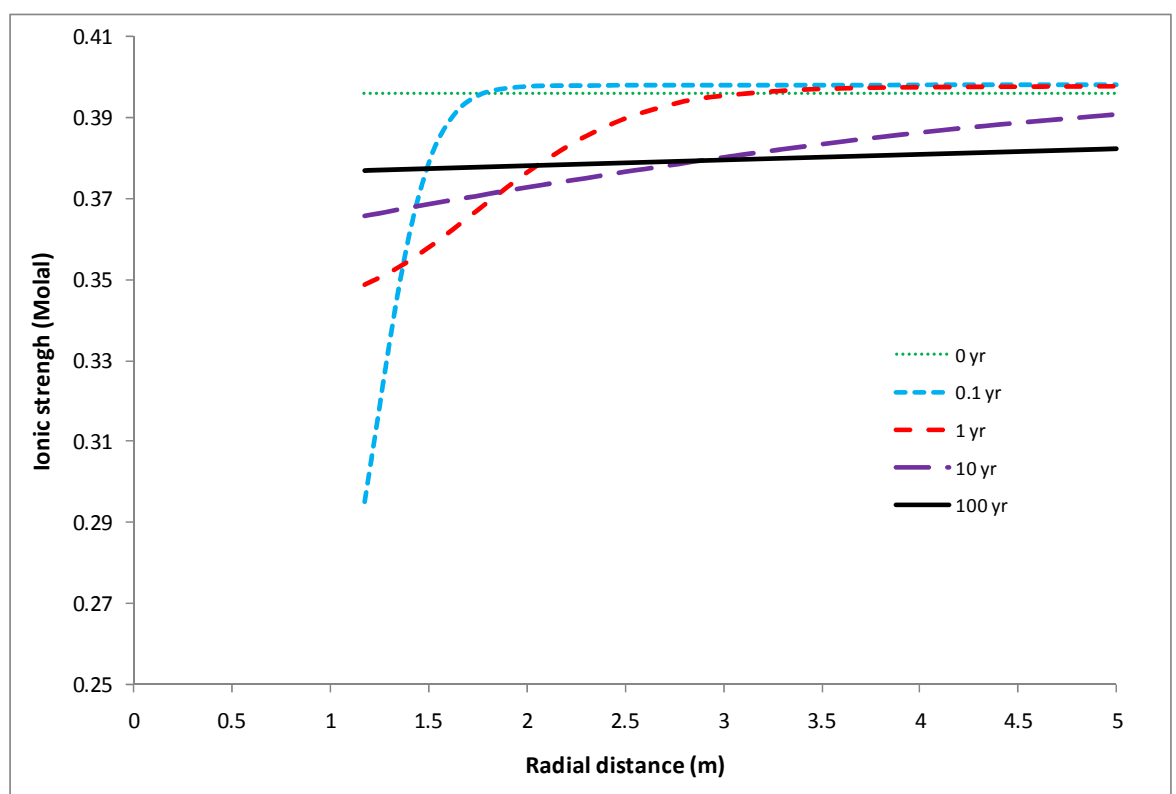

Figure 4-10. Spatial distribution of ionic strength at different times.

As mentioned above, illitization, the transformation from smectites to illite, is usually part of the diagenesis process of clay formation (Kamei et al., 2005; Cuadros, 2006). Our current model confirms such a transformation, as illustrated by Figures 4-11 and 4-12. As a result of smectite dissolution, chlorite precipitates as well (Figure 4-13), which leads to a decrease in the concentration of magnesium.

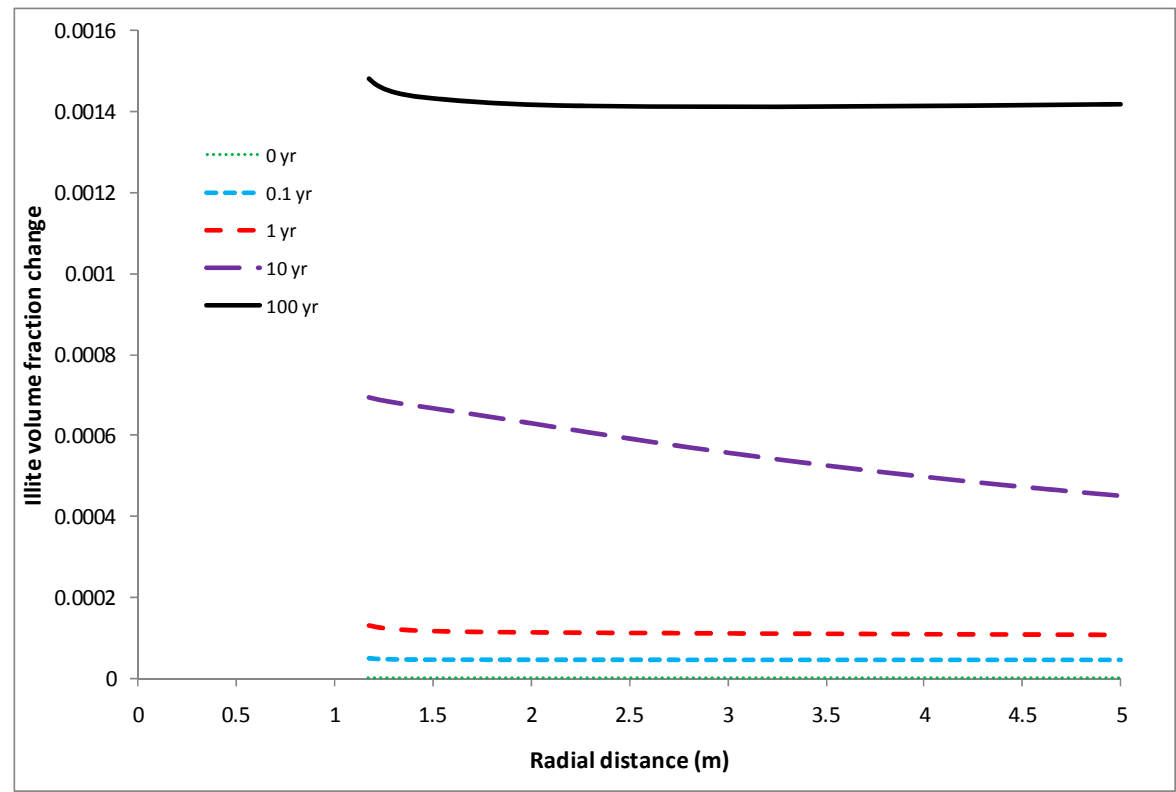

Figure 4-11. Spatial distribution of illite volume fraction change (dimensionless) at different times. 


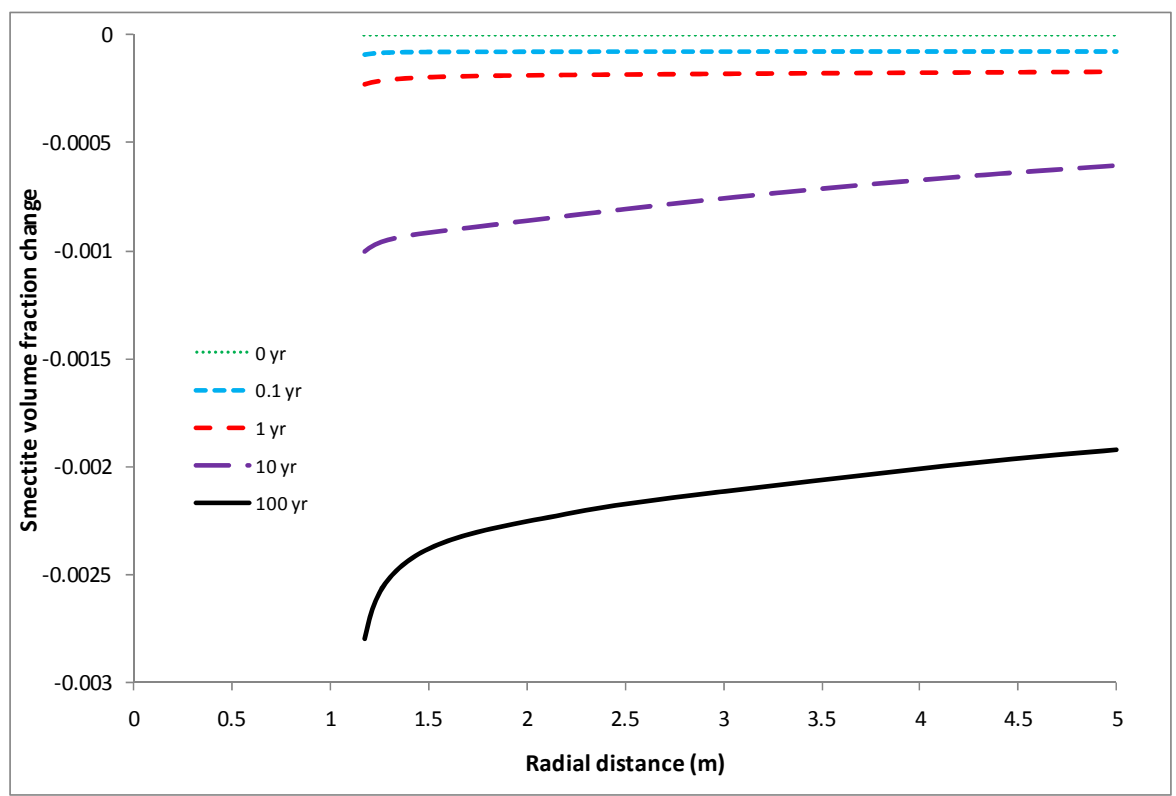

Figure 4-12. Spatial distribution of smectite volume fraction change (dimensionless) at different times.

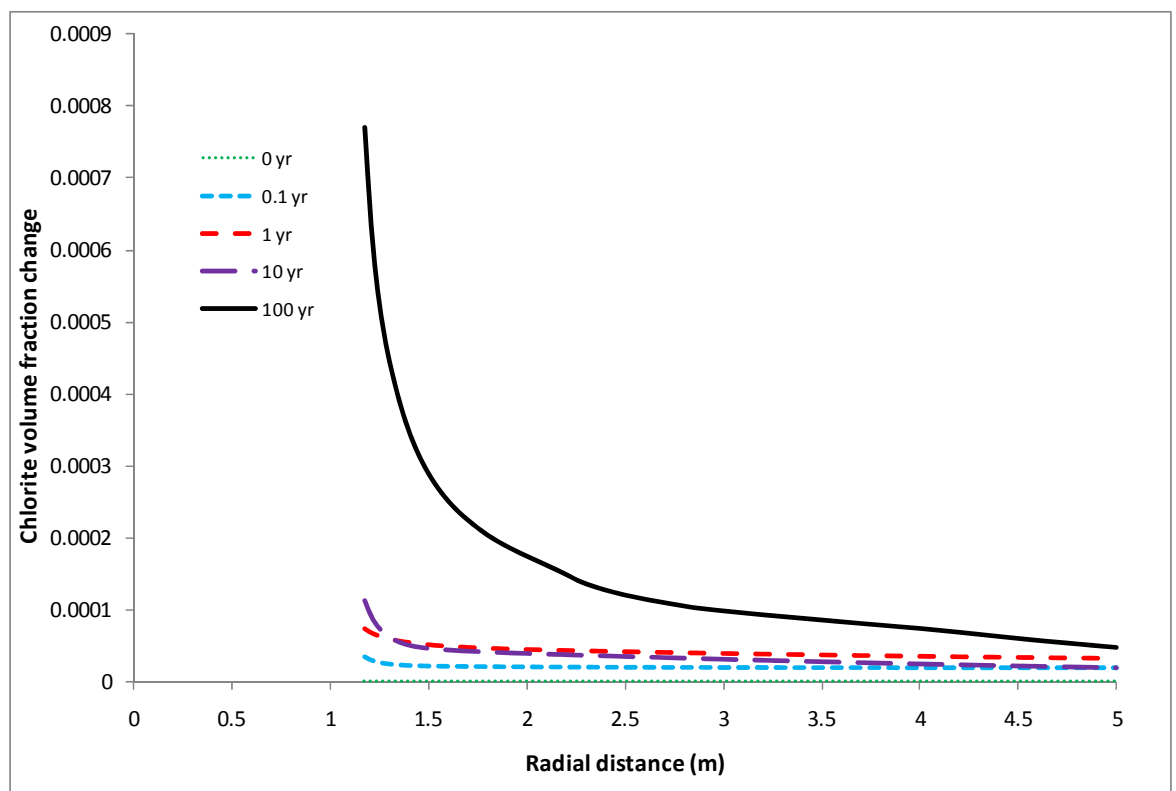

Figure 4-13. Spatial distribution of chlorite volume fraction change (dimensionless) at different times.

Mineral dissolution/precipitation affects the concentration of aqueous cations, which subsequently induce a change in the composition of exchangeable cations. The concentration of calcium increases because of the dissolution of calcite; the concentration of potassium decreases because of the precipitation of illite; the concentration of magnesium decreases because of the precipitation of chlorite. Figure 4-14 shows the concentration of exchangeable cations at the beginning and at 100 years. An increase in 
aqueous calcium drives the exchangeable calcium to an elevated level, whereas the decrease in aqueous potassium and magnesium leads to a significant drop in exchangeable potassium and magnesium (see Figure 4-15 for a clearer illustration when plotting Figure 4-14 in logarithmic scale). Exchangeable sodium also increases, due to the drop in exchangeable potassium and magnesium. In the formulations of DDL to calculate the swelling pressure, the composition of the exchangeable cations are not specifically included. Instead, the weight average of the valence of exchangeable cations (Tripathy et al., 2004) is used to account for the effect of change in exchangeable cations on the swelling pressure. The weighted average of the valence of exchangeable cations at different times is therefore plotted (see Figure 4-16), but only minimal changes are observed.

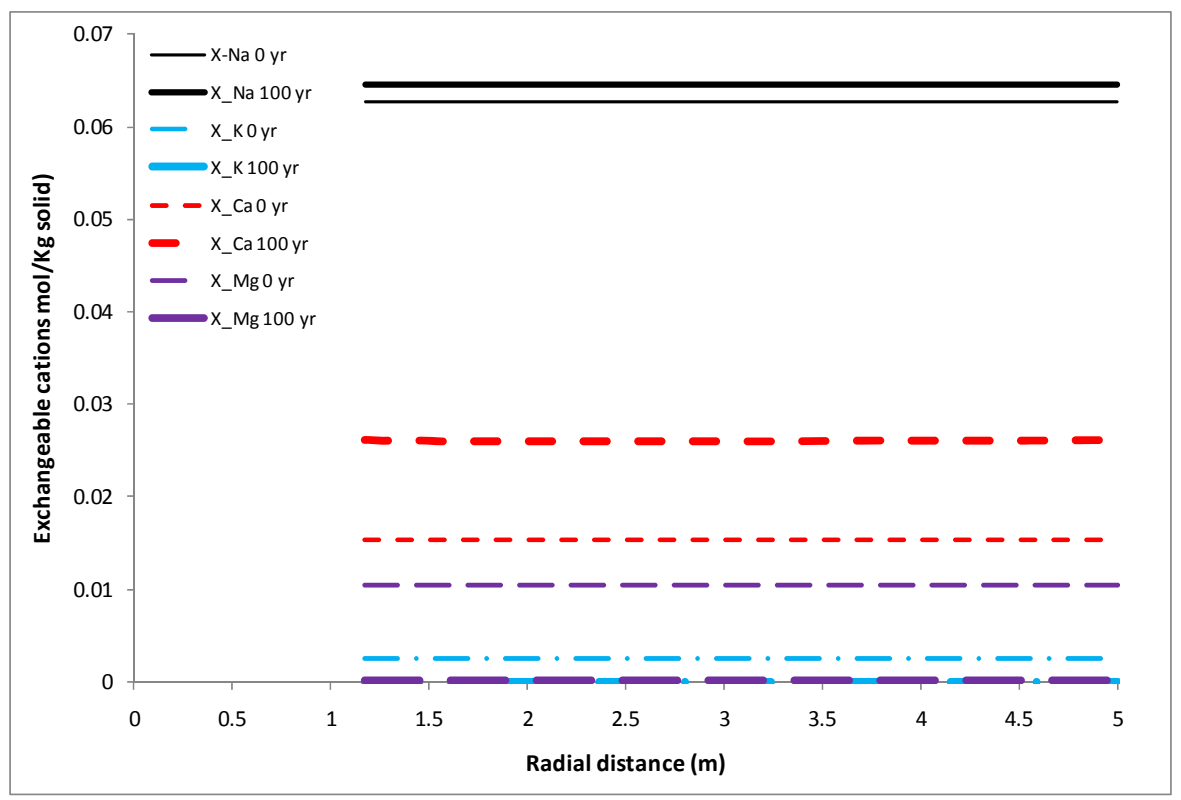

Figure 4-14. The concentration of exchangeable cations at the 0 and $100 \mathrm{yr}$ 


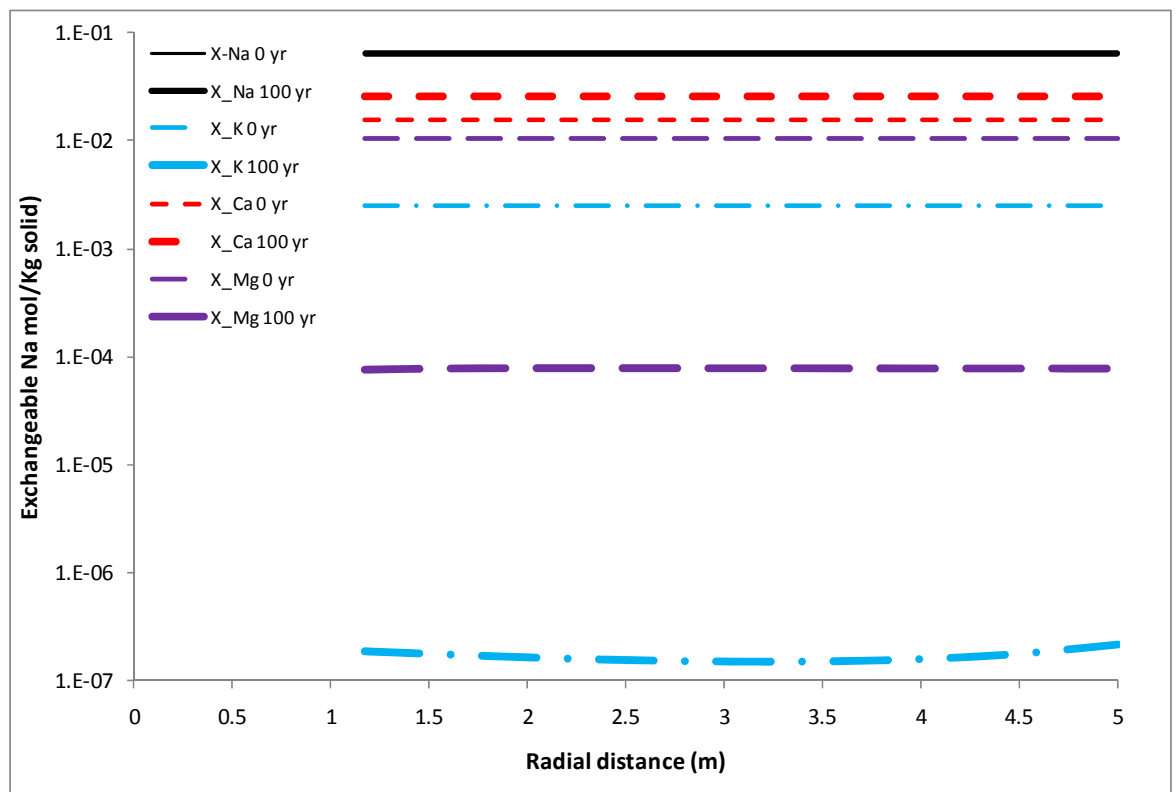

Figure 4-15. The concentration of exchangeable cations at the 0 and 100 year, with vertical axis in logarithmic scale.

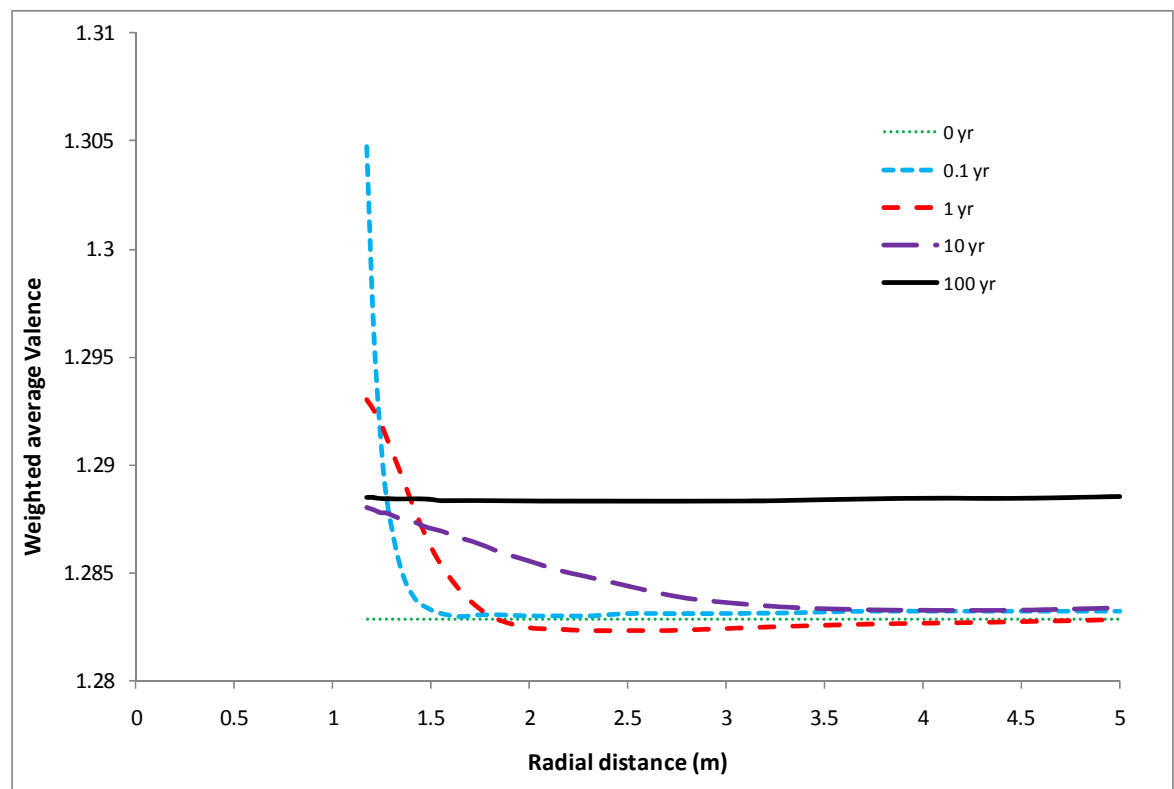

Figure 4-16. The weighted average valence of exchangeable cations at different times.

The geochemical evolution in the host clay rock-including the decrease in pore-water ionic strength, loss of the smectite due to illitization, and change in exchangeable cations - could lead to a change in the swelling pressure. Figure 4-17 shows the calculated swelling pressure at different times. The initial swelling pressure is around 7.5 bar, which is smaller than the measured swelling pressure (about 15 bar) of the lower Dogger Opalinum shale in northern Switzerland (Madsen and Muller-Vonmoss, 1985), because of the higher ion concentration of pore water for Opalinus Clay ( 0.4 molal in 
comparison with 0.01 molal for lower Dogger opalinum shale). The temporal and spatial change inswelling pressure follows the change in ionic strength, as shown in Figure 4-10. In the area close to the EBS-NS interface, the swelling pressure could rise to $9.5 \mathrm{bar}$. Figure 4-18 gives the relative change in swelling pressure, defined as:

$$
\left(P_{s}^{t}-P_{s}^{0}\right) / P_{s}^{0} \times 100
$$

where $P_{s}^{0}$ and $P_{s}^{t}$ are swelling pressure initially and at given time $t$. After 100 years, the swelling pressure increase about $5 \%$.

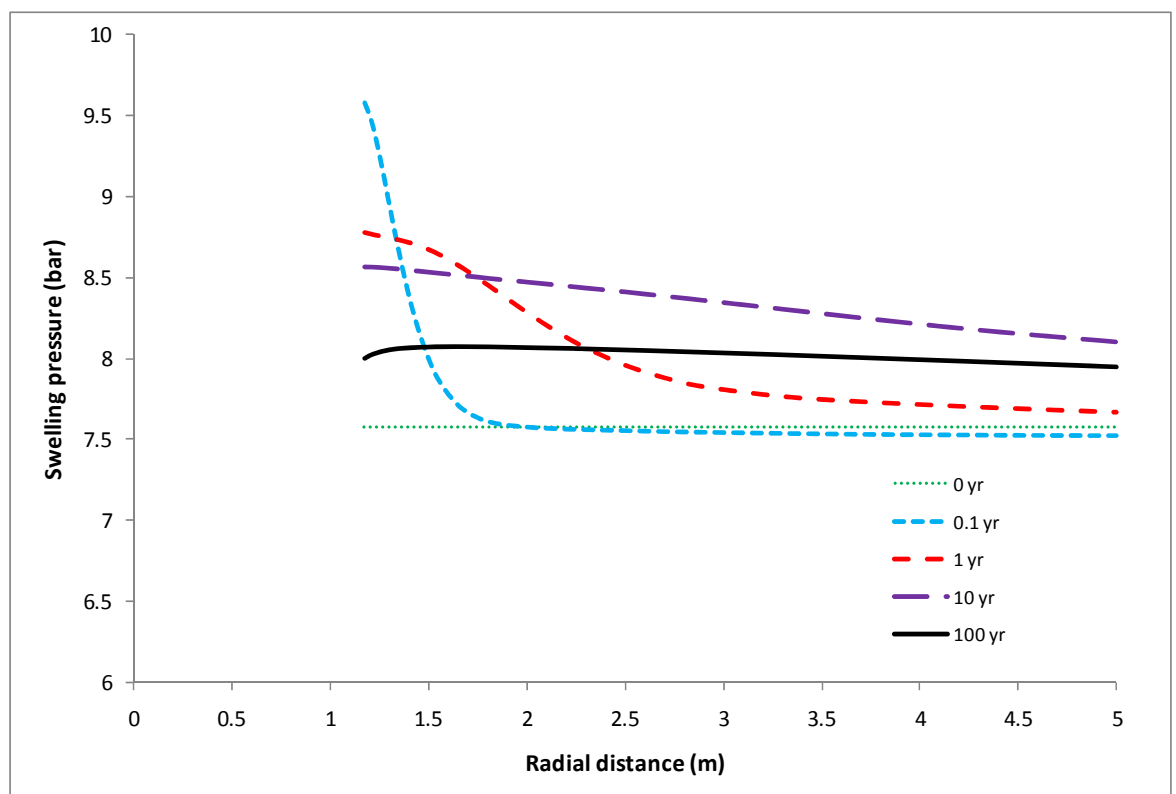

Figure 4-17. Spatial distribution of swelling pressure at different times. 


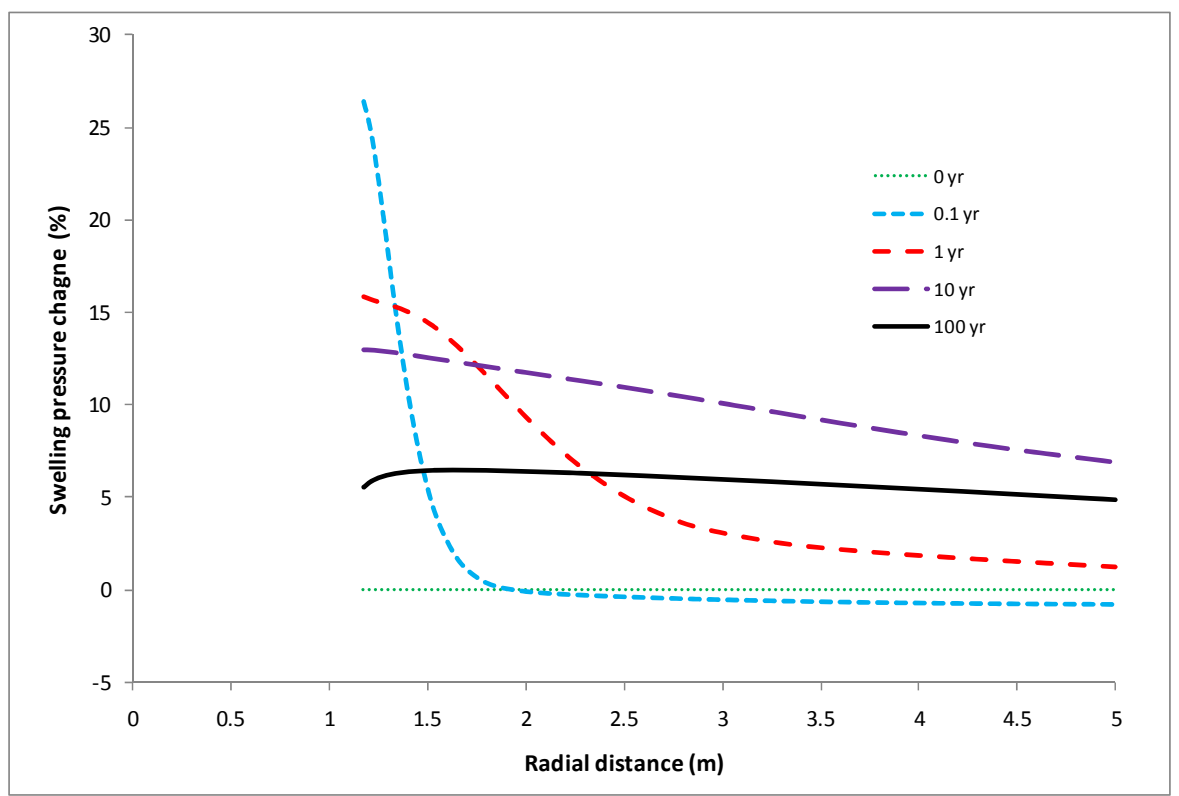

Figure 4-18. The percentage of swelling pressure change comparing with initial swelling pressure at different times.

The change in swelling pressure induces the change of porosity. Liu et al. (2010) proposed the following porosity-stress relation:

$$
\begin{gathered}
\phi=\phi_{e}\left(1-C_{e} \sigma\right)+\gamma_{t} \exp \left(\frac{\sigma}{K_{t}}\right) \\
\phi_{e}=\phi_{0}-\gamma_{t} \\
\gamma_{t}=\frac{V_{0, t}}{V_{0}}
\end{gathered}
$$

where $C_{e}$ is the compressibility for the hard fraction of pore volume, $\phi_{0}$ is the porosity under the unstressed state, $V_{0}$ is the total volume under unstressed state and $V_{0, t}$ is the volume of soft fraction, $K_{t}$ is the bulk moduli for the soft parts and $\sigma$ is the stress. Neglecting the soft part and assuming that stress is equal to the swelling pressure, Equation (4-4) can be simplified as:

$$
\phi=\phi_{0}\left(1-C_{e} P_{s}\right)
$$

where $P_{S}$ is swelling pressure $(\mathrm{Pa})$. Writing Equation (4-20) in incremental form, we have:

$$
\Delta \phi=-\phi_{0} C_{e} \Delta P_{s}
$$


Based on Equation (4-21), the relative porosity change due to swelling is calculated similarly to the relative swelling pressure change, Equation (4-16), and the results are shown in Figure 4-19. After 100 years, the porosity decreases insignificantly due to swelling, only about $0.01 \%$. On the other hand, porosity is also changed by mineral dissolution/precipitation (see Figure $4-20$ ); there is a $0.14 \%$ porosity increase resulting from geochemical processes, which overshadows the porosity change due to swelling.

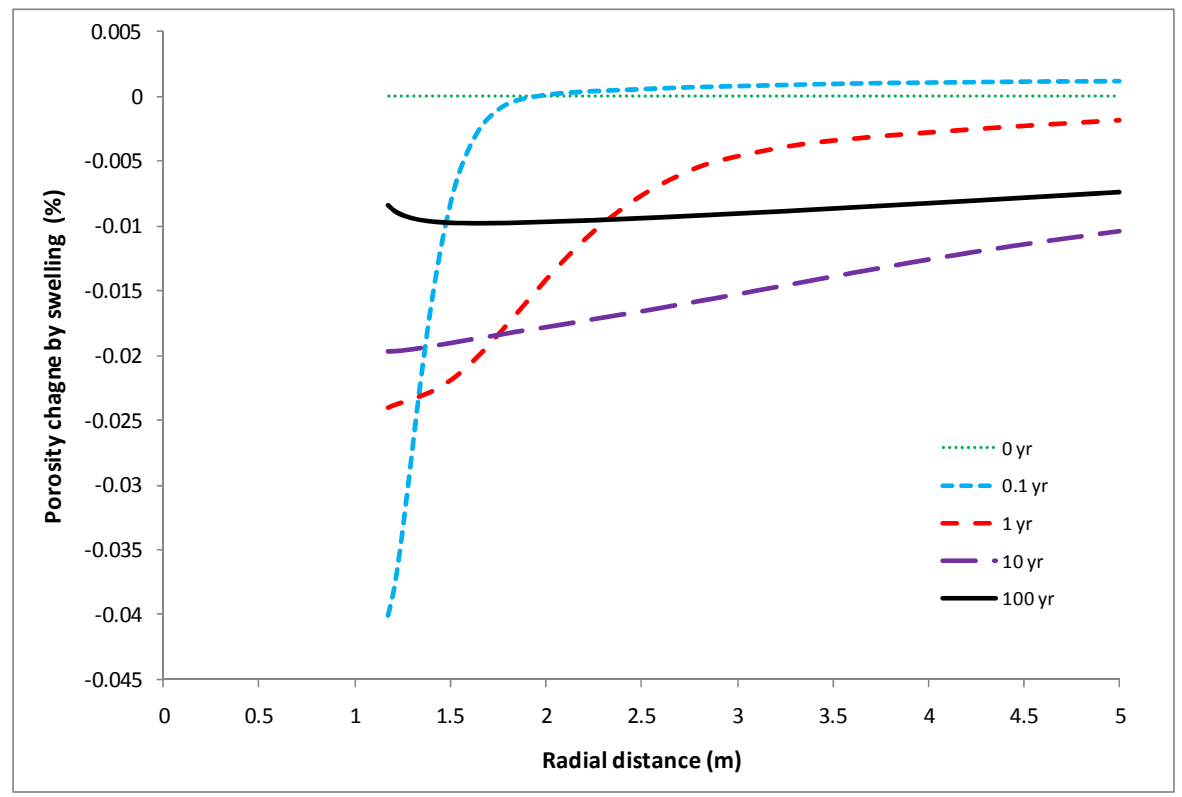

Figure 4-19. The change in porosity due to swelling at different times.

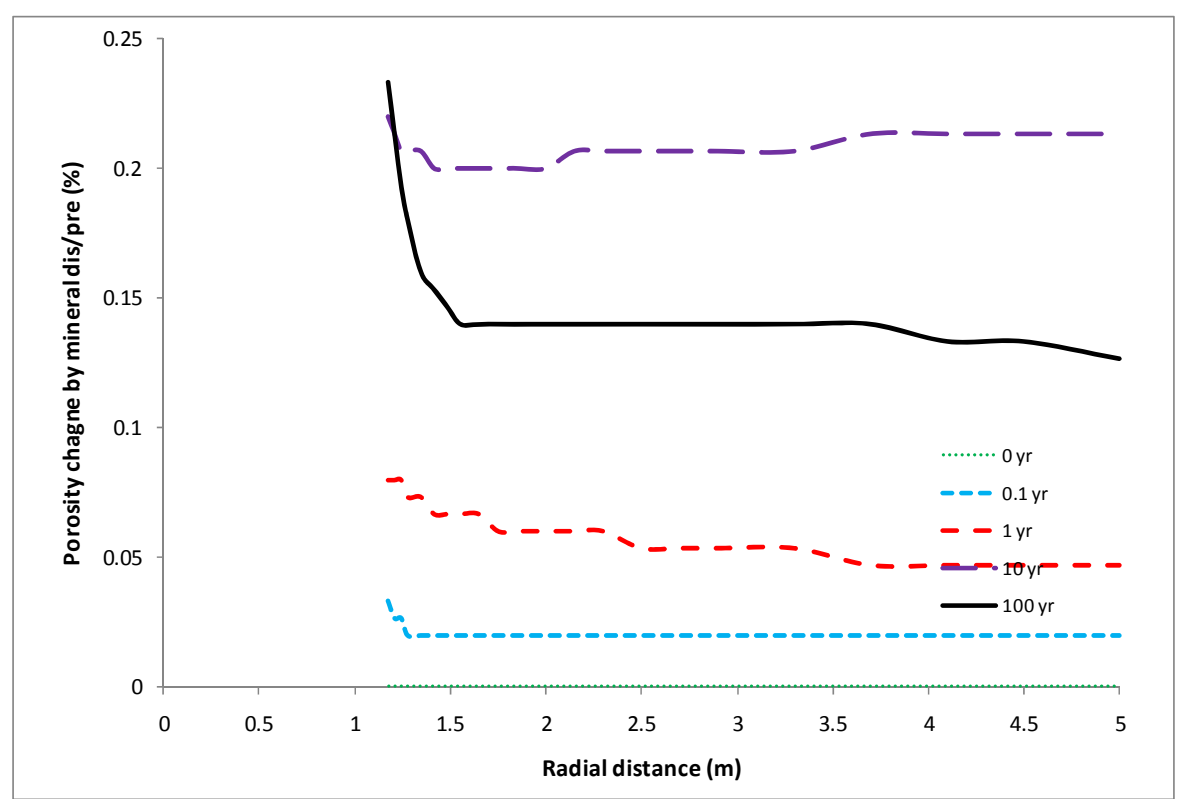

Figure 4-20. The change in porosity due to mineral precipitation/dissolution at different times. 
Just as the 1-D model allows us to analyze the geochemically induced swelling-pressure changes at rather low computational cost, the 2-D model helps us to evaluate the spatial change in swelling pressure. Figure 4-21 and 4-22 shows the spatial distribution of ionic strength at 1 year and 100 years, while Figures 4-23 and 4-24 show the spatial distribution of swelling pressure at 1 and 100 years. The 2D model gives similar results to the 1D model. Model results from the 2D model show that the significant change in swelling properties occurs within about $2-3 \mathrm{~m}$ from the EBS-NS interface into the host rock.

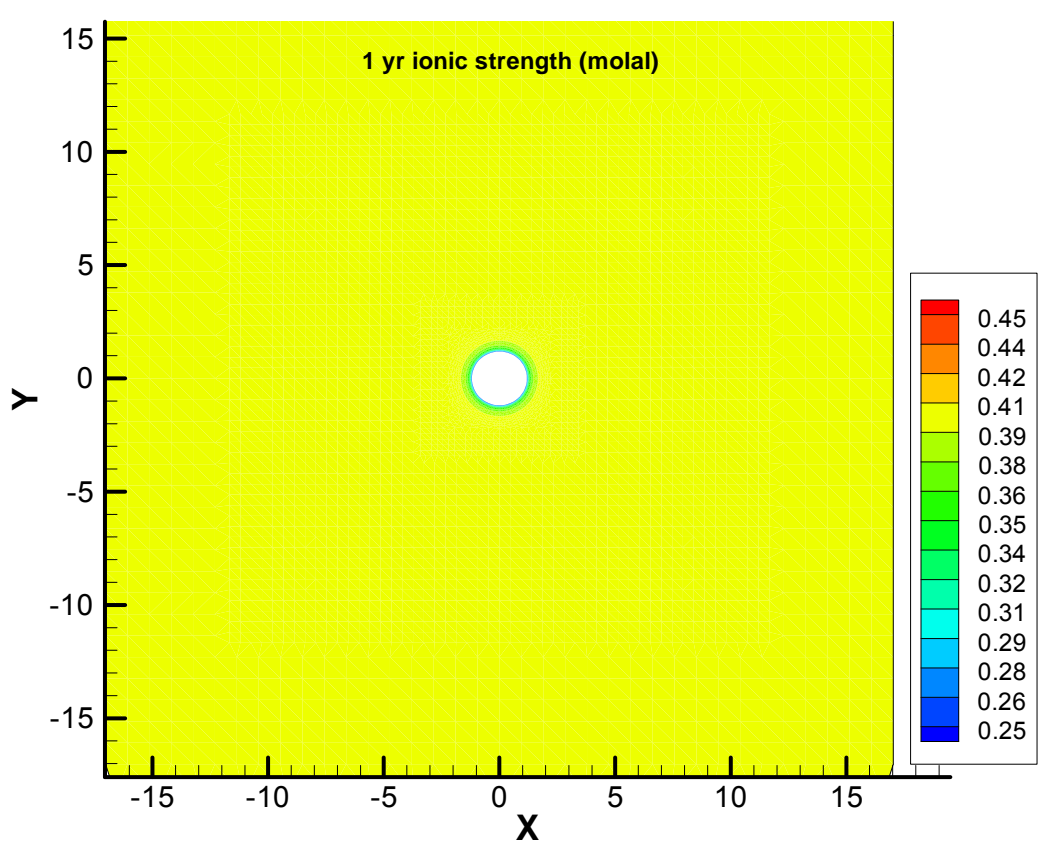

Figure 4-21. Spatial distribution of ionic strength at 1 year. 


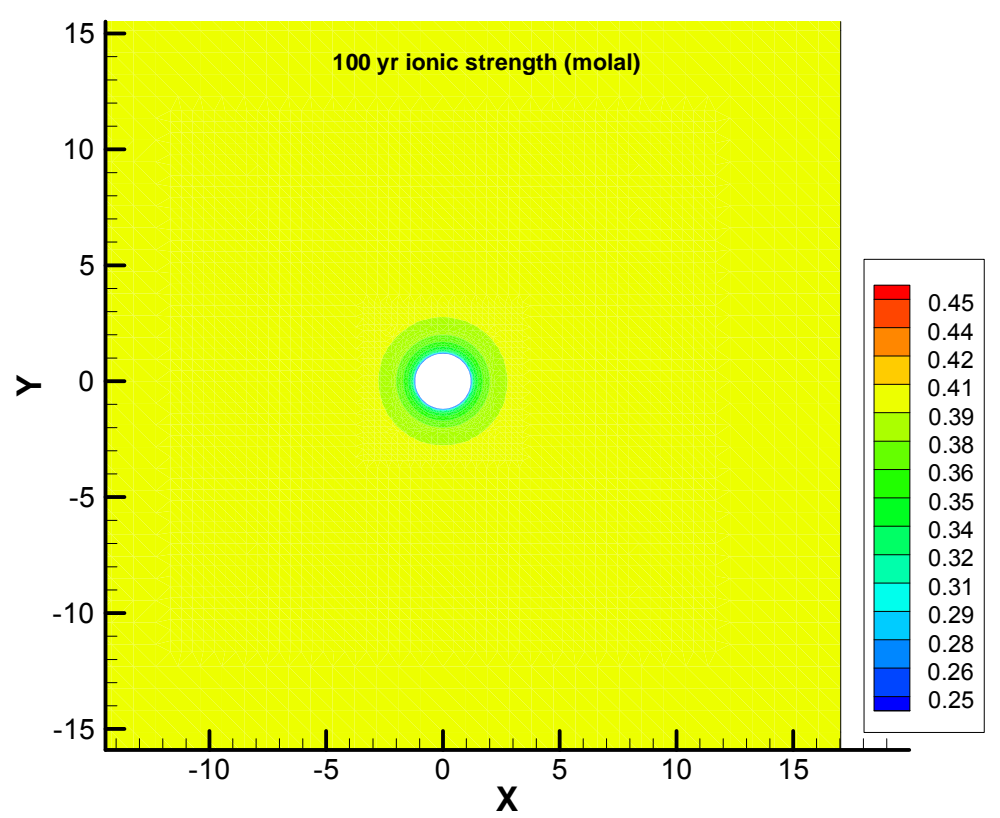

Figure 4-22. Spatial distribution of ionic strength at 100 years.

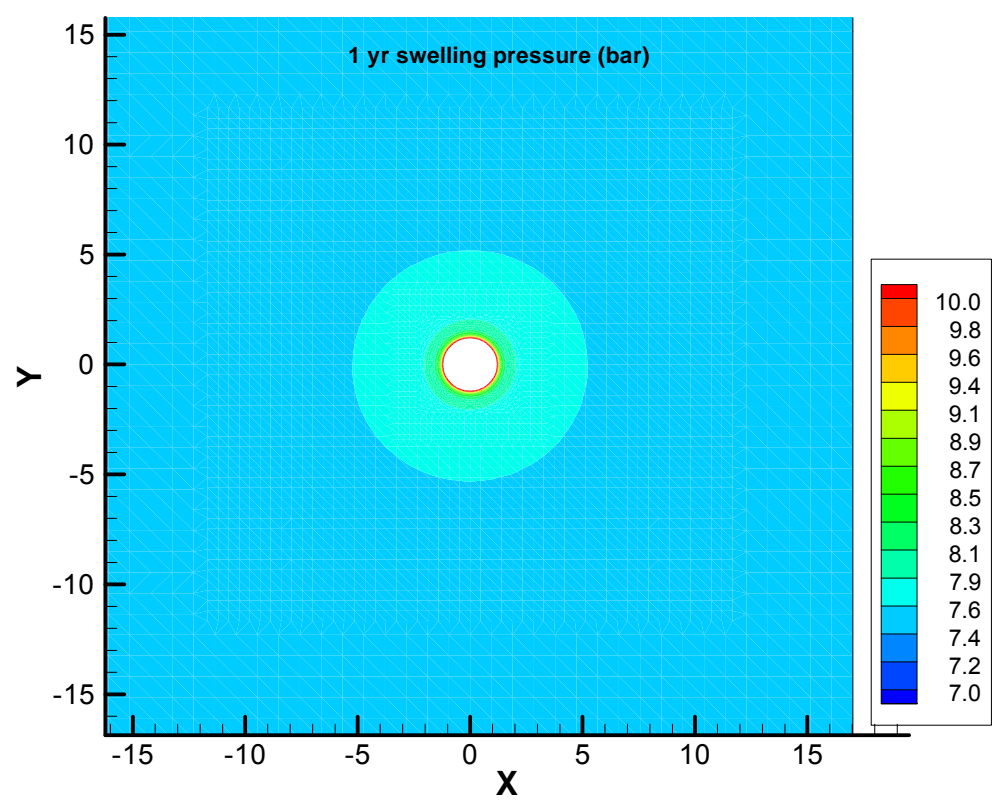

Figure 4-23. Spatial distribution of swelling pressure at 1 year. 


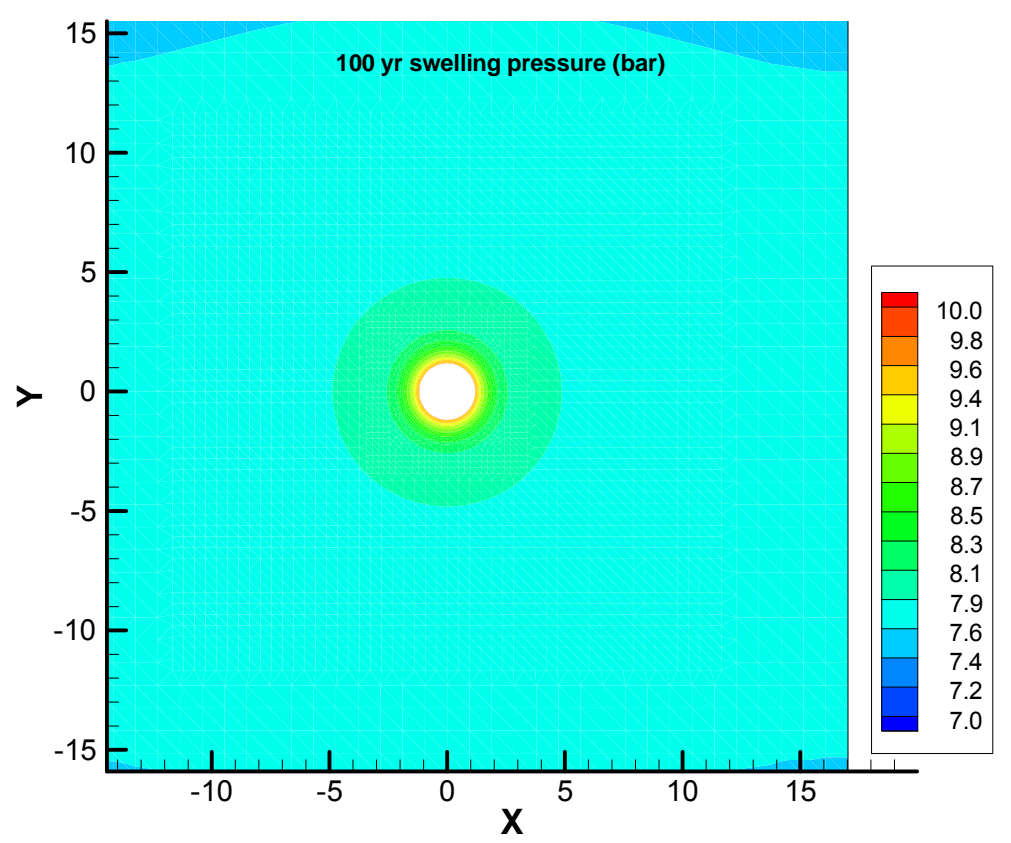

Figure 4-24. Spatial distribution of swelling pressure at 100 years.

\subsubsection{Sensitivity analysis}

\section{The key geochemical factors for the swelling pressure change}

Three types of geochemical change might affect the swelling pressure of clay rock: the ionic strength (ion concentration of pore water), the volume fraction of the smectite, and the exchangeable cations. Exchangeable cations affect the swelling pressure by changing the weighted average valence of interlayer cations. In the base model, as shown in Figure 4-16, the change in weighted average valence is rather minimal and therefore unlikely to affect the swelling pressure. The decrease in ionic strength (Figure 4-10) tends to increase the swelling pressure, whereas the decrease in the volume fraction of smectite (Figure 412) tends to lower the swelling pressure, although the overall effect is that eventually the swelling pressure increases. In order to evaluate how significantly the decrease in the volume fraction of smectite contributes to the final swelling pressure change, we conducted a sensitivity run in which the effect of the decrease in the volume fraction of smectite is not considered (Figure 4-25). As expected, the swelling pressure increases about $4 \%$ more in the sensitivity run than in the base model, indicating that more significant swelling could be calculated if the loss of smectite due to illitization is not considered. 


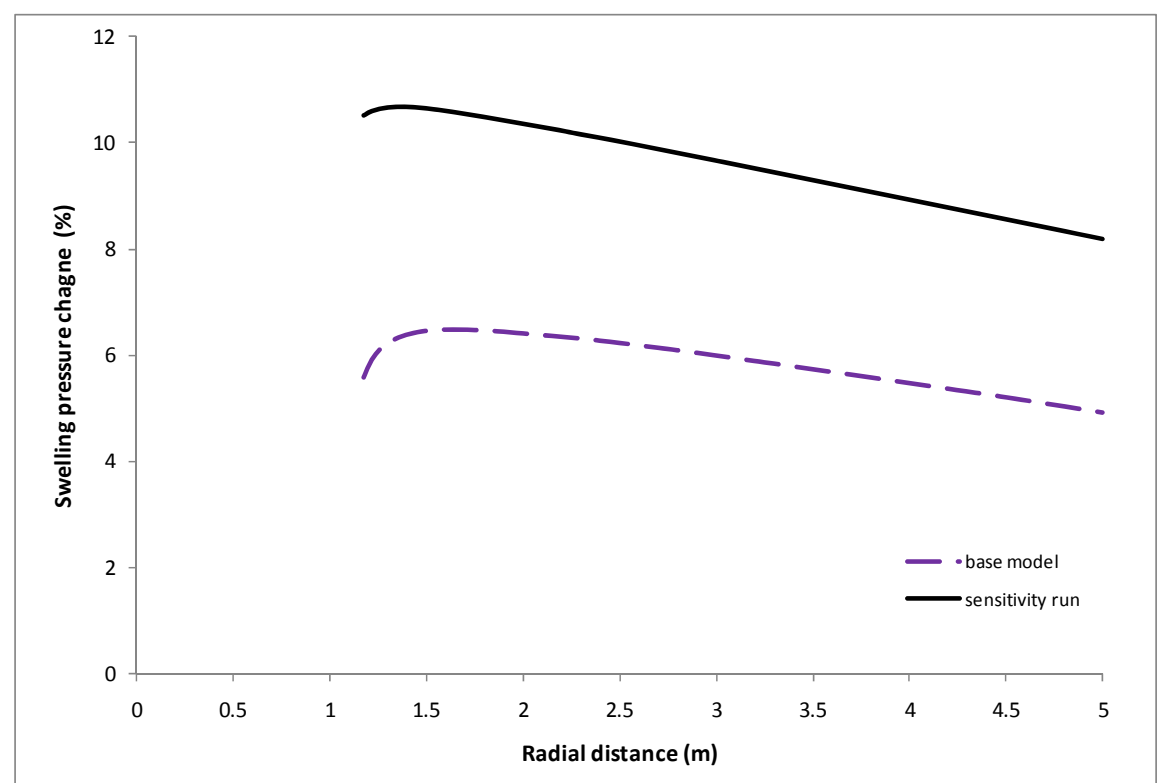

Figure 4-25. Comparison of swelling pressure at 100 years computed in the base model and a sensitivity run that does not consider the effect of the decrease of the volume fraction of smectite.

\section{The effect of EBS hydration on swelling pressure change in the host clay rock}

As the interaction of the EBS with host clay rock triggers all geochemical changes, the hydration rate of the EBS is expected to play a significant role in the geochemical evolution in the near field, and subsequently the changes in swelling properties. One of the key parameters that determine the hydration rate is the tortuosity of the vapor phase. Liu et al. (2010) shows that the geochemical evolution in EBS and the host clay rock is very sensitive to the tortuosity of the vapor phase in a coupled THC model. In the base model, the tortuosity is a function of the porosity and saturation degree (see Table 4-6), which is initially around 0.02 for bentonite and 0.5 for host clay rock. In a sensitivity run, the tortuosity is 0.8 for bentonite and 1.0 for host clay rock. An increase in tortuosity leads to a more rapid hydration of bentonite and therefore fast transport of ions from clay host rock to bentonite. As shown in Figure 4-26, at 1 year, the ionic strength drops sharply in the sensitivity run; after 100 years, the ionic strength in sensitivity runs lower than that in the base run. In the sensitivity run, because bentonite contains more readilydissolved minerals (mainly carbonate minerals) the dissolution of these minerals increases the ionic strength of the bentonite significantly. As a result, the ionic strength of the bentonite is slightly higher than that in the host clay rock after the bentonite becomes fully saturated, and the back-diffusion leads to an increase in ionic strength near the EBSNS interface. That is why the spatial trend of ionic strength in the sensitivity run is different from that of base run. 


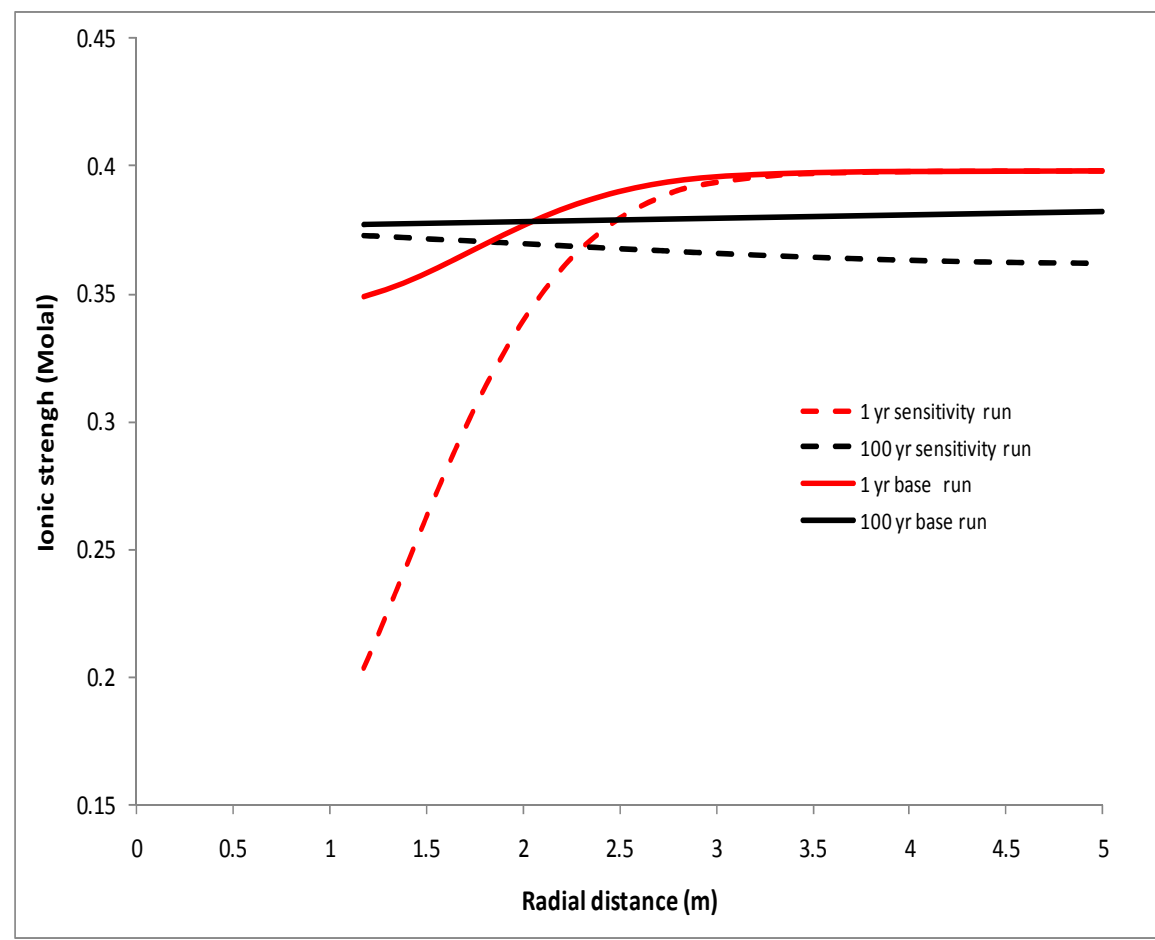

Figure 4-26. Computed ionic strength at 1 and 100 years in the base and sensitivity run

As a result of the rapid hydration of the bentonite, the illitization in the host clay rock is enhanced, as illustrated by the more significant dissolution of smectite (Figure 4-27) and precipitation of illite (Figure 4-28)

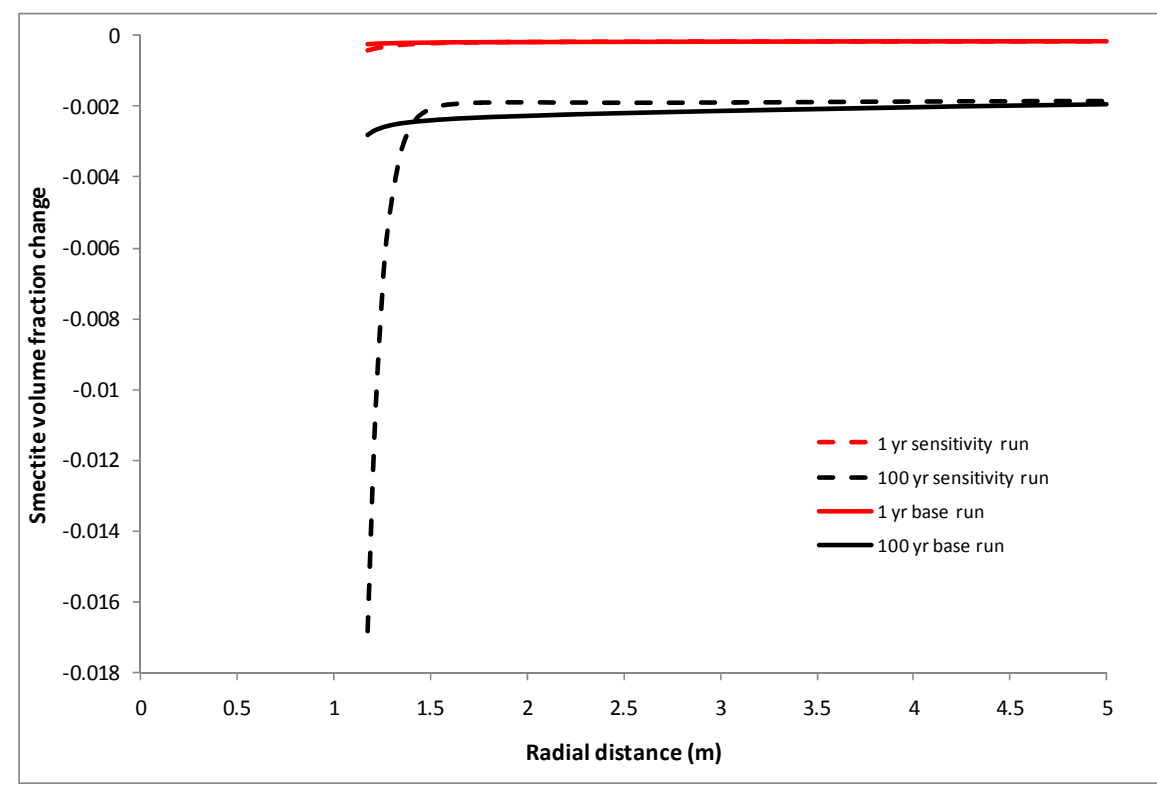

Figure 4-27. Computed smectite volume fraction change at 1 and 100 years in the base and sensitivity run. 


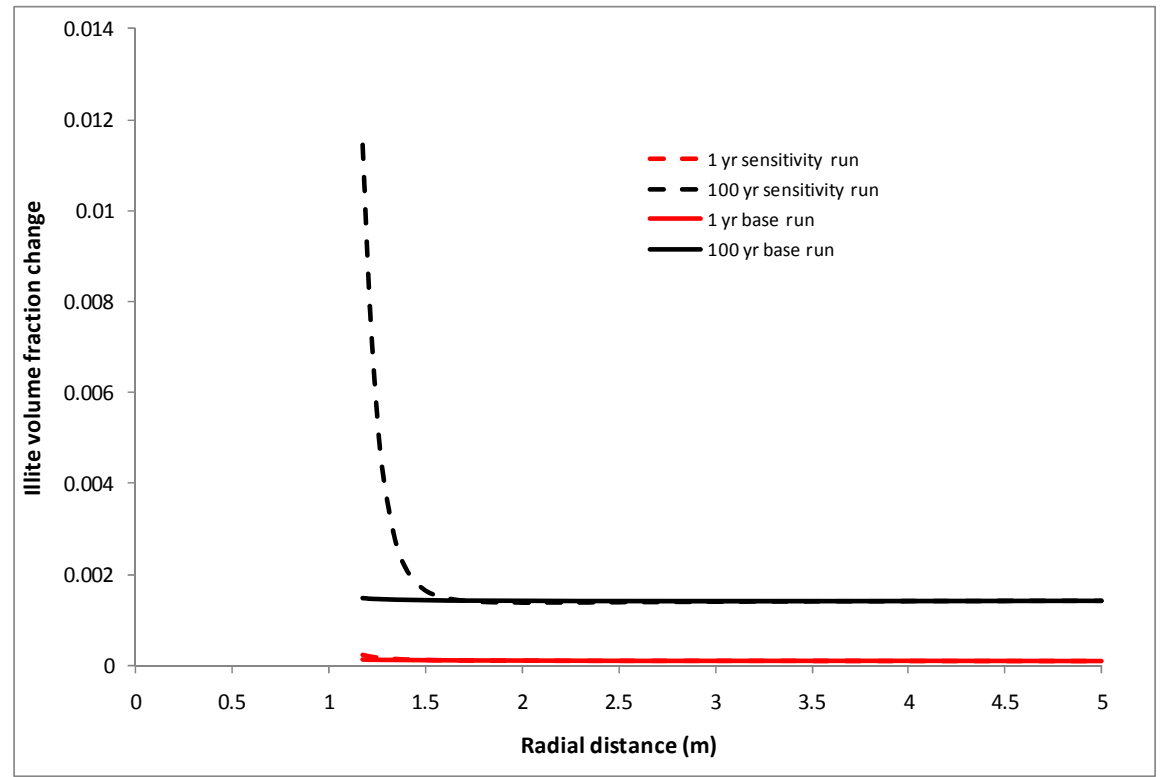

Figure 4-28. Computed illite volume fraction change at 1 and 100 years in base and sensitivity run.

Changes in the exchangeable cations are directly tied to the changes in concentration of aqueous cations. Figure 4-29 shows the changes in concentration of aqueous sodium and calcium. The concentration of aqueous sodium is mainly controlled by the transport processes, although the dissolution of the smectite affects it to some extent. After 100 years, the concentration of aqueous sodium shows a decreasing trend toward the EBS-HS interface. The concentration of aqueous calcium, on the other hand, is mainly controlled by the dissolution of calcite and shows an increasing trend toward the EBS-HS interface. As a consequence of the changes in concentration of aqueous sodium and calcium, exchangeable sodium and calcium exhibit a similar trend to their aqueous counterparts (Figure 4-30). Compared to the model result in the base run, exchangeable sodium and calcium show more significant change. As a result, the weighted average valence shows remarkable change, rising from 1.28 to as high as 1.46 , mainly caused by the increased exchangeable bi-valence cations (Figure 4-31). 


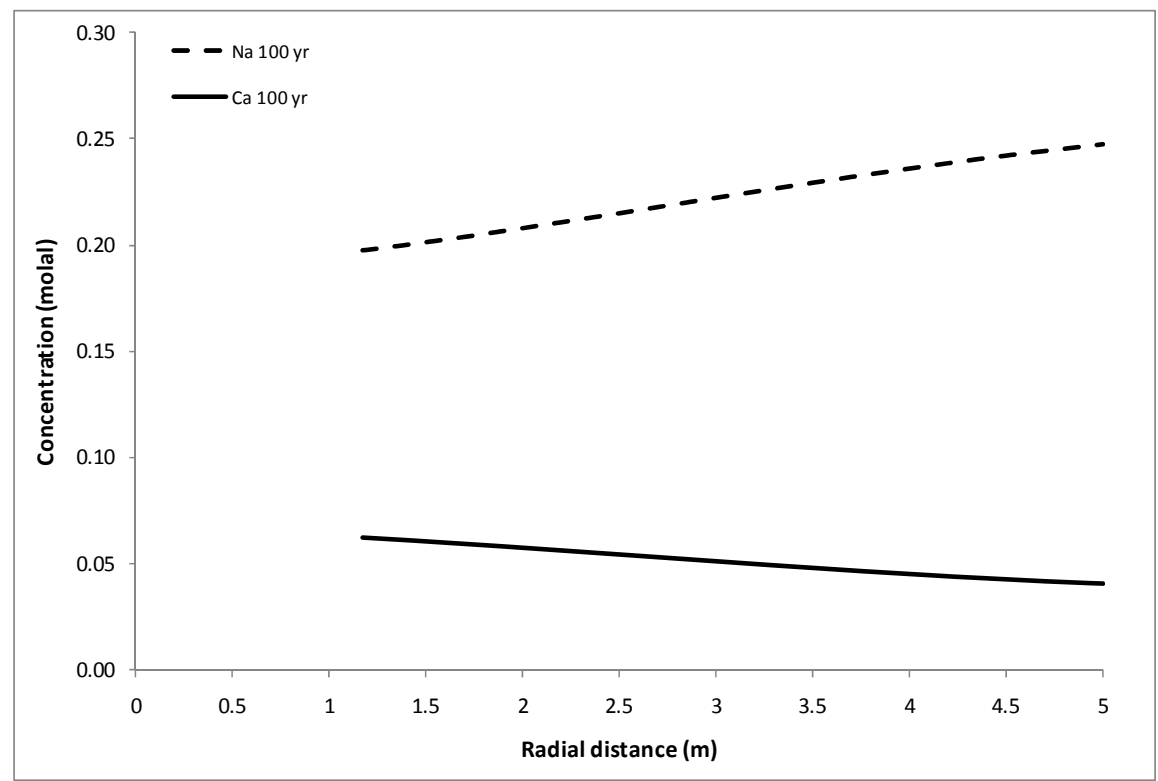

Figure 4-29. Computed concentration of aqueous sodium and calcium at 100 year in the sensitivity run.

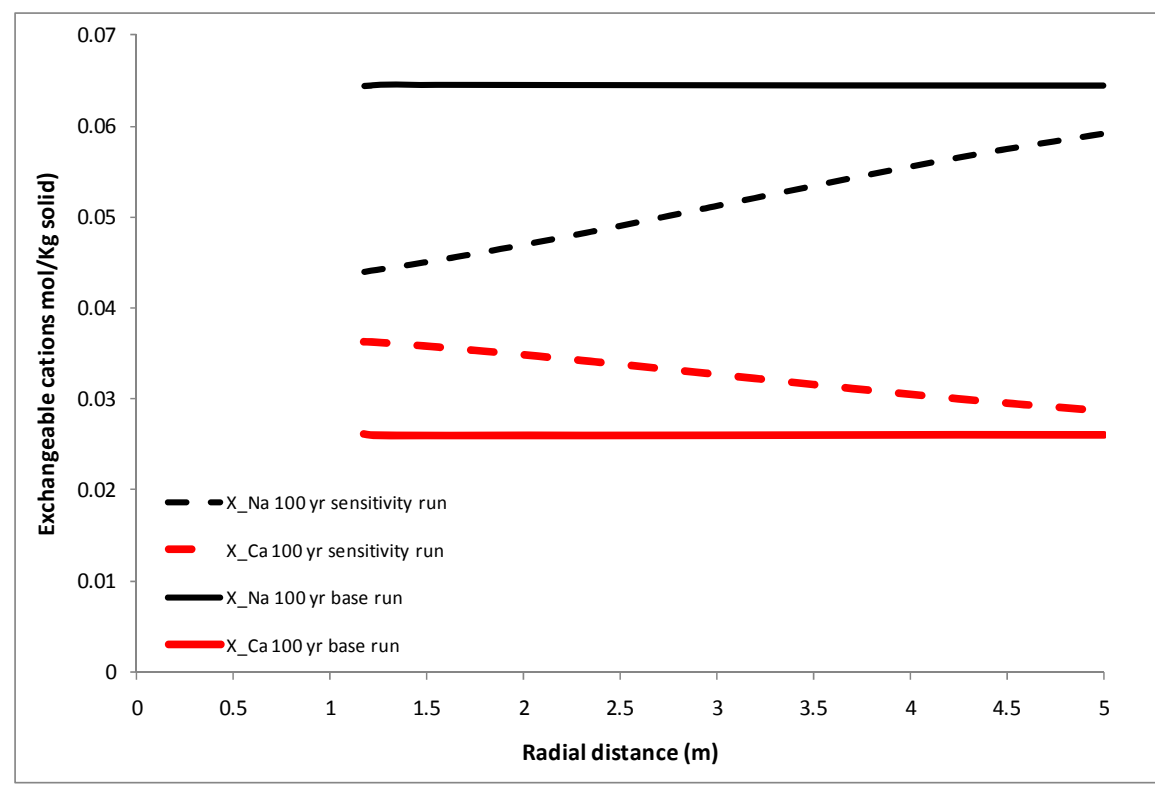

Figure 4-30. Computed concentration of exchangeable sodium and calcium at 100 year in the base and sensitivity run. 


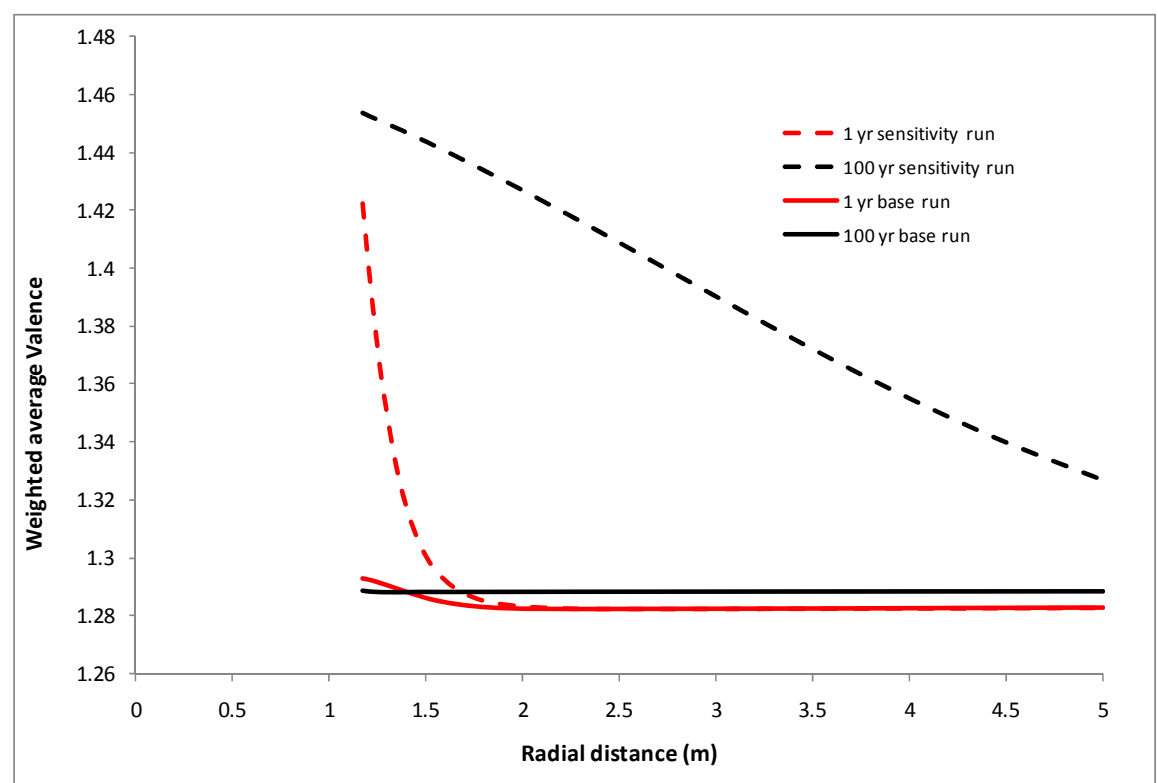

Figure 4-31. Computed weighted average valence at 1 and 100 year in the base and sensitivity run

As mentioned above, three types of geochemical change affect the swelling pressure: ionic strength, the volume fraction of smectite and the exchangeable cations (via weighted average valence). In the sensitivity run, the overall decrease in ionic strength tends to increase the swelling pressure, whereas the decrease in the volume fraction of smectite and increase in the weighted average valence of exchangeable cations tends to decrease the swelling pressure. The net effect is, as shown in Figure 4-32, a drop in swelling pressure, with a maximum drop of around $60 \%$ near the EBS-NS interface. Using Equation (4-21), the swelling induced porosity changes are calculated and the sensitivity run leads to a higher swelling-induced porosity, $+0.08 \%$ in comparison with about $-0.01 \%$ in the base run. However, the swelling-induced porosity change is still much smaller compared to the porosity change due to mineral precipitation/dissolution (Figure 4-33). 


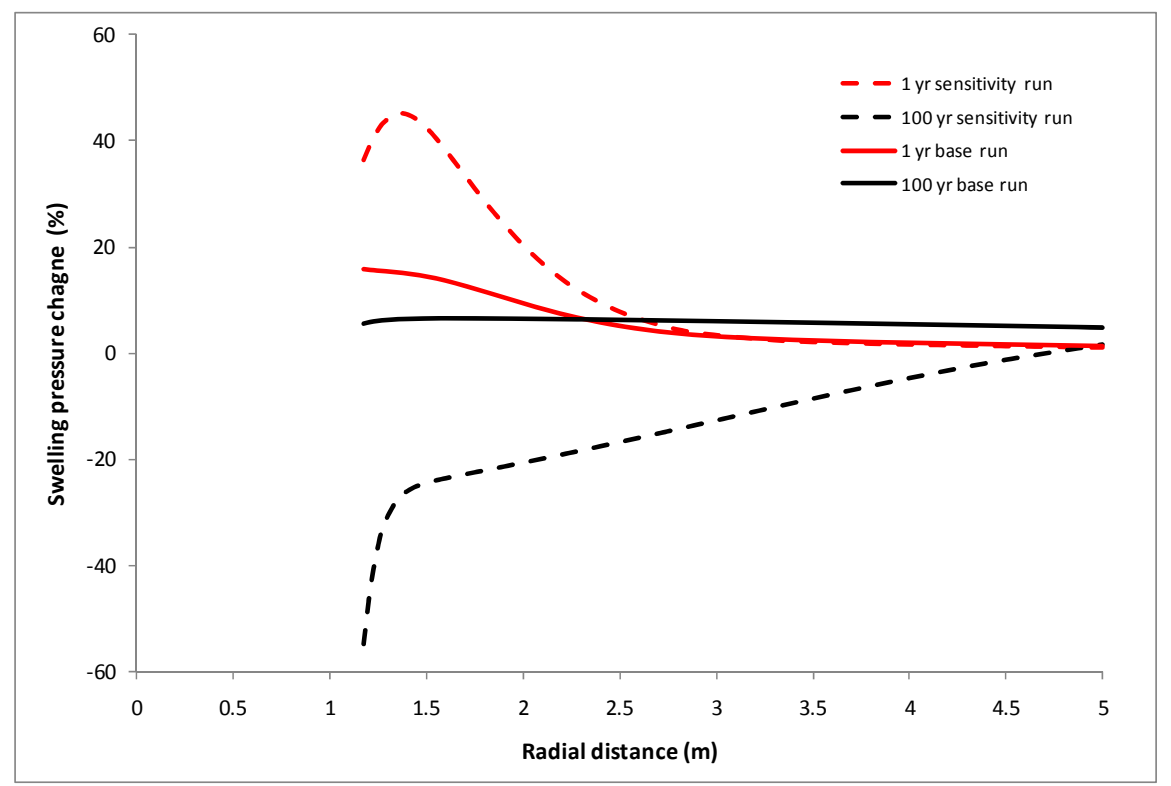

Figure 4-32. Computed swelling pressure at 1 and 100 years in the base and sensitivity run

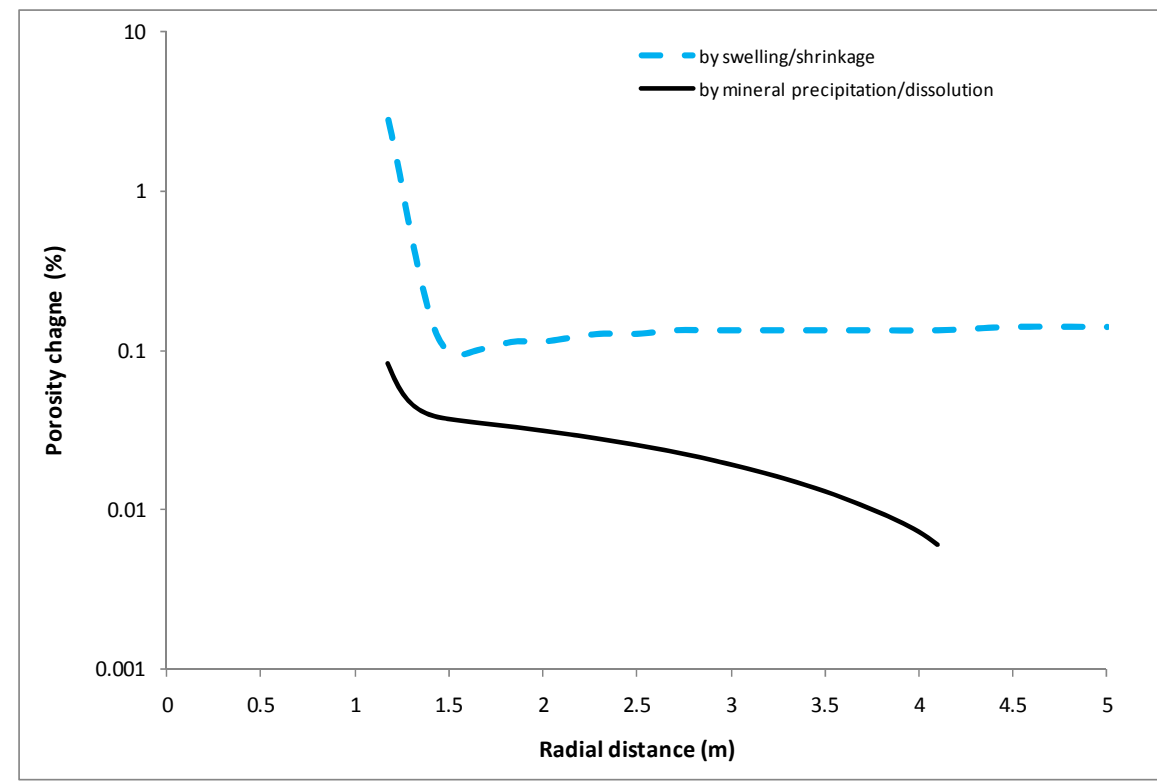

Figure 4-33. Porosity change (\%) due to mineral precipitation/dissolution and swelling at 100 years in the sensitivity run.

As we increase the hydration rate of the EBS in the sensitivity run, the geochemical response in the near-field host clay rock changes remarkably compared to the base run. One significant difference is the composition of exchangeable cations - a significant increase in exchangeable calcium in contrast with just a minor change in exchangeable calcium in the base run. As a result, the change in swelling pressure produced not only different magnitude of change but also a different trend - from a $+5 \%$ to $-60 \%$ decrease. 


\subsection{Conclusions}

One advantage of emplacing radioactive waste in a clay formation is the potential selfsealing capability of the clay formation, due to its capacity for swelling. The swelling properties of the near-field host clay rock might change due to geochemical reasons (Thury, 2002; Wakim et al., 2009), including a change in ion concentration, exchangeable cations, or the amount of swelling clay minerals. Host clay rock, especially in the near-field area, undergoes geochemical changes due to the interaction between EBS and host clay rock, as demonstrated by THC models for EBS and host rock (Liu et al., 2010). It is therefore necessary to evaluate the geochemically induced changes in swelling properties in near-field host clay rock. In this report, coupled THC models are linked with a swelling model based on DDL theory, and these models are used to evaluate swelling-property changes in the near field of host clay rock.

Major findings based on our current modeling work include:

1) Moderate changes in swelling pressure caused by geochemical effects could be expected, with the possibility that significant change could occur depending on many hydrogeological and geochemical parameters. Changes in hydration rate of the EBS (via the adjustment of tortuosity) could have a significant effect on the geochemically-induced changes in swelling pressure.

2) Geochemically induced swelling/shrinkage occurs exclusively in the near-field area, within about 2 to 3 meters of the EBS-NS interface.

3) The swelling/shrinkage-induced porosity change is generally much smaller than that caused by mineral precipitation/dissolution.

4) The geochemically induced swelling/shrinkage of host clay rock is the combined effect of variation in pore-water ion concentration, changes in exchangeable cations, and changes in the amount of smectite. Neglecting any of these three factors might lead to a miscalculation of geochemically induced swelling pressure. 


\section{SUMMARY AND FUTURE WORK}

\subsection{Summary}

This report has addressed several aspects of hydro-mechanical-chemical coupled processes that are critical for understanding the behavior of an argillaceous host rock for disposal of high-level radioactive waste. By definition, mined geologic disposal involves the excavation of access and waste emplacement openings. Therefore, it is essential to be able to quantitatively predict the behavior of the system that results from the excavation disturbance. Excavation disturbances at a minimum result in changes in mechanical stress near the opening, simply as a result of the removal of rock to create the opening. However, other operational conditions, including tunnel ventilation, emplacement of unsaturated bentonite backfill, and waste heat, result in desaturation of the near-field rock and changes in the chemical composition of the near-field pore water.

\section{Elastic strain-stress relationship under anisotropic stress conditions}

The development of a DRZ in argillaceous rock has been well-documented in several studies conducted at underground research laboratories in Switzerland, Belgium, and France. A significant factor defining the DRZ is the development of fractures. Therefore, geomechanical modeling of the DRZ requires the consideration of the effects of fractures on the constitutive relationship between stress and strain. A new constitutive relationship, relating stress and strain for fractured porous rock, that accounts for the different geomechanical behavior of fractures and the general rock mass was documented in Liu et al. (2010). The model development in the Liu et al. (2010) was limited to isotropic geomechanical behavior. The new constitutive relationship has been extended here to address anisotropic stress conditions. Furthermore, the model development has also been advanced to describe the functional dependence of porosity and bulk compressibility on stress. Several comparisons with laboratory data on the mechanical response of clay, shale, and other rock types have shown that the nonlinearity introduced by the new constitutive model is needed to reflect the observed behavior.

\section{Unsaturated properties for non-Darcian water flow in clay}

Ventilation and the introduction of unsaturated bentonite backfill leads to desaturation of the host rock in the vicinity of the excavation boundary. Desaturation impacts the mechanical and chemical conditions in the rock, and therefore is important in the evolution of the DRZ. In addition, postclosure rehydration of the DRZ and EBS, an essential factor in the swelling of bentonite and sealing of the EBS and DRZ, is dependent on the behavior of unsaturated flow in the near field. Experimental work on saturated and unsaturated flow through clay shows significant deviations from the traditional Darcy's law relationship between flux and the hydraulic gradient. A new 
constitutive relationship for unsaturated flow through clay, based on a non-Newtonian flow process, is presented. This leads to a nonlinear relationship between flux and the hydraulic gradient, and a new relationship between hydraulic conductivity and pore size. These results are used to develop a revised relationship between capillary pressure and relative permeability. The new constitutive relationships are fundamentally different from traditional relationships for saturated and unsaturated flow in porous media. Comparisons with data show that the new constitutive relationships are consistent with experimental observations of unsaturated flow through a compacted sand-bentonite mixture.

\section{THM modeling in clay/shale environment}

The TOUGH-FLAC thermal-hydrological-mechanical code was updated to include the new stress-strain constitutive model for isotropic conditions presented in Section 2.1. The code was used to model rock-mass deformation and pore pressure around an underground excavation, using published hydromechanical parameters and boundary conditions determined for the Opalinus Clay, Switzerland. The modeling considered water evaporation, volume shrinkage/swelling, and different orientations between the tunnel and clay bedding planes during the drying period, in addition to the newly implemented constitutive relationship. Results show that during a 3-year ventilation period: (1) rock dryout is limited to a $40 \mathrm{~cm}$ zone around the tunnel; (2) bedding-plane orientation relative to the tunnel has a pronounced effect on development of tensional stress, displacement in the roof and floor zone, and the pattern of extensional failure around the tunnel; and (3) the new constitutive model, as compared with a Hooke's law constitutive model, led to distinct differences in radial elastic deformation at roof and floor of the tunnel, stress distribution, porosity-permeability variation, and DRZ pattern around the tunnel.

\section{THC modeling in a clay/shale environment}

A Gouy-Chapman diffuse-double layer model for geochemically induced swelling and shrinkage was implemented in the TOUGHREACT thermal-hydrological-chemical code. Geochemical conditions, such as ion concentration and exchangeable cation compositon, can affect clay swelling. This process is important because fracture self-sealing in the DRZ is affected by swelling behavior. The main findings of the study are: (1) changes in swelling pressure caused by geochemical effects range from moderate to significant, depending on hydrogeologic and geochemical parameters, with particular sensitivity to the tortuosity; (2) geochemically induced swelling/shrinkage is limited to a 2 to $3 \mathrm{~m}$ zone at the drift wall; (3) mineral precipitation dissolution dominates changes in porosity as compared with swelling/shrinkage effects; (4) geochemically induced swelling/shrinkage depends on ion concentration, cation composition, and smectite content of the rock. 


\subsection{Future Work Activities}

This subsection provides recommendations for future work activities on coupled processes related to DRZ evolution and its impact on performance of the natural engineering barrier in clay/shale repositories. These activities directly and indirectly address a number of research topics identified in Research \& Development ( $\&$ \&) Plan for Used Fuel Disposition Campaign (UFDC) Natural System Evaluation and Tool Development (Wang, 2011), including Topics P4, Investigation of water movement and transport in low permeability media (clay formations); P8, Reactive transport modeling of groundwater chemistry evolution and radionuclide transport; P15 Modeling of disturbed rock zone (DRZ) evolution (clay repository), and P18, In-situ testing of DRZ development. While much progress has been made in improving our understand and predictive THM and THC capabilities for near-field behavior of clay/shale repositories, further developments are needed, as described below. It is expected, though, that our work will soon transition to a capability development and application/validation phase, in which international collaborations will be pursued to analyze/model relevant laboratory and particularly field data for clay rock.

\section{Development of constitutive relationship}

Constitutive relationships refer to relationships among hydraulic, mechanical, thermal, and mechanical properties. The overall objective of this task is to develop advanced constitutive relationships for coupled processes in clay repository. It is expected that these relationships, with minor modifications, can also be applied to other geological formations. Recommended future work activities include:

- Our current focus has been on the elastic deformation regime for clay rock. The constitutive relationships developed here need to be further extended to plastic regimes. The impact of damage on mechanical and hydraulic properties will be investigated as well.

- While fractures are the key feature within the DRZ, studies on constitutive relationships for fractures are extremely limited for clay rock, especially when swelling/shrinkage processes are involved. Liu et al. (2010) provided a preliminary model for a stress-dependence of fracture properties. We will continue the work to improve and validate that model. The fractured DRZ may also be characterized as a dual-continuum system. We will develop a dualcontinuum approach for coupled hydro-mechanical processes in clay DRZ.

- As indicated in Section 2.2, conventional unsaturated flow relationships may not be able to capture near-field flow behavior (e.g., non-Darcian behavior), although they are still widely used in related simulators because of a lack of alternatives. 
Building on our study of non-Darcian flow, we are planning to develop new unsaturated flow relationships (among saturation, capillary pressure, relative permeability, and swelling) for clay rock.

- The data are key for developing and validating a variety of constitutive relationships. International collaborations will be perused to access laboratory and field data for clay rock from relevant international groups.

\section{THM modeling}

Coupled THM processes are critical for DRZ formation and evolution in a clay repository. The overall objective of this task is to develop a modeling capability for the THM processes and an improved understanding of how these processes impact DRZ evolution within the context of performance assessment. Recommended work activities include:

- As demonstrated in Section 2, constitutive relationships have an important impact on THM simulation results. We will continue to incorporate the new development of constitutive relationships to improve our THM modeling capability.

- Understanding and modeling DRZ formation and evolution is both an important task and a great challenge. Recently, Tang and Hudson (2010) demonstrated that failure processes for brittle rocks could be realistically captured by using finegrid numerical simulations and taking into account the spatial variability of mechanical properties. Rock failure (or formation of DRZ) is more complex, because it involves unsaturated flow, swelling/shrinkage, and the saturation dependence of mechanical properties. We will explore the feasibility of using the Tang and Hudson's (2010) approach in clay rock. The TOUGH-FLAC3D will be used for this activity.

- We will apply our THM modeling capabilities to modeling the relevant field tests, with a focus on validating our models with experimental observations and improving our understanding of the coupled processes.

\section{THC modeling}

An understanding of the geochemical evolution of host clay formations (including the DRZ) is critical to understanding repository performance. With the objective of developing a model capability for the coupled THC processes and improving the understanding of the effect of THC processes on the transport of radionuclides through the clay formation, the following future research is recommended.

- Our current model focuses on changes in aqueous species and mineral precipitation/dissolution. Incorporation of surface complexation in the $\mathrm{THC}$ 
model is clearly needed, because surface complexation provides a useful tool to calculate the adsorption/desorption of behavior of ions (including radionuclides) while considering the competition between ions and changes in pore-water geochemistry

- Radionuclide transport will be coupled to the full THC model, to test the THC modeling tools and improve our understanding of radionuclide transport in coupled systems.

- The coupled THC behavior of clay formations will be greatly boosted by a better understanding of the in situ water-rock interaction, which requires a more accurate characterization of the geochemistry of pore water and of the solid phase. Any accomplishment archived under research topic P7, Novel in situ technique for groundwater chemistry characterization (Wang, 2011), should therefore be monitored, and any experimental results arising from international collaboration should be considered.

- When international opportunities that involve international field tests in clay formations arise, our THC model will applied to such field tests to validate the model and improve our understanding. 


\section{REFERENCES}

Alonso E. E., Gens A., and Josa A. (1990) A constitutive model for partially saturated soils. Géotechnique, 40(3): 405-430.

Barnichon J.D. and Volckaert G. (2003) Observations and Predictions of Hydromechanical Coupling Effects in the Boom Clay, Mol Underground Research Laboratory, Belgium, Hydrogeology Journal 11 (1), 193-202.

Bobet A., Atistorenas G., and Einstein H. (1998) Feasibility Analysis for a Radioactive Waste Repository Tunnel. Tunneling and Underground Space Technology, 13(4), 409-426.

Bock, H., Dehandschutter B., and Martin, C. D. (2010) Self-sealing of fractures in argillaceous formations in the context of geological disposal of radioactive waste, Review and Synthesis. Nuclear Energy Agency, ISBN 978-92-64-99095-1.

Bolt G. H. (1956) Physico-chemical analysis of the compressibility of pure clays. Géotechnique 6(2), 86-93.

Bossart P., Meier P. M., and Moeri, A. (2002) Geological and hydraulic characterization of the excavation disturbed zone in the Opalinus Clay of the Mont Terri Rock Laboratory. Engineering Geology, 66, 19-38.

Brady B. T. (1969) The nonlinear mechanical behavior of brittle rock Part I—Stressstrain behavior during regions I and II, International Journal of Rock Mechanics and Mining Sciences, 6,211-225

Brooks R. H. and Corey A. T. (1964) Hydraulic properties for porous media, Hydro. Rep. No. 3, Colorado State University, Fort Collins.

Brown E. T., Bray J. W., and Santarelli F.J. (1989) Influence of stress-dependent elasticmodulus on stresses and strains around axisymmetric boreholes, Rock mechanics and rock engineering ,22,189-203

Burdine N. T. (1953) Relative permeability calculations from pore size distribution data, Am. Ins. Min. Metail. Pet. Eng, 198, 71-77.

Causarano H. (1993) Factors affecting the tensile strength of soil aggregates. Soil \& Tillage Research, 28, 15-25.

Cazacu O. (1999) On the choice of stress-dependent elastic modulus for transversely isotropic solids, Mechanics Research Communications, 26, 45-54

Christopher R. H. and Middleman, S. (1965) Power-law flow through a packed tube, $I$ and EC Fundamentals, 4(4), 422-426. 
Corkum A. G. and Martin C. D. (2007a) The mechanical behaviour of weak mudstone (Opalinus Clay) at low stresses, International Journal of Rock Mechanics \& Mining Sciences, 44, 196-209.

Corkum A. G. and Martin C. D. (2007b) Modelling a mine-by test at the Mont Terri rock laboratory, Switzerland. International Journal of Rock Mechanics \& Mining Sciences, 44, 846-859.

Cuadros J. (2006) Modeling of smectite illitization in burial diagenesis environments. Geochimica et Cosmochimica Acta 70(16), 4181-4195.

Cui Y. J., Tang A. M., Loiseau C., and Delage P. (2008) Determining the unsaturarted hydraulic conductivity of a compacted sand-bentonite mixture under constantvolume and free-swell conditions, Physics and Chemistry of the Earth, 33, S462S471.

Daniel D. E. (1982) Measurement of hydraulic conductivity of unsaturated soils with thermocouple psychrometers, Soil Science Society of America Journal 20 (6) (1982), pp. 1125-1129.

Dixon D. A., Graham J., and Gray M.N. (1999) Hydraulic conductivity of clays in confined tests under low hydraulic gradients, Can. Geotech. J., 36, 815-825.

Edlefsen N. E., Anderson A. B. C. (1943) Thermodynamics of soil moisture, Hilgardia, $15(2), 31-298$.

El-Swaify S. A. and Henderson D. W. (1967) Water retention by osmotic swelling of certain colloidal clays with varying ionic composition. Journal of Soil Science $18(2), 223-232$.

ENRESA (2000) Full-scale engineered barriers experiment for a deep geological repository in crystalline host rock FEBEX Project, European Commission. EUR 19147 EN.

Erdal Ç. and Tilgen H. P. (2010) Shear strength-suction relationship of compacted Ankara clay. Applied Clay Science 49, 400-404.

Erguler Z. A., Ulusay R. (2009) Water-induced variations in mechanical properties of clay-bearing rocks. International Journalof Rock Mechanics \& Mining Sciences, $46,355-370$.

Fernández A. M., Turrero M. J., Sánchez D. M., Yllera A., Melón A. M., Sánchez M., Peña J., Garralón A., Rivas P., Bossart P., and Hernán, P. (2007) On site measurements of the redox and carbonate system parameters in the lowpermeability Opalinus Clay formation at the Mont Terri Rock Laboratory. Physics and Chemistry of the Earth, Parts A/B/C 32(1-7), 181-195. 
Fouche O., Wright H., Cleach J. L., and Pellenard P. (2004) Fabric Control on Strain and Rupture of Heterogeneous Shale Samples by Using a Non-Conventional Mechanical Test, Applied Clay Science 26, 367-387.

Freed A. D. (1995) Natural Strain, Journal of Engineering Materials and Technology, $117,379-385$

Gens A. and Alonso E. E. (1992) A framework for the behaviour of unsaturated expansive clays. Canadian Geotechnical Journal, 29: 1013-1032.

Gercek H. (2007) Poisson's ratio values for rocks, International Journal of Rock Mechanics and Mining Sciences, 44, 1-13

Ghassemi A. and Diek A. (2003) Linear chemo-poroelasticity for swelling shales: theory and application. Journal of Petroleum Science and Engineering 38(3-4), 199-212.

Ghorbani A., Zamora M., and Cosenza P. (2009) Effects of desiccation on the elastic wave velocities of clay-rocks. International Journal of Rock Mechanics \& Mining Sciences, 46, 1267-1272.

Gonzales S. and Johnson K. S. (1984) Shale and other argillaceous strata in the United States. Oak Ridge National Laboratory. ORNL/Sub/84-64794/1.

Guimarães L. D., Gens A., and Olivella S. (2007) Coupled thermo-hydro-mechanical and chemical analysis of expansive clay subjected to heating and hydration. Transport in Porous Media, 66 (3): 341-372.

Hansbo S. (2001) Consolidation equation valid for both Darcian and non-Darcian flow, Geotechnique, 51(1), 51-54.

$\mathrm{Hu}$ Y. and Liu G.T. (2004) Behavior of soft rock under multiaxial compression and its effects on design of arch dam, Chinese journal of rock mechanics and engineering , 23,2494-2498

Itasca Consulting Group Inc. (2001) FLAC-3D Manual: Fast Lagrangian analysis of continua in 3 dimensions-Version 3.1. Itasca Consulting Group Inc., Minnesota, USA.

Jaeger J. C., Cook N. G. W., and Zimmerman R.W. (2007) Fundamentals of rock mechanics,4th Edition, Blackwell, Oxford.

Jobmann M., Wilsnack Th., and Voigt H.-D. (2010) Investigation of damage-induced permeability of Opalinus clay. International Journal of Rock Mechanics \& Mining Sciences, 47, 279-285.

Johnson P. A. and Rasolofosaon P. N. J. (1996) Nonlinear elasticity and stress-induced anisotropy in rock, Journal of Geophysical Research, 101, 3113-3124 
Jougnot D., Revil A., Lu N., and Wayllace A. (2010) Transport properties of the CallovoOxfordian clay rock under partially saturated conditions. Water Resources Research 46.

Kamei G., Mitsui M. S., Futakuchi K., Hashimoto S., and Sakuramoto Y. (2005) Kinetics of long-term illitization of montmorillonite - a natural analogue of thermal alteration of bentonite in the radioactive waste disposal system. Journal of Physics and Chemistry of Solids 66(2-4), 612-614.

Komine H. and Ogata N. (1996) Prediction for swelling characteristics of compacted bentonite. Canadian Geotechnical Journal 33, 11-22.

Komine H. and Ogata N. (2003) New equations for swelling characteristics of bentonitebased buffer materials. Canadian Geotechnical Journal 40, 460-475.

Kouakou C. H. and Morel J. C. (2009) Strength and elasto-plastic properties of nonindustrial building materials manufactured with clay as a natural binder. Applied Clay Science, 44, 27-34.

Leverett M. C. (1941) Capillary behavior in porous solids, Trans. Am. Inst. Min. Metall. Eng., 142, 152-169.

Lionço A. and Assis A. (2000) Behavior of deep shafts in rock considering nonlinear elastic models, Tunnelling and Underground Space Technology, 15, 445-451

Liu H. H., Rutqvist J., and Berryman J. G. (2009) On the relationship between stress and elastic strain for porous and fractured rock, International Journal of Rock Mechanics and Mining Sciences ,46, 289-296

Liu H. H, Rutqvist J., Zheng L., Sonnenthal E., Houseworth J. and Birkholzer J. (2010) Modeling coupled process in clay formation for radioactive waste disposal. Lawrence Berkeley National Laboratory report, LBNL-3900E.

Lopez X., Valvatne P. H., Blunt M. J. (2003) Predictive network modeling of singlephase non-Newtonian flow in porous media, Journal of Colloid and Interface Science, 264, 256-265.

MacBeth C. (2004) A classification for the pressure-sensitivity properties of a sandstone rock frame, Geophysics, 69, 497-510

Madsen F. T. and Muller-vonmoss M. (1985) Swelling pressure calculated from mineralogical properties of a jurassic opalinum shale, switzerland. Clays and Clay Min. 33(6), 501-509.

Mavko G. M. and Nur A. (1978) The effect of nonelliptical cracks on the compressibility of rocks, Journal of Geophysical Research, 83,4459-4468 
Mayer G., Klubertanz G., and Croise J. (2007) Modelling of an in situ ventilation experiment in the Opalinus Clay. Physics and Chemistry of the Earth, 32, 629638.

Mayor J.-C., Velasco M., and García-Siñeriz, J.-L. (2007) Ventilation experiment in the Mont Terri underground laboratory. Physics and Chemistry of the Earth, 32, 616628.

Meier P., Trick T., Blumling P., and Volckaert G. (2000) Self-Healing of Fractures within the EDZ at the Mont Terri Rock Laboratory: Results after One Year of Experimental Work. In: Proceedings of the International Workshop on Geomechanics, hydromechanical and Thermomechanical Behavior of deep argillaceous Rocks: Theory and Experiments, Paris, October11-12, 2000.

Mitchell J. K. and Soga K. (2005) Fundamentals of Soil Behavior, John Wiley \& Sons INC.

Montes-Hernandez G., Duplay J., Martinez L., and Mendoza, C. (2003) Swellingshrinkage kinetics of MX80 bentonite. Applied Clay Science, 22, 279-293.

Montes-Hernandez G., Fritz B., Clement A., and Michau, N. (2005) A simplified method to evaluate the swelling capacity evolution of a bentonite barrier related to geochemical transformations. Appl. Geochem. 20(2), 409-422.

Morgenstern N. R. and Tamuly Phukan A. L. (1969) Non-linear stress-strain relations for a homogeneous sandstone, International Journal of Rock Mechanics and Mining Sciences, 6,127-142

Mualem Y. (1976) A new model for predicting the hydraulic conductivity of unsaturated porous media. Water Resour. Res, 12, 513-522.

Nur A. (1971) Effects of stress on velocity anisotropy in rocks with cracks, Journal of Geophysical Research ,76,2022-2034

Olalla C., Martin M., and Sáez J. (1999) ED-B experiment: geotechnical laboratory test on Opalinus Clay rock samples, Technical report TN98-57, Mont Terri Project

Onikata M., Kondo M., Hayashi N., and Yamanaka S. (1999) Complex formation of cation-exchanged montmorillonites with propylene carbonate; osmotic swelling in aqueous electrolyte solutions. Clay Clay Min. 47(5), 672-677.

Ochs M., Lothenbach B., Shibata M., and Yui M. (2004) Thermodynamic modeling and sensitivity analysis of porewater chemistry in compacted bentonite, Physics and Chemistry of the Earth, Parts A/B/C, Volume 29, Issue 1, 129-136.

Panayiotopoulos, K. P. (1996) The effect of matric suction on stress-strain relation and strength of three Alfisols. Soil \& Tillage Research, 39, 45-59. 
Pascal, H. (1983) Rheological behavior effect of non-Newtonian fluids on steady and unsteady flow through a porous medium, International Journal for Numerical and Analytical Methods in Geomechanics, 7, 289-303.

Patriarche D., Ledoux E., Simon-Coincon R., Michelot J., and Cabrera J. (2004) Characterization and Modeling of Diffusive Process for Mass Transport through the Tournemire Argillites Aveyron, France, Applied Clay Science 26: 109-122, 2004.

Peng S. P. and Zhang J. C. (2007) Engineering geology for underground rocks, Spring Berlin Heidelbery, New York

Pham O. T., Vales F., Malinsky L., Nguyen Minh D., and Gharbi H. (2007) Effects of desaturation-resaturation on mudstone. Physics and Chemistry of the Earth, 32, 646-655.

Poisson S.D. (1829) Mémoire sur les equations generates de l'équilibre et du nouvement des corps silides élastiques et de fluids, Journal de l'École Poly technique, 13,1174

Popp T., Salzer K., and Minkley W. (2008) Influence of bedding planes to EDZevolution and the coupled HM properties of Opalinus Clay. Physcis and Chemistry of the Earth, 33, S374-S387.

Pruess K. (2004) The TOUGH codes: A family of simulation tools for multiphase flow and transport processes in permeable media. Vadose Zone Journal, 3, 738-746.

Pruess K., Oldenburg C. M., Moridis G. (1999) TOUGH2 USER'S GUIDE, VERSION 2.0, Earth Sciences Division, Lawrence Berkeley National Laboratory, University of California, Berkeley, California 94720.

Pusch R. and Madsen F. T. (1995) Aspects on the illitization of the kinnekulle bentonites. Clay Clay Min. 43(3), 261-270.

Pusch R., Kasbohm J., and Thao, H. T. M. (2010) Chemical stability of montmorillonite buffer clay under repository-like conditions-A synthesis of relevant experimental data. Appl. Clay Sci. 47(1-2), 113-119.

Rutqvist J. (2011) Status of the TOUGH-FLAC simulator and recent applications related to coupled fluid flow and crustal deformations. Computers \&Geosciences, doi:10.1016/j.cageo.2010.08.006.

Rutqvist J. and Tsang, C.-F. (2003) TOUGH-FLAC: a numerical simulator for analysis of coupled thermal-hydrologic-mechanical processes in fractured and porous geological media under multi-phase flow conditions. In: Proceedings of the TOUGH Symposium 2003, Lawrence Berkeley National Laboratory, Berkeley, May 12-14. 
Rutqvist J., WuY.-S., Tsang C.-F., and Bodvarsson G. (2002) A modeling approach for analysis of coupled multiphase fluid flow, heat transfer, and deformation in fractured porous rock. International Journal of Rock Mechanics and Mining Sciences, 39, 429-442.

Rutqvist J., Ijiri Y., and Yamamoto H. (2011) Implementation of the Barcelona Basic Model into TOUGH-FLAC for simulations of the geomechanical behavior of unsaturated soils. Computers \&Geosciences, doi:10.1016/j.cageo.2010.10.011.

Samper J., Yang Q., Yi S., Garcia-Gutierrez M., Missana T., Mingarro M., Alonso U., and Cormenzana, J. L. (2008) Numerical modeling of large-scale solid-source diffusion experiments in Callovo-Oxfordian clay. Phys. Chem. Earth 33, S208S215.

Schanz T. and Tripathy S. (2009) Swelling pressure of a divalent-rich bentonite: Diffuse double-layer theory revisited. Water Resour. Res. 45, W00C12.

Shao H., Schuster K., Sönnke J., and Bräuer V. (2008) EDZ development in indurated clay formations - In situ borehole measurements and coupled HM modeling. Physics and Chemistry of the Earth, 33, S388-S395.

Shapiro S. A. and Kaselow A. (2005) Porosity and elastic anisotropy of rocks under tectonic stress and pore-pressure changes, Geophysics, 70,N27-N38

Sonnenthal E., Ito A., Spycher N., Yui M., Apps J., Sugita Y., Conrad M., and Kawakami S. (2005) Approaches to modeling coupled thermal, hydrological, and chemical processes in the Drift Scale Heater Test at Yucca Mountain. International Journal of Rock Mechanics and Mining Sciences, 42, 6987-719.

Spycher N.F., Sonnenthal E.L., Apps J.A. (2003) Fluid flow and reactive transport around potential nuclear waste emplacement tunnels at Yucca Mountain, Nevada. Journal of Contaminant Hydrology, 62-63, 653-673.

Sridharan A. and Jayadeva M. S. (1982) Double layer theory and compressibility of clays. Geotechnique 32(2), 133-144.

Tang C. A. and Hudson J.A. (2010) Rock Failure Mechanisms, Taylor \& Francis, London, UK.

Thomas H. R. and He Y. (1998) Modelling the behaviour of unsaturated soil using an elastoplastic constitutive model. Géotechnique, 48(5): 589-603.

Thury M. (2002) The characteristics of the Opalinus Clay investigated in the Mont Terri underground rock laboratory in Switzerland. Comptes Rendus Physique 3(7-8), 923-933. 
Tien Y. M., Lee D. H., and Juang C. H. (1990) Strain, pore pressure and fatigue characteristics of sandstone under various load conditions, International Journal of Rock Mechanics and Mining Sciences, 27, 283-289

Towner G. D. (1987) The Tensile Stress Generated in Clay through Drying. J. agric. Engng Res. 37, 279-289.

Tripathy S., Sridharan A., and Schanz T. (2004) Swelling pressures of compacted bentonites from diffuse double layer theory. Canadian Geotechnical Journal 41, 437-450.

Tsang C.-F., Bernier F., and Davies C. (2005) Geohydromechanical processes in the Excavation Damaged Zone in crystalline rock, rock salt, and indurated and plastic clays - in the context of radioactive waste disposal. International Journal of Rock Mechanics \& Mining Sciences, 42, 109-125.

Van Genuchten M. (1980) A closed-form equation for predicting the hydraulic conductivity of unsaturated soil, Soil. Sci. Soc. Am. J., 44(5), 892-898.

van Olphen H. (1977) An Introduction to Clay Colloid Chemistry: For Clay Technologists, Geologists and Soil Scientists, Wiley-Interscience, New York.

Wakim J., Hadj-Hassen F., and DeWindt L. (2009) Effect o faqueous solution chemistry on the swelling and shrinkage of the Tournemire shale. International Journal of Rock Mechanics \& Mining Sciences 46, 1378-1382.

Walsh J. B. (1965) The effect of cracks on the uniaxial elastic compression of rocks, Journal of Geophysical Research ,70, 399-411

Wang Y. (2011) Research \& Development (R\&D) Plan for Used Fuel Disposition Campain (UFDC) Natural System Evaluation and Tool Development, U.S. DOE Used Fuel Disposition Campaign.

Wayllace, A., 2008. Volume change and swelling pressure of expansive clay in the crystalline swelling regime, University of Missouri. Ph.D.

Wu Y.S. and Pruess K. (1998) A numerical method for simulating non-Newtonian fluid flow and displacement in porous media, Advances in Water Resources, 2, 351362.

Xu G. M., Liu Q. S., Peng W. W., and Chang X. (2006a) Experimental study on basic mechanical behaviors of rocks under low temperatures, Chinese Journal of Rock Mechanics and Engineering , 25,2502-2508

Xu T., Sonnenthal E., Spycher N., and Pruess K. (2006b) TOUGHREACT: A Simulation Program for Non-isothermal Multiphase Reactive Geochemical Transport in Variably Saturated Geologic Media. Computers and Geosciences, 32, 145-165. 
Xu T., and Pruess K. (2001) Modeling multiphase non-isothermal fluid flow and reactive geochemical transport in variably saturated fractured rocks: 1. Methodology. American Journal of Science, 301, 16-33.

Xu T., Spycher N., Sonnenthal E., Zhang G., Zheng L., and Pruess K. (2011) TOUGHREACT Version 2.0: A simulator for subsurface reactive transport under non-isothermal multiphase flow conditions. Computers \& Geosciences 37(6), 763-774.

Yang Y. L. and Aplin A. C. (2010) A permeability-porosity relationship for mudstones. Marine and Petroleum Geology, 27, 1692-1697.

Zhang C.-L. and Rothfuchs T. (2008a) Damage and sealing of clay rocks detected by measurements of gas permeability. Phys. \& Chem. Of the Earth, 33, 363-373.

Zhang C.-L., Rothfuchs T., Dittrich J., and Muller J. (2008b) Investigations on selfsealing of indurated clay. -GRS Report, GRS-230: 1-67, ISBN 978-3-939355-045 .

Zhang C.-L., Rothfuchs T., Su K., and Hoteit N. (2007) Experimental study of the thermo-hydro-mechanical behaviour of indurated clays. Physics and Chemistry of the Earth, 32, 957-965.

Zhang G., Spycher N., Sonnenthal E., Steefel C., and Xu T. (2008c) Modeling reactive multiphase flow and transport of concentrated aqueous solutions. Nuclear Technology, 164, 180-195.

Zheng L., Apps J. A., Zhang Y., Xu T., and Birkholzer J. (2009) On mobilization of lead and arsenic in groundwater in response to $\mathrm{CO}_{2}$ leakage from deep geological storage. Chemical geology, 268, 281-297.

Zou Y. (1996) A non-linear permeability relation depending on the activation energy of pore liquid, Geotechnique, 46(4), 769-774. 


\section{DISCLAIMER}

This document was prepared as an account of work sponsored by the United States Government. While this document is believed to contain correct information, neither the United States Government nor any agency thereof, nor The Regents of the University of California, nor any of their employees, makes any warranty, express or implied, or assumes any legal responsibility for the accuracy, completeness, or usefulness of any information, apparatus, product, or process disclosed, or represents that its use would not infringe privately owned rights. Reference herein to any specific commercial product, process, or service by its trade name, trademark, manufacturer, or otherwise, does not necessarily constitute or imply its endorsement, recommendation, or favoring by the United States Government or any agency thereof, or The Regents of the University of California. The views and opinions of authors expressed herein do not necessarily state or reflect those of the United States Government or any agency thereof or The Regents of the University of California.

Ernest Orlando Lawrence Berkeley National Laboratory is an equal opportunity employer. 